\title{
The glutaredoxin 1/protein S-glutathionylation axis in inflammatory lung disease : in vitro to clinical characterization
}

Citation for published version (APA):

Kuipers, I. (2013). The glutaredoxin 1/protein S-glutathionylation axis in inflammatory lung disease : in vitro to clinical characterization. [Doctoral Thesis, Maastricht University]. Maastricht University. https://doi.org/10.26481/dis.20130321ik

Document status and date:

Published: 01/01/2013

DOI:

10.26481/dis.20130321ik

Document Version:

Publisher's PDF, also known as Version of record

Please check the document version of this publication:

- A submitted manuscript is the version of the article upon submission and before peer-review. There can be important differences between the submitted version and the official published version of record.

People interested in the research are advised to contact the author for the final version of the publication, or visit the DOI to the publisher's website.

- The final author version and the galley proof are versions of the publication after peer review.

- The final published version features the final layout of the paper including the volume, issue and page numbers.

Link to publication

\footnotetext{
General rights rights.

- You may freely distribute the URL identifying the publication in the public portal. please follow below link for the End User Agreement:

www.umlib.nl/taverne-license

Take down policy

If you believe that this document breaches copyright please contact us at:

repository@maastrichtuniversity.nl

providing details and we will investigate your claim.
}

Copyright and moral rights for the publications made accessible in the public portal are retained by the authors and/or other copyright owners and it is a condition of accessing publications that users recognise and abide by the legal requirements associated with these

- Users may download and print one copy of any publication from the public portal for the purpose of private study or research.

- You may not further distribute the material or use it for any profit-making activity or commercial gain

If the publication is distributed under the terms of Article $25 \mathrm{fa}$ of the Dutch Copyright Act, indicated by the "Taverne" license above, 


\section{The Glutaredoxin 1/ protein S-glutathionylation axis in inflammatory lung disease}


ISBN 978-90-8891-591-8

(C) Ine Kuipers 2013, Washington DC, USA

Printed by: proefschriftmaken.nl

The studies persented in this thesis were supported by NUTRIM (Nutrition and Toxicology Research Institute Maastricht) and by a VENI grant from NWO/ZonMW (016.086.090) awarded to NL Reynaert. 


\section{The Glutaredoxin 1/ protein S-glutathionylation axis in inflammatory lung disease}

\section{In vitro to clinical characterization}

\section{Proefschrift}

Ter verkrijging van de graad van doctor aan de Universiteit Maastricht, op gezag van de rector Magnificus Prof. dr. LLG Soete volgens het besluit van het College van Decanen in het openbaar te verdedigen op 21 maart 2013 om $16.00 u$

$$
\text { door }
$$

\section{Ine Kuipers}

Geboren te Hasselt op 23 april 1985 


\section{Promotor}

Prof. dr. E.F.M. Wouters

Copromotor

Dr. N.L. Reynaert

Beoordelingscommissie

Prof. dr. B. Kramer (voorzitter), MUMC

Prof. dr. E.J.M. Speel, MUMC

Prof. dr. A. Bast, MUMC

Prof. dr. A. van Oosterhout, Rijksuniversiteit Groningen UMCG

Dr. Roel Schins, Leibniz Institute Dusseldorf

Printing of this thesis was financially supported by Stichting Pulmonologie. 
And now, the end is near and so I face the final curtain

Frank Sinatra 



\section{Table of contents}

$\begin{array}{lll}\text { Chapter } 1 \quad \text { General introduction } & 1\end{array}$

Chapter 2 Activation of the glutaredoxin-1 gene by Nuclear Factor kappa B 11 provides feed forward enhancement of signaling

Chapter 3 Cigarette smoke targets glutaredoxin 1, increasing

S-glutathionylation and epithelial cell death

Chapter 4 Smoke decreases reversible oxidations S-glutathionylation and S-nitrosylation in mice

Chapter 5 Altered cigarette smoke induced lung inflammation due to ablation of Grx1

Chapter $6 \quad$ Altered glutaredoxin 1- protein S-glutathionylation axis in COPD

Chapter 7 Decreased plasma protein S-glutathionylation in COPD; associations with glutaredoxin 1, glutathione-S-transferase and inflammation

Chapter 8 Increased glutaredoxin1 and decreased protein Sglutathionylation in sputum of asthmatics

Chapter 9 Discussion, Future Perspectives and Summary

Appendices Samenvatting

List of publications

CV

Dankwoord/Acknowledgements 



\section{CHAPTER 1}

\section{General introduction}

\section{Oxidants and the lung}

Given its direct contact to the external environment and their function, the lungs are highly susceptible to oxidant induced damage caused by oxidative stress and are therefore equipped with high levels of anti-oxidants to counteract oxidative insult. Oxidants can be inhaled from the environment, coming for instance from cigarette smoke that contains an estimated $10^{15}$ radicals per puff [1] or oxidants can be produced endogenously by non-phagocytic cells through mitochondrial respiration as well as by inflammatory cells upon activation following inhalation of pathogens or irritants. Oxidants or reactive oxygen species (ROS) are involved in cellular biology, but when their levels outbalance detoxifying anti-oxidants they can cause oxidative stress. Oxidative stress can result in macromolecule damage, including lipids, proteins, and nucleic acids, potentially causing cellular dysfunction and death [2-4].

\section{COPD and oxidative stress}

Chronic obstructive pulmonary disease or COPD is a chronic inflammatory disease of the lungs characterized by chronic bronchitis and emphysema [5]. COPD occurs primarily in chronic cigarette smokers and the pathogenesis of COPD is not yet fully resolved, but mechanisms like immune alterations, proteolytic and oxidative disruption and endothelial dysfunction are well established to contribute to the disease [6-9] . Other factors such as genetic predisposition, and environmental and dietary factors, are likely to influence the risk of a smoker to develop the disease as well as to the heterogeneity of the disease observed between patients $[10,11]$. Oxidative stress, due to imbalance between high oxidative insults by cigarette smoke and inflammation, and lowered or insufficient anti-oxidant levels, is an important hallmark of COPD. Oxidative stress in patients with COPD has been described locally in the lungs as well as in the systemic circulation [12] as the disease manifests itself also systemically, by elevated inflammatory cytokines in plasma. Increased levels of both oxidants and oxidative products of proteins, lipids, DNA and sugars have been measured. Oxidative stress is generally correlated to inflammation, as inflammatory cells are the main 
source of oxidant production [13]. Besides directly damaging cellular content, oxidants can also trigger the activation of several pathways in the cell. These pathways include the activator pathway-1 (AP-1) and nuclear factor KB (NF- KB), responsible for the gene transcription of the inflammatory cytokines associated with airway inflammation in COPD, such as interleukin (IL)-6 and 8 and tumor necrosis factor a (TNFa) [14-17]. Secretion of these cytokines leads to the recruitment of inflammatory cells like macrophages and neutrophils, the latter upon activation can cause even more oxidative damage to surrounding cells and tissue due to oxidative burst.

\section{COPD and glutathione}

As described above, the lung continuously encounters oxidants from inhalation and is therefore well equipped with a myriad of antioxidants, and in particular with a high concentration of the antioxidant glutathione (GSH). In the epithelial lining fluid, up to a 140-fold increase from plasma levels of GSH are present [18]. Glutathione alone can scavenge free radicals; however, it is most efficient when acting in concert with GSH peroxidase (GPx), glutathione reductase (GSR), and the hexose monophosphate shunt system that regenerates NADPH, the electron donor needed to reduce oxidized GSH, known as GSSG [18]. The ratio of GSH/GSSG is often used to asses the redox status of a cell or tissue. Cigarette smoke is known to acutely deplete GSH, for instance by directly reacting with GSH to form nonreducible glutathione-aldehyde derivatives [19], thereby decreasing the lungs' anti-oxidant capacity and making it vulnerable to oxidantinduced injury. Also, GSH plays an important role in maintaining the integrity of the lung airspace epithelial barrier. Upon depletion of GSH in epithelial cells of the lung, increased permeability and loss of barrier function was reported [20, 21].

Apart from activating inflammatory pathways, oxidants can also trigger transcription of antioxidant-protective genes. Many anti-oxidant genes, for example glutathione S-transferases, heme oxygenase-1 and the rate limiting enzyme in GSH synthesis $y$-glutamylcysteine ligase (GCL), are regulated by the transcription factor Nuclear Factor (erythroid-derived 2)-like 2 (Nrf2). Therefore, as an adaptive response to oxidative stress, levels of GSH have reported to be increased in the epithelial lining fluid of chronic smokers [22]. This increase in epithelial lining fluid GSH after chronic cigarette smoking might however not be sufficient to counteract the excessive oxidative burden that occurs upon acute smoke exposure [23]. Also, unlike in healthy smokers and patients with stable COPD, patients with acute exacerbations have been reported to have reduced levels of GSH because of inhibited activity and transcription of the GCL catalytic subunit (GCLC) [23-25], predisposing the lung to injury due to overwhelming oxidative burden from reactive oxygen species released by neutrophils present at the time. The downregulation of GCLC in COPD patients might be related to a decreased Nrf2 activation in COPD 
patients, which has been reported to be due to the loss of its positive regulator DJ1 [26].

\section{Cysteine oxidation}

Cysteine residues in proteins are the amino acids most susceptible to oxidative modification and therefore their functional implications and importance in cellular signaling pathways have been well characterized compared to other oxidized amino acids, including methionine, tyrosine and tryptophan [27]. It is the thiol group in a cysteine that can provide it with a low pKa, depending upon the amino acids in the environment surrounding the cysteine and make it more prone to post-translational modifications. In the presence of oxidative stress factors like ROS or reactive nitrogen species (RNS), the reduced cysteine in a protein can be oxidized to a thiyl radical (RS') that has high reactivity with oxygen, leading to further cysteine oxidation (Figure 1). The oxidized cysteine (RS.) can undergo numerous redox-based modifications, including sulfenic acid (PSOH), nitrosylation (PSNO), palmitoylation (PSPalm), glutathionylation (PSSG) and the formation of inter- and intramolecular disulphides (S-S), with each modification having the potential to modify not only protein structure but also function in diverse fashion [28-32]. These aforementioned redox-based cysteine modifications are all reversible, but cysteines are also targeted by alkylating agents such as acrolein and prostaglandins, which are generated both endogenously and through environmental exposure and are irreversible [33,34]. Also, cysteine amino acids in proteins can be oxidized to sulfenic $(\mathrm{SOH})$, sulfinic $\left(-\mathrm{SO}_{2} \mathrm{H}\right)$ or sulfonic $(-\mathrm{SO} 3 \mathrm{H})$ acids. In numerous classes of proteins throughout species free cysteines are found to be highly conserved within a protein's primary sequence and often play an important role in protein function, highlighting the specificity and tight regulatory measurements that have been acquired by cell organisms to control posttranslational modifications of these low pKa cysteines and their importance in cell physiology. 


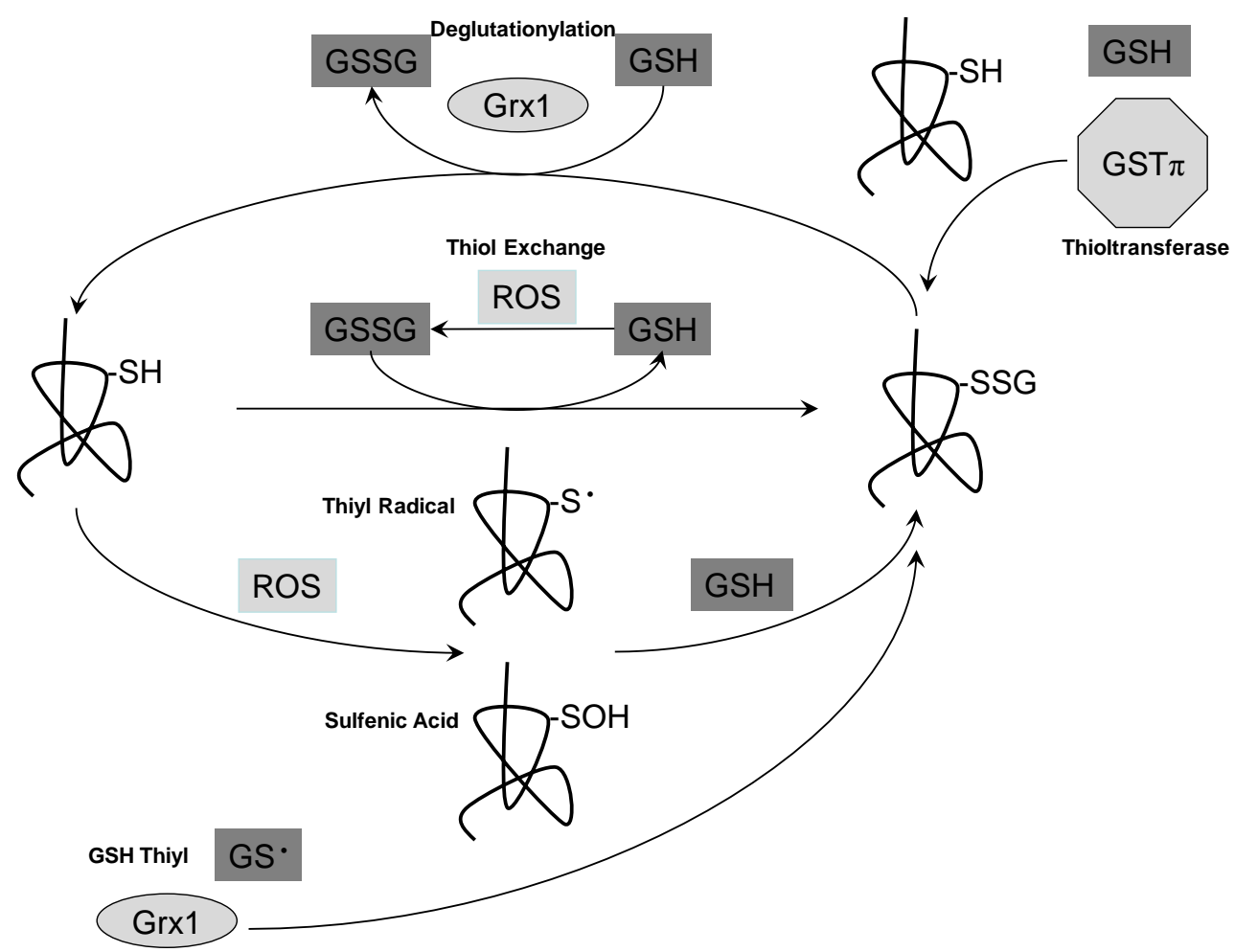

Figure 1: ROS induced protein $S$-glutathionylation and deglutathionylation [adapted with permission from S.Aesif]

\section{S-glutathionylation and its mediators}

The direct addition of GSH to low pKa cysteines upon mild oxidative stress creates an S-glutathionylated residue, with an increase in molecular weight of 305 and a net increase in negative charge, due to the glycine residue of GSH. As described, cysteines are among the most vulnerable with regard to oxidative modification and the conjugation of GSH to oxidized cysteines serves to protect against over oxidation. S-glutathionylation is a reversible post-translational modification, making it a potential biological switch for a number of critical oxidative signaling events. The added molecular weight of GSH to the thiol can change a proteins three dimensional conformation as well as alter its function. Pathways described to be altered by S-glutathionylation upon mild oxidation are involved in a wide variety of crucial cell functions, including energy metabolism, calcium homeostasis, inflammation, cell death and protein folding [35, 36]. Recently, it has been suggested that protein thiols may be a more accurate indicator of total cellular redox status, since they represent a potentially larger redox active pool that free GSH [37]. To gain more insight in these protein thiols and their oxidation, 
antibodies directed towards specific thiol oxidations have been developed. Combining mass spectrometry with affinity purification protocols has provided identification and quantification of S-glutathionylated proteins. For example, nitrosative and oxidative stress have been shown to be responsible for Sglutathionylation of GSTP on Cys47 and Cys101 [38] and haemoglobin A has been found to be S-glutathionylated on Cys 93 through a cysteine sulfenic acid intermediate [39].

Protein S-glutathionylation has been compared to phosphorylation with regard to its impact on protein function and structure and its ability to reversibly alter signaling pathways [40, 41]. Much like phosphorylation, where kinases and phosphatases respectively govern its formation and resolution in a regulated manner, a handful of proteins have been suggested to play a similar part in forward and reverse reactions in the S-glutathionylation cycle.

\section{Glutathione S-transferase Pi (GSTP)}

Although binding of GSH to proteins can be achieved non-enzymatically, there is some evidence that glutathione-S-transferase P1 (GSTP1) can catalyse this reaction [38, 42]. GSTP1 is a member of the GST superfamily that catalyses the conjugation of GSH to various hydrophobic and electrophilic compounds to aid in detoxification. The $\mathrm{P}$ isoform is expressed highly in lung tissue and was found to be increased in patients with mild COPD [43]. In fibroblasts, deletion of GST-P1 has been shown to lead to apoptosis [44] while overexpression was protective against cigarette smoke extract induced cell death [45]. Polymorphisms in GSTP1 have been linked to COPD, and suggested to be due to a lack of sufficient detoxification of, and antioxidant protection against cigarette smoke and associated products. However, to date none of these polymorphisms have been considered in the context of their impact on S-glutathionylation. Lastly, GSTP1 can contribute to pathogenesis through interacting with proteins such as $\mathrm{c}$-jun- $\mathrm{N}$-terminal kinase (JNK) and tumor necrosis factor receptor-associated factor (TRAF) 2 [36, 46, 47].

\section{Glutaredoxins}

Glutaredoxins ( $G r x)$ are part of the oxidoreductase class of enzymes and are found in virtually all organisms [48]. Several isoforms of glutaredoxin have been identified, but glutaredoxin 1 (Grx1) is the most extensively described and characterized. Grx1 was first discovered as a GSH-dependent electron donor for ribonucleotide reductase in E.Coli [49]. Later Grx1 has been described as catalyzing the removal of GSH from cysteines, known as deglutathionylation, unders physiological conditions [50], thereby liberating this reservoir of GSH. Changes in expression of Grx1 can result in differential protein S-gluathionylation and can thus impact function of proteins influenced by altered cysteine oxidation. 
Grx1 localizes primarily to the cytosol, whereas Grx2 is present in the mitochondria and nucleus. Grx2 exists as an inactive dimer with a $2 \mathrm{Fe}$ (iron)$2 S$ (sulfur) cluster which can be released in active enzyme monomers upon increased GSSG or oxidative stress. Grx3 is an isoform that does not exhibit deglutathionylating activity, but is reported to be altered in lung cancer [51]. Grx5 is located in the mitochondria and functions through a monothiol mechanism to reduce mixed protein disulfides. A role for Grx5 in heme synthesis and Fe-S cluster formation has been described [52].

\section{The NF- kB pathway}

The transcription factor, Nuclear Factor kappa B (NF-kB) is an important regulator of cell survival as well as immune and inflammatory responses. The canonical NF-KB pathway is activated following stimulation of various receptors including toll like receptors and cytokine receptors and results in activation of the Inhibitory kappa B kinase (IKK) complex which consists of the catalytic subunits $\mathrm{IKK} \alpha$, IKK $\beta$ and IKKY. Activation of IKK $\beta$ triggers phosphorylation of the NF-KB inhibitor $I K B \alpha$, resulting in its proteasomal degradation and the release of RelA to the nucleus for activation of transcription of target genes. Non canonical NF- KB signaling is activated by agonists such as CD40 and B cell activating factor receptor and is responsible for stabilizing NF-kB inducing kinase, which in turn phosphorylates and activates homodimers of $\mathrm{IKK}$, leading to nuclear translocation of RelB and gene transcription of target genes [53, 54]. (Figure 2)

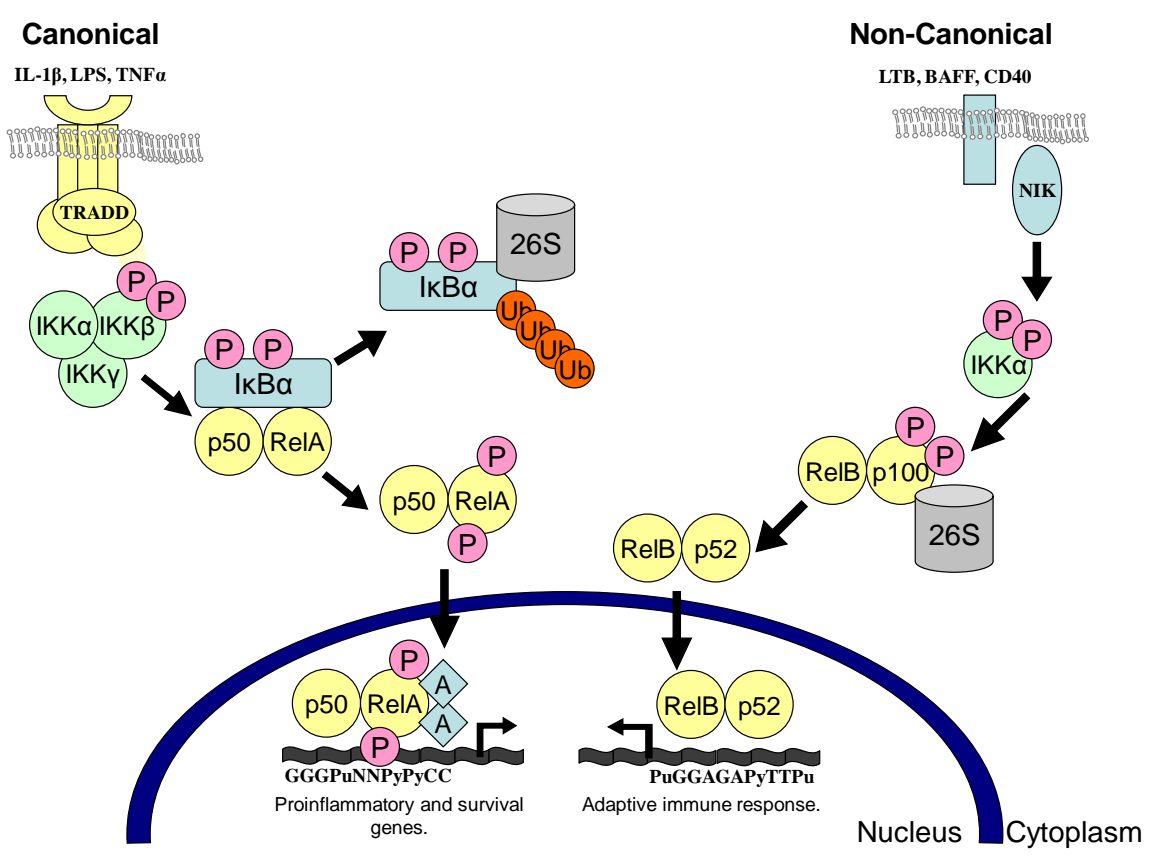

Figure 2: Canonical and non-canonical NF-KB pathways [adapted with permission from S.Aesif] 
Multiple members of the NF-KB pathway can be dynamically regulated through reversible cysteine oxidations, which include S-nitrosylation, sulfenic acid formation, disulfide formation, and S-glutathionylation [55]. S-glutathionylation of IKKB, RelA, and p50 have been documented and resulted in inhibition of the NF-KB pathway $[56,57]$. We previously demonstrated that ablation of Grx1 enhances Sglutathionylation of IKK $\beta$-Cys 179 induced by hydrogen peroxide and inhibits cytokine-induced NF-KB activation and pro-inflammatory mediators. Overexpression of Grx1 on the other hand, decreases S-glutathionylation of IKK $\beta$ Cys 179 and enhances NF-KB activation following oxidation by hydrogen peroxide. These data demonstrate that the cellular content of Grx1 regulates the extent to which NF-KB becomes activated [57]. Upon activation of NF-KB increased Grx1 levels have been reported in retinal glial cells [58], suggesting reciprocal regulation of Grx1 and NF- kB.

\section{Thesis outline}

We started off investigating into more detail this reciprocal regulation of NF-kB and glutaredoxin in lung epithelial cells in chapter 2 because overall little information is available on the mediators of glutaredoxin expression and activity. Next to investigating whether NF-kB indeed is involved in transcriptional regulation of grx1, we tried to tie these findings back into the role of $S$-glutathionylation of the NF-KB mediator IKK $\beta$ to the inflammatory response to LPS. In chapter 3 we investigated whether CSE could be responsible for the downregulation of grx1 that was previously shown in patients with COPD. Secondly, we investigated if this downregulation impacted total protein PSSG and mediated sensitivity to CSE induced death of lung epithelial cells. Grx and PSSG were next also investigated in lung tissue of mice exposed to cigarette smoke for four weeks in chapter 4 . In this chapter, another reversible cysteine oxidation, S-nitrosylation and its mediators ADH5 and iNOS were examined to establish a broader insight in the effects of cigarette smoke on reversible cysteine oxidations. The role of glutaredoxin 1 in cigarette smoke induced inflammation in mice was then assessed by using a glutaredoxin 1 knock out mouse in a four week exposure study. In chapter 5 a comprehensive study was set up to evaluate Grx in conjunction with PSSG in lung tissue and sputum and of COPD patients and to examine their relation to lung function and inflammatory parameters. As COPD also manifests itself by systemic inflammation and oxidative stress, PSSG of plasma proteins was assessed in COPD patients compared to controls in the next chapter, including the positive and negative enzyme mediators GSTP1 and glutaredoxin 1 respectively. Correlations between S-glutathionylation, its mediators, as well as systemic inflammatory markers and lung function were investigated. Lastly, in research previously conducted by our laboratory, Grx1 was reported to be increased in a mouse model for allergic airways disease. However, data on Grx and PSSG in asthma were lacking. We therefore measured levels of S-glutathionylation and glutaredoxin 1 in 


\section{sputum of asthmatic patients compared to controls and investigated correlations between the Grx1-PSSG axis, lung function and inflammation.}

\section{References}

1. Pryor, W.A., D.G. Prier, and D.F. Church, Electron-spin resonance study of mainstream and sidestream cigarette smoke: nature of the free radicals in gas-phase smoke and in cigarette tar. Environ Health Perspect, 1983. 47: p. 345-55.

2. Halliwell, B., Reactive oxygen species in living systems: source, biochemistry, and role in human disease. Am J Med, 1991. 91(3C): p. 14S-22S.

3. Magi, B., et al., Proteome analysis of bronchoalveolar lavage in lung diseases. Proteomics, 2006. 6(23): p. 6354-69.

4. Wallaert, B., et al., Superoxide anion generation by alveolar inflammatory cells in simple pneumoconiosis and in progressive massive fibrosis of nonsmoking coal workers. Am Rev Respir Dis, 1990. 141(1): p. 129-33.

5. Rabe, K.F., et al., Update in chronic obstructive pulmonary disease 2006. Am J Respir Crit Care Med, 2007. 175(12): p. 1222-32.

6. Chung, K.F. and J.A. Marwick, Molecular mechanisms of oxidative stress in airways and lungs with reference to asthma and chronic obstructive pulmonary disease. Ann N Y Acad Sci. 1203: p. 85-91.

7. Wanner, A. and E.S. Mendes, Airway endothelial dysfunction in asthma and chronic obstructive pulmonary disease: a challenge for future research. Am J Respir Crit Care Med. 182(11): p. 1344-51.

8. Huertas, A. and P. Palange, Circulating endothelial progenitor cells and chronic pulmonary diseases. Eur Respir J. 37(2): p. 426-31.

9. Barnes, P.J., Mechanisms and resistance in glucocorticoid control of inflammation. J Steroid Biochem Mol Biol. 120(2-3): p. 76-85.

10. Barnes, P.J., S.D. Shapiro, and R.A. Pauwels, Chronic obstructive pulmonary disease: molecular and cellular mechanisms. Eur Respir J, 2003. 22(4): p. 672-88.

11. MacNee, W., Pathogenesis of chronic obstructive pulmonary disease. Proc Am Thorac Soc, 2005. 2(4): p. 258-66; discussion 290-1.

12. MacNee, W., Pulmonary and systemic oxidant/antioxidant imbalance in chronic obstructive pulmonary disease. Proc Am Thorac Soc, 2005. 2(1): p. 50-60.

13. Rahman, I. and I.M. Adcock, Oxidative stress and redox regulation of lung inflammation in COPD. Eur Respir J, 2006. 28(1): p. 219-42.

14. Pesci, A., et al., Inflammatory cells and mediators in bronchial lavage of patients with chronic obstructive pulmonary disease. Eur Respir J, 1998. 12(2): p. 380-6.

15. Bhowmik, A., et al., Relation of sputum inflammatory markers to symptoms and lung function changes in COPD exacerbations. Thorax, 2000. 55(2): p. 114-20.

16. Toledano, M.B. and W.J. Leonard, Modulation of transcription factor NF-kappa B binding activity by oxidation-reduction in vitro. Proc Natl Acad Sci U S A, 1991. 88(10): p. 4328-32.

17. Schulze-Osthoff, K., M. Los, and P.A. Baeuerle, Redox signalling by transcription factors NF-kappa B and AP-1 in lymphocytes. Biochem Pharmacol, 1995. 50(6): p. 735-41.

18. Cantin, A.M., et al., Normal alveolar epithelial lining fluid contains high levels of glutathione. J Appl Physiol, 1987. 63(1): p. 152-7.

19. van der Toorn, M., et al., Lipid-soluble components in cigarette smoke induce mitochondrial production of reactive oxygen species in lung epithelial cells. Am J Physiol Lung Cell Mol Physiol, 2009. 297(1): p. L109-14.

20. Li, X.Y., et al., Mechanisms of cigarette smoke induced increased airspace permeability. Thorax, 1996. 51(5): p. 465-71.

21. Morrison, D., et al., Epithelial permeability, inflammation, and oxidant stress in the air spaces of smokers. Am J Respir Crit Care Med, 1999. 159(2): p. 473-9.

22. Rahman, I., Regulation of glutathione in inflammation and chronic lung diseases. Mutat Res, 2005. 579(1-2): p. 58-80.

23. Harju, T., et al., Diminished immunoreactivity of gamma-glutamylcysteine synthetase in the airways of smokers' lung. Am J Respir Crit Care Med, 2002. 166(5): p. 754-9.

24. Rahman, I., et al., Transcriptional regulation of gamma-glutamylcysteine synthetase-heavy subunit by oxidants in human alveolar epithelial cells. Biochem Biophys Res Commun, 1996. 229(3): p. 832-7.

25. Rahman, I., et al., Induction of gamma-glutamylcysteine synthetase by cigarette smoke is associated with AP-1 in human alveolar epithelial cells. FEBS Lett, 1996. 396(1): p. 21-5. 
26. Malhotra, D., et al., Decline in NRF2-regulated antioxidants in chronic obstructive pulmonary disease lungs due to loss of its positive regulator, DJ-1. Am J Respir Crit Care Med, 2008. 178(6): p. 592-604.

27. Forman, H.J., J.M. Fukuto, and M. Torres, Redox signaling: thiol chemistry defines which reactive oxygen and nitrogen species can act as second messengers. Am J Physiol Cell Physiol, 2004. 287(2): p. C246-56.

28. Giles, G.I., et al., Evaluation of sulfur, selenium and tellurium catalysts with antioxidant potential. Org Biomol Chem, 2003. 1(23): p. 4317-22.

29. Jacob, C., et al., Sulfur and selenium: the role of oxidation state in protein structure and function. Angew Chem Int Ed Engl, 2003. 42(39): p. 4742-58.

30. Ji, Y., et al., S-nitrosylation and S-glutathiolation of protein sulfhydryls by S-nitroso glutathione. Arch Biochem Biophys, 1999. 362(1): p. 67-78.

31. Kim, S.O., et al., OxyR: a molecular code for redox-related signaling. Cell, 2002. 109(3): p. 383-96. Mallis, R.J. and J.A. Thomas, Effect of S-nitrosothiols on cellular glutathione and reactive protein sulfhydryls. Arch Biochem Biophys, 2000. 383(1): p. 60-9.

33. Finkelstein, E.I., et al., Regulation of constitutive neutrophil apoptosis by the alpha,beta-unsaturated aldehydes acrolein and 4-hydroxynonenal. Am J Physiol Lung Cell Mol Physiol, 2005. 289(6): p. L1019-28.

34. Rossi, A., et al., Anti-inflammatory cyclopentenone prostaglandins are direct inhibitors of IkappaB kinase. Nature, 2000. 403(6765): p. 103-8.

35. Xiong, Y., et al., S-glutathionylation: from molecular mechanisms to health outcomes. Antioxid Redox Signal. 15(1): p. 233-70.

36. Townsend, D.M., S-glutathionylation: indicator of cell stress and regulator of the unfolded protein response. Mol Interv, 2007. 7(6): p. 313-24.

37. Hansen, R.E., D. Roth, and J.R. Winther, Quantifying the global cellular thiol-disulfide status. Proc Natl Acad Sci U S A, 2009. 106(2): p. 422-7.

38. Townsend, D.M., et al., Novel role for glutathione S-transferase pi. Regulator of protein $S$ Glutathionylation following oxidative and nitrosative stress. J Biol Chem, 2009. 284(1): p. 436-45.

39. Regazzoni, L., et al., Hemoglobin glutathionylation can occur through cysteine sulfenic acid intermediate: electrospray ionization LTQ-Orbitrap hybrid mass spectrometry studies. J Chromatogr B Analyt Technol Biomed Life Sci, 2009. 877(28): p. 3456-61.

40. Ghezzi, P., Regulation of protein function by glutathionylation. Free Radic Res, 2005. 39(6): p. 573-80.

41. Dalle-Donne, I., et al., S-glutathionylation in protein redox regulation. Free Radic Biol Med, 2007. 43(6): p. 883-98.

42. Manevich, Y., S.I. Feinstein, and A.B. Fisher, Activation of the antioxidant enzyme 1-CYS peroxiredoxin requires glutathionylation mediated by heterodimerization with pi GST. Proc Natl Acad Sci U S A, 2004. 101(11): p. 3780-5.

43. Harju, T., et al., Glutathione-S-transferases in lung and sputum specimens, effects of smoking and COPD severity. Respir Res, 2008. 9: p. 80.

44. Ishii, T., et al., Depletion of glutathione S-transferase P1 induces apoptosis in human lung fibroblasts. Exp Lung Res, 2003. 29(7): p. 523-36.

45. Ishii, T., et al., Tobacco smoke reduces viability in human lung fibroblasts: protective effect of glutathione S-transferase P1. Am J Physiol Lung Cell Mol Physiol, 2001. 280(6): p. L1189-95.

46. Adler, V., et al., Regulation of JNK signaling by GSTp. Embo J, 1999. 18(5): p. 1321-34.

47. Gate, L., et al., Increased myeloproliferation in glutathione S-transferase pi-deficient mice is associated with a deregulation of JNK and Janus kinase/STAT pathways. J Biol Chem, 2004. 279(10): p. 8608-16.

48. Fernandes, A.P. and A. Holmgren, Glutaredoxins: glutathione-dependent redox enzymes with functions far beyond a simple thioredoxin backup system. Antioxid Redox Signal, 2004. 6(1): p. 63-74.

49. Holmgren, A., Hydrogen donor system for Escherichia coli ribonucleoside-diphosphate reductase dependent upon glutathione. Proc Natl Acad Sci U S A, 1976. 73(7): p. 2275-9.

50. Mieyal, J.J., et al., Molecular mechanisms and clinical implications of reversible protein $S$ glutathionylation. Antioxid Redox Signal, 2008. 10(11): p. 1941-88.

51. Cha, M.K. and I.H. Kim, Preferential overexpression of glutaredoxin3 in human colon and lung carcinoma. Cancer Epidemiol, 2009. 33(3-4): p. 281-7.

52. Wingert, R.A., et al., Deficiency of glutaredoxin 5 reveals $\mathrm{Fe}$-S clusters are required for vertebrate haem synthesis. Nature, 2005. 436(7053): p. 1035-39.

53. Ghosh, S. and M.S. Hayden, New regulators of NF-kappaB in inflammation. Nat Rev Immunol, 2008. 8(11): p. 837-48.

54. Karin, M. and A. Lin, NF-kappaB at the crossroads of life and death. Nat Immunol, 2002. 3(3): p. 2217. 
55. Janssen-Heininger, Y.M., et al., Redox-based regulation of signal transduction: principles, pitfalls, and promises. Free Radic Biol Med, 2008. 45(1): p. 1-17.

56. Pineda-Molina, E., et al., Glutathionylation of the p50 subunit of NF-kappaB: a mechanism for redoxinduced inhibition of DNA binding. Biochemistry, 2001. 40(47): p. 14134-42.

57. Reynaert, N.L., et al., Dynamic redox control of NF-kappaB through glutaredoxin-regulated Sglutathionylation of inhibitory kappaB kinase beta. Proc Natl Acad Sci U S A, 2006. 103(35): p. 13086-91.

58. Shelton, M.D., et al., Glutaredoxin regulates autocrine and paracrine proinflammatory responses in retinal glial (muller) cells. J Biol Chem, 2009. 284(8): p. 4760-6. 


\section{CHAPTER 2}

\section{Activation of the glutaredoxin-1 gene by Nuclear Factor kappa B provides feed forward enhancement of signaling}

Scott W. Aesif ${ }^{a, 1}$, Ine Kuipers ${ }^{b, 1}$, Jos van der Velden ${ }^{a}$, Jane E. Tully ${ }^{a}$, Amy S. Guala $^{a}$, Vikas Anathy ${ }^{a}$, Juliana I. Sheely ${ }^{a}$, Niki L. Reynaert ${ }^{b}$, Emiel F. M. Wouters ${ }^{b}$, Albert van der Vliet ${ }^{a}$, and Yvonne M. W. Janssen-Heininger ${ }^{a}$,

Free Radical Biology and Medicine, 2011 Sep 15;51(6):1249-57

\section{Abstract}

The transcription factor, Nuclear Factor kappa B (NF-KB) is a critical regulator of inflammation and immunity, and is negatively regulated via S-glutathionylation. The ihibitory effect of S-glutathionylation is overcome by glutaredoxin-1 (Grx1), which under physiological conditions catalyses deglutathionylation and enhances NF-KB activation. The mechanisms whereby expression of the Glrx1 gene is regulated remain unknown. Here we examined the role of NF-KB in regulating activation of Glrx1. Transgenic mice which express a doxycyclin-inducible constitutively active version of inhibitory kappa $B$ kinase-beta (CA-IKKB) demonstrate elevated expression of Grx1. Transient transfection of CA-IKK $\beta$ also resulted in significant induction of Grx1. A $2 \mathrm{~kb}$ region Glrx1 promoter that contains two putative NF-KB binding sites was activated by CA-IKK $\beta$, RelA/p50, and lipopolysaccharide (LPS). Chromatin immunoprecipitation experiments confirmed binding of RelA to the promoter of Glrx1 in response to LPS. Stimulation of C10 lung epithelial cells with LPS caused transient increases in Grx1 mRNA expression, and time-dependent increases in S-glutathionylation of IKK $\beta$. Overexpression of Grx1 decreased Sglutathionylation of IKK $\beta$, prolonged NF-KB activation, and increased levels of proinflammatory mediators. Collectively, this study demonstrates that the Glrx1 gene is positively regulated by NF-KB, and suggests a feed forward mechanism to promote NF-KB signaling by decreasing S-glutathionylation. 


\section{Introduction}

The transcription factor, Nuclear Factor kappa B (NF-kB) is a cardinal regulator of cell survival, and immune and inflammatory responses. Its activation has been linked to a wide variety of chronic inflammatory, and immune diseases, as well as cancer [1]. NF-KB is comprised of diverse subunits of NF-KB/Rel proteins and inducibly regulates transcription of over 100 target genes. The canonical NF-KB pathway is activated following stimulation of various receptors including toll like receptors and cytokine receptors and results in activation of the Inhibitory kappa B kinase (IKK) complex which consists of the catalytic subunits IKKa and IKK $\beta$, and the regulatory protein, IKKY. The catalytic activity of IKK $\beta$ mediates phosphorylation of the NF-KB inhibitor $\mathrm{IKBa}$, leading to its proteasomal degradation. Non canonical signaling is activated by agonists such as CD40 and B cell activating factor receptor, stabilization of NF- KB inducing kinase, which in turn phosphorylates and activates homodimers of IKKa (Fig. 1A). IKKa and IKK $\beta$ also mediate additional phosphorylation events and collectively lead to enhanced transcriptional activation of target genes [2-4].

Redox-based regulation of cell signaling is receiving increased attention as a result of the demonstration that diverse pathways and transcription factors, including NF$\mathrm{KB}$ can be dynamically regulated through reversible cysteine oxidations $[5,6]$. Reactive, low pKa, cysteines in the thiolate state can be reversibly oxidized in diverse manners, which include S-nitrosylation, sulfenic acid formation, disulfide formation, and S-glutathionylation [5]. Protein S-glutathionylation (also referred to as S-glutathiolation or mixed disulfides) causes functional alterations in target proteins, and both activation and inhibition of physiological function has been observed [7-10]. We and others have previously demonstrated that the NF-KB pathway is inhibited via S-glutathionylation, and S-glutathionylation of IKK $\beta$, RelA, and p50 have been documented [10-12]. However, the exact proportion of Sglutathionylation of NF-kB members that occurs in intact cells, and impact for the strength of NF-KB signaling remains unknown to date. Steady state levels of Sglutathionylated proteins are controlled by glutaredoxins, members of the thioredoxin family of oxidoreductases. Glutaredoxins (Grx) under physiological conditions act to efficiently, and specifically deglutathionylate proteins [13]. We previously demonstrated that ablation of $\mathrm{Grx} 1$ enhances S-glutathionylation of IKK 3 -Cys 179 induced by hydrogen peroxide $\left(\mathrm{H}_{2} \mathrm{O}_{2}\right)$, and inhibits cytokine-induced $\mathrm{NF}-\mathrm{KB}$ activation and pro-inflammatory mediators, while overexpression of Grx1 decreases S-glutathionylation of IKK - -Cys179 and enhances NF-KB activation following oxidation by $\mathrm{H}_{2} \mathrm{O}_{2}$, collectively demonstrating that the cellular content of Grx1 regulates the extent to which NF-KB becomes activated under conditions of oxidative stress [10] (Fig. 1B).

We recently demonstrated that the cellular content of Grx 1 is modulated by diverse pro-inflammatory stimuli. In mice with allergic airway inflammation, Grx1 content was increased in bronchial epithelial cells [14], which also show activation of NF-KB 
[15]. Upregulation of Grx1 has also been observed in retinal glial cells cultured in high glucose medium, concomitant with activation of NF-KB [16]. These findings suggest that NF-KB and Grx1 may be regulated in a coordinate fashion. In the present study we sought to determine whether the glutaredoxin (G/rx1) gene is regulated via the NF-KB pathway, and to determine the functional implications of such regulation.

A

\begin{tabular}{|c|c|c|c|c|}
\hline Agonists & Kinases & Targets & NF-kB subunits & Outcomes \\
\hline & IKK $\beta$ & $\mathrm{IKBa}$ & RelA/p50 & activation, inflammatior \\
\hline BAFF, CD40L, & $\mathrm{NIK} \rightarrow \mathrm{IKK}$ & $\rightarrow \mathrm{p} 100$ & RelB/p52 & roliferation, Adaptive immune response \\
\hline
\end{tabular}

B

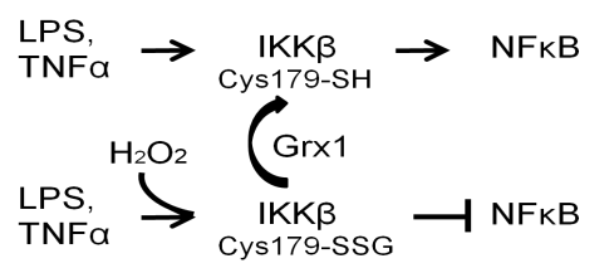

Figure 1. Overview of the NF-KB activation pathways and the impact of S-glutathionylation. A) Schematic representation of activation of classical (top) and alternative (bottom) NF-KB activation pathways, and outcomes. The classical pathway is activated by diverse ligands, such as LPS, Tumor Necrosis Factor-alpha (TNFa), Interleukin 1-beta (IL-1 $\beta$ ), among many others, which results in the activation of Inhibitory kappa B kinase beta (IKK $\beta$ ) which in turn mediates degradation of IKBa, resulting in the nuclear translocation and activation of RelA/p50 NF-kB subunits. The alternative NF-KB pathway is activated by distinct subsets of ligands, such as B cell Activating Factor (BAFF), CD40 ligand (CD4OL) etc. which result in NF-KB Inducing Kinase (NIK) dependent activation of I kappa B kinase alpha (IKKa) which phosphorylates p100, and resultant proteolytic processing to p52. RelB/p52 dimeric complexes then are translocated to the nucleus, to activate transcription of unique sets of genes. Note that this schematic is an oversimplification, as additional regulatory post-translational modifications, and chromatin remodeling events occur to enable transcriptional activation of genes. Cross talk between classical and alternative NF-KB pathways also occurs, and is not illustrated here. B) Impact of $\mathrm{H} 2 \mathrm{O} 2$ of IKK $\beta$ and NF-KB signaling. Stimulation of cells with LPS or TNFa leads to activation of IKK $\beta$, and downstream NF-KB signaling. In the presence of $\mathrm{H}_{2} \mathrm{O}_{2}(100-200 \mu \mathrm{M})$ or following overexpression of NOX1, IKK $\beta$ is inhibited via S-glutathionylation (PSSG) of Cys179. Overexpression of glutaredoxin-1 (Grx1) reverses S-glutathionylation of IKK $(\mathrm{P}-\mathrm{SH})$, and permits NF-KB signaling in the presence of $\mathrm{H} 2 \mathrm{O} 2$. This schematic is a summary of previously published data [10].

\section{Materials and methods}

\section{Plasmids and reagents}

Constitutively active IKK $\beta$ (CA-IKK $\beta)$ in which serines 177 and 181 are mutated to glutamic acid residues, dominant negative $1 \mathrm{~KB} \alpha(\mathrm{dn} \mid \mathrm{KB} \alpha)$ in which serines 32 and 36 are mutated to alanines, and flag tagged glutaredoxin-1 (Grx1) constructs were used as previously described $[9,17,18]$. All transfections were performed using the DharmaFECT reagent (Thermo Scientific) according to the manufacturer's 
instructions. Grx1 targeting SiRNA, and SiRNA controls (Invitrogen) were used as previously described, with modification [19]. Herein we will refer to glutaredoxin 1 using the commonly used abbreviation, Grx 1 . When referring to the mouse glutaredoxin 1 gene, we will use the Glrx1 as the abbreviation.

\section{Cell culture}

Murine type two lung epithelial (C10), and macrophage (RAW 264.7) cell lines were propagated in CMRL medium (C10), or Dulbecco's minimal essential medium (RAW 264.7), supplemented with $10 \%$ fetal bovine serum and $100 \mathrm{U} / \mathrm{ml}$ penicillin/streptomycin. For stimulation experiments, RAW 264.7 cells were plated and allowed to adhere for $1 \mathrm{~h}$ prior to treatment. Cells were stimulated with 5 $\mathrm{ng} / \mathrm{mL} \mathrm{IL}-1 \beta$ (Axxora), $10 \mathrm{ng} / \mathrm{mL}$ TNF- $\alpha$ (Calbiochem), or $0.5-10 \mu \mathrm{g} / \mathrm{mL}$ LPS (List Biological Laboratories) for the times indicated.

\section{Immunoblotting}

Cells were lysed in buffer containing $137 \mathrm{mM}$ Tris. $\mathrm{HCl}(\mathrm{pH} 8.0), 130 \mathrm{mM} \mathrm{NaCl}$, and $1 \%$ NP-40. Proteins were resolved by SDS-PAGE and blotted onto PVDF membranes (Millipore) prior to immunoblotting. In selected experiments, nuclear extracts were prepared according to previously published procedures [20], and nuclear proteins resolved by SDS-PAGE. The following antibodies were used for Western Blotting, Grx1 (American Diagnostica), $\beta$-actin (Sigma), IKK $\beta$ (Santa Cruz), RelA (Santa Cruz), and Histone H3 (Millipore).

\section{Glutaredoxin-1 activity assay}

Cells were lysed in buffer containing $137 \mathrm{mM}$ Tris. $\mathrm{HCl}(\mathrm{pH} 8.0), 130 \mathrm{mM} \mathrm{NaCl}$, and $1 \% \mathrm{NP}-40$, lysates were then cleared by centrifugation, and $100 \mu \mathrm{g}$ of protein incubated with reaction buffer containing $137 \mathrm{mM}$ Tris- $\mathrm{HCl}, \mathrm{pH} 8.0,0.5 \mathrm{mM}$ glutathione (Roche), $1.2 \mathrm{U}$ glutathione disulfide reductase (Roche), $0.35 \mathrm{mM}$ NADPH (Sigma), $1.5 \mathrm{mM}$ EDTA, and $2.5 \mathrm{mM}$ cysteine-SO3 (Sigma) for $10 \mathrm{~min}$. Consumption of NAPDH was determined spectrophotometrically at $340 \mathrm{~nm}$ and data are expressed as Units, in which 1 Unit equals the oxidation of $1 \mu \mathrm{mol}$ $\mathrm{NADPH} / \mathrm{min} / \mathrm{mg}$ protein.

\section{Assessment of protein-S-glutathionylation (PSSG)}

Protein S-glutathionylation in cells was determined using the glutathione/glutathione reductase/NADPH/ 5,5'-dithiobis (2-nitrobenzoic acid) recycling assay, according to procedures as described elsewhere [21] with minor modifications. Cells were lysed in $137 \mathrm{mM}$ Tris- $\mathrm{HCl}, \mathrm{pH} 8.0,130 \mathrm{mM} \mathrm{NaCl}$, and $1 \%$ NP-40. Protein content was determined, and samples equalized for protein content. $200 \mu \mathrm{g}$ of protein was precipitated with acetone. The pellet was resuspended in $0.1 \%$ Triton-X100, $0.6 \%$ sulfosalicylic acid containing buffer, and freeze thawed twice. Protein-associated glutathione was released with sodium borohydride, and GSH determined. The sodium borohydride sensitive fraction of 
GSH was calculated, and expressed as $\mathrm{nmol} \mathrm{GSH} / \mathrm{mg}$ of protein. Sglutathionylation of IKK $\beta$ was assessed in cells lysed in buffer containing $50 \mathrm{mM}$ Tris, pH 7.4, $150 \mathrm{mM} \mathrm{NaCl}, 0.25 \%$ SDS, $1 \%$ NP-40, 0.5\% CHAPS, and $20 \mathrm{mM} \mathrm{N}-$ ethylmaleimide with protease inhibitor cocktail (Sigma-Aldrich), via immunoprecipitation using and antibody directed against GSH (Virogen). As a reagent control, lysates were incubated in the presence of $1 \mathrm{mM}$ DTT to decompose S-glutathionylated proteins prior to immunoprecipitation [9].

\section{Chromatin Immunoprecipitation (ChIP)}

ChIP assays were carried out as described elsewhere with minor modifications [22]. Briefly, at the appropriate times of harvest, formaldehyde (Sigma) was added to the culture medium to a final concentration of $1 \%$ and cells were incubated for $10 \mathrm{~min}$. Glycine was then added to a final concentration of $125 \mathrm{mM}$. Cells were washed with ice cold PBS and scraped into buffer containing $25 \mathrm{mM}$ Hepes (pH 7.8), $1.5 \mathrm{mM} \mathrm{MgCl} 2,10 \mathrm{mM} \mathrm{KCl}, 0.1 \% \mathrm{NP}-40$, and protease inhibitor (Sigma). A Dounce homogenizer was used to isolate nuclei, which were then resuspended in buffer containing $50 \mathrm{mM}$ Hepes $\mathrm{pH}$ (7.8), $140 \mathrm{mM} \mathrm{NaCl}, 1 \mathrm{mM}$ EDTA, $1 \%$ SDS, and protease inhibitor (Sigma). Isolated nuclei were sonicated (VibraCell Sonicator) to produce chromatin fragments of 200-1000 nucleotides in length. Following sonication, isolated chromatin was diluted 1:10 and precleared with protein-G linked magnetic Dynabeads (Invitrogen). Immunoprecipitations were performed using $2 \mu \mathrm{g}$ anti-RelA antibody (Millipore), $2 \mu \mathrm{g}$ anti-RNA Polymerase 2 antibody (Millipore), $2 \mu \mathrm{g}$ Acetylated histone $\mathrm{H} 4$ antibody (Millipore), or IgG isotype control antibody, at $4^{\circ} \mathrm{C}$ overnight with constant agitation. Protein-G linked magnetic Dynabeads (Invitrogen) were added and immunoprecipitates isolated using a DynaMag (Invitrogen) magnet rack and washed four times according to protocol. Isolated chromatin was then incubated with $20 \mu \mathrm{g}$ of Proteinase K (Roche) for $2 \mathrm{~h}$ at $55^{\circ} \mathrm{C}$, and then $65^{\circ} \mathrm{C}$ overnight to reverse the cross-links. Isolated DNA was then purified by QAlquick column (Qiagen) purification according to the manufacturer's protocol, prior to PCR analysis. Primer sequences used for PCR were as follows, forward 5'-aacaggagtggcaaatattgaga-3' and reverse 5'-cttctggcaaccttctgatg-3'.

\section{Glutaredoxin Promoter Analysis}

The online promoter mining algorithm PROMO3.0 was used to analyze the $2 \mathrm{~kb}$ sequence upstream of the GIrx1 locus derived from the NCBI MGI build 37 of the Mus musculus genome [23]. Forward primer, 5'-ctcgagtaggagagcttggctattccatgt and reverse primer 3'-agatctgctgacaggctgcagcttctccag, were designed using NCBI MGI build 37 to clone the genomic sequence $2 \mathrm{~kb}$ upstream of the Glrx1 locus, introducing an Xho1 site 5' and Bgl2 site 3'. The resultant amplicon was inserted into the pGL4.0 (Promega) vector to create Glrx1-luc. C10 cells were transfected with Glrx1-luc, $\beta$-galactosidase ( $\beta$-gal), in the presence or absence of CA-IKK $\beta .24$ $\mathrm{h}$ post transfection, cells were lysed in luciferase lysis buffer (Promega), and luciferase (Promega) and $\beta$-gal (Applied Biosystems) activity measured according 
to the manufacturer's instructions. Luciferase units were expressed as relative light units (RLU) after correction for $\beta$-gal. In select experiments, cells $\mathrm{pRL}$-TK was employed to correct for differences in transfection efficiency, and cells were analyzed with the dual-luciferase reporter assay system (Promega) according to manufacturer's protocol instructions.

\section{Mice}

Bi-transgenic mice that inducibly express constitutively active IKK $\beta$ (CA-IKK $\beta$ ) under the control of the rat clara cell secretory protein, $10 \mathrm{kDa}$ promoter were used. In these mice, expression of the CA-IKK $\beta$ transgene is induced in nonciliated bronchiolar epithelial cells of the lung, upon administration of doxycycline, as previously described [18]. For all experiments, two month old CA-IKK $\beta$ transgenic mice, or transgene negative littermates were maintained on doxycycline containing chow $(6 \mathrm{~g} / \mathrm{kg}$ ) (Purina Diet Tech) for 1 week prior to analyses. All studies were approved by the Institutional Animal Care and Use Committee at the University of Vermont.

\section{mRNA analyses}

Total RNA was isolated from C10 cells or lung tissue using the RNeasy mini-kit (Qiagen, Valencia, CA), subjected to reverse transcription and DNase treatment to produce cDNA for Taqman gene analysis using SYBR green (Biorad, Hercules, $\mathrm{CA}$ ) or Assays on Demand for the individual target genes (Applied Biosystems, Foster City, CA). Results were normalized to house keeping genes, cyclophilin, or HPRT. Primer sequences are: Glutaredoxin-1: forward; TTT ACA ACA GCT CAC CGG AG, reverse; TCA CTG CAT CCG CCT ATG (accession number: NM 053108.4) Cyclophilin: forward; TTC CTC CTT TCA CAG AAT TAT TCC A, reverse; CCA GTG CCA TTA TGG (accession number: NM 008907.1), HPRT: forward; AGA ATG TCT TGA TTG TGG AAG A, reverse; ACC TTG ACC ATC TTT GGA TTA (accession number NM 13556.2)

\section{Scratch assays}

Scratch assays were performed as previously described with modifications [24]. On Day 1 C10 were transfected with pcDNA or CA-IKK $\beta$ expression plasmid, on Day 2 cells were transfected with Grx1 SiRNA or control SiRNA, on Day 3 medium was changed and cells were allowed to recover for $24 \mathrm{~h}$. On Day 5 cells were scratched in a linear fashion using a p1000 micropippette tip, immediately following the scratch a photograph was taken of the cells using an Olympus IX70 inverted light microscope with Qlmaging Retiga 2000R digital camera. Twenty four h later, an identical photograph was taken of the same location to assess scratch closure. Scratch closure analysis was performed using ImageJ software (http://rsb.info.nih.gov/ij). All experiments were performed in triplicate, with additional samples prepared simultaneously for biochemical analysis of gene over expression and SiRNA knockdown. 


\section{Statistics}

Analyses of all data were performed using the Graph Pad Prism software (Graphpad, Inc.) by one way ANOVA or Student's $t$ test where appropriate. Data from each experiment is presented plus/minus the standard error of the mean (SEM). All experiments were repeated twice. Analyses with resultant $p$ values of $<$ 0.05 were accepted as significant.

\section{Results}

Activation of the NF-KB pathway in lung epithelial cells in vitro and in vivo results in enhanced Grx1 expression

Previous reports have demonstrated that within the lung, Grx 1 is highly expressed in airway epithelial cells, in addition to macrophages [14, 25], and in mice with allergic airway inflammation, NF-KB activation and increases in Grx1 are apparent in lung epithelium $[14,15]$. In order to determine whether Glrx1 is regulated by NF$\mathrm{KB}$, we took advantage of a transgenic mouse model wherein NF-KB activation is selectively induced in lung epithelial cells, following doxycyclin-inducible expression of CA-IKK $\beta$ [18]. Results in Fig. 2A demonstrate that Grx1 content was increased in homogenized lung tissue of mice that express the CA-IKK $\beta$ transgene, while in the absence of doxycyclin, Grx1 expression was equal to controls (not shown). Increases in Grx1 content were accompanied by increases in Grx1 mRNA (Fig. 2B). Since CA-IKKß-expressing mice display marked neutrophilic inflammation [18], it is difficult to ascertain whether increases in Grx1 expression are the direct result of NF-KB activation, or a consequence of the inflammatory process. In order to directly determine whether Grx1 expression in epithelial cells is regulated by NF-KB activation, we over expressed CA-IKK $\beta$ in a line of mouse type II alveolar epithelial cells (C10). In pcDNA vector-transfected cells, Grx1 content increased over time in culture (Fig. 2C). Following expression of CA-IKK, Grx1 content and mRNA levels were further increased (Fig. $2 \mathrm{C}$ and D). In CA-IKK $\beta$ expressing lung epithelial cells, the overall content of protein-S-glutathionylation was decreased (Fig. 2E), consistent with the observed increases in Grx1 content, and the physiological role of Grx1 in catalyzing protein-deglutathionylation. Lipopolysaccharide (LPS) is a well known activator of NF-kB, and administration of LPS to airways results in activation of NF-KB in lung epithelium, and consequently neutrophilic inflammation. Moreover, in response to administration of LPS, increases in Grx1 content were observed in the lung [26]. We therefore assessed whether LPS also increased Grx1 expression in C10 cells. Results in Fig. 2F demonstrate that LPS induced transient increases in Grx1 mRNA expression after $30 \mathrm{~min}$ and $2 \mathrm{~h}$ of exposure. At later time points, no increased in Grx1 mRNA were 
A

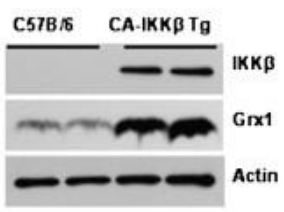

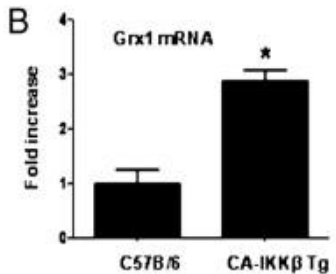

C

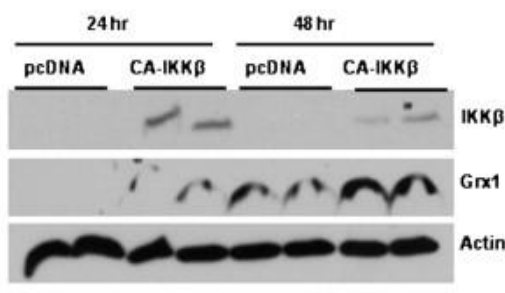

E

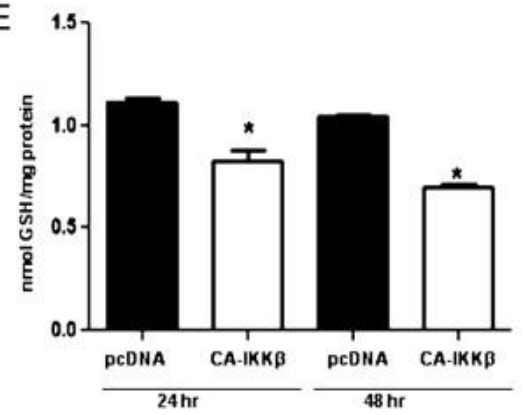

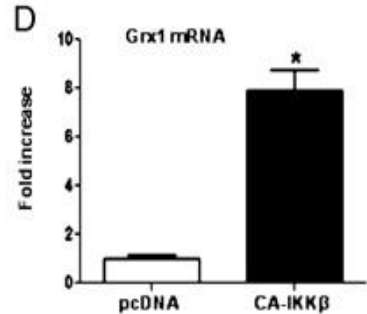

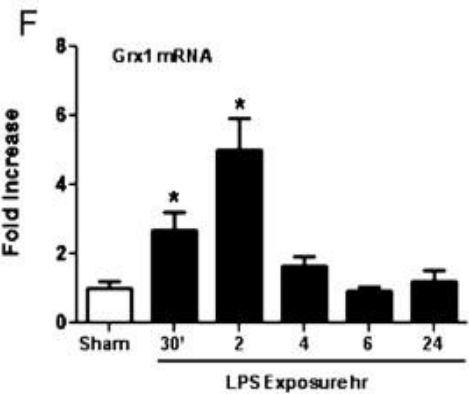

Figure 2. Increases of Grx1 expression following activation of the NF-KB pathway in lung epithelial cells. (A) Transgenic mice that express CA-IKK $\beta$ within the conducting airways, in a doxycycline inducible manner, or transgene negative littermate controls were maintained on doxycycline for 1 week. Mice were euthanized, and whole lung homogenates prepared for assessment of Grx1 expression by immunoblot analysis. IKK $\beta$ blot is shown to verify expression of trangenic IKK $\beta$. $\beta$-actin is shown as a loading control. (B) Assessment of Grx1 mRNA content by real time PCR is lung tissues from mice expressing the CA-IKK $\beta$ transgene, compared to C57B/6 littermates. Results were normalized to the housekeeping gene, HPRT, and expressed as fold increases compared to transgene negative littermate controls that were fed doxycycline containing food. Data reflect mean + SEM of 4 mice/group. ${ }^{*} p<0.05$ (ANOVA) compared to C57B/6 group. (C) Mouse alveolar type II cells (C10) were transfected with $1 \mu \mathrm{g}$ or pcDNA3 or CA-IKK $\beta$ plasmids. After 24 and $48 \mathrm{~h}$, whole cell lysates were evaluated for Grx1 expression by immunoblot analysis. $\beta$-actin: loading control. (D) Assessment of Grx1 mRNA expression via real time PCR in C10 cells transfected with $1 \mu \mathrm{g}$ or pcDNA3 or CA-IKK $\beta$ plasmids. Results were normalized to the housekeeping gene, cyclophilin, and expressed as fold increases compared to pcDNA controls. ${ }^{*} p<0.05$ (Student T Test) compared to pcDNA3 controls. (E) Assessment of protein Sglutathionylation in $\mathrm{C} 10$ cells following expression of CA-IKK 3 . 24 or 48 post transfection with PCDNA3 or CA-IKK $\beta$, cells were lysed and proteins precipitated for assessment of PSSG. The sodium borohydride dependent release of GSH was measured. Results are normalized to cellular protein content. * $\mathrm{p}<0.05$ (ANOVA) compared to pcDNA3 controls. (F) Assessment of Grx1 mRNA expression in C10 cells exposed to $1 \mathrm{\mu g} / \mathrm{ml}$ of LPS for the indicated times. Results were normalized to the housekeeping gene, cyclophilin, and expressed as fold increases compared to pcDNA controls. * $\mathrm{p}<0.05$ (ANOVA) compared to pcDNA3 controls. 
apparent. Collectively, these findings demonstrate that Grx1 expression can be induced in an NF-kB-dependent mechanism.

Stimulation of RAW264.7 cells with LPS induces expression of Grx1 in an NF-KB dependent manner

In addition to lung epithelial cells, Grx1 expression is also robust in alveolar macrophages [26]. We therefore next determined the impact of pro-inflammatory cytokines on Grx1 content in RAW264.7 macrophage like cells. RAW264.7 cells were stimulated for $24 \mathrm{~h}$ with LPS, IL-1 $\beta$, or TNF- $\alpha$, agonists known to induce NF$\mathrm{KB}$ activation. Exposure to IL-1 $\beta$ or TNF- $\alpha$, resulted in no or modest increases in Grx1 expression or activity. However, stimulation of cells with LPS resulted in a significant increase in Grx1 protein expression and activity (Fig. 3A-C).

We next sought to determine whether NF-KB activity was directly involved in LPSinduced increases in Grx1 content, by over expression of a dominant negative version of IKBa in RAW264.7 cells. As is demonstrated in Fig. 3D, over expression of dominant negative IKBa markedly inhibited LPS-induced increases in Grx1 content. As was demonstrated earlier in $\mathrm{C} 10$ lung epithelial cells (Fig. 2C), overexpression of CA-IKKR, also enhanced Grx1 expression in RAW264.7 cells in the presence or absence of LPS (Fig. 3D). Collectively these results demonstrate that LPS induces Grx1 expression in an NF-KB-dependent manner.

Identification of NF-KB binding sites within the promoter of the GIrx1 gene locus In order to further examine the molecular mechanisms regulating Grx1 expression in RAW264.7 cells, we analyzed the $2 \mathrm{~kb}$ sequence of genomic DNA upstream of the Glrx1 start codon for potential NF-KB binding sites. This sequence of genomic DNA was previously described and determined to be a transcriptionally competent promoter sequence [27]. Using the PROMO3.0 promoter mining software revealed of two regions containing putative NF-KB (p50) binding sites at -1247-1256 kb and 1307-1316 kb upstream of the transcriptional start site (Fig. 4A). We next assessed the transcriptional activity of the $2 \mathrm{~kb}$ region of the Glrx1 promoter containing the putative NF-KB sites, and assessed the impact of CA-IKK 3 , RelA/p50, or LPS on Glrx1 promoter activation. Transfection of $\mathrm{C} 10$ cells with Glrx1-luc resulted in enhanced luciferase expression over the PGL4 vector control (Fig. 4B). Cotransfection of cells with constitutively active IKK $\beta$ resulted in a concentration dependent increase in luciferase compared to vector controls (Fig. 4B). Similarly, transfection of RelA/p50 or exposure to LPS increased Glrx1-luciferase activity (Fig. 4C). In order to determine whether NF-KB could directly bind to the Glrx1 promoter, we next conducted chromatin immunoprecipitation analyses in RAW264.7 cells stimulated with LPS. Results in Fig. 4D demonstrate that binding of RelA to the Glrx1 promoter occurred between 4-24 h post stimulation of cells with LPS, which coincided with occupancy of the Glrx1 promoter with RNA polymerase II. In contrast, no RelA or RNA polymerase II was bound in unstimulated cells. Acetylated histone $\mathrm{H} 4$ was constitutively bound to the Glrx1 
promoter, suggesting that this genomic site is competent with respect to transcription factor binding [28]. In aggregate, these findings demonstrate that the Glrx1 gene can be activated by canonical NF-KB signaling.

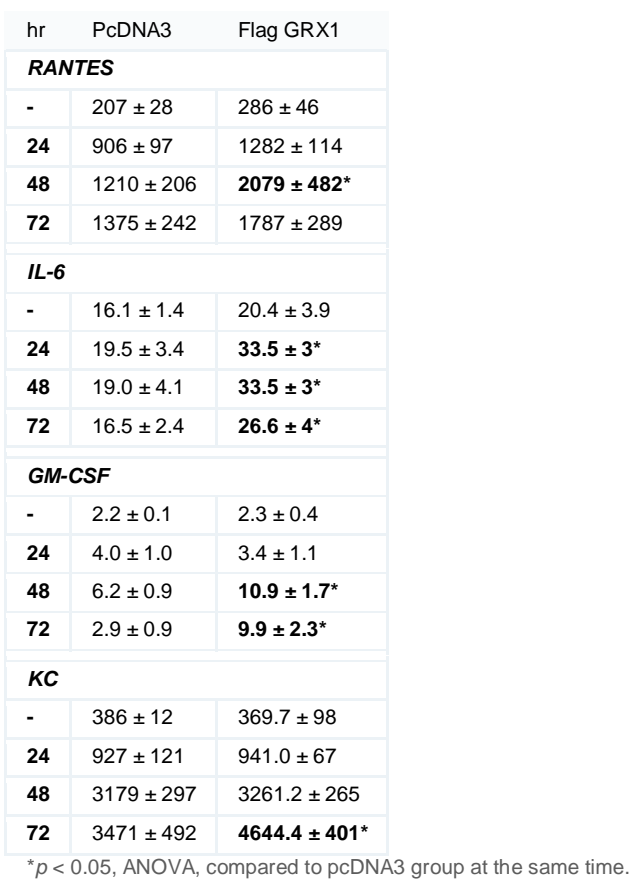

Table 1. Impact of overexpression of Grx1 on content of NF-KB dependent pro-inflammatory cytokines in C10 cells stimulated with LPS. C10 cells were transfected with $1 \mu \mathrm{g}$ of Flag-Grx1 plasmid, or PcDNA3 control, and $24 \mathrm{~h}$ later stimulated with $10 \mu \mathrm{g} / \mathrm{ml}$ of LPS for 24,48 or $72 \mathrm{~h}$. Cytokine content in medium was assessed via ELISA assays, ${ }^{*} p<0.05$, ANOVA, compared to PcDNA group at the same time.

Expression of Grx1 promotes LPS-induced NF-KB signaling in lung epithelial cells Activation of IKK 3 is the pre-requisite signal in NF-KB activation by LPS, and previously we determined that $\mathrm{H} 2 \mathrm{O} 2$ - induced S-glutathionylation of IKK $\beta$ inhibits is activity [10]. We next determined whether exposure of lung epithelial cells to LPS leads to S-glutathionylation of IKK . Indeed, results in Fig. 5A demonstrate that stimulation of $\mathrm{C} 10$ cells with LPS results in increases of $\mathrm{S}$-glutathionylation of IKK $\beta$. Incubation of cell lysates with $1 \mathrm{mM}$ dithiotreitol prior to immunoprecipitation with anti-glutathione antibody resulted in a complete loss of immunoprecipitation of IKK $\beta$ (data not shown). S-glutathionylation of IKK $\beta$ occurred at protracted time points relative to phosphorylation of RelA, degradation of $\mathrm{IKBa}$, and increases in nuclear RelA content, which are all reflective of activation of IKK 3 . We next assessed whether Grx1 overexpression would reverse increases in $S$ glutathionylation of IKK 3 in response to LPS, and the impact for NF-KB activation. 
Consistent with its physiological role in de-glutathionylation, overexpression of Grx1 prevented LPS-induced increases in S-glutathionylation of IKK $\beta$ (Fig. 5, top panel). Assessment of IKB $\alpha$ content, which is degraded upon IKK $\beta$-induced phosphorylation in response to LPS (Fig. 1A), demonstrated a second wave of IKBa degradation in cells overexpressing $\mathrm{Grx} 1$, in particular at the 4 and $6 \mathrm{~h}$ time points. Prolonged degradation of $\mathrm{I} \mathrm{KB} \alpha$ corresponded with increases in phoshorylation of RelA and nuclear content of RelA at those times, in Grx1 expressing cells, compared to pcDNA3 control cells exposed to LPS (Fig. 5). The content of LPS-induced NF-KB dependent pro-inflammatory cytokines, interleukin-6 (II-6), keratinocyte-derived chemokine (KC), granulocyte monocyte-colony stimulating factor (GM-CSF), and Regulated on Activation Normal $T$ Cell Expressed and Secreted (RANTES) in supernatants was markedly enhanced in Grx1 overexpressing cells, comparison to pcDNA3-transfected vector controls, in particular at the later time points (Table 1), demonstrating that increased expression of Grx1 enhances LPS-induced NF-KB dependent pro-inflammatory signaling.

In addition to its role in inflammation, activation of NF-KB has been demonstrated to be important in wound healing [29]. We recently demonstrated that Sglutathionylation is prominent in cells at the leading edge of a wound [19]. We therefore conducted scratch assays to determine the impact of CA-IKK $\beta$ expression of wound closure in lung epithelial cells, and the role of Grx1 therein. Results of Fig. 6 demonstrate that CA-IKK $\beta$ expressing cells showed an enhanced ability to close the wound area. However, following siRNA-mediated knock down of Grx1, the enhanced ability of CA-IKK $\beta$ expressing cells to close the wound area was completely abolished. These results suggest that Grx1 induction following CAIKK $\beta$ mediated activation of NF-KB is critical in promoting wound repair.

In aggregate, these findings suggest that NF-KB-dependent induction of Grx1 represents a feed forward regulatory mechanism to promote NF-KB signaling, by decreasing levels of protein-S-glutathionylation, which inhibit the NF-KB pathway (Fig. 7).

\section{Discussion}

NF-KB has been considered a prototypic redox-sensitive transcription factor that is induced following oxidative stress. While convincing studies exist which document activation of NF-KB following activation of NADPH oxidases or oxidative stress [30, 31], other studies have demonstrated that NF-KB is inhibited following oxidative insults [32]. The exact oxidative events that regulate the activity of NF-KB have remained elusive. Our laboratory recently demonstrated that canonical NF-KB signaling is inhibited via S-glutathionylation. Specifically we demonstrated that Sglutathionylation of cysteine 179 of the IKK $\beta$ following exposure to hydrogen peroxide $\left(\mathrm{H}_{2} \mathrm{O}_{2}, 100-200 \mu \mathrm{M}\right)$ resulted in the reversible inactivation of IKK $[10]$. 

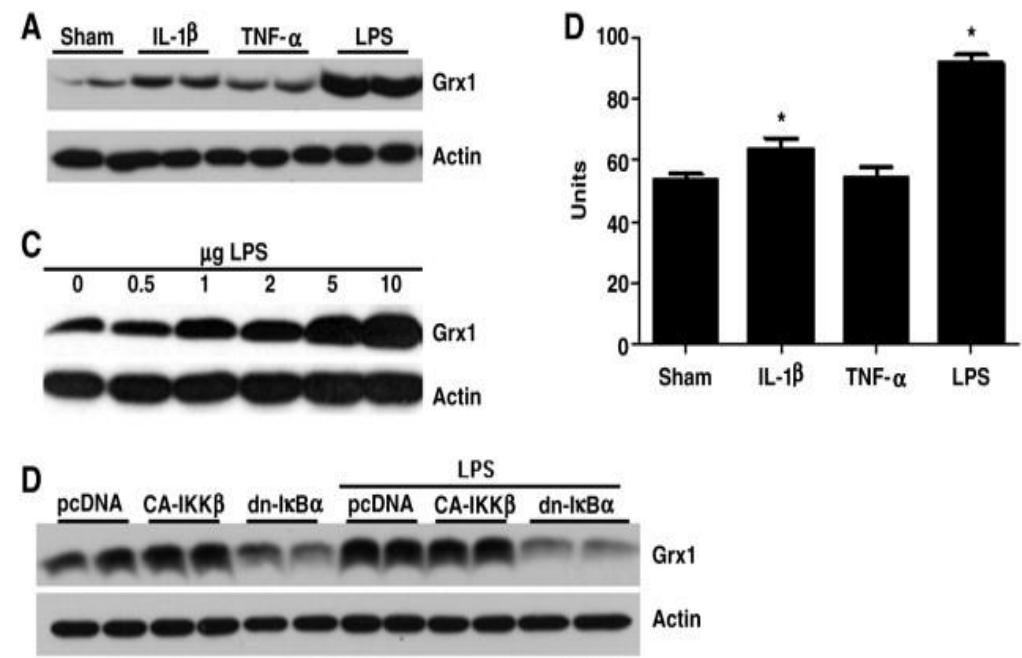

Figure 3. Expression of Grx1 in RAW264.7 macrophage like cells following stimulation with known NFKB agonists. (A) RAW264.7 cells were stimulated with $\mathrm{IL}-1 \beta(5 \mathrm{ng} / \mathrm{mL})$, TNF- $\alpha(10 \mathrm{ng} / \mathrm{mL})$, or LPS $(1 \mu \mathrm{g} / \mathrm{mL})$ for $24 \mathrm{~h}$. Whole cell lysates were resolved by SDS-PAGE and immunoblotted for Grx1, and $\beta$ actin. (B) Assessment of Grx1 activity RAW264.7 cells, $24 \mathrm{~h}$ post stimulation with agonists, as in A. Data are expressed as mean ( \pm SEM) units. ${ }^{*} p<0.05$ (ANOVA) compared to sham controls. (C) Dose dependent modulation of Grx1 content in RAW264.7 cells $24 \mathrm{~h}$ after stimulation with LPS. RAW264.7 cells were stimulated with the indicated concentrations of LPS, and after $24 \mathrm{~h}$, whole cell lysates were prepared for Western Blot analysis. (D) RAW264.7 cells were transfected with vector control (pcDNA3.0), constitutively active IKK $\beta$ (CA-IKKß), or dominant negative IKBa (dn-IKBa). $24 \mathrm{~h}$ later, cells were exposed to LPS $(1 \mu \mathrm{g} / \mathrm{ml})$ for an additional $24 \mathrm{~h}$ before immunoblot analysis for Grx1. Actin is shown as a loading control.

Importantly, the thioltransferase Grx1 effectively reversed the $\mathrm{H}_{2} \mathrm{O}_{2}$-induced Sglutathionylation of $\mathrm{IKK}$, and permitted activation of $\mathrm{NF}-\mathrm{KB}$ in the presence of $\mathrm{H}_{2} \mathrm{O}_{2}$ [10]. Other members of the NF-KB pathway have also been identified as targets for S-glutathionylation, including p50 and RelA (p65), in association with impaired DNA binding and transcriptional activation [11, 12]. A consensus cysteine has been identified in rel homology domains of all members of the NF-KB family [33], suggesting that other members of the NF-kB family also may be susceptible to redox modification.

The present study expands upon previous observations in that we demonstrate that a physiological ligand of NF-KB, LPS, results in S-glutathionylation of IKK $\beta$. Sglutathionylation of IKK $\beta$ occurred at relatively protracted times relative to IKK $\beta$ mediated phosphorylation, suggesting that $\mathrm{S}$-glutathionylation may be a negative feedback mechanism in order to decrease kinase activity. We were not able to accurately determine this using in vitro kinase assays due to the requirement of reducing agents in these assays which reverse S-glutathionylation, and additional studies are needed to determine the exact mechanism whereby S-glutathionylation inhibits the activity of IKK . Additional studies are also needed to elucidate the exact stoichiometry of S-glutathionylation of NF-KB family members in intact cells, 


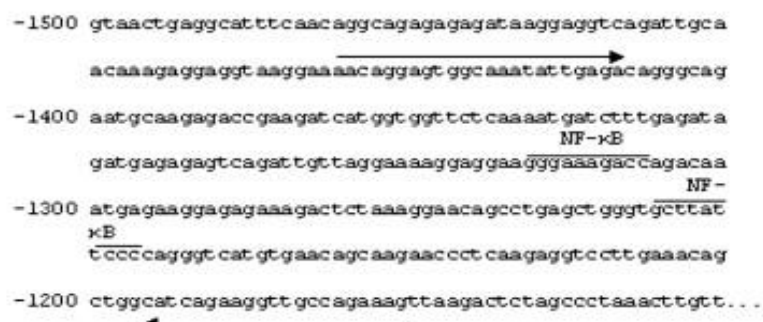

B

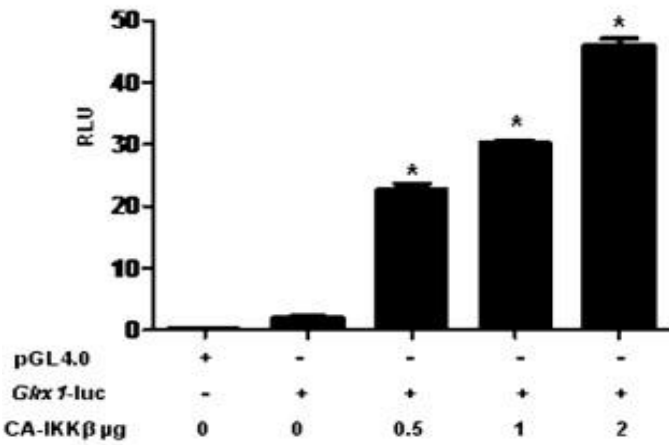

\section{СА-ІКKß $\mu$ g}

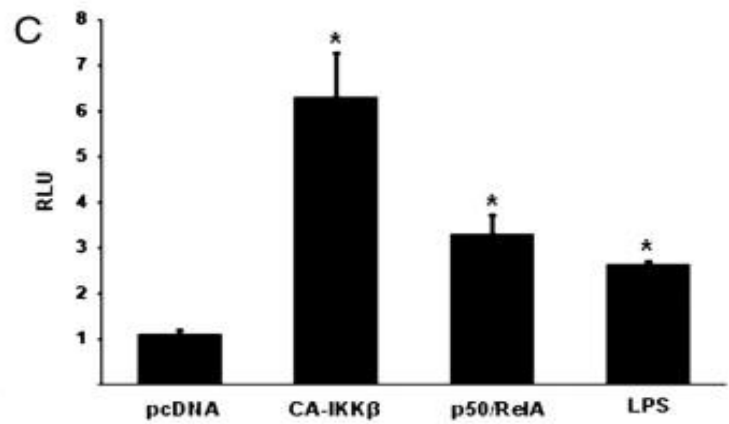

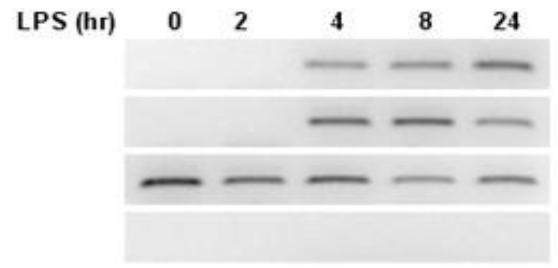

RelA

PollI

$\mathrm{AcH} 4$

$\lg G$

Figure 4. Assessment of activation of the glrx 1 promoter by NF-KB. (A) Schematic depiction of the $g / r \times 1$ promoter highlighting two putative NF-KB1 (p50) binding sites at -1250 base pairs (bp) and $-1310 \mathrm{bp}$. Arrows indicate the primer sequences used for ChIP analysis. (B) C10 cells were transfected with vector encoding $\beta$-galactosidase, empty PGL4.0 vector, or PGL4.0 vector containing the 2000 bp sequence up stream of the glrx1 gene locus (Glrx1-luc), in the presence or absence of increasing amounts of PcDNA3, or CA-IKK 3 . Cells were incubated $24 \mathrm{~h}$ prior to luciferase activity analysis. All data are expressed as mean ( \pm SEM) relative light units (RLU) normalized to $\beta$-galactosidase activity. ${ }^{*} p<0.05$ (ANOVA) compared to Glrx1-luc controls. (C) Cells were transfected with Glrx1-luc and renilla luciferase (pRL-TK), and where either co-transfected with $1 \mu \mathrm{g}$, pcDNA3, CA-IKK , or $0.5 \mu \mathrm{g}$ RelA plus $0.5 \mu \mathrm{g}$ p50. After $24 \mathrm{~h}$, pcDNA3-transfected cells were stimulated with $1 \mu \mathrm{g} / \mathrm{ml}$ LPS. All cells were harvested 24 $\mathrm{h}$ later using the dual-luciferase reporter assay system (Promega) according to manufacturer's instructions. Data are expressed as mean ( \pm SEM) relative light units (RLU) normalized to Renilla activity. ${ }^{*} p<0.05$ (ANOVA) compared to PcDNA3 controls. (D) Assessment of RelA binding to the Glrx1 promoter via ChIP analysis. RAW264.7 cells were stimulated with $1 \mu \mathrm{g} / \mathrm{ml}$ of LPS for the indicated times. Chromatin was crosslinked, sheared, and precipitated with antibodies recognizing RelA, RNA polymerase II (Pol II), or aceylated Histone H4. Pre-immune IgG antibody was used at a control. Immmunoprecipitated DNA was subjected to PCR analysis, using primer sequences indicated in Fig. $3 A$. 


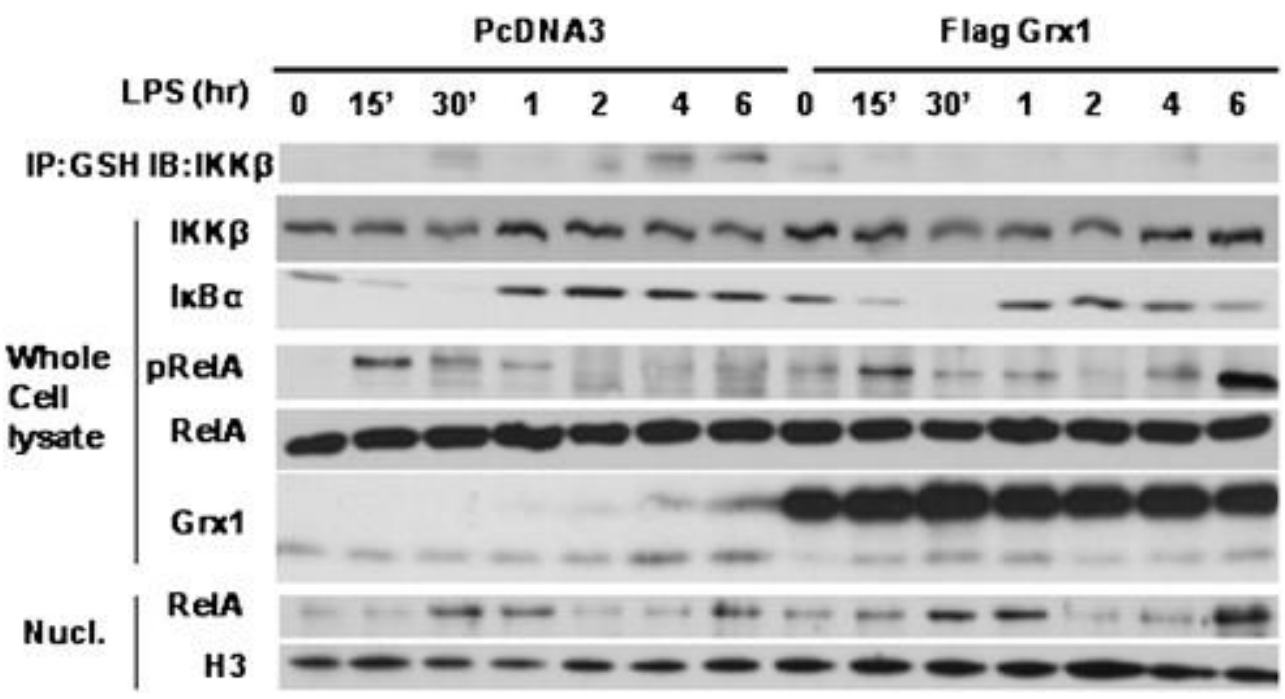

Figure 5. Assessment of the impact of over expression of Grx1 on LPS-induced NF-KB activation and S-glutathionylation of IKK $\beta$ (IKKß-SSG) in C10 lung epithelial cells. Top panel: S-glutathionylation of IKK $\beta$. At the indicated times, S-glutathionylated proteins were immunoprecipitated (IP) with anti-GSH antibody, and subjected to Western Blotting to detect IKK $\beta$. No immunoreactivity occurred in IgG control immunoprecipitations or following decomposition of protein-S-glutathionylation with DTT (data not shown). Whole cell lysates (WCL); Assessment of IKK 3 content as a control in samples used for IP, and IKBa content, and phoshorylation of RelA at serine 536 (pRelA) as measures of NF-KB activation. Total RelA: loading control, Grx1: confirmation of Grx1 overexpression. Bottom panels: Assessment of nuclear content (Nucl) of RelA in response to LPS in cells transfected with PcDNA3 (left), or Grx1 (right). H3: histone $\mathrm{H} 3$ as a loading control.

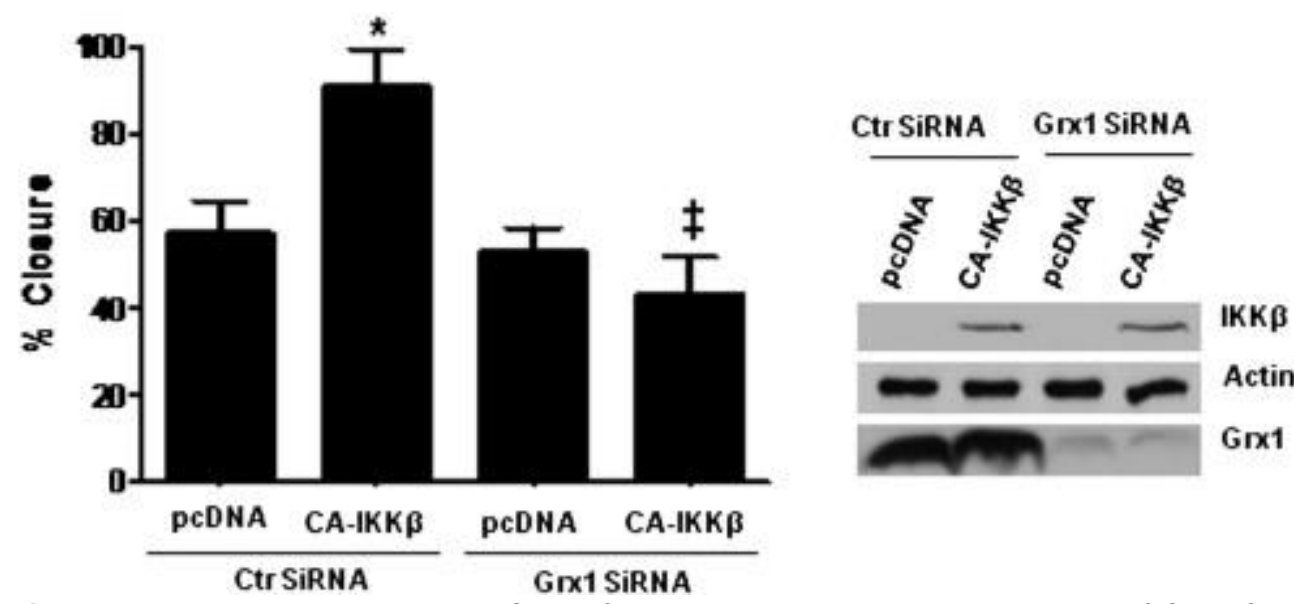

Figure 6. Enhanced wound closure in CA-IKK $\beta$ expressing cells requires the presence of Grx1. C10 cells were transfected with control SiRNA, or Grx1 SiRNA, and $24 \mathrm{~h}$ thereafter transfected with PcDNA3 or CA-IKKß. $24 \mathrm{~h}$ later, a scratch was made with a pipet tip, and $24 \mathrm{~h}$ thereafter, the \% closure of the wound area quantified. Results are representative of 6 observations conducted in two separate experiments. * $p<0.05$ (ANOVA) compared to the pcDNA group; $\ddagger p<0.05$ (ANOVA) compared to the control siRNA, CA-IKK $\beta$-transfected group. 
with consideration of formation of IKK signalsomes, subcellular localization, and unique pools of NF-KB complexes in those settings. The link between $\mathrm{S}$ glutathionylation of IKK $\beta$ and activation of NADPH oxidases also needs further study. Furthermore, the specificity of S-glutathionylation of IKK $\beta$ also will need to be unraveled, in light of the existence of many proteins with reactive cysteines that are potential targets for oxidation. Nonetheless, it is worthy of mention that glutathione S-transferase $\mathrm{P}$ was recently unraveled as a catalyst of $\mathrm{S}$ glutathionylation reactions [34, 35], and could be a major determinant for which proteins constitute biologically relevant targets for S-glutathionylation, together with Grx enzymes.

In C10 cells, which transiently increased Grx1 mRNA expression in response to LPS, overexpression of Grx1 largely prevented the LPS-induced increases in Sglutathionylation of $\mathrm{IKK} \beta$, and prolonged degradation of $\mathrm{IKB \alpha}$, phoshorylation of RelA, nuclear localization of RelA, and led to further increases in expression of diverse NF-KB dependent pro-inflammatory cytokines. In addition to its role in inflammation, NF-KB also plays a role in wound healing [29]. Results from our present study indeed demonstrate enhanced wound closure in epithelial cells expressing active $I \mathrm{KK} \beta$, and that the ability of IKK $\beta$ to facilitate wound closure required the presence of Grx1, findings which suggest a role for Grx1 in wound healing. Using a technique of Grx1-based cysteine derivatization, we previously demonstrated that S-glutathionylation was preferentially apparent in cells at the leading edge of the wound [19], which potentially is due to activation of NADPH oxidases [36]. We did not unravel whether NF-KB subunits or IKK 3 are Sglutathionylated during wound healing nor do we know the functional implications of such events. Alternatively, S-glutathionylation of actin has been shown to occur and interferes with its ability to polymerize [37]. Grx1-catalysed de-glutathionylation may be required to facilitate actin remodeling, and cell migration.

Given the functional significance of Grx1 in prolonging the activation of the NF-KB pathway, and its role in CA-IKK -induced wound closure we sought to further explore the molecular mechanisms by which Grx1 expression is regulated. The results of the present study demonstrate that Glrx1 expression is increased by activation of the canonical NF-KB pathway itself, through the direct interaction of the NF-kB subunit RelA (p65) with the glrx1 promoter. To date, little information exists regarding the transcriptional regulation of Glrx1. The human Glrx1 gene contains putative activator protein-1 (AP-1) sites in its promoter, which links expression of Glrx 1 to signaling pathways that control Fos and Jun family members [27]. Indeed, the chicken Glrx1 gene was demonstrated to be a direct target of oncogenic Jun [38], and similarly, under conditions of oxidative stress, in lens epithelial cells the human Glrx1 gene was induced in an AP-1 dependent manner [39]. Results from the present study demonstrate that both in RAW 264.7 macrophages and $\mathrm{C} 10$ lung epithelial cells, Grx1 protein expression was increased following activation of NF-KB through expression of CA-IKK 3 . The present data also clearly demonstrate that Glrx1 induction is agonist specific. Despite its well- 
known ability to activate NF-kB,TNF- $\alpha$ failed to increase Grx1 expression or activity in RAW 264.7 macrophages (Fig. 2A and B). These data suggest that besides canonical NF-KB pathway activation, other pathways may either enhance or dampen Glrx1 gene activation. Computational analysis of the Glrx1 promoter, revealed a putative PU.1 binding site adjacent to the NF-KB binding sites. PU.1 is an ETS family transcription factor associated with hematopoietic differentiation and maturation, which has been described to antagonize NF-KB signaling in macrophages [40]. Of relevance to our findings, silencing of PU.1 using short interfering RNA resulted in enhanced NF-KB signaling following stimulation of RAW264.7 cells with LPS, while conversely, overexpression of PU.1 dampened NF-KB-dependent signaling [40]. Additional studies are necessary to formally determine the repressive role of PU.1 in the activation of the Glrx1 gene, and to unravel the other transcription factors or signaling events that either enhance or dampen activation of the Glrx1 gene in response to different ligands.

Canonical NF-KB signaling is critical to the initiation of innate immune responses following exposure to bacterial toxins such as LPS. Our laboratory has demonstrated that over expression of a dominant negative version of $1 \mathrm{KBa}$ specifically within the airway epithelium is sufficient to inhibit influx of neutrophils into the lung and block inflammatory cytokine production following exposure to LPS [17]. Furthermore, we and others have demonstrated that activation of canonical NF-KB signaling within the airway epithelium is sufficient to induce an inflammatory response in the lungs, which is associated with neutrophil influx and enhanced production of inflammatory cytokines [18]. Results from the present study suggest a direct link between Grx1 expression and a feed forward mechanism for the propagation of NF-KB signaling (Fig. 7). These results would suggest that under conditions wherein Grx1 expression is increased, inflammatory responses in the lung are potentiated, while conversely, in the absence of Grx1, NF-kB-dependent inflammatory responses would be attenuated. A recent study from our laboratory demonstrated that in GIrx1 deficient mice the ability of LPS to induce acute inflammation was identical to WT mice exposed to LPS. However, a clear trend toward more rapid resolution of LPS-induced inflammation was apparent in Glrx1-/mice, which corresponded with time-dependent increases in protein-Sglutathionylation [26]. Studies examining patients with chronic obstructive pulmonary disease have correlated increases in expression of Grx1 in alveolar macrophage with disease progression and decreased lung function. In contrast, patients with sarcoidosis and allergic alveolitis show decreased expression of Grx1 in alveolar macrophages [25]. Based upon those observations, additional studies are needed to unravel the impact of Grx1 status in lung tissue on the extent and resolution of inflammatory responses, and to functionally link these associations with S-glutathionylation of NF-KB. Such endeavors will be important, given the documented roles of LPS, and Toll like receptor 4 signaling in the orchestration not only of acute inflammatory responses, and lung injury, but also in promoting allergic airways disease. 
In summary, results from the present study demonstrate that activation of the Glrx1 gene by canonical NF-KB signaling represents a feed forward mechanism to prolong NF-KB activation (Fig. 7). These findings suggest that Grx1-based control of protein-S-glutathionylation represents a post-translational mechanism to control the timing of the NF-KB activation, and point to Grx1 as a possible target to combat diseases characterized by NF-KB-driven chronic inflammation.

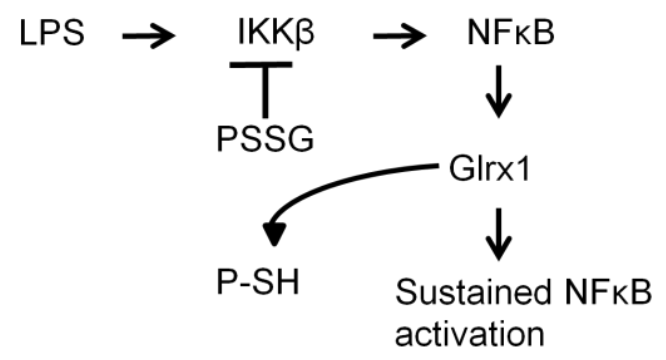

Figure 7. Model depicting the potential impact of Grx1 on prolonging activation of NF-kB. In response to stimulation with LPS, S-glutathionylation (PSSG) of IKK 3 is important to shut down the activity of NF-KB. Activation of the Glrx1 gene via canonical NF-KB activation prevents the accumulation of IKK $\beta$-SSG, thereby prolonging activation of the NF-KB pathway, and the production of pro-inflammatory mediators. Note that Grx1-catalyzed deglutathionylation results in the formation of protein sulfhydryl groups ( $\mathrm{P}-\mathrm{SH}$ ). It is plausible that in addition to IKK 3 , other members of the NF-KB pathway are regulated via Sglutathionylation and Grx1-catalyzed deglutationylation (not shown).

\section{Acknowledgements}

This work was supported by grant T32 HL076122 and R01 HL060014 from the National Institutes of Health.

\section{References}

[1] Karin, M.; Greten, F. R. NF-kappaB: linking inflammation and immunity to cancer development and progression. Nat. Rev. Immunol. 5:749-759; 2005.

[2] Ghosh, S.; Hayden, M. S. New regulators of NF-kappaB in inflammation. Nat. Rev. Immunol. 8:837$848 ; 2008$.

[3] Hayden, M. S.; Ghosh, S. Shared principles in NF-kappaB signaling. Cell 132:344-362; 2008.

[4] Karin, M.; Lin, A. NF-kappaB at the crossroads of life and death. Nat. Immunol. 3:221-227; 2002.

[5] Janssen-Heininger, Y. M.; Mossman, B. T.; Heintz, N. H.; Forman, H. J.; Kalyanaraman, B.; Finkel,

T.; Stamler, J. S.; Rhee, S. G.; van der Vliet, A. Redox-based regulation of signal transduction: principles, pitfalls, and promises. Free Radic. Biol. Med. 45:1-17; 2008.

[6] Forman, H. J.; Fukuto, J. M.; Torres, M. Redox signaling: thiol chemistry defines which reactive oxygen and nitrogen species can act as second messengers. Am. J. Physiol. Cell Physiol. 287:C246256; 2004.

[7] Adachi, T.; Weisbrod, R. M.; Pimentel, D. R.; Ying, J.; Sharov, V. S.; Schoneich, C.; Cohen, R. A. SGlutathiolation by peroxynitrite activates SERCA during arterial relaxation by nitric oxide. Nat. Med. 10:1200-1207; 2004. 
[8] Adachi, T.; Pimentel, D. R.; Heibeck, T.; Hou, X.; Lee, Y. J.; Jiang, B.; Ido, Y.; Cohen, R. A. Sglutathiolation of Ras mediates redox-sensitive signaling by angiotensin II in vascular smooth muscle cells. J. Biol. Chem. 279:29857-29862; 2004.

[9] Anathy, V.; Aesif, S. W.; Guala, A. S.; Havermans, M.; Reynaert, N. L.; Ho, Y. S.; Budd, R. C.; Janssen-Heininger, Y. M. Redox amplification of apoptosis by caspase-dependent cleavage of glutaredoxin 1 and S-glutathionylation of Fas. J. Cell Biol. 184:241-252; 2009.

[10] Reynaert, N. L.; van der Vliet, A.; Guala, A. S.; McGovern, T.; Hristova, M.; Pantano, C.; Heintz, N. H.; Heim, J.; Ho, Y. S.; Matthews, D. E.; Wouters, E. F.; Janssen-Heininger, Y. M. Dynamic redox control of NF-kappaB through glutaredoxin-regulated S-glutathionylation of inhibitory kappaB kinase beta. Proc. Natl. Acad. Sci. U. S. A. 103:13086-13091; 2006.

[11] Pineda-Molina, E.; Klatt, P.; Vazquez, J.; Marina, A.; Garcia de Lacoba, M.; Perez-Sala, D.; Lamas, S. Glutathionylation of the p50 subunit of NF-kappaB: a mechanism for redox-induced inhibition of DNA binding. Biochemistry 40:14134-14142; 2001.

[12] Qanungo, S.; Starke, D. W.; Pai, H. V.; Mieyal, J. J.; Nieminen, A. L. Glutathione supplementation potentiates hypoxic apoptosis by S-glutathionylation of p65-NFkappaB. J. Biol. Chem. 282:1842718436; 2007.

[13] Shelton, M. D.; Chock, P. B.; Mieyal, J. J. Glutaredoxin: role in reversible protein s-glutathionylation and regulation of redox signal transduction and protein translocation. Antioxid. Redox Signal. 7:348366; 2005.

[14] Reynaert, N. L.; Wouters, E. F.; Janssen-Heininger, Y. M. Modulation of glutaredoxin-1 expression in a mouse model of allergic airway disease. Am. J. Respir. Cell Mol. Biol. 36:147-151; 2007.

[15] Poynter, M. E.; Irvin, C. G.; Janssen-Heininger, Y. M. Rapid activation of nuclear factor-kappaB in airway epithelium in a murine model of allergic airway inflammation. Am. J. Pathol. 160:1325-1334; 2002.

[16] Shelton, M. D.; Distler, A. M.; Kern, T. S.; Mieyal, J. J. Glutaredoxin regulates autocrine and paracrine proinflammatory responses in retinal glial (muller) cells. J. Biol. Chem. 284:4760-4766; 2009.

[17] Poynter, M. E.; Irvin, C. G.; Janssen-Heininger, Y. M. A prominent role for airway epithelial NFkappa B activation in lipopolysaccharide-induced airway inflammation. J. Immunol. 170:6257-6265; 2003.

[18] Pantano, C.; Ather, J. L.; Alcorn, J. F.; Poynter, M. E.; Brown, A. L.; Guala, A. S.; Beuschel, S. L.; Allen, G. B.; Whittaker, L. A.; Bevelander, M.; Irvin, C. G.; Janssen-Heininger, Y. M. Nuclear factorkappaB activation in airway epithelium induces inflammation and hyperresponsiveness. Am. J. Respir. Crit. Care Med. 177:959-969; 2008.

[19] Reynaert, N. L.; Ckless, K.; Guala, A. S.; Wouters, E. F.; van der Vliet, A.; Janssen-Heininger, Y. M. In situ detection of S-glutathionylated proteins following glutaredoxin-1 catalyzed cysteine derivatization. Biochim. Biophys. Acta 1760:380-387; 2006.

[20] Janssen, Y. M.; Driscoll, K. E.; Howard, B.; Quinlan, T. R.; Treadwell, M.; Barchowsky, A.; Mossman, B. T. Asbestos causes translocation of p65 protein and increases NF-kappa B DNA binding activity in rat lung epithelial and pleural mesothelial cells. Am. J. Pathol. 151:389-401; 1997.

[21] Rahman, I.; Kode, A.; Biswas, S. K. Assay for quantitative determination of glutathione and glutathione disulfide levels using enzymatic recycling method. Nat. Protoc. 1:3159-3165; 2006.

[22] Carey, M. F.; Peterson, C. L.; Smale, S. T. Chromatin immunoprecipitation (ChIP). Cold Spring Harb. Protoc. 2009:pdb prot5279; 2009.

[23] Messeguer, X.; Escudero, R.; Farre, D.; Nunez, O.; Martinez, J.; Alba, M. M. PROMO: detection of known transcription regulatory elements using species-tailored searches. Bioinformatics 18:333-334; 2002.

[24] Bove, P. F.; Hristova, M.; Wesley, U. V.; Olson, N.; Lounsbury, K. M.; van der Vliet, A. Inflammatory levels of nitric oxide inhibit airway epithelial cell migration by inhibition of the kinase ERK1/2 and activation of hypoxia-inducible factor-1 alpha. J. Biol. Chem. 283:17919-17928; 2008.

[25] Peltoniemi, M.; Kaarteenaho-Wiik, R.; Saily, M.; Sormunen, R.; Paakko, P.; Holmgren, A.; Soini, Y.; Kinnula, V. L. Expression of glutaredoxin is highly cell specific in human lung and is decreased by transforming growth factor-beta in vitro and in interstitial lung diseases in vivo. Hum. Pathol. 35:10001007; 2004. 
[26] Aesif, S. W.; Anathy, V.; Kuipers, I.; Guala, A. S.; Reiss, J. N.; Ho, Y. S.; Janssen-Heininger, Y. M. Ablation of glutaredoxin-1 attenuates lipopolysaccharide-induced lung inflammation and alveolar macrophage activation. Am. J. Respir. Cell Mol. Biol. 44:491-499; 2011.

[27] Park, J. B.; Levine, M. The human glutaredoxin gene: determination of its organization, transcription start point, and promoter analysis. Gene 197:189-193; 1997.

[28] Vettese-Dadey, M.; Grant, P. A.; Hebbes, T. R.; Crane- Robinson, C.; Allis, C. D.; Workman, J. L. Acetylation of histone $\mathrm{H} 4$ plays a primary role in enhancing transcription factor binding to nucleosomal DNA in vitro. EMBO J. 15:2508-2518; 1996.

[29] Egan, L. J.; de Lecea, A.; Lehrman, E. D.; Myhre, G. M.; Eckmann, L.; Kagnoff, M. F. Nuclear factor-kappa B activation promotes restitution of wounded intestinal epithelial monolayers. Am. J. Physiol. Cell Physiol. 285:C1028-1035; 2003.

[30] Li, Q.; Harraz, M. M.; Zhou, W.; Zhang, L. N.; Ding, W.; Zhang, Y.; Eggleston, T.; Yeaman, C.; Banfi, B.; Engelhardt, J. F. Nox2 and Rac1 regulate H2O2-dependent recruitment of TRAF6 to endosomal interleukin-1 receptor complexes. Mol. Cell. Biol. 26:140-154; 2006.

[31] Schreck, R.; Rieber, P.; Baeuerle, P. A. Reactive oxygen intermediates as apparently widely used messengers in the activation of the NF-kappa B transcription factor and HIV-1. EMBO J. 10:2247-2258; 1991.

[32] Hayakawa, M.; Miyashita, H.; Sakamoto, I.; Kitagawa, M.; Tanaka, H.; Yasuda, H.; Karin, M.; Kikugawa, K. Evidence that reactive oxygen species do not mediate NF-kappaB activation. EMBO J. 22:3356-3366; 2003.

[33] Kelleher, Z. T.; Matsumoto, A.; Stamler, J. S.; Marshall, H. E. NOS2 regulation of NF-kappaB by Snitrosylation of p65. J. Biol. Chem. 282:30667-30672; 2007.

[34] Xiong, Y.; Uys, J. D.; Tew, K. D.; Townsend, D. M. S-glutathionylation: from molecular mechanisms to health outcomes. Antioxidants \& redox signaling 15:233-270; 2011.

[35] Townsend, D. M.; Manevich, Y.; He, L.; Hutchens, S.; Pazoles, C. J.; Tew, K. D. Novel role for glutathione S-transferase pi. Regulator of protein S-Glutathionylation following oxidative and nitrosative stress. The Journal of biological chemistry 284:436-445; 2009.

[36] Wesley, U. V.; Bove, P. F.; Hristova, M.; McCarthy, S.; van der Vliet, A. Airway epithelial cell migration and wound repair by ATP-mediated activation of dual oxidase 1. J. Biol. Chem. 282:32133220; 2007.

[37] Dalle-Donne, I.; Giustarini, D.; Rossi, R.; Colombo, R.; Milzani, A. Reversible S-glutathionylation of Cys 374 regulates actin filament formation by inducing structural changes in the actin molecule. Free Radic. Biol. Med. 34:23-32; 2003.

[38] Goller, M. E.; lacovoni, J. S.; Vogt, P. K.; Kruse, U. Glutaredoxin is a direct target of oncogenic jun. Oncogene 16:2945-2948; 1998.

[39] Krysan, K.; Lou, M. F. Regulation of human thioltransferase (hTTase) gene by AP-1 transcription factor under oxidative stress. Invest. Ophthalmol. Vis. Sci. 43:1876-1883; 2002.

[40] Zeng, H.; Ornatowska, M.; Joo, M. S.; Sadikot, R. T. TREM-1 expression in macrophages is regulated at transcriptional level by NF-kappaB and PU.1. Eur. J. Immunol. 37:2300-2308; 2007. 


\section{CHAPTER 3}

\section{Cigarette smoke targets glutaredoxin 1, increasing S- glutathionylation and epithelial cell death}

Ine Kuipers*, Amy S Guala ${ }^{\ddagger}$, Scott W Aesif ${ }^{\ddagger}$, Gonda Konings ${ }^{*}$, Freek G Bouwman ${ }^{\dagger}$, Edwin C Mariman ${ }^{\dagger}$, Emiel FM Wouters ${ }^{*}$, Yvonne MW Janssen-Heininger ${ }^{\ddagger}$, and Niki L Reynaert*§

American Journal of Respiratory Cell \& Molecular Biology. 2011 Nov;45(5):931-7

\section{Abstract}

It is established that cigarette smoke causes irreversible oxidations in lung epithelial cells and can lead to their death. However, its impact on reversible and physiologically relevant redox-dependent protein modifications remains to be investigated. Glutathione is an important anti-oxidant against inhaled reactive oxygen species as a direct scavenger, but it can also covalently bind protein thiols upon mild oxidative stress to protect them against irreversible oxidation. This posttranslational modification, known as S-glutathionylation, can be reversed under physiological conditions by the enzyme glutaredoxin 1 (Grx1). The aim of this study was to investigate if cigarette smoke modifies Grx1 and if this impacts on protein Sglutathionylation and epithelial cell death. Upon exposure of alveolar epithelial cells to cigarette smoke extract (CSE) a decrease in Grx1 mRNA and protein expression was observed, in conjunction with decreased activity and increased protein Sglutathionylation. Using mass spectrometry, irreversible oxidation of recombinant Grx1 by CSE and acrolein was demonstrated, which was associated with attenuated enzyme activity. Furthermore, carbonylation of Grx1 in epithelial cells after exposure to CSE was shown. Overexpression of Grx1 attenuated CSEinduced increases in protein S-glutathionylation and increased survival. Conversely, primary tracheal epithelial cells of mice lacking Grx1 were more sensitive to cigarette smoke-induce cell death with corresponding increases in protein S-glutathionylation.

These results show that cigarette smoke can modulate Grx1 not only at the expression level, but can also directly modify Grx1 itself, decreasing its activity. These findings demonstrate a role for the Grx1/S-glutathionylation redox system in cigarette smoke induced lung epithelial cell death. 


\section{Background}

Chronic Obstructive Pulmonary Disease (COPD) is a leading cause of morbidity and mortality in the United States (1) that is mainly caused by cigarette smoking. Cigarette smoke (CS) contains $10^{16}$ free radicals per cigarette (2), including reactive oxygen (ROS) and reactive nitrogen species (RNS). Inhalation of these oxidants in combination with the production of ROS/RNS by macrophages and neutrophils leads to oxidative stress. Oxidants in CS can cause direct cellular damage by lipid peroxidation (3), DNA damage (4) and irreversible protein oxidations $(5,6)$.

The pulmonary epithelium is equipped with lining fluid (ELF) that contains high concentrations of glutathione (GSH) (7), which is an important anti-oxidant against inhaled ROS. CS is known to acutely deplete GSH, thereby decreasing the lungs' anti-oxidant capacity and making it vulnerable to oxidant-induced injury. As an adaptive response to oxidative stress, such as in smokers, GSH levels increase in the ELF due to upregulation of the rate limiting enzyme in GSH synthesis, $\square$ glutamylcysteine ligase (8). GSH in concert with its redox cycle partners serves to maintain the reduced state of protein thiol groups. This can be achieved by direct scavenging of oxidants or by covalently and reversibly binding protein thiols. The latter formation of mixed disulfides between protein thiols and GSH occurs under physiological conditions and can be induced upon mild oxidative stress, and is known as S-glutathionylation or S-glutathiolation. S-glutathionylation is believed to protect its targeted protein thiols from further irreversible oxidations. Additionally, S-glutathionylation can modulate protein function. For instance, our laboratory previously described the inhibition of Inhibitory kappa B kinase $\beta$ (IKK $\beta$ ) activity, the enzyme responsible for NF- $\square \mathrm{B}$ activation under pro-inflammatory conditions, through S-glutathionylation of cysteine 179 after oxidative challenge of lung epithelial cells (9).

Under physiological conditions, S-glutathionylation can be reduced by glutaredoxins (Grx) (10). Several mammalian Grxs have been identified. Grx1 localizes primarily to the cytosol while Grx2 is present in mitochondria and the nucleus. Recently, Grx3 has gained interest for its altered expression in lung cancer, although this isoform does not exhibit deglutathionylation activity (11).

In the lungs, Grx1 expression is predominant in macrophages and bronchial epithelium and has been shown to be altered in allergic airway disease (12), COPD (13) and after acute exposure to LPS (14). So far, little is known about the regulation of Grx expression. In the context of COPD for instance, it is unknown if CS itself influences Grx expression or can modify its activity. Moreover, the effects of CS on protein S-glutathionylation remain to be determined. The aim of this study was therefore to investigate the effects of CS on the Grx/protein S- 
glutathionylation axis in lung epithelial cells, and furthermore to investigate their role in CS induced-cell death.

\section{Materials and Methods}

\section{Cell Culture}

A human transformed alveolar epithelial cell line, A549, was obtained from the American Type Culture Collection (Manassas, VA, USA) and cultured in RPMI 1640 (Gibco, Grand Island, NY, USA) containing 10\% FBS (Biochrome, Berlin, Germany), L-glutamine (2 $\mathrm{mM}$ ) and penicillin/streptomycin (Invitrogen, Grand Island, NY,USA). Twenty-four hours before stimulation, cells were cultured in DMEM/F12 without phenol red and $0.5 \%$ FBS.

Glrx $1^{-/}$mice, a kind gift of dr. Ho (Wayne State University, Detroit, MI), and their littermate controls were used to isolate primary tracheal epithelial cells (MTE) as described previously (15) with minor modifications (16). Cells were cultured in full medium lacking phenol red for $24 \mathrm{~h}$ prior to stimulation. The institutional Animal Care and Use Committee granted approval for all procedures.

Cigarette smoke extract

3R4F Research Cigarettes, from the University of Kentucky (Lexington, KT, USA), were removed from their filters and cigarette smoke extract (CSE) was made according to (17).

\section{Grx1 luciferase reporter assay}

Transient transfections were performed using Fugene (Roche) according to the manufacturer's instructions using $1.75 \mu \mathrm{g}$ human grx1 promotor luciferase plasmid, kindly provided by Dr. Park (US Department of Agriculture). Co-transfection with $0.25 \mu \mathrm{g}$ pSV- $\beta$-galactosidase was employed to correct for differences in transfection efficiency. Luciferase (Promega) and $\beta$-galactosidase (Tropix) activity were measured according to the manufacturer's instructions.

Grx1 activity assay

Grx1 activity assay was performed as described in (18). Data were expressed as $\mu \mathrm{mol} \mathrm{NADPH} /$ minutes/mg protein (19).

Grx1 catalyzed cysteine derivatization for in situ detection of S-glutathionylated proteins

S-glutathionylated proteins were detected in cells as described earlier (16).

Quantitative determination of protein S-glutathionylation using 5,5'-dithio-bis(2nitrobenzoic acid) (dTNB)

Cells were lysed in $137 \mathrm{mM}$ Tris- $\mathrm{HCl}, \mathrm{pH} 8.0,130 \mathrm{mM} \mathrm{NaCl}$, and 1\% NP-40 and cleared by centrifugation. $200 \mu \mathrm{g}$ of protein was acetone precipitated for $20 \mathrm{~min}$ at - 
$20^{\circ} \mathrm{C}$ and next resuspended and sonicated in extraction buffer. Furthermore the determination of protein S-glutathionylation was conducted as described in (20).

\section{Mass spectrometry}

Recombinant Grx1 was incubated for $24 \mathrm{~h}$ at RT in the dark in $0.1 \%$ trifluoroacetic acid (TFA) with $2.5 \%$ or $5 \%$ CSE, or equimolar concentrations of acrolein. For mass spectrometric analysis, $1 \mu \mathrm{l}$ of recombinant Grx $1(10 \mathrm{pmol} / \mu \mathrm{l})$ and $1 \mu \mathrm{l}$ matrix solution ( $10 \mathrm{mg} / \mathrm{ml}$ Sinapinic acid in $40 \%$ acetonitrile/ $0.1 \%$ TFA) were spotted on a 384-well target plate of a MALDI-TOF/TOF (4800 MALDI TOF/TOF analyzer, Applied Biosystems). The instrument was operated in positive linear mode, mid mass range. Acquisition mass range was 10000-15000 Da.

\section{Detection of Grx1 carbonylation in vitro}

Grx1 was immunoprecipitated from A549 cells and carbonyls were derivatized using an oxyblot kit (Millipore). Carbonylation of Grx1 was visualized on an SDSPAGE gel using the DNP antibody.

\section{Assessment of cell viability}

Cells were harvested by trypsinization, pelleted and washed twice with PBS. Next propidium iodide $(1 \mu \mathrm{g} / \mathrm{ml})$ was added and cell viability assessed by flow cytometry.

\section{Results}

\section{CSE downregulates Grx1 expression}

In order to investigate the effect of CS on Grx1 expression, we first exposed A549 cells transiently expressing a human Grx1 promotor luciferase construct to CSE and measured Grx1 promoter activity using a luciferase assay. Results in Fig. 1A demonstrate that $\beta$-galactosidase corrected Grx1 luciferase activity was dosedependently inhibited by treatment with CSE for $48 \mathrm{~h}$. Significant attenuation of Grx1 promoter activity was also observed after $24 \mathrm{~h}$ of exposure to $2.5 \% \mathrm{CSE}$, but not after 4h (Fig 1B). Grx1 mRNA (Fig. 1C) was negatively affected by 5\% CSE after both 24 and $48 \mathrm{~h}$ of exposure. In contrast, no significant alterations in the expression of Grx2 mRNA were observed (data not shown). Protein levels of Grx1 were decreased upon CSE exposure in A549 cells (Fig. 1D, left) as well as in MTE cells (Fig. 1D, right). 
Figure 1

A

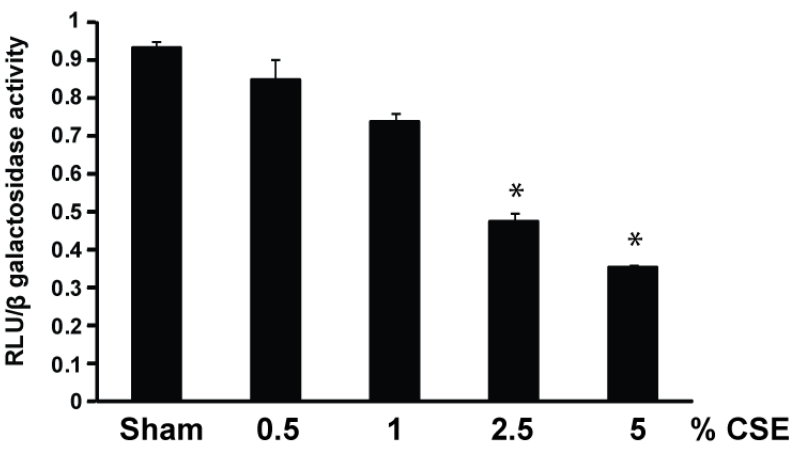

B

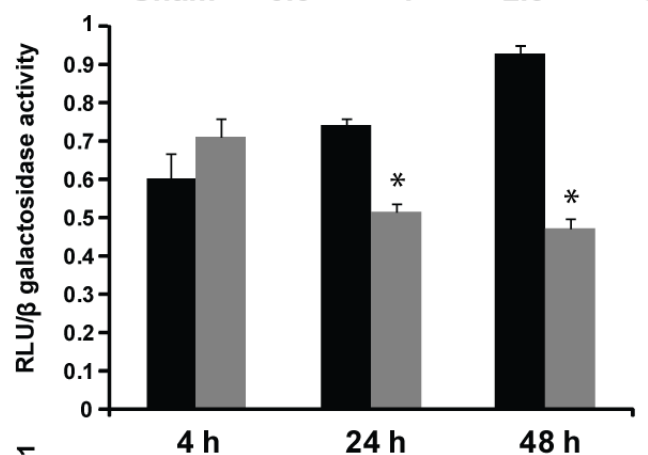

C

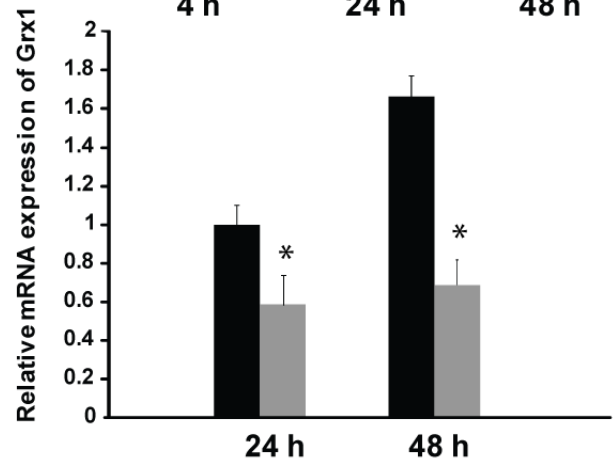

D
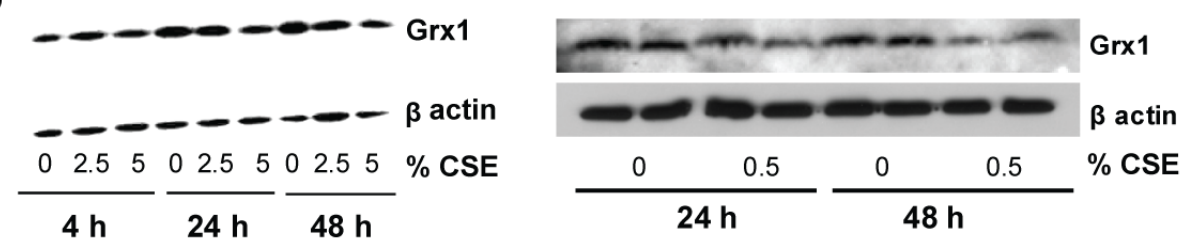

Fig. 1: CSE downregulates Grx1 expression. A549 cells were transiently transfected with a human Grx1 promotor luciferase construct and $\beta$-galactosidase and exposed to CSE. (A) Cells were treated for $48 \mathrm{~h}$ with indicated doses of CSE and luciferase activity was measured and corrected for $\beta$-galactosidase. 
(B) Cells were control treated (black bars) or exposed to 2.5\% CSE (grey bars). After 4, 24 and $48 \mathrm{~h}$ luciferase activity was measured and corrected for $\beta$-galactosidase. (C) A549 cells were control treated (black bars) or exposed to 5\% CSE (grey bars) and expression of Grx1 mRNA was measured by QPCR and corrected for HPRT. Data are expressed as fold-change over control treated cells at $24 \mathrm{~h}$. (D) Protein expression of Grx1 was determined by Western blotting in A549 cells (left panel) and in primary MTE cells exposed to CSE (right panel). The level of $\beta$-actin was measured as a loading control. * $p$ value $<0.05$ compared to untreated controls, analyzed by ANOVA.

Grx activity is attenuated and protein S-glutathionylation increased by CSE exposure

Because of the observed attenuation of Grx1 expression by CSE, we next assessed Grx activity and protein S-glutathionylation in A549 and MTE cells. As expected, Grx activity was attenuated by 2.5 and $5 \%$ CSE in A549 cells after 24 and 48h, although not significant (Fig. 2A, left), in agreement with results on mRNA and protein expression. In MTE cells Grx1 activity decreased as well after 48h, but not $24 \mathrm{~h}$ of exposure to $0.5 \%$ CSE (Fig. 2A, right). We next assessed the impact of decreased Grx levels and activity on the overall content of cellular protein Sglutathionylation. Results in the left panel of Fig. 2B demonstrate that protein Sglutathionylation was augmented after CSE exposure in a dose and time dependent fashion in A549 cells. MTE cells showed a significant induction of Sglutathionylated proteins only after $48 \mathrm{~h}$ of CSE exposure (Fig. 2B, right), coinciding with the decreased activity at this time point. CSE-induced increases in protein Sglutathionylation were corroborated by in situ detection of S-glutathionylated proteins using Grx1-catalyzed cysteine derivatization in MTE cells stimulated with $0.5 \%$ CSE for $48 \mathrm{~h}$ (Fig. 2C). Total free GSH in A549 cells was measured using the DTNB recycling method and showed $50 \%$ depletion of GSH upon stimulation with $5 \%$ CSE for 24 and 48h (data not shown). This attenuation of free GSH levels occurs in conjunction with enhanced protein S-glutathionylation.

\section{Modulation of Grx1 protein by CS}

A recent study demonstrated that Grx1 can be oxidized and inhibited by a variety of oxidants (21). In order to investigate whether CS could directly modify the Grx1 protein, we incubated recombinant human Grx 1 with 2.5 and $5 \%$ CSE for $24 \mathrm{~h}$ and assessed mass modifications by MALDI-TOF mass spectrometry, as well as activity. Incubation of Grx 1 with $2.5 \%$ CSE resulted in a mass addition of approximately $58 \mathrm{Da}$ compared to untreated protein (Fig. 3A). This mass addition occurred in a concentration dependent manner as incubation with 5\% CSE further increased the presence of the modified protein to $63.5 \%$ and was non-reversible by DTT (Table 1). Moreover, mass addition did not occur after pre-incubation of Grx1 with the cysteine alkylating agent $\mathrm{N}$-ethylmaleimide (NEM) (data not shown), implying that the mass addition occurs on a cysteine residue. Acrolein is a $58 \mathrm{Da}$ highly oxidative component of CS, which is reactive towards cysteine residues. We next incubated recombinant Grx1 with an equimolar amount of acrolein to assess 
Figure 2

A
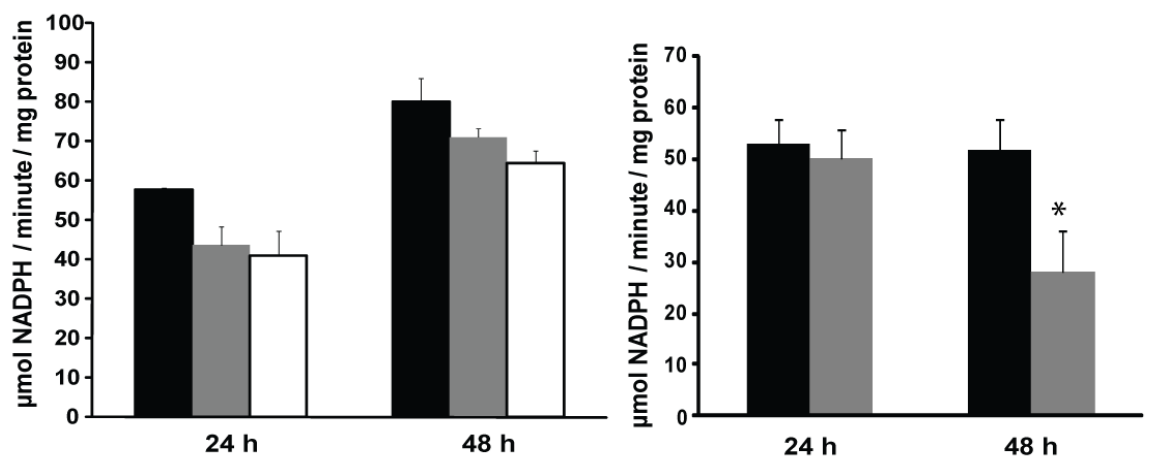

B
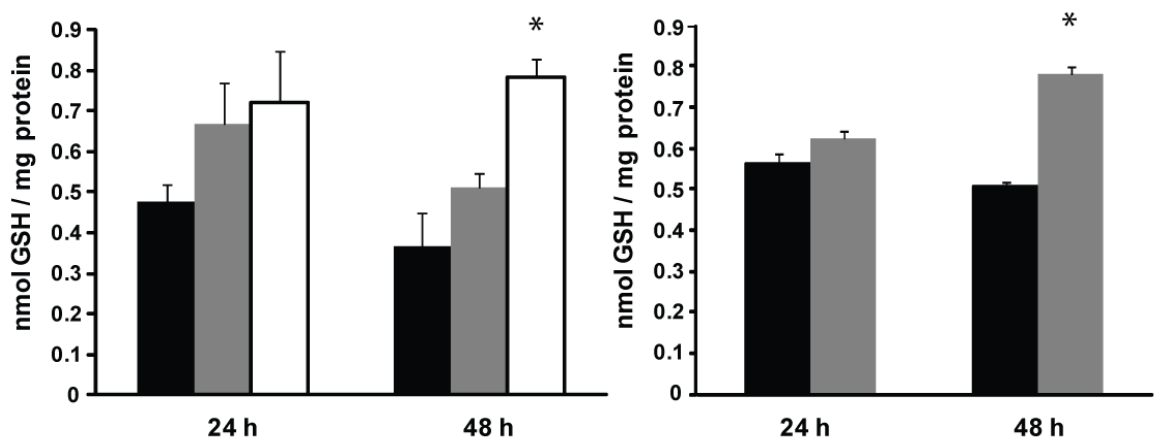

C
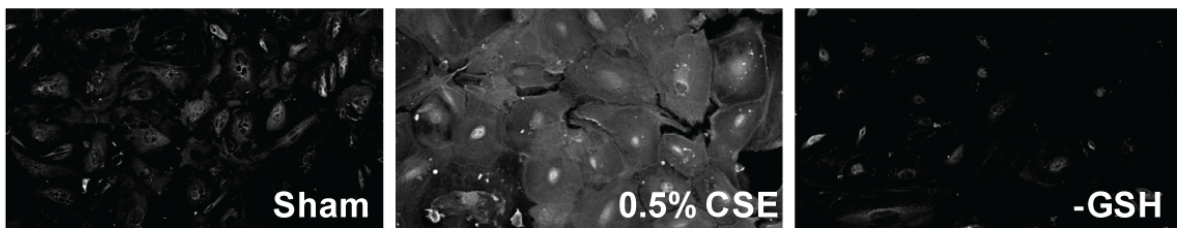

Fig. 2: Grx activity is attenuated and protein S-glutathionylation increased by CS. A549 cells were control treated (black bars), exposed to $2.5 \%$ (grey bars) or 5\% (white bars) CSE. After 24 and $48 \mathrm{~h}$ Grx activity (Fig. 2A, left panel) and protein S-glutathionylation (Fig. 2B, left panel) were measured. MTE cells were control treated (black bars) or exposed to $0.5 \%$ CSE (grey bars) for 24 and $48 \mathrm{~h}$ and Grx activity (Fig. 2A, right panel) and protein S-glutathionylation (Fig. 2B, right panel) were measured. (C) Protein S-glutathionylation was visualized using Grx1-catalyzed cysteine derivatization in primary MTE cells treated for $48 \mathrm{~h}$ with $0.5 \% \mathrm{CSE}$. $-\mathrm{GSH}$ : omission of glutathione in the Grx1 reduction mix as a negative control. * $p$-value $<0.05$ compared to untreated controls, analyzed by ANOVA. 
whether the mass addition observed by CSE could be due to acrolein present in CSE. Indeed, here we also detected a DTT irreversible mass addition of $58 \mathrm{Da}$ (Table 1). Addition of $116 \mathrm{Da}$, indicative of oxidation of 2 cysteine residues by acrolein could also be found in Grx1 using higher concentration of CSE or acrolein (Table 1). Incubation of recombinant Grx1 with CSE dose dependently attenuated its activity in a DTT irreversible fashion and similar effects were observed following exposure to acrolein (Fig. 3B).

\section{Table 1}

Grx1 untreated

Grx1 $+2.5 \%$ CSE

$\mathrm{Grx} 1+5 \% \mathrm{CSE}$

Grx1 + 5\% CSE + DTT

Grx1+acrolein equimolar

Grx1+acrolein equimolar+DTT

\begin{tabular}{ccc} 
\% unmodified & \% addition of $58 \mathrm{Da}$ & $\%$ addition of $116 \mathrm{Da}$ \\
\hline 100 & & \\
61.1 & 33.4 & 5.5 \\
36.5 & 53.3 & 10.2 \\
30.2 & 58.1 & 11.7 \\
& 83.3 & 16.7 \\
& 84.7 & 15.3
\end{tabular}

Table 1: Percentage of recombinant Grx1 that is modified by either CSE or purified acrolein in an equimolar concentration of the recombinant protein. Both conditions show no changes when preincubated with DTT.

To investigate whether oxidation of Grx1 also occurs in cells, Grx1 was immunoprecipitated form A549 cells stimulated with CSE for $48 \mathrm{~h}$. Carbonylation of Grx1 was then investigated using an oxyblot kit. Results in Fig. $3 \mathrm{C}$ indicated that 2,5 and $5 \%$ CSE exposure resulted in carbonylation of Grx1, demonstrating that Grx1 is not only oxidized by CSE in a cell free environment, but that oxidation of Grx1 also takes place in epithelial cells. As a positive control recombinant Grx1 exposed to CSE was derivatized which showed carbonylation as well.

Effect of Grx1 modulation on CS-induced protein S-glutathionylation and epithelial cell death

We next sought to investigate whether the observed attenuation of Grx1 by CSE is linked to CSE-induced cell death. We therefore first exposed A549 cells that were transiently transfected with Flag-tagged Grx1 to CSE. In pcDNA transfected cells, CSE dose dependently induced cell death. After 24h, cells overexpressing Grx1 demonstrated significant protection against CSE-induced cell death at high doses of CSE. Moreover, transfection with $1 \mu \mathrm{g}$ Flag-Grx1 offered better protection compared to transfection with $0.5 \mu \mathrm{g}$ (Fig. 4A). In agreement with Fig. 2B, CSE increased total protein S-glutathionylation in pcDNA transfected cells. Flag-Grx1 overexpression however, provided protection against smoke-induced Sglutathionylation in a dose dependent manner (Fig. 4B). 
Figure 3
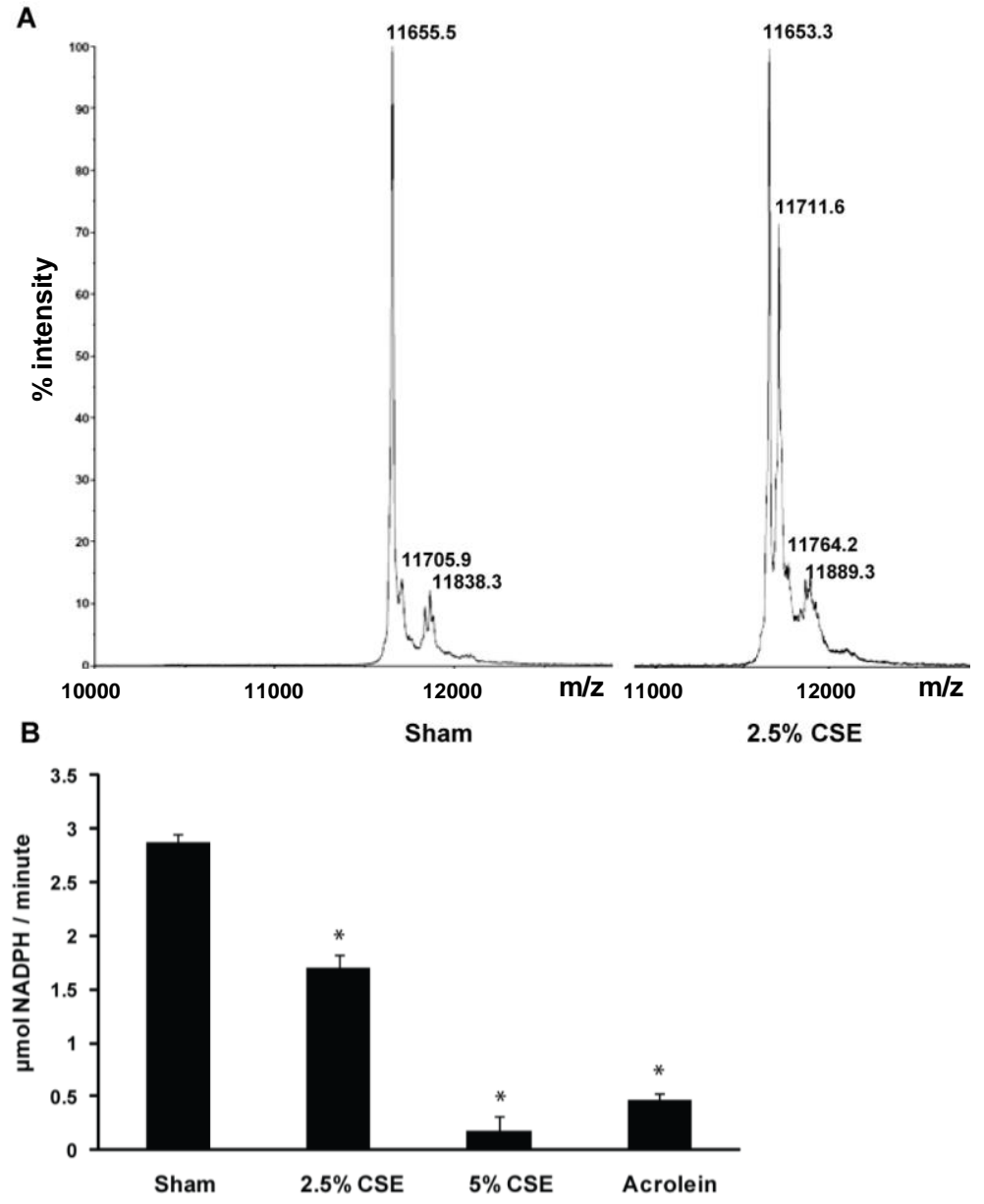

C derivatization

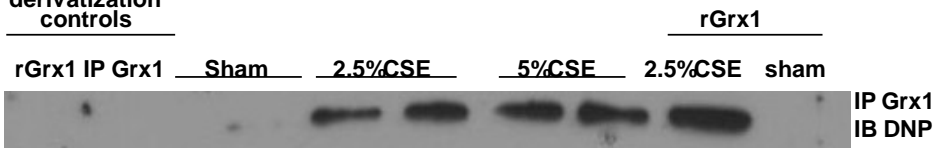

IB Grx1

Fig. 3: Modulation of Grx1 protein by CS. (A) Recombinant human Grx1 control (left spectrum), or exposed to $2.5 \%$ CSE (right spectrum) for $24 \mathrm{~h}$ at RT and analyzed by MALDI-TOF mass spectrometry. Numbers in spectra indicate the mass of the product. (B) Assessment of recombinant Grx1 activity after 24h of treatments. (C) Carbonylation of immunoprecipitated Grx1 from lysates of A549 cells. Negative derivatization control for recombinant Grx1 (rGrx1) and Grx1 immunoprecipitated from lysates (IP Grx1) exposed to CSE. Derivatization of recombinant Grx1 exposed to CSE and control in the last two lanes. * p-value $<0.05$ compared to untreated control, analyzed by ANOVA. 
To further investigate the importance of Grx1 in CS-induced cell death MTE cells isolated from Glrx $1^{-1}$ mice were used. MTE cells in general were more sensitive to CSE-induced cell death compared to A549 cells as marked death was observed with concentrations as low as $1 \%$. MTE cells lacking Glrx1 demonstrated significantly more cell death compared to cells isolated from littermate controls at all doses of CSE tested (Fig. 5A). Total protein S-glutathionylation was furthermore only increased in cells isolated from Glrx $1^{-/}$mice using $1 \%$ CSE (Fig. 5B).

Taken together, these data indicate that the decreased content and activity of Grx1 after CSE exposure is indeed responsible for observed increases in total protein Sglutathionylation and contributes to CSE-induced death of lung epithelial cells.

\section{Discussion}

Previous research regarding CS-induced oxidative stress has focused on irreversible oxidations linked to damage, while ignoring the effects of CS on physiologically relevant oxidations that can reversibly modify function. The objective of the present study therefore was to investigate whether CS can cause changes in protein S-glutathionylation, an oxidation which can be reversed by glutaredoxins, and if changes in this S-glutathionylation-Grx1 redox system play a role in epithelial cell death provoked by CS.

This is the first report to demonstrate attenuation of Grx1 expression and Grx activity by CSE, in concert with increased protein S-glutathionylation in lung epithelial cells. In patients with COPD it has been shown that the number of Grx1 positive macrophages was decreased in the lungs along with decreases in Grx1 protein levels in whole lung homogenates. In contrast, in sputum supernatants more Grx1 was detected during acute exacerbations (13). Protein Sglutathionylation was not investigated in the latter study, but elevated levels were reported in blood samples of smokers compared to non-smokers (22). The present study in cell culture models confirms the previous reports regarding the modulation of Grx1 expression and protein S-glutathionylation in patients with COPD and healthy smokers. However, CS probably did not directly affect mRNA expression of Grx1, since attenuated levels of Grx1 mRNA could only be observed after at least $24 \mathrm{~h}$ of exposure. It would appear more likely that CS acts on signaling pathways that modulate transcription factors that in turn regulate Grx1 mRNA expression. Interestingly, the decreased expression of Grx1 observed after TGF $\beta$ treatment also occurred only after $24 \mathrm{~h}$ (mRNA, (12)) or $72 \mathrm{~h}$ (protein, (23)). The signaling intermediates and transcription factors involved in the modulation of Grx1 mRNA remain to be investigated. There is only a single study regarding potentially important transcription factor binding sites and regulatory regions in the human Grx1 promoter (24), which need to be evaluated in detail in future research. CSE and TGF $\beta$ both downregulate Grx1 mRNA expression, which for TGF $\beta$ appears to fit into a general repressive effect on antioxidant genes, whereas this is not the case for smoke. No effects of CS on Grx2 mRNA were observed, which is in line 
Figure 4

A

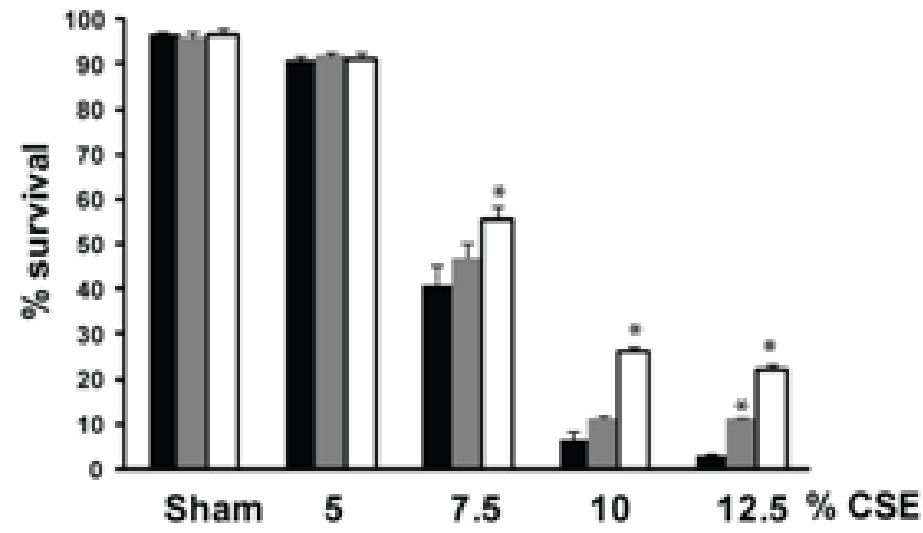

B

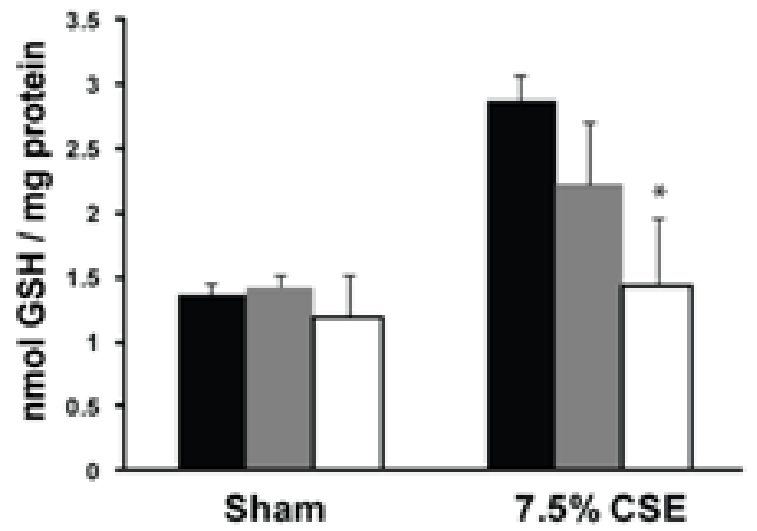

Fig. 4: Overexpression of Grx1 confers partial protection against CS-induced epithelial cell death and smoke-induced increases in protein S-glutathionylation. A549 cells were transiently transfected with PcDNA (black bars), $0.5 \square \mathrm{g}$ Flag-Grx1 (grey bars) or $1 \mu \mathrm{g}$ Flag-Grx1 (white bars) and treated with CSE for $24 \mathrm{~h}$. (A) Cell death was assessed by flow cytometry using PI uptake. The percentage of analyzed cells that did not take up PI was expressed as \% survival. (B) Protein S-glutathionylation. ${ }^{*}$ p-value < 0.05 compared to pcDNA control exposed to CSE, analyzed by ANOVA. 
with previous studies in which only levels of Grx1 were affected, but not of Grx2 (12). It is however possible that the activity of Grx2 is altered by smoke exposure, as this isoform is actived when the active site is opened up upon monomerization, which can be accomplished by oxidation (25). The activity assay used here furthermore does not distinguish between the different isoforms. Together this could explain why the strong effects observed on Grx1 expression and on recombinant Grx1 activity after CSE exposure do not translate into equally strong effects on total cellular Grx activity.

In addition to the attenuated expression of Grx1 in response to CSE exposure, we observed elevated levels of Grx1 mRNA, protein and activity in control cells over time in culture. Accordingly, protein S-glutathionylation levels were also decreased over time in culture. Some previous reports have linked Grx1 to cell proliferation. For instance, the enzyme was first discovered as an alternative electron donor for ribonucleotide reductase in $E$. coli, an enzyme essential to DNA synthesis in proliferating cells (26). In addition, Grx1 has been shown to control actin Sglutathionylation and its polymerization status after growth factor stimulation, which was postulated to play a role in the formation of signal transduction scaffolds and the cellular response to growth factors (27). The increased levels of Grx1 in culture over time could potentially be linked to proliferation as the experiments were performed at subconfluency and minor proliferation could still be observed using $0.5 \%$ FBS.

In the present study we show that CS not only attenuated Grx1 expression, but that the Grx1 protein itself was modified by CSE, thereby decreasing its activity (Fig. 3A and $\mathrm{C}$ and table I). It was determined that CSE exposure resulted in Grx1 adduct formation through both alkylation by acrolein, and carbonylation. Acrolein is the most highly oxidative compound in CS and is known to irreversibly bind proteins, probing them for rapid proteolytic degradation (6). It is therefore plausible that alkylation of Grx1 leads to proteolytic degradation, a scenario that needs to be formally tested. Nonetheless, results from the present study demonstrate that CS targets Grx1 via multiple mechanisms which have implications for cell survival.

Cysteines with a low pKa are prone to S-glutathionylation upon mild oxidative stress, and when S-glutathionylation occurs at a critical cysteine, this can modify the activity and conformation of the targeted protein. In the present study we demonstrated that CS exposure enhanced total levels of protein Sglutathionylation (Fig 2B and C). Further studies are needed to investigate which particular proteins are targeted by S-glutathionylation. The function of proteins potentially involved in disease pathogenesis such as IKK 3 and NF-KB, AP-1 and matrix metalloproteases have been shown to be affected by $S$-glutathionylation and in some instances by alterations in $\operatorname{Grx} 1$ levels $(9,28)$. Variations in $\mathrm{Grx} 1$ and 
S-glutathionylation of these proteins could therefore contribute to the pathophysiology of COPD.

Some of the target proteins of S-glutathionylation are known to modulate cell death (18), a process that has gained interest as a mechanism in the development of COPD (29). Here we demonstrate that modulation of Grx1 expression, in conjunction with alterations in protein S-glutathionylation in lung epithelial cells affects their survival in response to CS. So far, Grx1 has been reported to have a cardioprotective role and reduce ROS production after ischemia and reperfusion in Glrx1 transgenic mouse hearts. Conversely, Glrx $1^{-1}$ mice and Grx1 inhibition by cadmium increased infarct size and ROS production (30). In addition, lens epithelial cells of Glrx $1^{-1 /}$ mice exhibited increased sensitivity to oxidative stress as they had a reduced ability to clear $\mathrm{H}_{2} \mathrm{O}_{2}$ and administration of recombinant $\mathrm{Grx} 1$ restored anti-oxidant capacity (31). In the present study, we show that primary MTE cells isolated from Glrx $1^{-/}$mice were more sensitive to CS-induced cell death compared to wild type controls, in association with enhanced protein S-glutathionylation. Conversely, overexpression of Grx1 in an epithelial cell line was found to protect against CS-induced cell death, while attenuating the induction of $\mathrm{S}$ glutathionylation in response to CSE. Collectively, these data indicate that the decreased expression of Grx1 and attenuation of Grx activity after CSE exposure are indeed responsible for observed increases in total protein S-glutathionylation and contribute to CSE-induced death of lung epithelial cells. However, additional studies need to be conducted to unravel the target proteins for increased Sglutathionylation that contribute to cell death after CS. Mediators of apoptosis and cell death shown to be modulated by the S-glutathionylation / Grx1 axis include procaspase-3 (32), multiple members of the NF-KB survival pathway (33), ASK1 (34) and Fas (18).

Taken together, there is increasing evidence for Grx1 as a potentially therapeutically relevant candidate for enhancing cell survival upon CS exposure. A previous study showed a similar protective effect using recombinant Thioredoxin-1, another member of the thioredoxin family, in the CS exposure model for COPD in mice (35). Restoring Grx1 content in the lungs after exposure to CS may therefore have implications in enhancing cell survival and therefore potentially help to prevent the development of emphysema. 
Figure 5

A

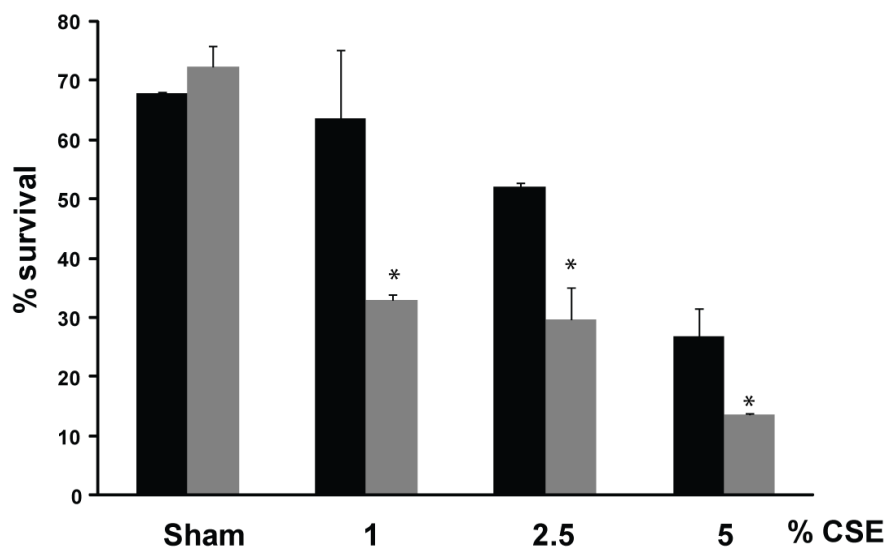

B

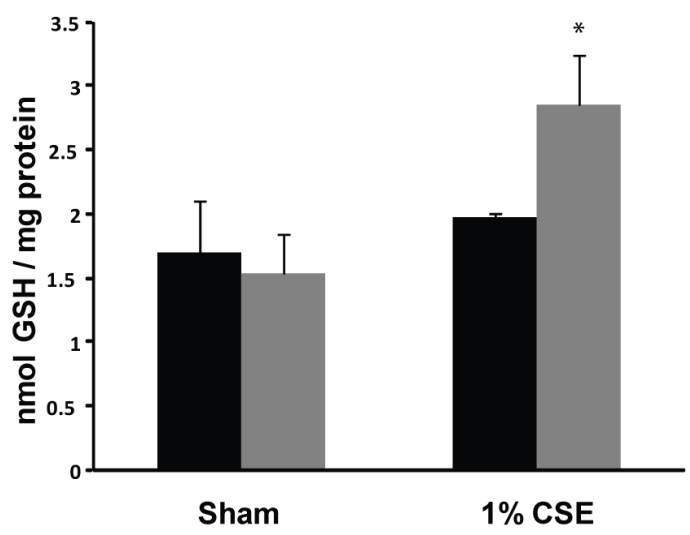

Fig. 5: Increased smoke-induced cell death and protein S-glutathionylation in MTE cells from Glrx $1^{-1}$ mice. MTE cells isolated from wild type (black bars) or Glr $\times 1^{-/-}$mice (gray bars) were treated with CSE for 24h. (A) Cell death was assessed by flow cytometry using PI uptake. (B) Protein S-glutathionylation. * $p$-value $<0.05$ compared to cells from litter mate controls exposed to CSE, analyzed by ANOVA. 


\section{References}

1. Mannino DM. COPD: Epidemiology, prevalence, morbidity and mortality, and disease heterogeneity. Chest 2002;121(5 Suppl):121S-126S.

2. Pryor WA, Prier DG, and Church DF. Electron-spin resonance study of mainstream and sidestream cigarette smoke: Nature of the free radicals in gas-phase smoke and in cigarette tar. Environ Health Perspect 1983;47:345-55.

3. Frei B, Forte TM, Ames BN, and Cross CE. Gas phase oxidants of cigarette smoke induce lipid peroxidation and changes in lipoprotein properties in human blood plasma. Protective effects of ascorbic acid. Biochem J 1991;277 ( Pt 1):133-8.

4. Kiyosawa $H$, Suko M, Okudaira $H$, Murata K, Miyamoto $T$, Chung $M H$, Kasai $H$, and Nishimura S. Cigarette smoking induces formation of 8-hydroxydeoxyguanosine, one of the oxidative DNA damages in human peripheral leukocytes. Free Radic Res Commun 1990;11(1-3):23-7.

5. Reznick AZ, Cross CE, Hu ML, Suzuki YJ, Khwaja S, Safadi A, Motchnik PA, Packer L, and Halliwell B. Modification of plasma proteins by cigarette smoke as measured by protein carbonyl formation. Biochem J 1992;286 ( Pt 2):607-11.

6. Panda K, Chattopadhyay R, Chattopadhyay D, and Chatterjee IB. Cigarette smoke-induced protein oxidation and proteolysis is exclusively caused by its tar phase: Prevention by vitamin c. Toxicol Lett 2001;123(1):21-32.

7. Cantin AM, North SL, Hubbard RC, and Crystal RG. Normal alveolar epithelial lining fluid contains high levels of glutathione. J Appl Physiol 1987;63(1):152-7.

8. Rahman I. Regulation of glutathione in inflammation and chronic lung diseases. Mutat Res 2005;579(1-2):58-80.

9. Reynaert NL, van der Vliet A, Guala AS, McGovern T, Hristova M, Pantano C, Heintz NH, Heim J, Ho YS, Matthews DE, Wouters EF, and Janssen-Heininger YM. Dynamic redox control of nf-kappab through glutaredoxin-regulated s-glutathionylation of inhibitory kappab kinase beta. Proc Natl Acad Sci U S A 2006;103(35):13086-91.

10. Yang Y, Jao S, Nanduri S, Starke DW, Mieyal JJ, and Qin J. Reactivity of the human thioltransferase (glutaredoxin) c7s, c25s, c78s, c82s mutant and nmr solution structure of its glutathionyl mixed disulfide intermediate reflect catalytic specificity. Biochemistry 1998;37(49):17145-56.

11. Cha MK, and Kim IH. Preferential overexpression of glutaredoxin3 in human colon and lung carcinoma. Cancer Epidemiol 2009;33(3-4):281-7.

12. Reynaert NL, Wouters EF, and Janssen-Heininger YM. Modulation of glutaredoxin-1 expression in a mouse model of allergic airway disease. Am J Respir Cell Mol Biol 2007;36(2):147-51.

13. Peltoniemi MJ, Rytila PH, Harju TH, Soini YM, Salmenkivi KM, Ruddock LW, and Kinnula VL. Modulation of glutaredoxin in the lung and sputum of cigarette smokers and chronic obstructive pulmonary disease. Respir Res 2006;7(1):133.

14. Aesif SW, Kuipers I, Anathy V, Guala AS, Reiss JN, Ho YS, and Janssen-Heininger YM. Ablation of glutaredoxin-1 attenuates lipopolysaccharide-induced lung inflammation and alveolar macrophage activation. Am J Respir Cell Mol Biol;(In press).

15. Wu R, and Smith D. Continuous multiplication of rabbit tracheal epithelial cells in a defined, hormone-supplemented medium. In Vitro 1982;18(9):800-12.

16. Reynaert NL, Ckless K, Guala AS, Wouters EF, van der Vliet A, and Janssen-Heininger YM. In situ detection of s-glutathionylated proteins following glutaredoxin-1 catalyzed cysteine derivatization. Biochim Biophys Acta 2006;1760(3):180-7.

17. Carp H, and Janoff A. Possible mechanisms of emphysema in smokers. In vitro suppression of serum elastase-inhibitory capacity by fresh cigarette smoke and its prevention by antioxidants. Am Rev Respir Dis 1978;118(3):617-21. 
18. Anathy V, Aesif SW, Guala AS, Havermans M, Reynaert NL, Ho YS, Budd RC, and JanssenHeininger YM. Redox amplification of apoptosis by caspase-dependent cleavage of glutaredoxin 1 and s-glutathionylation of fas. J Cell Biol 2009;184(2):241-52.

19. Gan ZR, and Wells WW. Purification and properties of thioltransferase. J Biol Chem 1986;261(3):996-1001.

20. Rahman I, Kode A, and Biswas SK. Assay for quantitative determination of glutathione and glutathione disulfide levels using enzymatic recycling method. Nat Protoc 2006;1(6):3159-65.

21. Hashemy SI, Johansson $\mathrm{C}$, Berndt $\mathrm{C}$, Lillig $\mathrm{CH}$, and Holmgren A. Oxidation and Snitrosylation of cysteines in human cytosolic and mitochondrial glutaredoxins: Effects on structure and activity. J Biol Chem 2007;282(19):14428-36.

22. Muscat JE, Kleinman W, Colosimo S, Muir A, Lazarus P, Park J, and Richie JP, Jr. Enhanced protein glutathiolation and oxidative stress in cigarette smokers. Free Radic Biol Med 2004;36(4):464-70.

23. Peltoniemi M, Kaarteenaho-Wiik R, Saily M, Sormunen R, Paakko P, Holmgren A, Soini Y, and Kinnula VL. Expression of glutaredoxin is highly cell specific in human lung and is decreased by transforming growth factor-beta in vitro and in interstitial lung diseases in vivo. Hum Pathol 2004;35(8):1000-7.

24. Park JB, and Levine M. The human glutaredoxin gene: Determination of its organization, transcription start point, and promoter analysis. Gene 1997;197(1-2):189-93.

25. Lillig $\mathrm{CH}$, Berndt $\mathrm{C}$, Vergnolle O, Lonn ME, Hudemann C, Bill E, and Holmgren A. Characterization of human glutaredoxin 2 as iron-sulfur protein: A possible role as redox sensor. Proc Natl Acad Sci U S A 2005;102(23):8168-73.

26. Holmgren A. Hydrogen donor system for escherichia coli ribonucleoside-diphosphate reductase dependent upon glutathione. Proc Natl Acad Sci U S A 1976;73(7):2275-9.

27. Wang J, Tekle E, Oubrahim H, Mieyal JJ, Stadtman ER, and Chock PB. Stable and controllable rna interference: Investigating the physiological function of glutathionylated actin. Proc Natl Acad Sci U S A 2003;100(9):5103-6.

28. Krysan K, and Lou MF. Regulation of human thioltransferase (httase) gene by AP-1 transcription factor under oxidative stress. Invest Ophthalmol Vis Sci 2002;43(6):1876-83.

29. Demedts IK, Demoor T, Bracke KR, Joos GF, and Brusselle GG. Role of apoptosis in the pathogenesis of copd and pulmonary emphysema. Respir Res 2006;7:53.

30. Malik G, Nagy N, Ho YS, Maulik N, and Das DK. Role of glutaredoxin-1 in cardioprotection: An insight with glrx1 transgenic and knockout animals. J Mol Cell Cardiol 2008;44(2):261-9.

31. Lofgren S, Fernando MR, Xing KY, Wang Y, Kuszynski CA, Ho YS, and Lou MF. Effect of thioltransferase (glutaredoxin) deletion on cellular sensitivity to oxidative stress and cell proliferation in lens epithelial cells of thioltransferase knockout mouse. Invest Ophthalmol Vis Sci 2008;49(10):4497-505.

32. Pan S, and Berk BC. Glutathiolation regulates tumor necrosis factor-alpha-induced caspase-3 cleavage and apoptosis: Key role for glutaredoxin in the death pathway. Circ Res 2007;100(2):213-9.

33. Mieyal JJ, Gallogly MM, Qanungo S, Sabens EA, and Shelton MD. Molecular mechanisms and clinical implications of reversible protein S-glutathionylation. Antioxid Redox Signal 2008;10(11):1941-88.

34. Song JJ, Rhee JG, Suntharalingam M, Walsh SA, Spitz DR, and Lee YJ. Role of glutaredoxin in metabolic oxidative stress. Glutaredoxin as a sensor of oxidative stress mediated by $\mathrm{H}_{2} \mathrm{O}_{2}$. J Biol Chem 2002;277(48):46566-75.

35. Sato A, Hoshino Y, Hara T, Muro S, Nakamura H, Mishima M, and Yodoi J. Thioredoxin-1 ameliorates cigarette smoke-induced lung inflammation and emphysema in mice. $\mathrm{J}$ Pharmacol Exp Ther 2008;325(2):380-8. 


\title{
CHAPTER 4
}

\section{Smoke decreases revesible oxidations S- glutathionylation and S-nitrosylation in mice}

Ine Kuipers ${ }^{1}$, Ken R Bracke ${ }^{2}$, Guy G Brusselle ${ }^{2}$, Emiel FM Wouters ${ }^{1}$ and Niki L Reynaert ${ }^{*}$

Free Radic Res. 2012 Feb;46(2):164-73

\begin{abstract}
Cigarette smoke causes irreversible oxidations in lungs, but its impact on reversible and physiologically relevant redox-dependent protein modifications remains to be investigated.

Here the effect of cigarette smoke exposure in mice was investigated on the covalent binding of glutathione to protein thiols, known as S-glutathionylation (PSSG), which can be reversed by glutaredoxins (Grx). Also, protein Snitrosylation (PSNO) which is the modification of protein thiols by NO and which is reversed by the enzyme alcohol dehydrogenase (ADH) 5 was examined.

Both PSSG and PSNO levels in lung tissue were markedly decreased after four weeks of cigarette smoke exposure. This coincided with attenuated protein free thiol levels and increased protein carbonylation. The mRNA expression of oxidant generating enzyme NOX4, DHE sensitive oxidant production and iNOS mRNA and protein levels were induced by cigarette smoke, whereas Grx 1 mRNA expression and activity were attenuated. Free GSH levels were unaffected by smoke exposure and no alterations in protein expression or activity of ADH5 were observed.

Taken together, smoke exposure decreases reversible cysteine oxidations PSSG and PSNO, and enhances protein carbonylation. These alterations are not associated with differences in some of the regulatory enzymes, but are likely the result of oxidative stress. It remains to be investigated which specific proteins are differentially modified, to what extent their function is affected and if this contributes to pathology.
\end{abstract}




\section{Introduction}

1.3 billion people worldwide smoke tobacco, exposing themselves directly to a mixture of over 4000 hazardous chemicals and oxidative compounds associated with various pulmonary and cardiovascular diseases. Cigarette smoking is the most important risk factor for chronic obstructive pulmonary disease (COPD), which is characterized by chronic bronchitis and emphysema. Oxidative stress is an important hallmark of COPD, which is defined by an accumulation of oxidants that outweighs the anti-oxidant protective system present in the lung. Free radicals, reactive oxygen (ROS) and nitrogen (RNS) species are directly produced during cigarette smoking and their release is induced upon activation and infiltration of phagocytes into the lungs.

Cellular damage by free radicals and oxidants includes lipid peroxidation (1), DNA damage (2) and irreversible protein oxidations $(3,4)$, which have been demonstrated in patients with COPD and in cigarette smoke exposed mice and are used as oxidative stress measures $(5,6)$. Less well studied are mild reversible protein oxidations that occur on specific cysteine residues and that have been shown to modulate protein function in a regulatable fashion. These oxidations that are therefore considered posttranslational modifications have furthermore been shown to protect against damaging, irreversible oxidations. In oxidative stress mediated diseases such as COPD these reversible oxidations could therefore play a very important role, through their protective as well as modulating effects. It should be noted that the modulating effects are not always protective and that a loss of these redox-dependent posttranslational modifications that are considered protective from the chemical perspective could actual not be beneficial with respect to altered protein function.

The two most studied protein oxidations linked to protective redox signaling are S-nitrosylation and S-glutathionylation. S-nitrosylation is the attachment of NO to the thiol group of cysteine amino acids in proteins. Chemically, the thiol group needs to be oxidized first or $\mathrm{NO}$ needs to be activated to $\mathrm{NO}^{+}$for protein $\mathrm{S}$ nitrosylation to occur. Alternatively, the NO group can be transferred between proteins or delivered by glutathione (GSH). S-nitrosylation can be reversed by non enzymatic pathways such as by metal ions, ascorbic acid and light. The major enzyme related to denitrosylation is alcohol dehydrogenase 5 (ADH5) which is also referred to as nitrosoglutathione (GSNO) reductase $(7,8)$.

GSH serves to protect the reduced state of protein thiol groups by either directly scavenging oxidants or alternatively by covalently and reversibly binding to protein thiols. The latter formation of mixed disulfides occurs under physiological conditions, can be induced upon mild oxidative stress and is known as S-

glutathionylation. Under physiological conditions, S-glutathionylation can be reduced by glutaredoxins (Grx). Several mammalian Grx have been identified. Grx1 localizes primarily to the cytosol while Grx2 is present in the mitochondria and 
nucleus (9). Recently, Grx3 has gained interest for its altered expression in lung cancer, although this isoform does not exhibit deglutathionylation activity (10).

There is major overlap between the proteins targeted by S-nitrosylation and Sglutathionylation. This is not surprising since $S$-nitrosylation can be considered an intermediate oxidation that can precede S-glutathionylation. Examples of target proteins whose function is altered by these oxidations include the transcription factors NF-KB and AP-1 and some of their regulatory enzymes (11-15), MMP9 (16, 17) and caspase $3(18,19)$.

Redox signaling can thus be manifested trough S-nitrosylation and Sglutathionylation in a highly specific and regulated manner. Potential alterations in these posttranslational modifications and functional consequences should therefore be considered in addition to damaging oxidations in oxidative stress mediated diseases. In this paper, we thus investigated S-nitrosylation and Sglutathionylation in mice exposed to cigarette smoke. It was hypothesized that smoke exposure would lead to a switch from protective to damaging oxidations, possibly through alterations in regulatory enzymes.

\section{Materials and methods}

\section{Animals and smoke exposure}

Eight week old male C57BL/6 mice were obtained from The Jackson Laboratory (Bar Harbor, ME, USA). They received food and water ad libitum and were exposed to cigarette smoke as described previously (20). Briefly, a group of 7 mice were exposed whole body to the tobacco smoke of five cigarettes (Cigarette 3R4F, without filter, University of Kentucky, Lexington, KY) four times a day with 30-min smoke-free intervals, 5 days a week for 4 weeks, leading to a serum level of carboxyhemoglobin of $8.3 \pm 1.4 \%$, which is similar to the level observed in smokers. The control group was exposed to air. The local Ethics Committee for animal experimentation of the Faculty of Medicine and Health Sciences of Ghent University approved the in vivo manipulations.

Grx1 catalyzed cysteine derivatization for in situ detection of S-Glutathionylated proteins

Frozen tissue sections were thawed and washed twice with PBS before being fixed with $4 \%$ paraformaldehyde (PFA) for 10 minutes at RT. After three washes with PBS slides were permeabilized and free thiol groups were blocked using $25 \mathrm{mM}$ Hepes, pH 7.4, 0.1 mM EDTA, pH 8.0, $0.01 \mathrm{mM}$ neocuproine (Sigma), $40 \mathrm{mM} \mathrm{N}$ ethylmaleimide (Sigma) and $1 \%$ Triton (Sigma) for 30 minutes. After three washes with PBS, S-glutathionylated cysteine groups were reduced by incubation with 13.5 $\mu \mathrm{g} / \mathrm{ml}$ human Grx1 (Lab Frontiers), $35 \mu \mathrm{g} / \mathrm{ml} \mathrm{GSSG}$ reductase (Roche), $1 \mathrm{mM} \mathrm{GSH}$ (Sigma), $1 \mathrm{mM} \mathrm{NADPH}$ (Sigma), $18 \mu \mathrm{mol}$ EDTA and $137 \mathrm{mM}$ Tris, pH 8.0, for 20 minutes. As a control GSH was left out of this mix. After three washes with PBS, newly reduced cysteine residues were labelled with $1 \mathrm{mM} \mathrm{N}$-(3- 
maleimidylpropionyl) biocytin (MPB) (Roche) for 1 hour, after which excess MPB was removed by three washes with PBS. Next, tissue was incubated with $0.5 \mu \mathrm{g} / \mathrm{ml}$ streptavidin-conjugated Alexa Fluor 568 for 30 minutes and nuclei were stained using $0.5 \mu \mathrm{g} / \mathrm{ml}$ DAPI Blue. Tissue was mounted, coverslipped and analyzed by fluorescent microscopy using a Nikon Eclipse E800 microscope. All conditions were scanned using identical instrument settings that did not result in saturation of pixel intensities.

Quantitative determination of S-Glutathionylated proteins and free GSH using 5,5'dithio-bis(2-nitrobenzoic acid) (DTNB)

Lungs were lysed in $137 \mathrm{mM}$ Tris- $\mathrm{HCl}, \mathrm{pH} 8.0,130 \mathrm{mM} \mathrm{NaCl}$, and 1\% NP-40 and cleared by centrifugation. A portion of the lysate was used to determine free GSH and $200 \mu \mathrm{g}$ of protein was acetone precipitated for 20 minutes at $-20^{\circ} \mathrm{C}$. Pellets were resuspended and sonicated in $200 \mu \mathrm{l}$ of ice-cold extraction buffer containing $0.2 \%$ Triton-X 100 and $0.6 \%$ sulfosalicyclic acid in $0.1 \mathrm{M}$ potassium phosphate buffer with $5 \mathrm{mM}$ EDTA disodium salt (KPE), pH 7.5. After 2 freeze-thaw cycles, samples were centrifuged at $3000 \mathrm{xg}$ for $4 \mathrm{~min}$ at $4^{\circ} \mathrm{C}$. To remove glutathione (GSH) from proteins, the pellet was treated with $100 \mu \mathrm{l}$ of $1 \% \mathrm{NaBH}_{4}$ and neutralized with $40 \mu \mathrm{l}$ of $30 \%$ metaphosphoric acid. Samples were centrifuged at $1000 \times$ for $15 \mathrm{~min}$ and the GSH content in the supernatant was determined using the DTNB GSSG reductase recycling method (21). To this end $20 \mu \mathrm{l}$ of KPE, GSH standards and samples were pipetted into a 96-well microtiter plate and freshly prepared, equal volumes of DTNB and GSSG reductase were added in the dark. After 30 seconds, $\beta$-NADPH was added to start the conversion of DTNB to TNB and the absorbance at $412 \mathrm{~nm}$ was read every 30 seconds for 2 minutes. A standard curve was performed using a concentration range of $\mathrm{GSH}$. $\mathrm{NaBH}_{4}$ was omitted for each sample, as a negative control.

Visualisation of S-glutathionylated proteins using GSH IP and Coommassie blue staining

S-Glutathionylated proteins were immunoprecipitated from lung lysates using a GSH antibody (Virogen) as reported previously (22). After SDS-PAGE separation, proteins were visualized by Coommassie blue staining of the gel. As a loading control, a GAPDH Western blot was performed on pre-IP lysates.

In situ detection of S-nitrosylated proteins

The procedure was identical to the visualization of PSSG, except that Snitrosothiols were reduced using $1 \mathrm{mM}$ vitamin $\mathrm{C}$. Vitamin $\mathrm{C}$ was omitted for each tissue section, as a negative control (23). 
Figure 1

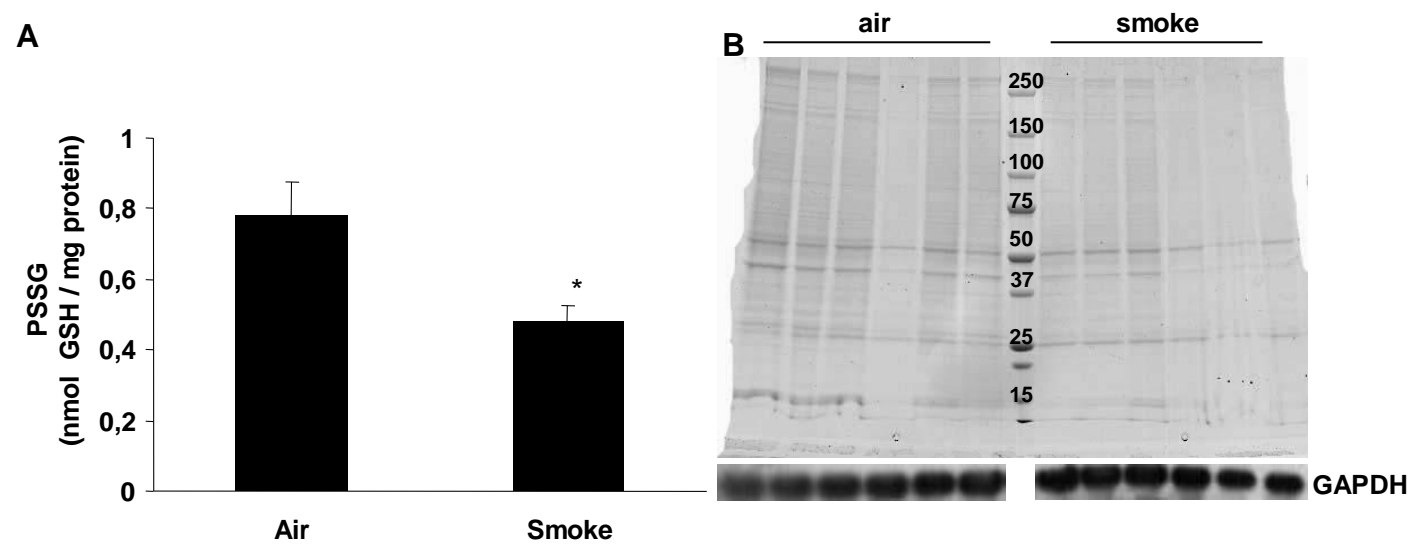

C
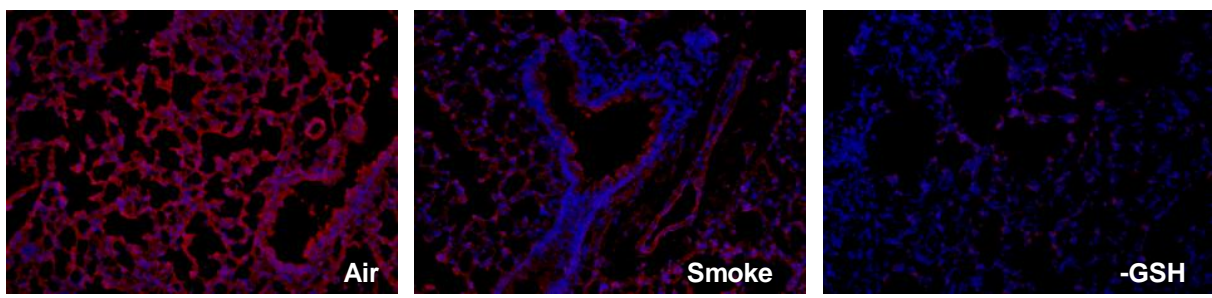

D
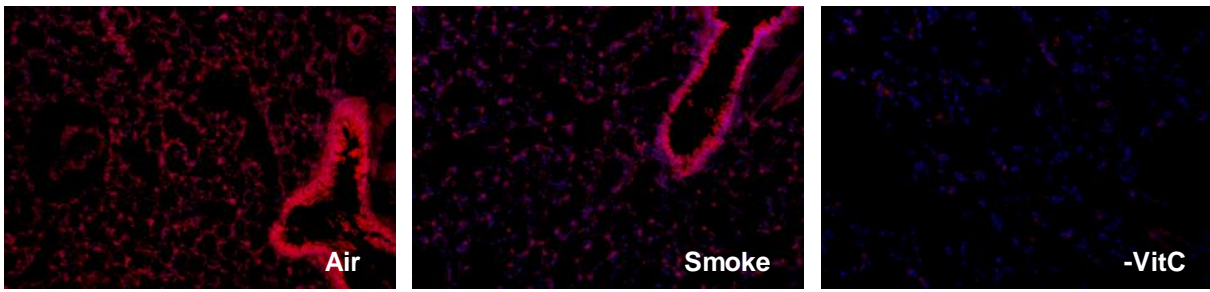
Figure 1: Decreased levels of reversible cysteine oxidations PSSG and PSNO in lung tissue of smoke exposed mice. Protein S-glutathionylation (PSSG) in lung tissue of control and smoke exposed mice was assessed biochemically using DTNB (A), by immunoprecipitation of S-glutathionylated proteins using a GSH antibody and SDS-PAGE combined with Coommassie blue staining and control Western blot on pre-IP samples using a GAPDH antibody (B) or visualized using Grx1 catalyzed cysteine derivatization in red, nuclei in blue (C). As a negative control, GSH was omitted from the reduction mix (-GSH). Protein S-nitrosylation (PSNO) was visualized in lung tissue of control and smoke exposed mice using chemical derivatization in red, nuclei in blue (D). Vitamin $\mathrm{C}$ was omitted as a negative control (-vitC).

\section{Measurement of free thiols in tissue lysate}

Lungs were lysed as described above and $12 \mathrm{mM}$ DTNB was added to $100 \mu \mathrm{g}$ of protein lysate. Free thiols groups were measured at $405 \mathrm{~nm}$ and GSH was used as a standard (24).

\section{Oxyblot}

Lung protein carbonyls were derivatized using an oxyblot kit (Millipore). Carbonylation was visualized on an SDS-PAGE gel using the DNP antibody.

\section{DHE staining}

Oxidant production was visualized by incubating frozen sections for 5 min with 5 $\mu \mathrm{M}$ dihydroethidium (DHE). After washing sections with PBS, nuclei were counterstained with DAPI, tissue mounted, coverslipped and analyzed by fluorescent microscopy using a Nikon Eclipse E800 microscope. Semi-quanititative assessment of the intensity of DHE reactivity in bronchial epithelium and parenchymal regions was conducted by evaluating mean red fluorescence intensity (DHE) in each region of interest and divided by the mean blue fluorescence intenstiy (nuclear DAPI staining) present in the same region using Image $\mathrm{J}$ software. Mean relative fluoresence intensity $(\mathrm{RFI})$ values and SEM were obtained by evaluating images obtained from 7 different animals in each group.

\section{Grx1 activity assay}

Lungs were lysed in $137 \mathrm{mM}$ Tris- $\mathrm{HCl}, \mathrm{pH} 8.0,130 \mathrm{mM} \mathrm{NaCl}$, and 1\% NP-40. Lysates were cleared by centrifugation and $100 \mu \mathrm{g}$ of protein was incubated with reaction buffer (137 mM Tris- $\mathrm{HCl}, \mathrm{pH} 8.0,0.5 \mathrm{mM}$ glutathione, $1.2 \mathrm{U}$ glutathione disulfide reductase (Roche), $0.35 \mathrm{mM} N A D P H, 1.5 \mathrm{mM}$ EDTA, pH 8.0, and $2.5 \mathrm{mM}$ cysteine- $\mathrm{SO}_{3}$ ). Consumption of NAPDH was followed spectrophotometrically over 10 minutes at $340 \mathrm{~nm}$. The specific enzymatic reaction rate was obtained by subtracting the enzymatic rate omitting the substrate cysteine- $\mathrm{SO}_{3}$ from the enzymatic rate including the substrate in the reaction mixture (25).

Alcohol dehydrogenase 5 (ADH5) activity assay

Lungs were lysed as described above and NADH and freshly prepared GSNO were added at a final concentration of $100 \mu \mathrm{M}$ to $100 \mu \mathrm{g}$ of protein. NADH 
consumption was measured for 2 minutes at $340 \mathrm{~nm}$ (8). The non specific NADH consumption obtained in the absence of the substrate GSNO was subtracted for each sample.

\section{Quantitative Polymerase Chain Reaction}

Total RNA was isolated from lungs using the RNeasy Mini kit (QIAGEN, California, USA) and an equal amount was reverse transcribed into cDNA using the ReverseiT 1st strand Synthesis Kit (Abgene, Epsom, UK). Primers for mouse HPRT (FW: TGGATATGCCCTTGACTATAATGAGTAC;

REV: AGGACTCCTCGTATTTGCAGATTC), Grx1 (FW:TTTACAACAGCTCACCGGAG; REV:TCACTGCATCCGCCTATG), Grx2 (FW:AAATCTTCTTGGCCATGGAA; REV:AACAGCACATCGTCGTTTTG), non-phagocytic NADPH oxidase 4 (NOX4, FW: TGTTGGGCCTAGGATTGTGTT; REV:AGGGACCTTCTGTGATCCTCCT) and iNOS (FW: GCAGCTACTGGGTCAAAGACA; REV TCTCTGCCTATCCGTCTCGT) were used. PCR reactions were performed on an iCycler $i Q$ Real-Time PCR system (BioRad, Hercules, California, USA) using SYBRgreen (BioRad). Relative mRNA expression of genes was calculated using the standard curve method.

\section{Western Blot}

Lung lysates were loaded onto a $10 \%$ polyacrylamide gel and transferred onto a nitrocellulose membrane. The membrane was blocked at RT for $1 \mathrm{~h}$ in $5 \%$ BSA or milk in Tris-buffered Saline (TBS) containing 0.05\% Tween 20 (TBST). After two washes in TBST, the membrane was incubated overnight at $4^{\circ} \mathrm{C}$ with primary antibody against ADH5 (Abnova, Heidelberg, Germany), GAPDH (Cell Signaling) and iNOS (Millipore). After three washes, peroxidase-conjugated secondary antibody was incubated for $1 \mathrm{~h}$ at RT. After three washes with TBST, conjugated peroxidase was detected by chemiluminescence using the Pierce ECL Western Blotting Substrate (Thermo Scientific, Rockford, IL, USA).

\section{Statistical analysis}

Data were analyzed by the Mann-Whitney U test (SPSS 17). Data were expressed as mean values \pm SEM. Differences were considered significant when $p<0.05$, indicated by * symbol.

\section{Results}

Decreased PSSG and PSNO after smoke exposure in mice

We first investigated the reversible cysteine oxidations S-glutathionylation and Snitrosylation in mice exposed to cigarette smoke for 4 weeks. Using the biochemical determination of glutathione bound to proteins we found that cigarette 
Figure 2

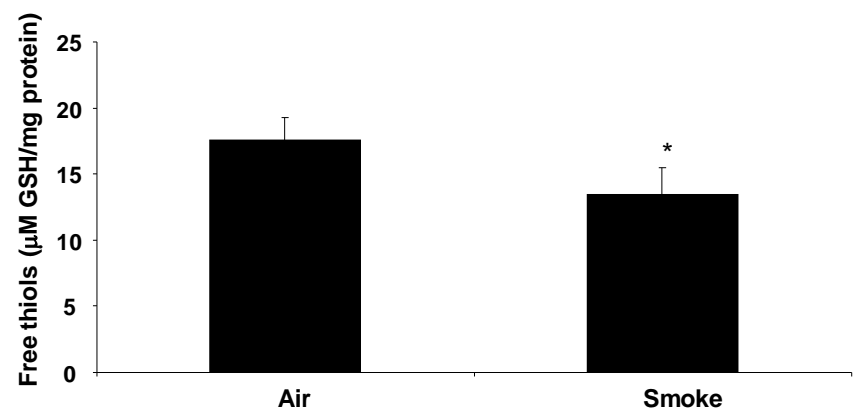

Figure 2: Decreased levels of protein free thiol groups in lung tissue of smoke exposed mice. Protein free thiol levels were assessed in lung tissue of control and smoke exposed mice using DTNB.

smoke exposure significantly decreased protein S-glutationylation in lung tissue (Fig. 1A). Also, using an immunological approach performing an immunoprecipitation of S-glutathionylated proteins, we found that this trend was observed for most all targeted proteins as visualized on the Coommassie stained gel in Fig. 1B. Lastly, this finding was corroborated using Grx1 catalysed derivatisation which demonstrated that this decrease occurred in airways as well as in the alveolar compartment (Fig. 1C). When we visualized protein Snitrosylation, an attenuation of this oxidation was also observed, in airways as well as alveolar regions (Fig. 1D).

Figure 3

A

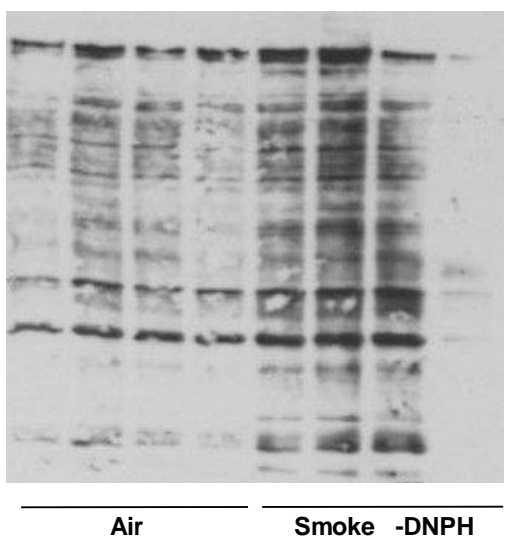

B

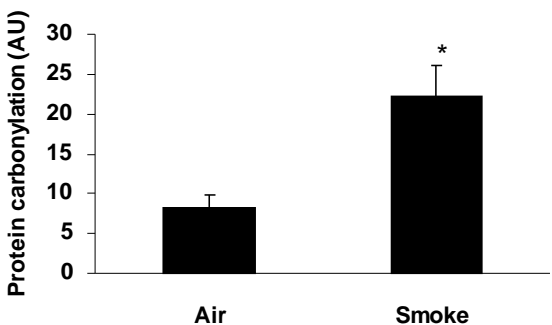

Air

Figure 3: Increased protein carbonylation in lung tissue of smoke exposed mice. Protein carbonylation in lung tissue was examined from air and smoke exposed mice by oxyblot. As a control, DNPH derivatization was omitted from the procedure in a smoke exposed lung sample (-DNPH). Quantification on the right in arbitrary units (AU). 
Increased carbonylation, DHE sensitive oxidant production and expression of NOX4 and iNOS

We next asked whether the loss of these reversible modifications was associated with chemical or enzymatic reduction to free thiols. As expected however, results in Fig. 2 show that cigarette smoke exposure causes a decrease in protein free thiol levels. Since free thiol levels are decreased after smoke exposure and also PSSG and PSNO are attenuated, protein thiols are likely in an overoxidized state. With respect to overoxidation, cigarette smoke exposure has been shown to lead to protein carbonylation which can also target cysteine amino acids. Fig. 3A indeed demonstrates that protein carbonylation is enhanced in lungs of mice exposed to cigarette smoke. A minimal signal was detected when the derivatization solution was omitted in a smoke-exposed lung lysate as a negative control. The mRNA expression of the superoxide generating enzyme NOX4 was found to be enhanced by smoke exposure and also DHE sensitive oxidant production in lung tissue of mice exposed to smoke was increased (Fig. 4B and C). Cigarette smoke exposure was furthermore found to increase the mRNA as well as protein expression of iNOS (Fig 4D and E).

\section{Regulatory enzymes Grx and ADH5}

Both PSSG and PSNO are reversible oxidations, for which the reverse reactions are catalyzed by specific enzymes. The attenuation of both modifications could thus be due to increased expression and/or activity of these enzymes. The expression of glutaredoxin 1, which catalyses deglutathionylation under physiological conditions, was however found to be decreased. The mRNA levels of the other isoform, glutaredoxin 2 were unaffected (Fig. 5A). When assessing total lung Grx activity this was found to be significantly decreased in lung tissue of smoke exposed mice (Fig. 4B). Since protein S-glutathionylation levels and Grx activity can also be affected by GSH levels, these were also assessed. Results in Fig. 5C demonstrate however, that free GSH levels in lung tissue were not affected by smoke exposure. GSSG levels could not be determined as they were found to be below the detection limit of the assay. With respect to PSNO, the protein levels as well as activity of ADH5 were not affected by cigarette smoke exposure (Fig. 6A and $\mathrm{B})$.

\section{Discussion}

In this paper, we show a decrease in reversible cysteine oxidations Sglutathionylation and S-nitrosylation in lungs of mice exposed to cigarette smoke for 4 weeks, in conjunction with an increase in irreversible protein carbonylation. With respect to irreversible protein oxidations, cigarette smoke extract in vitro has been reported to increase carbonylation of proteins in alveolar macrophages in a concentration and time dependent manner (26). Examples of specific proteins targeted by irreversible post-translational modifications induced by smoke include 
Figure 4

A

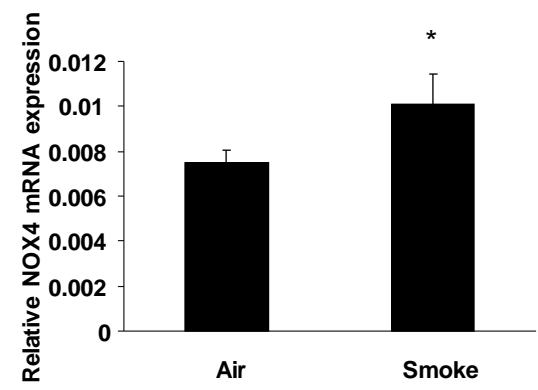

B
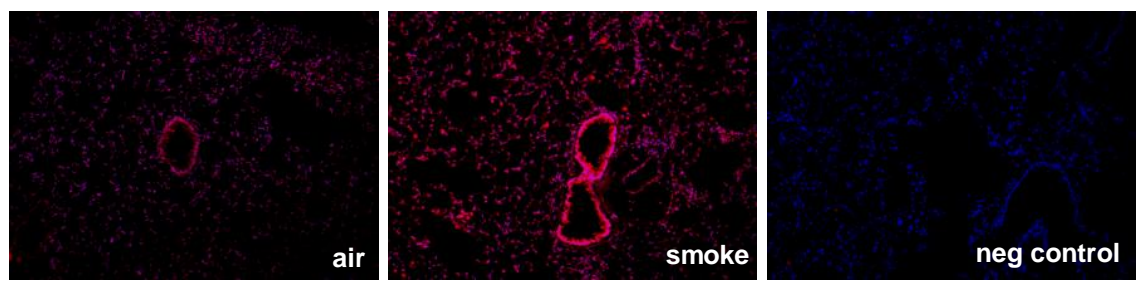

C

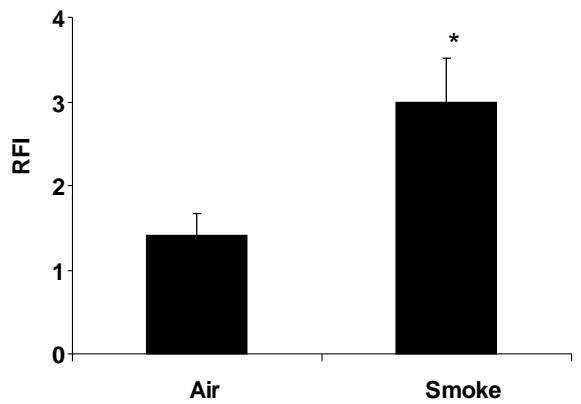

D

E

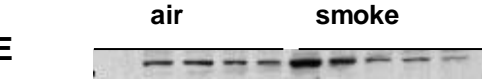

iNOS

(5)
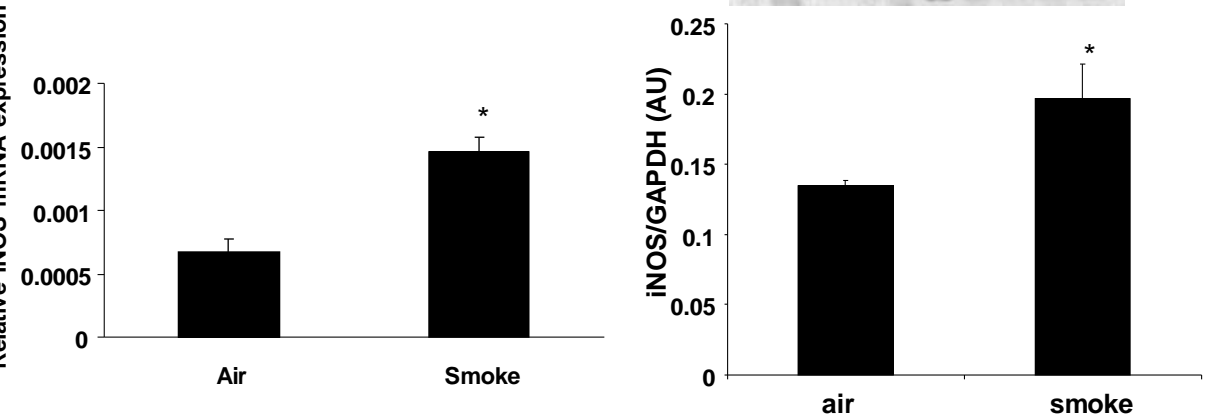
Figure 4: Increased NOX4 expression and oxidant production and increased iNOS expression in lung tissue of smoke exposed mice. (A) mRNA levels of NOX4 in lung tissue of air and smoke exposed mice, using HPRT as a reference gene. (B) Oxidant production in situ visualized using DHE in red and nuclei counterstained using DAPI in blue. As a negative control, DHE was omitted. (C) The mean red fluorescence intensity in each region of interest was divided by the mean blue fluorescence intensity present in the same region to obtain mean relative fluoresence intensity (RFI) values.

(D) iNOS mRNA levels in lung tissue of air and smoke exposed mice, using HPRT as a reference gene. (E) iNOS protein levels by Western blotting of lung tissue of mice exposed to air or cigarette smoke. GAPDH was used as a loading control. Quantification in bottom panel. AU: arbitrary units.

Sirtuin 1, for which adducts with 4-Hydroxy-2-nonenol and nitration of tyrosine residues have been demonstrated (27) and Grx1 which was shown to contain acrolein and carbonyl adducts (28). Furthermore, plasma protein carbonylation was increased in smokers and COPD patients (29), indicating that irreversible oxidation of proteins is increased upon smoking. Fewer reports can be found on effects of cigarette smoke on reversible protein oxidations. We previously revealed increased protein S-glutathionylation in lung epithelial cells upon exposure to cigarette smoke extract, together with decreased expression and activity of Grx1 (28). In this study however, we report that, although Grx1 expression and total Grx activity are decreased in lung tissue of smoke exposed mice, a significant decrease in protein S-glutathionylation was measured following four weeks exposure. These alterations in PSSG levels moreover likely did not arise from differences in free GSH levels as these were unaffected by smoke exposure as shown in Fig 5C. These data are in contrast with a paper by Chung et al that reported increased protein S-glutathionylation in the lungs of mice exposed to smoke for 3 days (30). Grx1 levels were decreased in this acute model, as in our sub-acute study. The primary difference in experimental protocols is the duration of exposure. Sglutathionylation is induced by relatively mild oxidative stress which is in agreement with our published in vitro findings and the 3 day exposure in mice. A further increase in oxidative stress by prolonged exposure to smoke could however lead to the reaching of a tipping point that results in depletion of protein S-glutathionylation to increase free GSH levels to combat oxidative stress, leaving protein thiols vulnerable to overoxidation. This hypothesis is also in line with the gradation of oxidative cysteine modifications outlined in (7).

Enhanced nitrosative stress has been reported in patients with COPD by measurement of elevated nitrosothiols and NO in exhaled breath condensate (31) and NO derivatives in sputum (32). To our knowledge, we are the first to report on the influence of cigarette smoke exposure on protein S-nitrosylation in lung tissue. We observed a significant decrease in S-nitrosylation in situ following smoke exposure for four weeks, in the bronchial and alveolar compartment. This appears to be in contrast with the reported increased levels of nitrosothiols in exhaled breath condensate of COPD patients. In asthma however, nitrosothiols are also exhaled in higher levels compared to healthy controls, whereas pulmonary levels are decreased $(8,31,33)$. As nitrosothiols and nitrosoglutathione in 
Figure 5

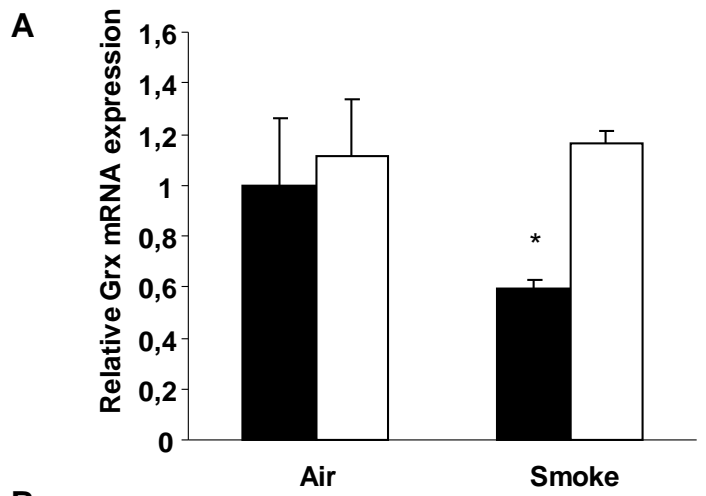

B

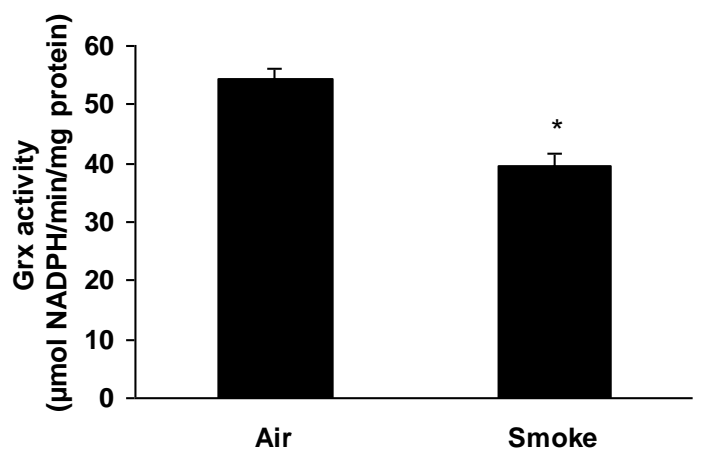

C

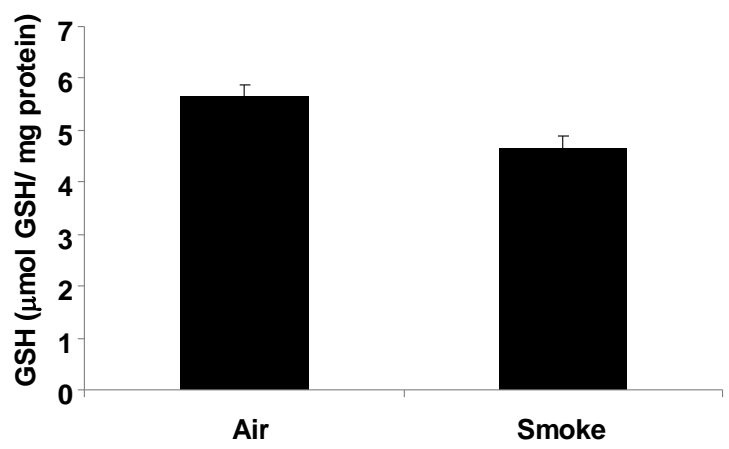

Figure 5: Decreased expression and activity of glutaredoxin, no alterations in free GSH levels in lung tissue of smoke exposed mice. (A) mRNA levels of Grx1 (black bars) and Grx2 (white bars) in lung tissue of air and smoke exposed mice, using HPRT as a reference gene. (B) Total lung Grx activity in air and smoke exposed mice, expressed as $\mu \mathrm{mol}$ NADPH per minute and per mg protein. (C) Free GSH levels in lung tissue of air and smoke exposed mice, expressed as $\mu \mathrm{mol}$ per mg protein. 
particular represent an important pool of $\mathrm{NO}$ activity and nitrosoglutathione acts as a potent bronchodilator (33), this depletion of nitrosothiols could have important pathophysiological consequences in COPD as well. A major difference is the fact that in asthma the enzyme AHD5 appears to be responsible for the decreased levels of nitrosothiols $(8,34)$, whereas at least in this subacute exposure model, cigarette smoke does not appear to influence ADH5 expression or activity.

ROS in cigarette smoke are reported to deplete free thiols in alveolar epithelial cells in vitro (24). In this manuscript we extend these findings to show that cigarette smoke has a similar effect in mouse lungs as well. The levels of free thiols and reversible cysteine oxidations in the lungs after four weeks of cigarette smoke exposure appear to be declined in favor of irreversible oxidations. This was indeed measured in the form of enhanced protein carbonylation in lungs of smoke compared to air exposed mice. Carbonylation result from direct reactions of acrolein or aldehydes present in cigarette smoke or of secondary formation of carbonyl species. It occurs on cysteine, lysine, arginine, proline and threonine amino acids (35), and carbonylation is therefore not specific for thiol oxidation. Although protein carbonylation is typically regarded as an irreversible oxidation, there is some evidence that a detoxification system could exist (36). Since Grx1 levels and total Grx activity were decreased and ADH5 levels and activity remained unaltered, the switch from reversible oxidations to carbonylation is likely due to oxidative stress per se. Next to oxidative stress from smoke itself, DHE sensitive oxidant production and the expression of the oxidant producing enzymes NOX4 and iNOS were found to be increased in the lungs of smoke exposed mice. NOX4 is an NAPDH oxidase that generates superoxide in non-phagocytic cells. It has been shown to be induced by TGF $\beta$ and important in eliciting the cellular responses to this growth factor. This is the first report on the increased expression of this enzyme in response to cigarette smoke exposure.

Irreversible oxidations can cause protein degradation through proteasomal targeting by ubiquitination or damaged proteins can accumulate. Cigarette smoke can on the other hand also induce protein ubiquitination such as in Akt (37) and HDAC2 (38) and in lungs of COPD patients, an accumulation of ubiquitinated proteins in conjunction with oxidative stress and aberrant proteasomal degradation have recently been shown and were hypothesized to contribute to the development of emphysema (39). Reversible oxidations on the other hand, are known to protect proteins from further irreversible oxidations, and they can regulate protein function due to the highly conserved and functionally important nature of the cysteine residues they target. Mediators of cell death and inflammation including procaspase-3 (18), multiple members of the NF-KB survival pathway (reviewed in (9)), ASK1 (40) and Fas (41), have been shown to be regulated by Sglutathionylation and S-nitrosylation, as were matrixmetalloproteases (16). Inhibition has been shown for caspase 3 , as well as NF-KB, whereas the Fas 


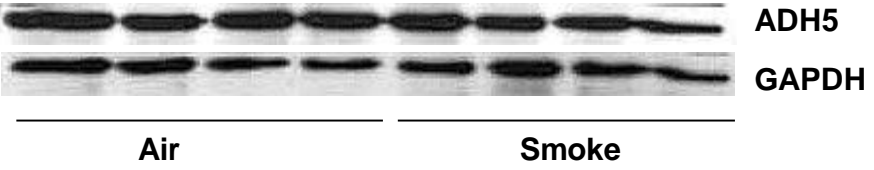

B

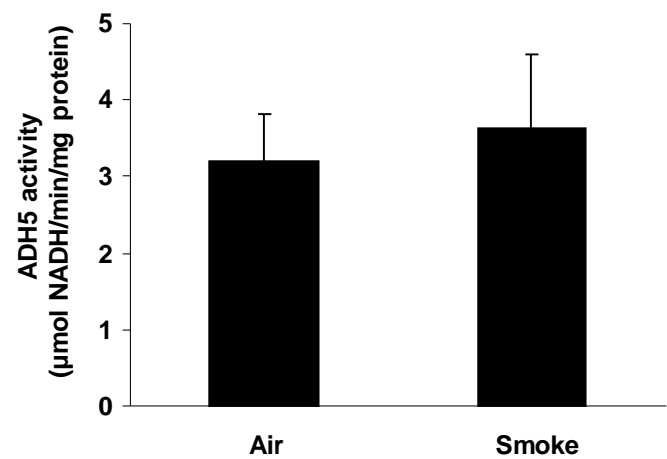

Figure 6: $A D H 5$ protein and activity levels in lung tissue are unaffected by smoke exposure in mice. (A) ADH5 protein levels by Western blotting of lung tissue of mice exposed to air or cigarette smoke. GAPDH was used as a loading control. AU: arbitrary units. (B) ADH5 activity in lung tissue of mice exposed to air or cigarette smoke, expressed as $\mu \mathrm{mol} \mathrm{NADH}$ per minute and per mg protein.

pathway and MMP9 have been shown to be activated by these redox modifications. Given the impact of S-glutathionylation and S-nitrosylation on these important regulatory pathways and the insight we provide in this manuscript regarding decreases of these reversible oxidations, further study is needed to elucidate the overall impact of reported changes in cysteine oxidations in the development of cigarette smoke induced lung disease. In addition, restoration of these reversible oxidations might be a more promising therapeutic strategy over the use of general antioxidants that have been tested to date.

\section{Acknowledgements}

The authors would like to thank Gonda Konings, Greet Barbier, Eliane Castrique, Indra De Borle, Kathleen De Saedeleer, Anouk Goethals, Marie-Rose Mouton, Ann Neesen, Christelle Snauwaert and Evelyn Spruyt for technical assistance and Kirstin Wingler for discussion. 


\section{References}

1. Frei B, Forte TM, Ames BN, Cross CE. Gas phase oxidants of cigarette smoke induce lipid peroxidation and changes in lipoprotein properties in human blood plasma. Protective effects of ascorbic acid. Biochem J. 1991 Jul 1;277 ( Pt 1):133-8.

2. Kiyosawa $\mathrm{H}$, Suko M, Okudaira H, Murata K, Miyamoto T, Chung MH, et al. Cigarette smoking induces formation of 8-hydroxydeoxyguanosine, one of the oxidative DNA damages in human peripheral leukocytes. Free Radic Res Commun. 1990;11(1-3):23-7.

3. Reznick AZ, Cross CE, Hu ML, Suzuki YJ, Khwaja S, Safadi A, et al. Modification of plasma proteins by cigarette smoke as measured by protein carbonyl formation. Biochem J. $1992 \mathrm{Sep}$ 1;286 ( Pt 2):607-11.

4. Panda K, Chattopadhyay R, Chattopadhyay D, Chatterjee IB. Cigarette smoke-induced protein oxidation and proteolysis is exclusively caused by its tar phase: prevention by vitamin C. Toxicol Lett. 2001 Aug 6;123(1):21-32.

5. Sugiura $H$, Ichinose $M$, Tomaki M, Ogawa $H$, Koarai A, Kitamuro T, et al. Quantitative assessment of protein-bound tyrosine nitration in airway secretions from patients with inflammatory airway disease. Free Radic Res. 2004 Jan;38(1):49-57.

6. Mesia-Vela S, Yeh CC, Austin JH, Dounel M, Powell CA, Reeves A, et al. Plasma carbonyls do not correlate with lung function or computed tomography measures of lung density in older smokers. Biomarkers. 2008 Jun;13(4):422-34.

7. Hess DT, Matsumoto A, Kim SO, Marshall HE, Stamler JS. Protein S-nitrosylation: purview and parameters. Nat Rev Mol Cell Biol. 2005 Feb;6(2):150-66.

8. Que LG, Liu L, Yan Y, Whitehead GS, Gavett SH, Schwartz DA, et al. Protection from experimental asthma by an endogenous bronchodilator. Science. 2005 Jun 10;308(5728):1618-21.

9. Mieyal JJ, Gallogly MM, Qanungo S, Sabens EA, Shelton MD. Molecular mechanisms and clinical implications of reversible protein S-glutathionylation. Antioxid Redox Signal. 2008 Nov;10(11):1941-88.

10. Cha MK, Kim IH. Preferential overexpression of glutaredoxin3 in human colon and lung carcinoma. Cancer Epidemiol. 2009 Oct;33(3-4):281-7.

11. Klatt P, Lamas S. c-Jun regulation by S-glutathionylation. Methods Enzymol. 2002;348:15774.

12. Pineda-Molina E, Klatt $P$, Vazquez J, Marina A, Garcia de Lacoba M, Perez-Sala D, et al. Glutathionylation of the p50 subunit of NF-kappaB: a mechanism for redox-induced inhibition of DNA binding. Biochemistry. 2001 Nov 27;40(47):14134-42.

13. Klatt $\mathrm{P}$, Molina EP, Lamas S. Nitric oxide inhibits C-Jun DNA binding by specifically targeted S-glutathionylation. J Biol Chem. 1999 May 28;274(22):15857-64.

14. Marshall HE, Stamler JS. Inhibition of NF-kappa B by S-nitrosylation. Biochemistry. 2001 Feb 13;40(6):1688-93.

15. Reynaert NL, Ckless K, Korn SH, Vos N, Guala AS, Wouters EF, et al. Nitric oxide represses inhibitory kappaB kinase through S-nitrosylation. Proc Natl Acad Sci U S A. 2004 Jun 15;101(24):8945-50.

16. Okamoto T, Valacchi G, Gohil K, Akaike T, van der Vliet A. S-nitrosothiols inhibit cytokinemediated induction of matrix metalloproteinase-9 in airway epithelial cells. Am J Respir Cell Mol Biol. 2002 Oct;27(4):463-73.

17. Okamoto T, Akaike T, Sawa T, Miyamoto $\mathrm{Y}$, van der Vliet A, Maeda H. Activation of matrix metalloproteinases by peroxynitrite-induced protein S-glutathiolation via disulfide S-oxide formation. J Biol Chem. 2001;276(31):29596-602.

18. Pan S, Berk BC. Glutathiolation regulates tumor necrosis factor-alpha-induced caspase-3 cleavage and apoptosis: key role for glutaredoxin in the death pathway. Circ Res. $2007 \mathrm{Feb}$ 2;100(2):213-9.

19. Mannick JB, Schonhoff C, Papeta N, Ghafourifar P, Szibor M, Fang K, et al. S-Nitrosylation of mitochondrial caspases. J Cell Biol. 2001 Sep 17;154(6):1111-6. 
20. D'Hulst A I, Vermaelen KY, Brusselle GG, Joos GF, Pauwels RA. Time course of cigarette smoke-induced pulmonary inflammation in mice. Eur Respir J. 2005 Aug;26(2):204-13.

21. Rahman I, Kode A, Biswas SK. Assay for quantitative determination of glutathione and glutathione disulfide levels using enzymatic recycling method. Nat Protoc. 2006;1(6):3159-65.

22. Reynaert NL, van der Vliet A, Guala AS, McGovern T, Hristova M, Pantano C, et al. Dynamic redox control of NF-kappaB through glutaredoxin-regulated S-glutathionylation of inhibitory kappaB kinase beta. Proc Natl Acad Sci U S A. 2006 Aug 29;103(35):13086-91.

23. Aesif SW, Janssen-Heininger YM, Reynaert NL. Protocols for the detection of sglutathionylated and s-nitrosylated proteins in situ. Methods Enzymol. 2010;474:289-96.

24. van der Toorn M, Rezayat D, Kauffman HF, Bakker SJ, Gans RO, Koeter GH, et al. Lipidsoluble components in cigarette smoke induce mitochondrial production of reactive oxygen species in lung epithelial cells. Am J Physiol Lung Cell Mol Physiol. 2009 Jul;297(1):L109-14.

25. Gan ZR, Wells WW. Purification and properties of thioltransferase. J Biol Chem. 1986 Jan 25;261(3):996-1001.

26. Bozinovski S, Vlahos R, Zhang Y, Lah LC, Seow HJ, Mansell A, et al. Carbonylation Caused by Cigarette Smoke Extract is Associated with Defective Macrophage Immunity. Am J Respir Cell Mol Biol. Oct 8;epub ehead of print.

27. Rajendrasozhan S, Yang SR, Kinnula VL, Rahman I. SIRT1, an antiinflammatory and antiaging protein, is decreased in lungs of patients with chronic obstructive pulmonary disease. Am J Respir Crit Care Med. 2008 Apr 15;177(8):861-70.

28. Kuipers I, Guala AS, Aesif SW, Konings G, Bouwman FG, Mariman EC, et al. Cigarette Smoke Targets Glutaredoxin 1, Increasing S-glutathionylation and Epithelial Cell Death. Am J Respir Cell Mol Biol. 2011 Nov;45(5):931-7.

29. Ceylan E, Gencer M, Uzer E, Celik H. Measurement of the total antioxidant potential in chronic obstructive pulmonary diseases with a novel automated method. Saudi Med J. 2007 Sep;28(9):1339-43.

30. Chung S, Sundar IK, Yao H, Ho YS, Rahman I. Glutaredoxin 1 regulates cigarette smokemediated lung inflammation through differential modulation of lkappaB kinases in mice: impact on histone acetylation. Am J Physiol Lung Cell Mol Physiol. 2010;299(2):L192-203.

31. Corradi M, Montuschi P, Donnelly LE, Pesci A, Kharitonov SA, Barnes PJ. Increased nitrosothiols in exhaled breath condensate in inflammatory airway diseases. Am J Respir Crit Care Med. 2001 Mar;163(4):854-8.

32. Kanazawa H, Shoji S, Yoshikawa T, Hirata K, Yoshikawa J. Increased production of endogenous nitric oxide in patients with bronchial asthma and chronic obstructive pulmonary disease. Clin Exp Allergy. 1998 Oct;28(10):1244-50.

33. Gaston B, Sears S, Woods J, Hunt J, Ponaman M, McMahon T, et al. Bronchodilator Snitrosothiol deficiency in asthmatic respiratory failure. Lancet. 1998 May 2;351(9112):1317-9.

34. Que LG, Yang Z, Stamler JS, Lugogo NL, Kraft M. S-nitrosoglutathione reductase: an important regulator in human asthma. Am J Respir Crit Care Med. 2009 Aug 1;180(3):226-31.

35. Suzuki YJ, Carini M, Butterfield DA. Protein carbonylation. Antioxid Redox Signal. Mar;12(3):323-5.

36. Fulceri R, Pompella A, Benedetti A, Comporti M. On the role of lipid peroxidation and proteinbound aldehydes in the haloalkane-induced inactivation of microsomal glucose 6 phosphatase. Res Commun Chem Pathol Pharmacol. 1990 Apr;68(1):73-88.

37. Kim SY, Lee JH, Huh JW, Ro JY, Oh YM, Lee SD, et al. Cigarette smoke induces Akt protein degradation by the ubiquitin-proteasome system. J Biol Chem. 2011 Sep 16;286(37):3193243.

38. Adenuga D, Yao H, March TH, Seagrave J, Rahman I. Histone deacetylase 2 is phosphorylated, ubiquitinated, and degraded by cigarette smoke. Am J Respir Cell Mol Biol. 2009 Apr;40(4):464-73.

39. Min T, Bodas M, Mazur S, Vij N. Critical role of proteostasis-imbalance in pathogenesis of COPD and severe emphysema. J Mol Med. 2011 jun;89(6):577-93. 
40. Song JJ, Rhee JG, Suntharalingam M, Walsh SA, Spitz DR, Lee YJ. Role of glutaredoxin in metabolic oxidative stress. Glutaredoxin as a sensor of oxidative stress mediated by H2O2. J Biol Chem. 2002 Nov 29;277(48):46566-75.

41. Anathy V, Aesif SW, Guala AS, Havermans M, Reynaert NL, Ho YS, et al. Redox amplification of apoptosis by caspase-dependent cleavage of glutaredoxin 1 and $\mathrm{S}$ glutathionylation of Fas. J Cell Biol. 2009 Jan 26;184(2):241-52. 


\section{CHAPTER 5}

\section{Altered cigarette smoke induced lung inflammation due to ablation of Grx1}

Ine Kuipers ${ }^{*}$, Ken R Bracke ${ }^{\dagger}$, Guy G Brusselle ${ }^{\dagger}$, Scott W Aesif ${ }^{\ddagger}$, Renske Krijgsman ${ }^{*}$, Ilja C Arts $^{\S}$, Emiel FM Wouters ${ }^{*}$, Niki L Reynaert ${ }^{\star}$

PLoS One (Epub June 2012)

\section{Abstract}

Glutaredoxins ( $\mathrm{Grx}$ ) are redox enzymes that remove glutathione bound to protein thiols, know as S-glutathionylation (PSSG). PSSG is a reservoir of GSH and can affect the function of proteins. It inhibits the NF-KB pathway and LPS aspiration in Grx1 KO mice decreased inflammatory cytokine levels. In this study we investigated whether absence of Grx1 similarly repressed cigarette smoke-induced inflammation in an exposure model in mice.

Cigarette smoke exposure for 4 weeks decreased lung PSSG levels, but increased PSSG in lavaged cells and lavage fluid (BALF). Grx1 KO mice had increased levels of PSSG in lung tissue, BALF and BAL cells in response to smoke compared to wt mice. Importantly levels of multiple inflammatory mediators in the BALF were decreased in Grx1 KO animals following cigarette smoke exposure compared to wt mice, as were levels of neutrophils, dendritic cells and lymphocytes. Macrophage numbers on the other hand were higher in Grx1 KO mice in response to smoke. Although cigarette smoke in vivo caused inverse effects in inflammatory and resident cells with respect to PSSG, primary macrophages and epithelial cells cultured from Grx1 KO mice both produced less KC compared to cells isolated from WT mice after smoke extract exposure.

In this manuscript, we provide evidence that Grx1 has an important role in regulating cigarette smoke induced lung inflammation which seems to diverge from its effects on total PSSG. Secondly, these data expose the differential effect of cigarette smoke on PSSG in inflammatory versus resident lung cells. 


\section{Introduction}

The lung continuously encounters oxidants from inhalation and is therefore well equipped with a high concentration of the antioxidant glutathione (GSH). GSH acts as an electron donor and is used by glutathione peroxidase to reduce peroxides, resulting in oxidized glutathione (GSSG) (1). Cigarette smoke is known to acutely deplete $\mathrm{GSH}$, for instance by directly reacting with $\mathrm{GSH}$ to form nonreducible glutathione-aldehyde derivatives (2), thereby decreasing the lungs' antioxidant capacity and making it vulnerable to oxidant-induced injury. On the other hand, as an adaptive response to oxidative stress, such as upon chronic smoking, levels of GSH increase in the epithelial lining fluid due to upregulation of the rate limiting enzyme in GSH synthesis, $y$-glutamylcysteine ligase (3).

Besides being oxidized itself, glutathione can in conditions of mild oxidative stress, also bind to cysteine residues in proteins. This posttranslational modification is known as S-glutathionylation and protects proteins from irreversible oxidations. Glutaredoxins (Grx) or thioltransferases are redox enzymes that, under physiological conditions, can reverse S-glutathionylation. S-glutathionylation does not only protect the targeted protein thiol groups from further irreversible oxidations, but also has been shown to modulate protein function when the targeted cysteine residue is critical to its function (4). Examples include mediators of cell death and inflammation such as procaspase-3 (5), multiple members of the NF-KB pathway (reviewed in (6)), and matrix metalloproteases (7). Inhibition has been shown for caspase 3, as well as NF-KB, whereas MMP9 has been shown to be activated by this redox modification. Therefore glutaredoxins play an important role in redox-modulated protein function by regulating S-glutathionylation. Several mammalian Grxs have been identified. Grx1 localizes primarily to the cytosol and Grx2 is present in the mitochondria and nucleus (8).

In many pulmonary diseases, including COPD, the importance of glutathione homeostasis is described (3), whereas S-glutathionylation and Grxs have hardly been investigated. Grx1 expression in the lungs has been found to be predominantly localized in macrophages and bronchial epithelium. In a mouse model of allergic airway disease and after acute exposure to LPS Grx1 expression was increased (9-11). In patients with COPD on the other hand, Grx1 was decreased and specifically the number of Grx1 positive macrophages was found to be positively correlated with lung function (10). In line with these clinical findings, we have previously reported that cigarette smoke extract downregulated Grx1 levels, which was associated with increased protein S-glutathionylation in lung epithelial cells. Moreover, primary epithelial cells from Grx1 knock out mice were more prone to smoke-induced cell death and displayed higher levels of protein Sglutathionylation compared to controls (12). In vivo on the other hand, we found smoke exposure to decrease protein S-glutathionylation, while also decreasing Grx1 levels and total Grx activity (13). 
Targeted S-glutathionylation is described to inhibit multiple members of the pro-inflammatory NF-KB pathway, including IKKa, IKK $\beta$ and Rel A $(14,15)$. We have previously described that LPS exposure in the context of ablation of Grx1 failed to activate NF-KB and decreased inflammatory cytokine levels (11). In the current study we set out to investigate whether absence of Grx1 similarly represses cigarette smoke-induced inflammation in a subacute exposure model in mice. Rather than focusing on individual NF-KB members, we investigated the differential inflammatory response of mouse lungs as well as primary epithelial cells and macrophages to cigarette smoke.

\section{Material and methods}

\section{Mice and primary cell culture}

Male Grx $1^{-/}$mice, a kind gift of Dr. Ho (Wayne State University, Detroit, MI), and WT C57BL/6 controls ( $n=10$ per group) were exposed to cigarette smoke for four weeks as described previously (16). Briefly, mice were exposed whole body to the tobacco smoke of 5 Reference Cigarettes 3R4F without filter (University of Kentucky, Lexington, KY) four times a day with 30 min smoke-free intervals, 5 days a week for 4 weeks. During the exposure an optimal smoke to air ratio of 1:6 was obtained. The control groups were exposed to room air. Additional unexposed mice were used to isolate primary tracheal epithelial cells (MTE) as described previously (17) with minor modifications (18) and pulmonary macrophages by saline lavage. Cells were cultured in full medium lacking phenol red for $24 \mathrm{~h}$ prior to stimulation. The local ethics committee for animal experimentation of the faculty of medicine and health sciences (Ghent University, Belgium) granted approval for all in vivo procedures.

\section{Bronchoalveolar lavage (BAL)}

5 days after the last exposure mice were euthanized with an overdose of pentobarbital and a cannula was inserted into the trachea. Three times $300 \mu \mathrm{l}$ HBSS, free of $\mathrm{Ca}^{2+}$ and $\mathrm{Mg}^{2+}$ and supplemented with $1 \% \mathrm{BSA}$, followed by 3 times $1 \mathrm{ml}$ HBSS supplemented with 0.05 mM EDTA, was instilled through the cannula and recovered by gentle aspiration. All lavage fractions were pooled, centrifuged and the cell pellet washed twice and resuspended in $1 \mathrm{ml} \mathrm{HBSS}$. Total and differential cell counts were performed in a Bürker chamber and cytocentrifuged preparations stained with May-Grünwald-Giemsa respectively. Flow cytometric analysis of BAL cells was performed as described previously to enumerate dendritic cells, macrophages, neutrophils and T-lymphocyte subsets (19).

\section{Lung tissue processing and cell counts}

After rinsing of the pulmonary and systemic circulation, the left lung was used for histology by intratracheal infusion of $4 \%$ PFA and embedding in paraffin. Single cell suspensions were prepared from the right lung by mincing thoroughly, digesting 
and RBC lysis. Cell counts were performed with a Beckman Coulter counter and flow cytometric analysis was performed as described previously to enumerate dendritic cells, macrophages, neutrophils and T-lymphocyte subsets (19). The other part of the right lung was snap frozen in liquid nitrogen for biochemical assessments.

\section{Cigarette smoke extract}

3R4F Research Cigarettes, from the University of Kentucky (Lexington, KT, USA), were removed from their filters and cigarette smoke extract (CSE) was made fresh before every experiment according to (20).

Quantitative determination of S-Glutathionylated proteins using 5,5'-dithio-bis(2nitrobenzoic acid) (dTNB)

$200 \mu \mathrm{l}$ of BAL fluid or $200 \mu \mathrm{g}$ of lung protein homogenate was acetone precipitated for 20 minutes at $-20^{\circ} \mathrm{C}$ and spun down for 5 minutes at $3000 \mathrm{xg}$. Pellets were next resuspended and sonicated in $200 \mu \mathrm{l}$ of ice-cold extraction buffer containing $0.2 \%$ Triton-X 100 and $0.6 \%$ sulfosalicyclic acid in $0.1 \mathrm{M}$ potassium phosphate buffer with 5mM EDTA disodium salt (KPE), pH 7.5. After 2 freeze-thaw cycles, samples were centrifuged at $3000 \mathrm{xg}$ for $4 \mathrm{~min}$ at $4^{\circ} \mathrm{C}$. To remove glutathione (GSH) from proteins, the pellet was treated with $100 \mu \mathrm{l}$ of $1 \% \mathrm{NaBH}_{4}$ in water and neutralized with $40 \mu \mathrm{l}$ of $30 \%$ metaphosphoric acid. Samples were centrifuged at $1000 \mathrm{xg}$ for 15 min and the supernatant was used to determine the GSH content using the dTNB GSSG reductase recycling method (21). $20 \mu \mathrm{l}$ of KPE, GSH standards and samples were pipetted into a 96 -well microtiter plate and freshly prepared, equal volumes of dTNB and GSSG reductase were added in the dark. After 30 seconds, $\beta-N A D P H$ was added to start the conversion of dTNB to TNB and the absorbance at $412 \mathrm{~nm}$ was read every 30 seconds for 2 minutes. A standard curve was performed using a concentration range of $\mathrm{GSH}$. $\mathrm{NaBH}_{4}$ was omitted for each sample, as a negative control. Values were corrected for protein content and data are expressed as nmol GSH per milligram of protein.

Grx1 catalyzed cysteine derivatization for in situ detection of S-glutathionylated proteins

Frozen cytospins were thawed and washed twice with PBS before being fixed with $4 \%$ paraformaldehyde (PFA) for 10 minutes at RT. After three washes with PBS slides were permeabilized and free thiol groups were blocked using a buffer containing $25 \mathrm{mmol} / \mathrm{L}$ 4-(2-hydroxyethyl)-1-piperazineethanesulfonic acid, $\mathrm{pH}$ 7.4, $0.1 \mathrm{mmol} / \mathrm{L}$ EDTA, pH 8.0, $0.01 \mathrm{mmol} / \mathrm{L}$ neocuproine, $40 \mathrm{mmol} / \mathrm{L} \mathrm{N}$-ethylmaleimide (Sigma) and 1\% Triton (Sigma) for 30 minutes to an hour. After three washes with PBS, S-glutathionylated cysteine groups were reduced by incubation with 13.5 $\mu \mathrm{g} / \mathrm{ml}$ human Grx1 (Lab Frontiers), $35 \mu \mathrm{g} / \mathrm{ml}$ GSSG reductase (Roche), $1 \mathrm{mmol} / \mathrm{L}$ GSH (Sigma), $1 \mathrm{mmol} / \mathrm{L} \mathrm{NADPH}$ (Sigma), $18 \mu \mathrm{mol}$ EDTA and $137 \mathrm{mmol} / \mathrm{L}$ Tris . $\mathrm{HCl}, \mathrm{pH} 8.0$, for 20 minutes. As a control GSH was left out of this mix. After three 


\section{Figure 1}

A

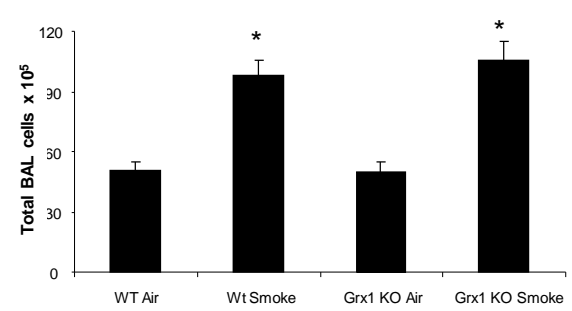

C

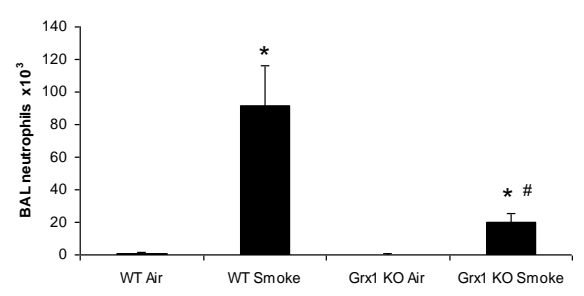

E

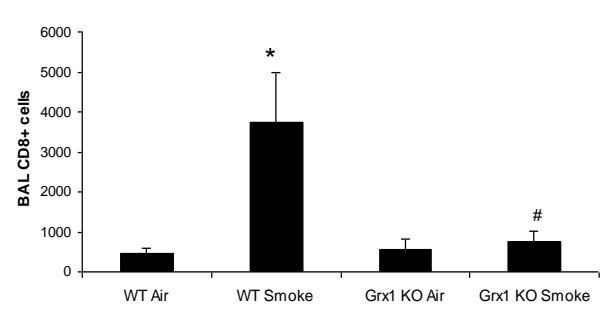

B

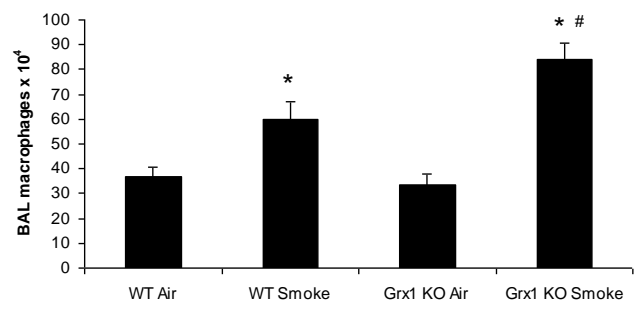

D

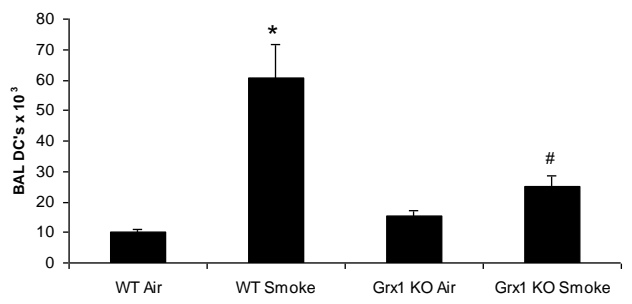

$\mathrm{F}$

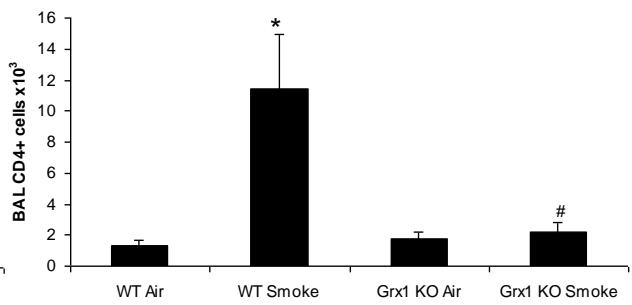

G

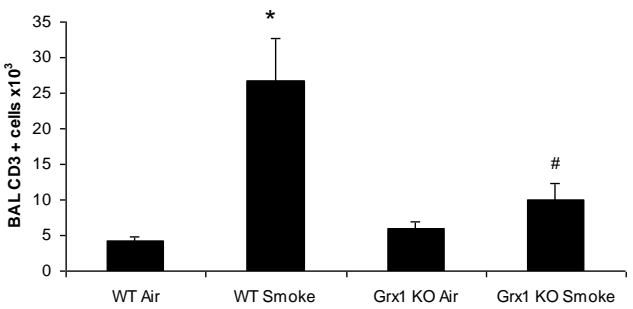

Figure 1: BAL fluid cell counts and differentials in wild type versus Grx1 KO mice exposed to air and smoke. Total BAL fluid cells (A), total numbers of macrophages (B), neutrophils (C), dendritic cells (D), CD3+ cells $(F), C D 4+$ cells $(G)$ and CD8+ cells $(H)$ in BAL fluid represented as mean \pm SD. * represents $p<0.05$ between air and smoke exposed mice, \# represents $p<0.05$ between WT smoke and KO smoke. 
washes with PBS, newly reduced cysteine residues were labelled with $1 \mathrm{mmol} / \mathrm{L} N$ (3-maleimidylpropionyl) biocytin (MPB) (Roche) for 1 hour, after which excess MPB was removed by three washes with PBS. Next, cells were incubated with $0.5 \mu \mathrm{g} / \mathrm{ml}$ streptavidin-conjugated Alexa Fluor 568 for 30 minutes. Nuclei were stained using $0.5 \mu \mathrm{g} / \mathrm{ml}$ DAPI Blue. Cells were then mounted, coverslipped and analyzed by fluorescent microscopy using a Nikon Eclipse E800 microscope. All conditions were scanned using identical instrument settings that did not result in saturation of pixel intensities. Semi-quanititative assessment of the staining intensity was conducted by dividing mean red fluorescence intensity (PSSG staining) by the mean blue fluorescence intensity (nuclear DAPI staining) using Image $\mathrm{J}$ software. Mean relative fluorescence intensity (RFI) values and SEM were thus obtained.

\section{Grx1 staining}

Macrophages were fixed with 4\% PFA for $10 \mathrm{~min}$ at RT. After permeabilization and blocking non-specific binding sites using $0.1 \%$ triton, $1 \%$ BSA in PBS, primary antibody against Grx1 (Imco) was incubated for $1 \mathrm{~h}$ followed by Alexa fluor 488 labelled secondary anti-goat antibody for $1 \mathrm{~h}$. Nuclei were counterstained with DAPI and cells were coverslipped. Semi-quanititative assessment of the staining intensity was conducted by dividing mean green fluorescence intensity (Grx1 staining) by the mean blue fluorescence intenstiy (nuclear DAPI staining) using Image $\mathrm{J}$ software. Mean relative fluoresence intensity (RFI) values and SEM were thus obtained.

\section{Multiplex for cytokine measurement}

To quantify concentrations of 23 cytokines and chemokines in BALF we used a Bio-Plex mouse cytokine 23-plex Panel (IL-1a, IL-1 $\beta$, IL-2, IL-3, IL-4, IL-5. IL-6, KC, IL-9, IL-10, IL-12(p40), IL-12(p70), IL-13, IL-17, Eotaxin, G-CSF, GM-CSF, IFN- Y, MCP-1(MCAF), MIP-1 $\alpha$, MIP-1 $\beta$, RANTES and TNF- $\alpha$ ). Assays were performed as described by the manufacturer's instructions. The analysis was done with a Luminex 100 IS 2.3 system using the Bio-Plex Manager 4.1.1. software.

\section{KC ELISA}

$\mathrm{KC}$ levels in cell culture medium were measured using a commercially available ELISA kit (R\&D systems, Inc. Minneapolis, USA) according to the manufacturer's instructions.

\section{QPCR}

Total RNA was isolated from lungs or cells using the RNeasy Mini kit (QIAGEN, California, USA) and an equal amount was reverse transcribed into cDNA using the Reverse-iT 1st strand Synthesis Kit (Abgene, Epsom, UK). Primers for human HPRT

(FW:AGAATGTCTTGATTGTGGAAGA; REV:ACCTTGACCATCTTTGGATTA), Grx1 (FW:TTTACAACAGCTCACCGGAG; REV:TCACTGCATCCGCCTATG) and KC (Fw: CACTGCACCCAAACCGAAG; 


\section{Figure 2}

A
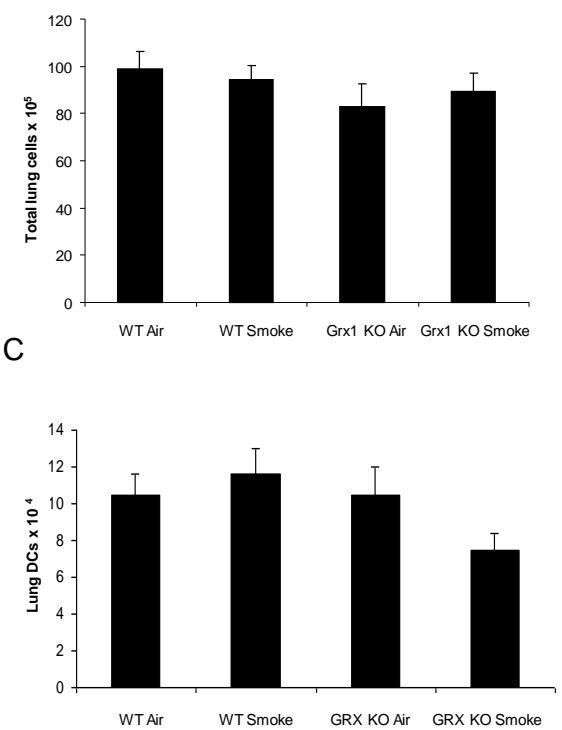

$\mathrm{E}$

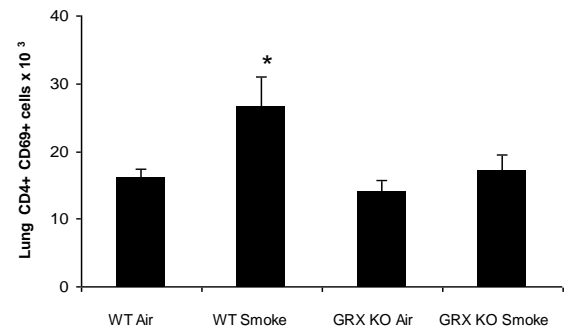

G

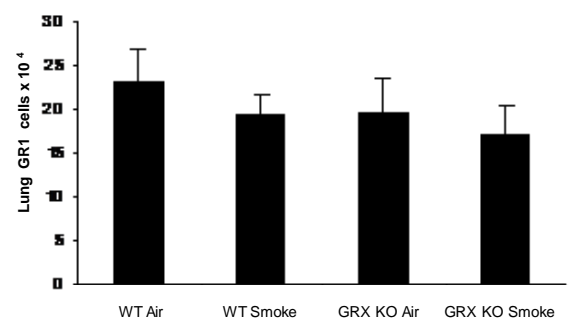

B
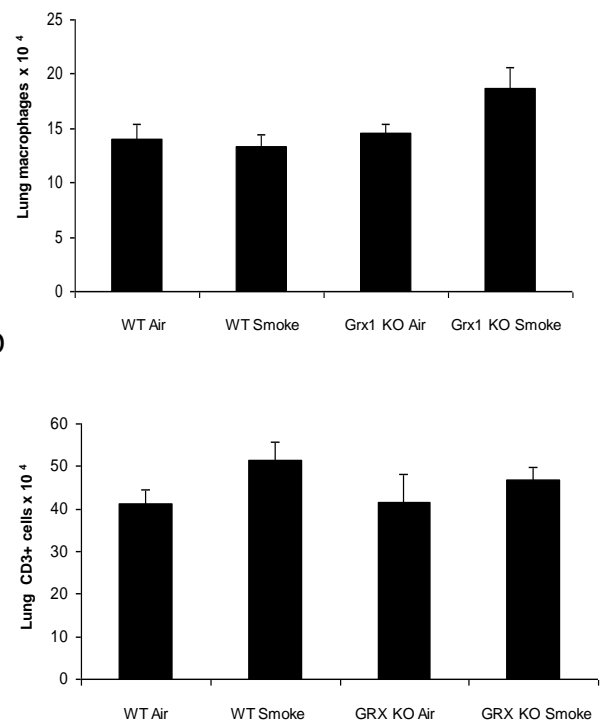

$\mathrm{F}$

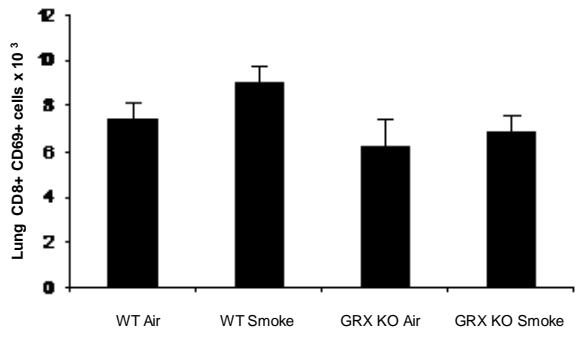

Figure 2: Lung tissue differential cell counts in wild type versus Grx1 KO mice exposed to air or smoke. Total lung cells (A), total numbers of lung macrophages (B), dendritic cells (C), CD3+ cells (D), CD4+ CD69+ cells (E) CD8+ CD69+ cells (F) and GR1 cells $(G)$, represented as mean \pm SD. * represents $\mathrm{p}<0.05$ between air and smoke exposed mice. 
REV: TCAGGGTCAAGGCAAGCC) were used. PCR reactions were performed on an iCycler iQ Real-Time PCR system (BioRad, Hercules, California, USA) using the SYBRgreen dye (BioRad). Relative mRNA expression of genes was calculated using the standard curve method.

\section{Statistical analyses}

Between-group comparisons were analyzed using the Kruskal-Wallis test, followed by Mann-Whitney $U$ test (SPSS 17). Unless indicated otherwise, data are expressed as mean and standard deviation. A $p$-value $<0.05$ was considered statistically significant.

\section{Results}

BAL fluid cell counts and differentials in wild type versus Grx1 KO mice exposed to air and smoke

When analyzing lavaged cells, the total number of BALF cells was found to be significantly elevated in wild type and Grx1 KO mice due to cigarette smoke compared to respective air exposed controls. The level of increase in total cell numbers in the BALF did not differ between the two mouse strains (Figure 1A). Macrophage cell counts in BALF also increased with cigarette smoke compared to respective air exposed controls, but significantly more so in Grx1 KO mice than in WT (Figure 1B). The smoke-induced increase in the number of neutrophils, dendritic cells, CD8+, CD4+ and CD3+ cells on the other hand was significantly dampened in Grx1 KO compared to WT mice (Figure 1 C-G).

Lung tissue differential cell counts in wild type versus Grx1 KO mice exposed to air or smoke

Next, we investigated total and differential cell numbers in lung tissue of the wild type and Grx1 KO mice. Figure 2A shows that there is no significant difference in total cell numbers of the lung tissue between the Grx1 KO and wild type mice, under basal conditions and after exposure to cigarette smoke.

Although the numbers of macrophages tended to be higher in lung tissue of Grx1 $\mathrm{KO}$ mice compared to wild type controls, this was not statistically significant (Figure 2B). In addition, the numbers of lung dendritic cells (Figure 2C), lung CD3+ cells (Figure 2D), lung CD8+CD69+ (Figure 2F) and GR1+ cells (Figure 2G) were not affected by smoke exposure in the WT animals, or in the Grx1 KO mice. The numbers of lung CD4+CD69+ cells on the other hand was significantly increased in wild type mice exposed to cigarette smoke. This increase was however not present in the Grx1 KO mice after cigarette smoke exposure (Figure 2E). 


\section{Figure 3}
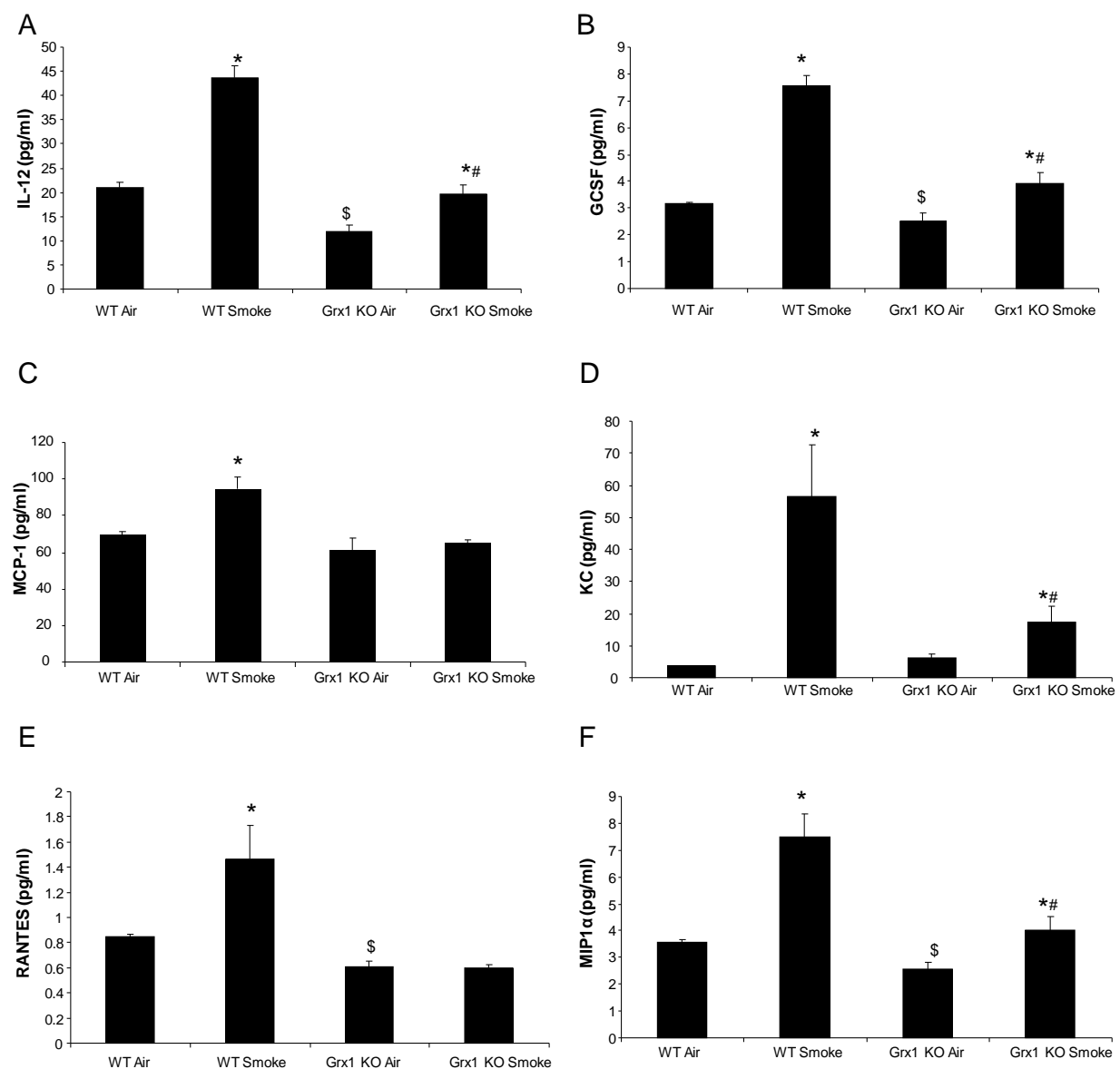

Figure 3: BAL fluid cytokines in wild type versus Grx1 KO mice exposed to air and cigarette smoke. Measurement of cytokines in the BAL fluid by multiplex: IL 12 (A), GCSF (B), MCP1 (C), KC (D), RANTES (E) and MIP1 $\alpha(F)$ expressed in $\mathrm{pg} / \mathrm{ml}$ and represented as mean \pm SD. * represents $p<0.05$ between air and smoke exposed mice, \# represents $p<0.05$ between WT smoke and KO smoke and \$ represents $p<0.05$ between WT air and Grx1 KO air.

BAL fluid cytokines in wild type versus Grx1 KO mice exposed to air and cigarette smoke

We next assessed a broad panel of inflammatory mediators in BALF in order to determine a cause for the diminished influx of inflammatory cells into the lungs of Grx1 mice after smoke exposure. While analyzing the inflammatory mediators measured in the BAL fluid of wild type versus Grx1 KO mice, the general observation was that these are decreased in Grx1 KO mice after exposure to cigarette smoke compared to wild type controls exposed to cigarette smoke (Figure 3). Specifically, cigarette smoke exposure significantly increased the BALF 


\section{Figure 4}

A

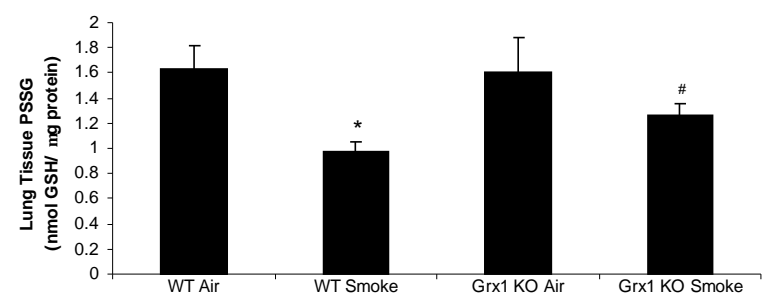

B

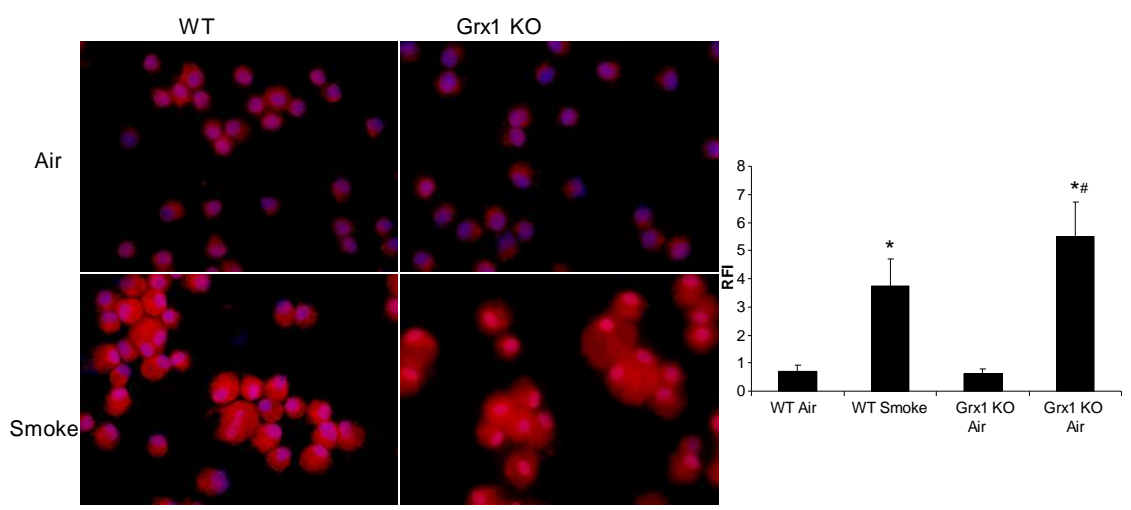

C

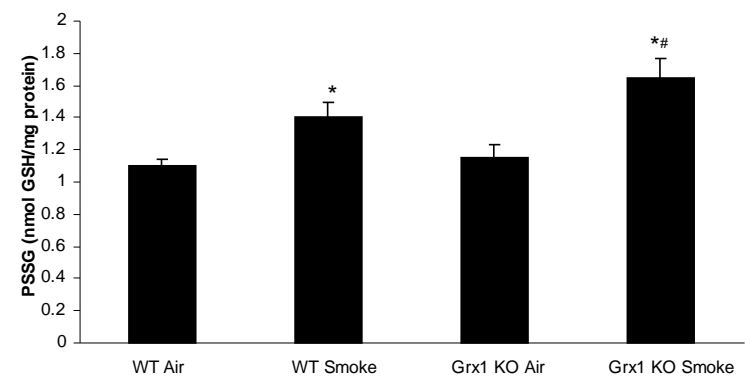

Figure 4: S-glutathionylation in lungs and BAL fluid cells and BAL fluid of Grx1 KO compared to wild type mice exposed to cigarette smoke and air. S-glutathionylation of proteins quantified by the DTNB assay in lung tissue of Grx1 KO compared to wild type mice exposed to cigarette smoke and air, data shown in $\mathrm{nmol} \mathrm{GSH} / \mathrm{mg}$ protein and represented as mean $\pm \mathrm{SD}$ (A). S-glutathionylation of proteins visualised by the biotin switch staining in BAL fluid cells of Grx1 KO compared to wild type mice exposed to cigarette smoke and air, the outer right panel shows the quantification of staining expressed as relative fluorescent intensity of red staining (S-glutathionylated proteins) compared to blue, nuclear DAPI staining and represented as mean $\pm S D(B)$. S-glutathionylation of proteins quantified by the DTNB assay in BAL fluid of Grx1 KO compared to wild type mice exposed to cigarette smoke and air, data shown in $\mathrm{nmol} \mathrm{GSH} / \mu \mathrm{g}$ protein and represented as mean $\pm \mathrm{SD}(\mathrm{C}) .{ }^{*}$ represents $p<0.05$ between air and smoke exposed mice, \# represents $p<0.05$ between WT smoke and KO smoke. 
concentration of IL12(p40), GCSF, MCP-1, KC, RANTES and MIP-1alpha in wild type mice. In the Grx1 KO, the cigarette smoke-induced upregulation of these cytokines was significantly impaired, compared to the wild type controls. Moreover, the baseline levels of IL12(p40), GCSF, RANTES, MIP-1a, TNFa (data not shown) and IFNy (data not shown) were found to be lower in the BAL fluid of Grx1 KO mice compared to wild type mice.

S-glutathionylation in lungs and BAL fluid cells of Grx1 KO compared to wild type mice exposed to cigarette smoke and air

Since the major function of Grx1 is to catalyze deglutathionylation under physiological conditions, we next investigated the levels of total protein Sglutathionylation in lung tissue. As demonstrated in Figure 4A, exposure to cigarette smoke for four weeks lead to a significant decrease in S-glutathionylation of proteins in the lung tissue of wild type mice as reported previously. In the Grx1 $\mathrm{KO}$ mice, the smoke-induced decrease in protein S-glutathionylation did not reach statistical significance, but the levels observed after smoke exposure were significantly elevated compared to those in the wild type mice exposed to smoke. The levels of free GSH were decreased after smoke exposure as well, but no differences were observed between Grx1 KO and wild type mice (data not shown). When previously visualizing protein S-glutathionylation in whole lung tissue, we noted that this was not decreased in inflammatory cells after smoke exposure (13). We therefore analyzed protein S-glutathionylation in cells obtained by BAL using the biotin-switch approach and found that protein S-glutathionylation in these BAL fluid cells of mice exposed to smoke was increased compared to BAL fluid cells from air exposed mice. Moreover, S-glutathionylation in BAL fluid cells of Grx1 KO mice was higher after cigarette smoke exposure than in the wild type controls (Figure 4B-C). As expected, most of the cells in the cytospins had the morphological characteristics of macrophages. In cell free BALF, similar trends were observed with increased protein S-glutathionylation after smoke exposure and heightened levels in Grx1 KO mice compared to wt controls (Fig. 4D). At baseline, no differences were observed between WT and Grx1 KO mice.

Grx expression in lung tissue and macrophages of mice exposed to cigarette smoke

We have previously shown that exposure of pulmonary epithelial cells to cigarette smoke extract (CSE) leads to decreased expression of Grx1 mRNA and protein. In Figure $5 \mathrm{~A}$ we first confirmed these data in lung tissue of smoke exposed mice. Indeed, Grx1, but not Grx2 (data not shown) mRNA levels are significantly decreased after four weeks of cigarette smoke exposure compared to air exposed controls in wild type mice. Given the differential response of structural and inflammatory cells to smoke with respect to protein S-glutathionylation, we also assessed the effects of CSE on Grx expression in primary macrophages isolated 


\section{Figure 5}

A

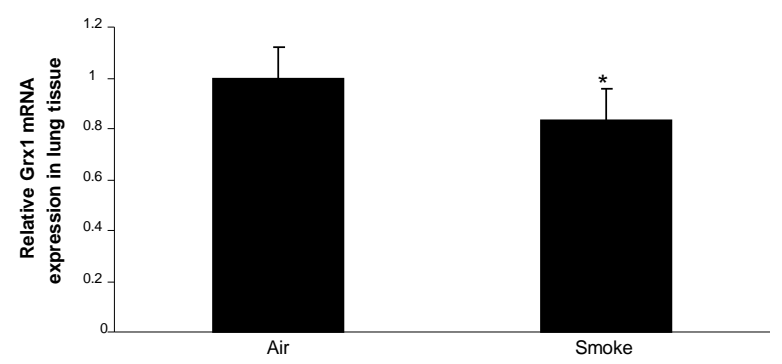

$\mathrm{B}$

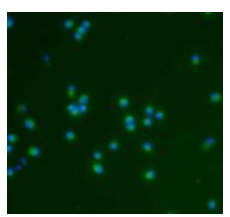

Control

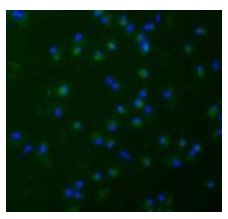

$0.5 \%$ CSE

C

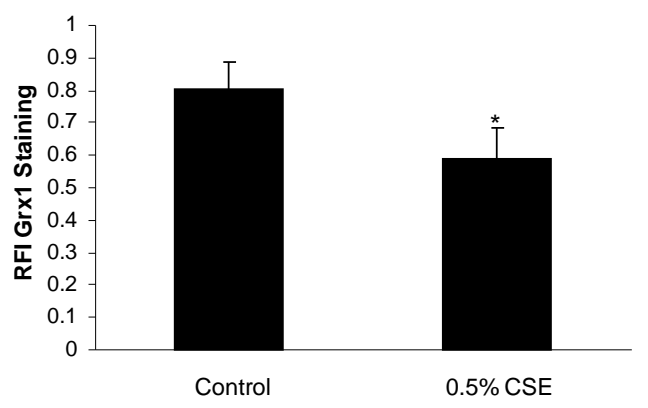

Figure 5: Grx1 expression in lung tissue and primary macrophages of mice exposed to cigarette smoke. (A) Grx1 mRNA expression corrected for HPRT mRNA expression in lung tissue of mice exposed to air and cigarette smoke, represented as mean \pm SD. (B) Fluorescent Grx1 staining in primary macrophages after 24 hours of control or $0.5 \%$ cigarette smoke extract exposure. The green staining represents Grx1 protein expression, whereas blue represents the nuclear DAPI staining. Quantification of fluorescent Grx1 staining is expressed as RFI in (C). 
from mice by fluorescent staining for Grx1 (represented in figure 5B and $C$ ) and confirm that smoke exposure also represses Grx1 protein levels in these cells.

$K C$ in primary macrophages versus primary epithelial cells from wild type and Grx1 KO mice after exposure to cigarette smoke extract

Protein S-glutathionylation appears thus to be differentially regulated in structural and inflammatory cells after smoke exposure, albeit independently from Grx1. We therefore asked whether this would differentially impact inflammatory mediator production in these cell types in response to cigarette smoke, given that we have previously shown that the Grx1-PSSG axis is important in determining the extent of $\mathrm{NF}-\mathrm{KB}$ activation and the levels of cytokines and chemokines such as KC in response to pro-inflammatory stimuli. When performing an ELISA for KC on culture supernatants of macrophages isolated from wild type mice, we found a significant increase in KC after exposure to CSE. In contrast, the Grx1 KO macrophages displayed decreased $\mathrm{KC}$ concentrations in their medium after exposure to CSE (Figure 6A). Also in MTECs the production of this chemokine was increased by cigarette smoke from both WT and Grx1 KO mice. Moreover, this response to CSE was significantly decreased in the Grx1 KO MTECs compared to the cells from wild types (Figure 6B).

Figure 6

A

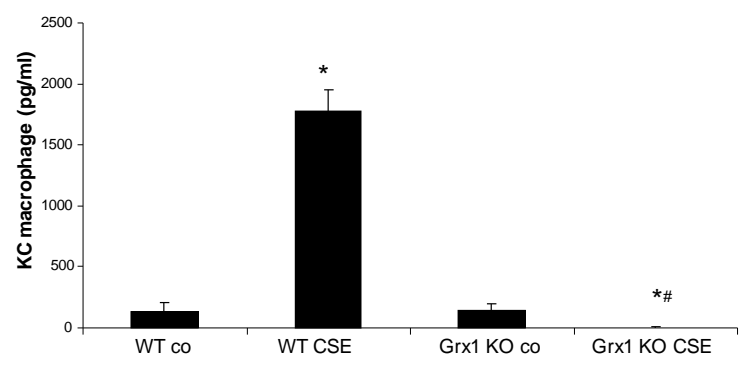

B

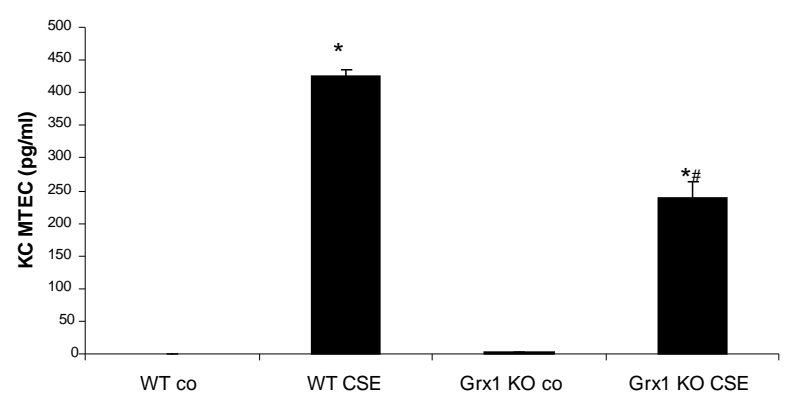

Figure 6: KC in primary macrophages versus primary epithelial cells from wild type and Grx1 KO mice after cigarette smoke extract exposure. $\mathrm{KC}$ in medium of primary macrophages (B) and of mouse tracheal epithelial cells (D) from wild type and Grx1 $\mathrm{KO}$ mice exposed to air or $0.1 \%$ cigarette smoke extract for 24 hours expressed in $\mathrm{pg} / \mathrm{ml}$. 


\section{Discussion}

It is becoming increasingly clear that GSH and its associated enzymes and the redox state of cells in general do not only play a role in protection against oxidative stress and damage, but also determine the outcome of discrete receptor-induced ROS-mediated signaling events involved in immune responses. Specifically shown here is that Grx1 and PSSG are key modulators of the in vivo response to cigarette smoke. Although there was no difference in the total amount of BAL fluid and lung cells between wild type and Grx $1 \mathrm{KO}$ mice after smoke exposure, the pattern of inflammatory cells found in the BAL fluid was different. The Grx1 KO mice actually accumulate macrophages in the BAL fluid after 4 weeks of cigarette smoke exposure, while in contrast to the wild type mice the increase of neutrophils, dendritic cells and CD3+, CD4+ and CD8+ T-cells was significantly impaired. This altered pattern of inflammatory cells in the BALF was mirrored by significant differences in the levels of chemokines and cytokines. After four weeks of cigarette smoke exposure the BALF of Grx1 KO mice contained significantly less KC, RANTES, MCP-1, IL12, GCSF and MIP1 $\alpha$ compared to the wild type controls exposed to the same amount and duration of cigarette smoke. The decreased levels of inflammatory mediators in the BAL fluid of Grx1 KO mice can be caused by the diminished levels of inflammatory cells other than macrophages. On the other hand, it could be attributed to the immaturity of these macrophages as we reported previously that alveolar macrophages isolated from Grx1 KO mice are smaller, express lower levels of the hematopoietic cell specific transcription factor PU.1 and displayed decreased phagocytosis capacity in vitro compared to alveolar macrophages from wild type animals (11). Also, LPS-induced NF-KB activation and inflammatory mediator production were found to be attenuated in the Grx1 KO macrophages as well as primary tracheal epithelial cells.

The Grx1 KO mice have been used by others to investigate the role of Grx1 in cigarette smoke induced lung inflammation. This study however employed a three day smoke exposure protocol and showed a much different outcome compared to the results obtained here. After a three day exposure regimen, the number of neutrophils were reported to be elevated in the Grx1 KO mice, in conjunction with increased levels of KC and MCP-1 compared to wild type controls (15). The main difference between studies is the length of exposure and might indicate that the role of Grx1 is opposite in an acute versus a more chronic exposure to cigarette smoke. This is also supported by the early increase in $\mathrm{KC}$ levels observed after LPS exposure in the Grx1 KO mice, compared to the attenuation of other mediators at more protracted time points (11). Not only the role of Grx1 in smokeinduced inflammation was found to be different, but in our model smoke exposure was found to decrease protein S-glutathionylation compared to the increase observed in the acute three day model of cigarette smoke exposure. We did not observe a difference in basal level of protein S-glutathionylation between WT and 
Grx1 KO mice, but smoke failed to affect PSSG in Grx1 KO mice. The level of PSSG in the lungs of Grx1 KO mice was significantly higher after smoke compared to the wild type animals. The differential response in S-glutathionylation of proteins in the two models might thus be involved in the discrepancies found in lung inflammation between acute and chronic smoke exposure. It has been reported by our laboratory that upon oxidative stress, targeted S-glutathionylation of IKK $\beta$ inhibits its activity and thus inhibits Rel A nuclear translocation. Binding of NF-KB to its consensus sequence has also been shown to be negatively affected by $S$ glutathionylation (14). Secondly, we have previously shown that Grx1 KO mice and primary epithelial cells isolated from these mice, show a markedly diminished response to LPS with respect to NF-KB activation and inflammatory mediator production (11). Since the Grx1 KO mice have more overall S-glutathionylation in the lung and in the BAL cells after smoke exposure, this might, through the inhibition of nuclear Rel A translocation, contribute to the decreased inflammatory cytokine production observed in the Grx1 KO mice after four weeks of cigarette smoke exposure, compared to wild type mice. So it is likely that the differential response in PSSG levels in the acute versus the more chronic cigarette smoke exposure causes the difference in phenotype in the mouse lung.

When we assessed PSSG in lavaged cells and fluid from smoke compared to air exposed mice, we found increased S-glutathionylation of proteins in contrast to the observed decrease in whole lung tissue. In lung tissue, S-glutathionylation was decreased despite a decrease in Grx1 mRNA expression. When we isolated primary macrophages from mice and exposed them to cigarette smoke extract, there was a decrease in Grx1 protein levels. These findings in macrophages are in line with our previously published data showing decreased Grx1 levels in various pulmonary epithelial cells after smoke exposure (12). Together these data indicate that overall protein S-glutathionylation can alter independently of differences in Grx1 and that the patterns of S-glutathionylation depend on cell type as well as stimuli and duration of stimulation.

It should be noted that the alteration in the overall protein S-glutathionylation pattern does not mean that all individually targeted proteins would be affected in the same direction. Although we did not investigate individual targets, in figure 6 of this manuscript we demonstrate that a differential effect on overall $S$ glutathionylation of proteins in response to smoke observed in different cell types, can still result in the same outcome. In particular, we demonstrate that smokeinduced KC production is decreased in both tracheal epithelial cells and macrophages isolated from Grx1 KO mice, irrespective of the effect on total protein S-glutathionylation. 
Taken together, we demonstrate in this manuscript that by using a knock out mouse model for glutaredoxin 1, this redox mediating enzyme has an important role in regulating cigarette smoke induced lung inflammation.

\section{Acknowledgements}

The authors thank Yvonne Janssen-Heininger for providing the mice, and Esther Theunisz, Gonda Konings, Greet Barbier, Eliane Castrique, Indra De Borle, Philippe De Gryze, Katleen De Saedeleer, Anouck Goethals, Marie-Rose Mouton, Ann Neessen, Christelle Snauwaert and Evelyn Spruyt for their technical assistance.

\section{References}

1. Cantin, A. M., S. L. North, R. C. Hubbard, and R. G. Crystal. 1987. Normal alveolar epithelial lining fluid contains high levels of glutathione. J Appl Physiol 63:152-157.

2. van der Toorn, M., D. Rezayat, H. F. Kauffman, S. J. Bakker, R. O. Gans, G. H. Koeter, A. M. Choi, A. J. van Oosterhout, and D. J. Slebos. 2009. Lipid-soluble components in cigarette smoke induce mitochondrial production of reactive oxygen species in lung epithelial cells. $\mathrm{Am}$ J Physiol Lung Cell Mol Physiol 297:L109-114.

3. Rahman, I. 2005. Regulation of glutathione in inflammation and chronic lung diseases. Mutat Res 579:58-80.

4. Mieyal, J. J., M. M. Gallogly, S. Qanungo, E. A. Sabens, and M. D. Shelton. 2008. Molecular mechanisms and clinical implications of reversible protein S-glutathionylation. Antioxid Redox Signal 10:1941-1988.

5. Huang, Z., J. T. Pinto, H. Deng, and J. P. Richie, Jr. 2008. Inhibition of caspase-3 activity and activation by protein glutathionylation. Biochem Pharmacol 75:2234-2244.

6. Janssen-Heininger, Y. M., M. E. Poynter, S. W. Aesif, C. Pantano, J. L. Ather, N. L. Reynaert, K. Ckless, V. Anathy, J. van der Velden, C. G. Irvin, and A. van der Vliet. 2009. Nuclear factor kappaB, airway epithelium, and asthma: avenues for redox control. Proc Am Thorac Soc 6:249-255.

7. Okamoto, T., T. Akaike, T. Sawa, Y. Miyamoto, A. van der Vliet, and H. Maeda. 2001. Activation of matrix metalloproteinases by peroxynitrite-induced protein S-glutathiolation via disulfide S-oxide formation. J Biol Chem 276:29596-29602.

8. Yang, Y., S. Jao, S. Nanduri, D. W. Starke, J. J. Mieyal, and J. Qin. 1998. Reactivity of the human thioltransferase (glutaredoxin) C7S, C25S, C78S, C82S mutant and NMR solution structure of its glutathionyl mixed disulfide intermediate reflect catalytic specificity. Biochemistry 37:17145-17156.

9. Reynaert, N. L., E. F. Wouters, and Y. M. Janssen-Heininger. 2007. Modulation of Glutaredoxin-1 Expression in a Mouse Model of Allergic Airway Disease. Am J Respir Cell Mol Biol 36(2):147-151.

10. Peltoniemi, M. J., P. H. Rytila, T. H. Harju, Y. M. Soini, K. M. Salmenkivi, L. W. Ruddock, and V. L. Kinnula. 2006. Modulation of glutaredoxin in the lung and sputum of cigarette smokers and chronic obstructive pulmonary disease. Respir Res 7:133.

11. Aesif, S. W., V. Anathy, A. S. Guala, J. N. Reiss, Y. S. Ho, and Y. M. Janssen-Heininger. 2011. Ablation of glutaredoxin-1 attenuates lipopolysaccharide-induced lung inflammation and alveolar macrophage activation. Am J Respir Cell Mol Biol 44(4):491-499.

12. Kuipers, I., A. S. Guala, S. W. Aesif, G. Konings, F. G. Bouwman, E. C. Mariman, E. F. Wouters, Y. M. Janssen-Heininger, and N. L. Reynaert. 2011. Cigarette Smoke Targets 
Glutaredoxin 1, Increasing S-glutathionylation and Epithelial Cell Death. Am J Respir Cell Mol Biol 45(5):931-937.

13. Kuipers, I., K. R. Bracke, G. G. Brusselle, E. F. Wouters, and N. L. Reynaert. 2012. Smoke decreases reversible oxidations s-glutathionylation and s-nitrosylation in mice. Free Radic Res. doi:10.3109/10715762.2011.647011.

14. Reynaert, N. L., A. van der Vliet, A. S. Guala, T. McGovern, M. Hristova, C. Pantano, N. H. Heintz, J. Heim, Y. S. Ho, D. E. Matthews, E. F. Wouters, and Y. M. Janssen-Heininger. 2006. Dynamic redox control of NF-kappaB through glutaredoxin-regulated Sglutathionylation of inhibitory kappaB kinase beta. Proc Natl Acad Sci U S A 103:1308613091.

15. Chung, S., I. K. Sundar, H. Yao, Y. S. Ho, and I. Rahman. Glutaredoxin 1 regulates cigarette smoke-mediated lung inflammation through differential modulation of I\{kappa\}B kinases in mice: impact on histone acetylation. Am J Physiol Lung Cell Mol Physiol 299:L192-203.

16. D'Hulst A, I., K. Y. Vermaelen, G. G. Brusselle, G. F. Joos, and R. A. Pauwels. 2005. Time course of cigarette smoke-induced pulmonary inflammation in mice. Eur Respir J 26:204-213.

17. Wu, R., and D. Smith. 1982. Continuous multiplication of rabbit tracheal epithelial cells in a defined, hormone-supplemented medium. In Vitro 18:800-812.

18. Reynaert, N. L., K. Ckless, A. S. Guala, E. F. Wouters, A. van der Vliet, and Y. M. JanssenHeininger. 2006. In situ detection of S-glutathionylated proteins following glutaredoxin-1 catalyzed cysteine derivatization. Biochim Biophys Acta 1760:180-187.

19. Demoor, T., K. R. Bracke, L. L. Dupont, M. Plantinga, B. Bondue, M. O. Roy, V. Lannoy, B. N. Lambrecht, G. G. Brusselle, and G. F. Joos. The role of ChemR23 in the induction and resolution of cigarette smoke-induced inflammation. J Immunol 186:5457-5467.

20. Carp, H., and A. Janoff. 1978. Possible mechanisms of emphysema in smokers. In vitro suppression of serum elastase-inhibitory capacity by fresh cigarette smoke and its prevention by antioxidants. Am Rev Respir Dis 118:617-621.

21. Rahman, I., A. Kode, and S. K. Biswas. 2006. Assay for quantitative determination of glutathione and glutathione disulfide levels using enzymatic recycling method. Nat Protoc 1:3159-3165. 


\title{
CHAPTER 6
}

\section{Altered glutaredoxin 1- protein S-glutathionylation axis in COPD}

Ine Kuipers ${ }^{1}$, Renaud Louis ${ }^{2}$, Jean-Louis Corhay ${ }^{2}$, Renske Krijgsman ${ }^{1}$, Ilja C Arts $^{3}$, Juanita H Vernooy ${ }^{1}$, Emiel FM Wouters ${ }^{1}$, Niki L Reynaert ${ }^{1^{*}}$

\begin{abstract}
Oxidative stress is a hallmark of COPD and alterations in glutathione levels and its associated enzymes are thought to contribute to the oxidant-anti-oxidant imbalance. Not investigated so far is the pool of glutathione bound to proteins, which is a sink of the important antioxidant and protects proteins against irreversible oxidative damage. This post-translational modification, Sglutahionylation is reversed by the enzyme glutaredoxin. We therefore measured protein S-glutathionylation, glutaredoxin 1 protein levels and total glutaredoxin activity in sputum and lung tissue of controls and COPD patients.

In induced sputum of patients experiencing an acute exacerbation, the level of glutathione bound to protein was found to be significantly decreased and Grx1 protein as well as total Grx activity were increased compared to stable disease. No differences in all three parameters were found between healthy smokers and stable COPD patients. Glutathione bound protein levels negatively correlated with sputum neutrophil percentages as well as IL8 and IL1 $1 \alpha$ levels and positively with lung function. Grx1 protein levels in contrast positively correlated with IL8 and IL1 $\beta$ and negatively with lung function.

In lung tissue the inverse trends were observed; glutathione bound to proteins was increased and Grx1 protein levels and total Grx activity were decreased in stable patients. Grx1 positively correlated with lung function in lung tissue.

In conclusion, this study highlights the importance of this new redox axis in COPD, both in stable condition and during acute exacerbations. Future research should examine in more detail the intricate relation with lung function and inflammation.
\end{abstract}




\section{Introduction}

COPD, hallmarked by pulmonary inflammation and emphysema, is mainly caused by smoking. Cigarette smoke contains $10^{16}$ free radicals per cigarette [1] and is responsible for activation and recruitment of macrophages and neutrophils into the lungs. These inflammatory cells secrete more oxidants, leading to oxidative stress. Because of the lungs' high risk of oxidative injury, they are equipped with a lining fluid containing high concentrations of glutathione $(\mathrm{GSH})[2]$. The ratio between GSH and its oxidized form GSSG provides information on the redox status of cells and tissues. Cigarette smoke acutely depletes GSH, but as an adaptive response to oxidative stress, such as upon chronic smoking, levels of GSH increase due to upregulation of the rate limiting enzyme in GSH synthesis, $\gamma^{-}$ glutamylcysteine ligase [3]. GSH, together with its redox cycle partners serves to maintain the reduced state of protein thiol groups by direct scavenging of oxidants or by the covalent reversible binding of GSH to these protein thiols. The latter formation of mixed disulfides occurs under physiological conditions, is induced upon mild oxidative stress and is known as S-glutathionylation [4]. Sglutathionylation also has the ability to modulate protein function. For instance, the kinase activity of Inhibitory kappa B kinase $\beta$ (IKK $\beta$ ), the enzyme responsible for NF-KB activation under pro-inflammatory conditions, was shown to be inhibited through S-glutathionylation after oxidative challenge of lung epithelial cells [5]. Also, DNA binding of both NF-KB and AP-1 has been shown to be inhibited by Sglutathionylation of their respective p50 and c-jun subunits $[6,7]$.

Glutaredoxins (Grx) or thioltransferases are redox enzymes that reverse Sglutathionylation of proteins under physiological conditions and are therefore important modulators of redox-mediated protein function [4]. Several mammalian Grxs have been identified. Grx1 localizes primarily to the cytosol and Grx2 is present in the mitochondria and nucleus. Grx3 is an isoform that does not exhibit deglutathionylating activity, but is reported to be altered in lung cancer [8].

With respect to COPD, the number of Grx1 positive alveolar macrophages was found to be decreased in patients versus healthy controls and importantly positively correlated with lung function. Additionally, increased levels of Grx1 were observed in sputum during exacerbations [9]. However, in this study Grx1 expression was not linked to Grx activity or the level of protein S-glutathionylation. We recently reported that cigarette smoke exposure decreased Grx1 expression and modified its activity through direct oxidation of the enzyme in lung epithelial cells. Moreover this was shown to be associated with increased protein Sglutathionylation and implicated the Grx1/S-glutathionylation axis in modulation of sensitivity to smoke-induced epithelial cell death [10]. 
Given these reports, the aim of the current study was to investigate the Grx1/S-glutathionylation axis in lung tissue and induced sputum of COPD patients compared to controls and to investigate the correlation thereof with measures of lung function and inflammation.

Table 1: Subject demographics and lung function for sputum study

\begin{tabular}{|l|l|l|l|l|}
\hline & $\begin{array}{l}\text { Healthy non- } \\
\text { smokers }\end{array}$ & $\begin{array}{l}\text { Control } \\
\text { smokers }\end{array}$ & $\begin{array}{l}\text { Stable COPD } \\
\text { patients }\end{array}$ & $\begin{array}{l}\text { COPD } \\
\text { exacerbations }\end{array}$ \\
\hline $\begin{array}{l}\text { Number of } \\
\text { subjects }\end{array}$ & 12 & 12 & 16 & 13 \\
\hline Age & $49.8 \pm 10.3$ & $53.9 \pm 10.7$ & $58.6 \pm 9.6$ & $63.9 \pm 8.8^{* *}$ \\
\hline Sex, M/F & $6 / 6$ & $7 / 5$ & $12 / 4$ & $11 / 2$ \\
\hline $\begin{array}{l}\text { Smoking status } \\
\text { (ex/current) }\end{array}$ & & $9 / 3$ & $13 / 3$ & $8 / 5$ \\
\hline Pack years & & $19.9 \pm 18.3$ & $44.5 \pm 11.1^{*}$ & $39.3 \pm 17.2^{*}$ \\
\hline BMI & $26 \pm 5.1$ & $24.8 \pm 3.1$ & $26.3 \pm 4.5$ & $28.0 \pm 5.1$ \\
\hline FEV $\%$ predicted & $101.4 \pm 17.6$ & $95.5 \pm 17.8$ & $49.2 \pm 14.5^{*},{ }^{* *}$ & $43.2 \pm 18.4^{*, * *}$ \\
\hline FVC \% predicted & $105.4 \pm 13.8$ & $107.7 \pm 21.2$ & $82.6 \pm 22.3^{*},{ }^{* *}$ & $69.9 \pm 22.2^{*, * *}$ \\
\hline $\begin{array}{l}\text { FEV } / \text { FVC, \% } \\
\text { predicted }\end{array}$ & $80.0 \pm 6.2$ & $75.6 \pm 9.6$ & $49.9 \pm 9.5^{*},{ }^{* *}$ & $47.5 \pm 9.8^{*, * *}$ \\
\hline GOLD II & & & 10 & 6 \\
\hline GOLD III & & & 4 & 4 \\
\hline GOLD IV & & & 2 & 3 \\
\hline $\begin{array}{l}\text { Inhaled CS (eq } \\
\text { budesonide/day) }\end{array}$ & & & $1600(0-1600)$ & $800(0-1600)$ \\
\hline SABA (n) & & & 10 & 10 \\
\hline LABA (n) & & & 0 & 13 \\
\hline Anticholinergic $(\mathrm{n})$ & & & & 3 \\
\hline Oral CS & & & & 12 \\
\hline
\end{tabular}

${ }^{*} \mathrm{p}<0.05$ vs control smokers, ${ }^{* *} \mathrm{p}<0.05$ vs non-smokers

Note pack years not available from 1 stable patient and 8 healthy smokers

CS: corticosteroids; SABA: short acting beta 2 agonist; LABA: long acting beta 2 agonist 


\section{Methods}

Study design and subject characteristics

We studied induced sputum obtained from 16 stable COPD patients and 14 COPD patients on day 1 or 2 during an acute exacerbation and compared them to 25 healthy subjects. Demographic and functional characteristics of these subjects are given in Table 1. All of the COPD patients fulfilled the criteria proposed by the Global Initiative for Chronic Obstructive Lung Disease (GOLD) guidelines [11]. Stable patients did not have an upper respiratory tract infection or any exacerbations requiring a change in maintenance treatment or oral corticosteroid and antibiotic prescription for at least 12 weeks prior to the study. Four patients with an exacerbation were recruited from consultations and 9 were hospitalized patients, admitted at the service of pneumology of $\mathrm{CHU}$ of Liège. Acute exacerbation of COPD is defined as an event in the natural course of the disease characterized by a change in the patient's baseline dyspnoea, cough and/or sputum that is beyond normal day-to-day variations, is acute in onset, and may warrant a change in regular medication. These patients were treated according to good clinical practice. Control subjects never had asthma or chronic bronchitis, nor had they experienced any bronchial or respiratory tract infection during the 8 weeks preceding the study. Their pulmonary function was within the normal range. Human lung tissue was obtained from 20 stable COPD patients and 8 control subjects. 10 patients with GOLD stage 4 COPD were admitted to the pulmonary rehabilitation centre CIRO Horn, Horn, the Netherlands before undergoing lung volume reduction surgery (LVRS). Lung tissue was also obtained from 10 GOLD 2 patients and control subjects with normal lung function who underwent a lobectomy or pneumectomy for lung cancer at the University Hospital Maastricht. Demographic and functional characteristics of these subjects are given in Table 5. Tissue was snap frozen in liquid nitrogen for biochemical analyses. The study was approved by the medical ethical committees of the University Hospital Maastricht. All subjects gave their informed consent in writing.

\section{Sputum induction and processing}

Sputum was induced by inhalation of hypertonic saline $(\mathrm{NaCl} 5 \%)$ when $\mathrm{FEV}_{1}$ postsalbutamol was $\geq 65 \%$ predicted and isotonic saline $(\mathrm{NaCl} 0.9 \%)$ when $\mathrm{FEV}_{1}$ was $<65 \%$ predicted. The whole sputum was collected in a plastic container, weighed, and homogenized by adding three volumes of phosphate-buffered saline, vortexed for $30 \mathrm{~s}$, and centrifuged at $800 \mathrm{~g}$ for $10 \mathrm{~min}$ at $4^{\circ} \mathrm{C}$. Supernatant was separated from cell pellet, in which squamous cells, total cell counts, and cell viability were checked by trypan blue exclusion. The differential cell count was performed on cytospins stained with Diff-Quick after counting 400 cells. 
$100 \mu \mathrm{l}$ of sputum or $100 \mu \mathrm{g}$ protein of lung homogenate in $100 \mu \mathrm{l}$ of lysis buffer (137 mM Tris- $\mathrm{HCl}, \mathrm{pH} 8.0,130 \mathrm{mM} \mathrm{NaCl}$, and 1\% NP-4) was incubated with an equal volume of reaction buffer (137 mM Tris- $\mathrm{HCl}, \mathrm{pH} 8.0,0.5 \mathrm{mM}$ glutathione, 1.2 $\mathrm{U}$ glutathione disulfide reductase (Roche), $0.35 \mathrm{mM} \mathrm{NADPH}, 1.5 \mathrm{mM}$ EDTA, pH 8.0 , and $2.5 \mathrm{mM}$ cysteine- $\mathrm{SO}_{3}$ ). Consumption of $\mathrm{NAPDH}$ was followed spectrophotometrically over 10 minutes at $340 \mathrm{~nm}$. The specific enzymatic reaction rate was obtained by subtracting the enzymatic rate omitting the substrate cysteine- $\mathrm{SO}_{3}$ from the enzymatic rate including the substrate in the reaction mixture. Data are expressed as $\mu \mathrm{mol} \mathrm{NADPH} /$ minute for induced sputum and as $\mu \mathrm{mol} \mathrm{NADPH} / \mathrm{minute} / \mathrm{mg}$ protein for lung homogenates [12].

\section{Western Blotting for Grx1}

Laemmli sample buffer containing DTT was added to $25 \mu$ of sputum or, to $25 \mu \mathrm{g}$ of lung homogenate and boiled for 10 minutes. Samples were loaded onto a $16,5 \%$ polyacrylamide gel and transferred onto a nitrocellulose membrane. The membrane was blocked at RT for $1 \mathrm{~h}$ in $5 \%$ BSA in Tris-buffered Saline (TBS) containing $0.05 \%$ Tween 20 (TBST). After two washes in TBST, the membrane was incubated overnight at $4^{\circ} \mathrm{C}$ with primary antibody against Grx1 (Imco). After three washes, peroxidase-conjugated secondary antibody was incubated for $1 \mathrm{~h}$ at RT. After three washes with TBST, conjugated peroxidase was detected by chemiluminescence using the Pierce ECL Western Blotting Substrate (Thermo Scientific, Rockford, IL, USA). Quantification of films was done using a Biorad scanner and was expressed as arbitrary units relative to diluted human Grx1 recombinant standard (Labfrontier) on each gel for the induced sputum samples and as arbitrary units compared to GAPDH protein levels on the same blot for lung homogenates.

Table 2: Correlations between the Grx1-PSSG axis in induced sputum and lung function in COPD from the whole group of subjects
All subjects
PSSG
Grx activity
Grx1 protein

\begin{tabular}{lrll}
\hline FEV $\%$ predicted & $0.372(0.007)$ & n.s. & $-0.336(0.015)$ \\
FVC\% predicted & $0.372(0.008)$ & n.s. & $-0.436(0.001)$ \\
FEV $_{1} /$ FVC\% predicted $0.336(0.016)$ & n.s. & $-0.273(0.051)$
\end{tabular}

$\mathrm{R}$ ( $p$-value)

n.s. non significant 
Figure 1
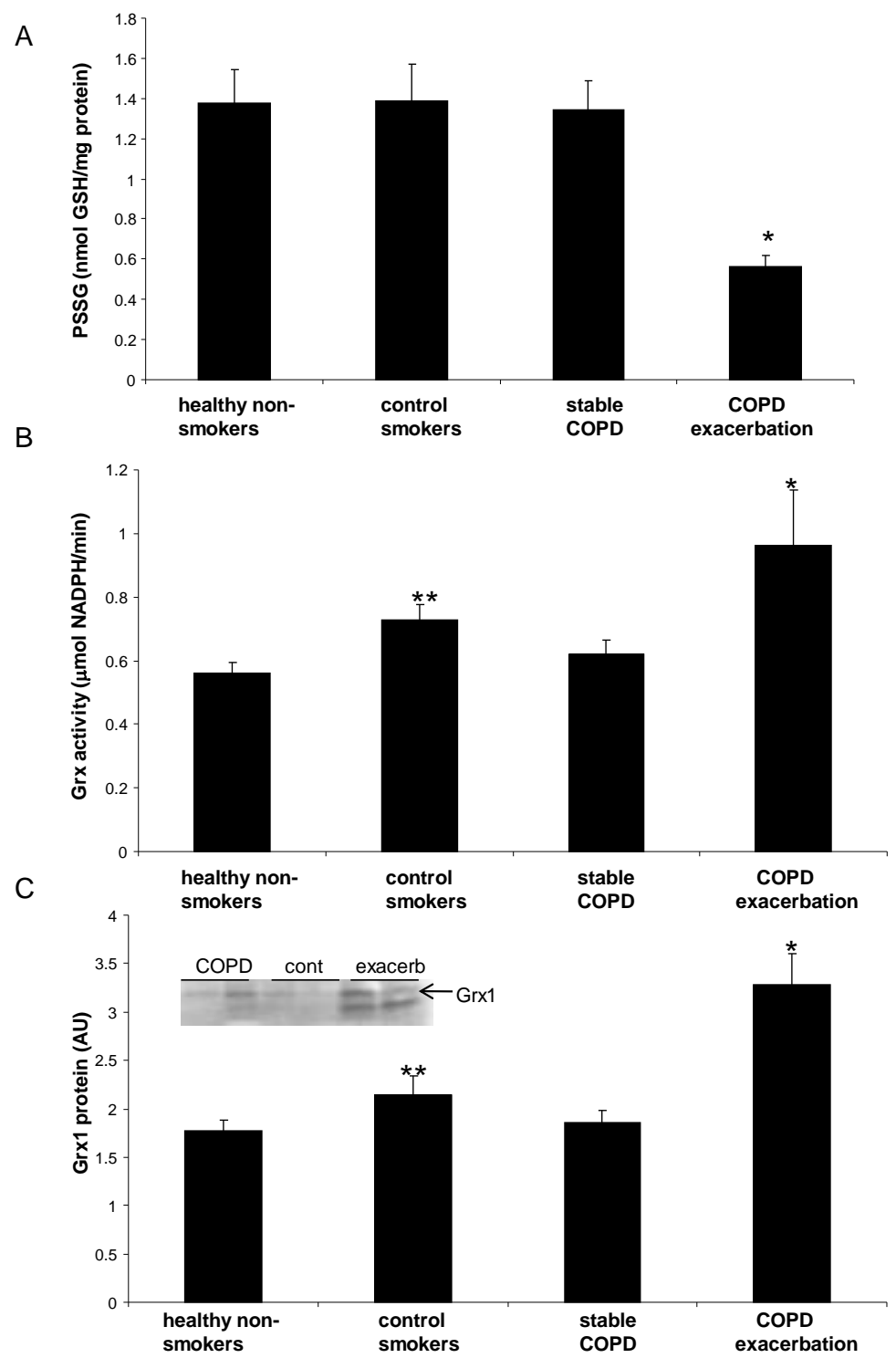

Figure 1: The Grx1-PSSG axis in induced sputum of healthy non-smokers, control smokers, stable COPD patients and COPD exacerbators. (A) Level of protein S-glutathionylation (PSSG) in induced sputum expressed as nmol GSH released per $\mathrm{mg}$ protein and represented as mean $\pm \mathrm{SD}$. (B) Total Grx activity in induced sputum expresssed as $\square \mathrm{mol}$ NADPH per minute and represented as mean \pm SD. (C) Grx1 protein level in induced sputum assessed by Western blot. Data are expressed in arbitrary units (AU) where Grx1 levels were corrected for a sample of recombinant human Grx1 on each gel and represented as mean \pm SD. The insert is a representative Western blot. * represents $p<0.05$ vs stable COPD and ${ }^{* *}$ represents $p<0.05$ vs healthy non-smokers. 
Quantitative determination of S-Glutathionylated proteins using 5,5'-dithio-bis(2nitrobenzoic acid) (dTNB)

$200 \mu \mathrm{l}$ of sputum or $200 \mu \mathrm{g}$ of lung homogenate was acetone precipitated for 20 minutes at $-20^{\circ} \mathrm{C}$ and spun down for 5 minutes at high speed. Pellets were next resuspended and sonicated in $200 \mu \mathrm{l}$ of ice-cold extraction buffer containing $0.2 \%$ Triton-X 100 and $0.6 \%$ sulfosalicyclic acid in $0.1 \mathrm{M}$ potassium phosphate buffer with $5 \mathrm{mM}$ EDTA disodium salt (KPE), pH 7.5. After 2 freeze-thaw cycles, samples were centrifuged at $3000 \mathrm{xg}$ for $4 \mathrm{~min}$ at $4^{\circ} \mathrm{C}$. To remove glutathione (GSH) from proteins, the pellet was treated with $100 \mu \mathrm{l}$ of $1 \% \mathrm{NaBH}_{4}$ in water and neutralized with $40 \mu \mathrm{l}$ of $30 \%$ metaphosphoric acid. Samples were centrifuged at $1000 \mathrm{xg}$ for 15 min and the supernatant was used to determine the GSH content using the dTNB GSSG reductase recycling method [13]. $20 \mu \mathrm{l}$ of KPE, GSH standards and samples were pipetted into a 96-well microtiter plate and freshly prepared, equal volumes of dTNB and GSSG reductase were added in the dark. After 30 seconds, $\beta$-NADPH was added to start the conversion of dTNB to TNB and the absorbance at $412 \mathrm{~nm}$ was read every 30 seconds for 2 minutes. A standard curve was performed using a concentration range of $\mathrm{GSH}$. $\mathrm{NaBH}_{4}$ was omitted for each sample, as a negative control. Values were corrected for protein content and data is expressed as nmol GSH per milligram of protein.

\section{Luminex analyses}

27 cytokines and chemokines in sputum supernatants were quantified using a BioPlex human cytokine 27-plex Panel according to the manufacturer's instructions. The analysis was done with a Luminex 100 IS 2.3 system using the Bio-Plex Manager 4.1.1. software.

\section{Statistical analyses}

SPSS (version 15) was used for data analyses. Unless indicated otherwise, data are expressed as mean and standard deviation. Between-group comparisons were analyzed using the Kruskal-Wallis test, followed by the Mann-Whitney $U$ test. Correlations between variables were determined using Spearman's rho. A $p$-value $<0.05$ was considered statistically significant.

\section{Results}

The Grx1-PSSG axis in induced sputum samples

Healthy smokers and non-smokers, stable COPD patients and patients with an exacerbation were well matched for age and BMI (Table 1). Patients had smoked more pack years compared to controls and were significantly older compared to healthy non-smokers. As expected, COPD patients exhibited poorer lung function compared to healthy non smokers and healthy smokers. 
Table 3 : Sputum cell differentials and inflammatory cytokines

\begin{tabular}{|c|c|c|c|c|}
\hline & Healthy non- smokers & Control smokers & Stable COPD & $\begin{array}{l}\text { COPD } \\
\text { Exacerbation }\end{array}$ \\
\hline Total cells & $0.4(0.05-1.74)$ & $0.4(0.07-3.60)$ & $0.98(0.04-35.00)$ & $6(1.14-83.4)^{\star \star \star}$ \\
\hline \%macrophages & " $60(13-96)$ & (14-74.8) & " $11.3(0.4-77.5)$ & $8.4(0-32)$ \\
\hline \%neutrophils & $17.8(0-84)$ & $(7.6-75.8)$ & $82.05(3-95)^{\star *}$ & $83.5(25.5-99.5)$ \\
\hline \%epithelial cells & $5.4(1.75-67)$ & $(1.2-66.2)$ & $4.8(0-59)$ & $3.2(0-31)$ \\
\hline \%eosinophils & $0(0-3.2)$ & $0(0-5.8)$ & $1.8(0-5)$ & $0.75(0-23.3)$ \\
\hline \%lymphocytes & $1.8(0-3.4)$ & $1.6(0-10)$ & $0.5(0-3)$ & $1.62(0-6.3)$ \\
\hline \%squamous cells & $33.1(6-78.4)$ & $32.5(2-72.7)$ & $28(0-68)$ & $7(0-35)^{\star \star \star}$ \\
\hline \%viable cells & $59(27.3-80.6)$ & $64.5(22.2-88)$ & $52.0(0.97-81)$ & $79(45-99)^{\star \star *}$ \\
\hline$\overline{\overline{\mathrm{IL}} 1 \beta}$ & $1.18(0.43-8.58)$ & $1.4(0.43-2.37)$ & $1.34(0.41-31.24)$ & $3.3(0.64-602.6)^{* * *}$ \\
\hline IL8 & $25.7(7.32-131.6)$ & 74.7 (15.51-243.9) & $186.7(12.06-3989)$ & 237 (60.1-1990) \\
\hline IL10 & $0.88(0.23-1.59)$ & $1.6(0.67-2.74)^{*}$ & $0.91(0.35-2.91)$ & $2.01(0.63-4.2)^{* * *}$ \\
\hline IL12 & $3.99(1.06-7.22)$ & $6.3(4.48-16.33)^{*}$ & $1.51(0.76-7.07)^{\star \star}$ & $6.8(2.52-14.99)^{\star \star *}$ \\
\hline
\end{tabular}

Median (range), $\mathrm{pg} / \mathrm{ml}$ for inflammatory cytokines

${ }^{*} p<0.05$ smokers vs non-smokers, ${ }^{* *} p<0.05$ stable COPD vs smokers, ${ }^{* * *} p<0.05$ exacerbation vs stable COPD

PSSG levels in induced sputum were not different between the healthy smokers and non-smokers, and also not between stable COPD patients and healthy smokers. However, PSSG levels in induced sputum of COPD patients experiencing an acute exacerbation were significantly decreased compared to stable patients (Fig. 1A). Total Grx activity in sputum was increased in healthy smokers compared to non-smokers and also in COPD patients with an exacerbation compared to stable patients (Fig.1B). There was also no significant difference in sputum Grx activity between healthy smokers and stable patients. The observed alterations in total Grx activity were reflected by altered Grx1 protein levels in induced sputum, where an increase in Grx1 protein was observed in healthy smokers compared to non-smokers and in COPD patients with an exacerbation compared to stable COPD (Fig. 1C). Again, the Grx1 protein level was not different between healthy smokers and stable patients. Interestingly, in all 
COPD patients with an exacerbation an extra band was observed below that of Grx1 which could indicate a degradation product (Fig 1C, insert).

Importantly, in agreement with the function of Grx to remove GSH from proteins, negative correlations were observed between PSSG and Grx1 protein levels (Fig. $2 \mathrm{~A}$ ), and between PSSG and total Grx activity (Fig. 2B).

Figure 2

A

$$
r=-0.658, p<0.001
$$

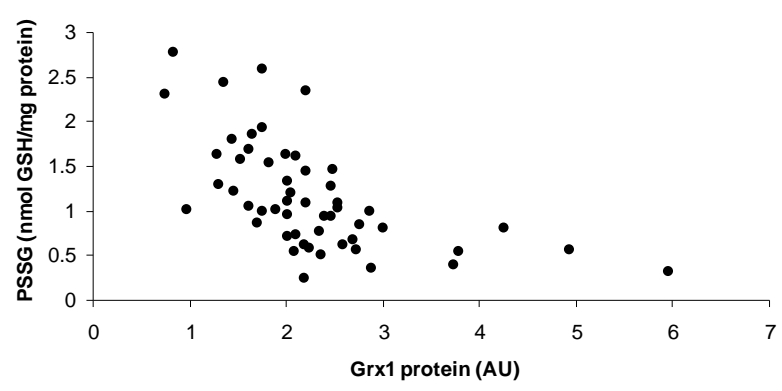

B

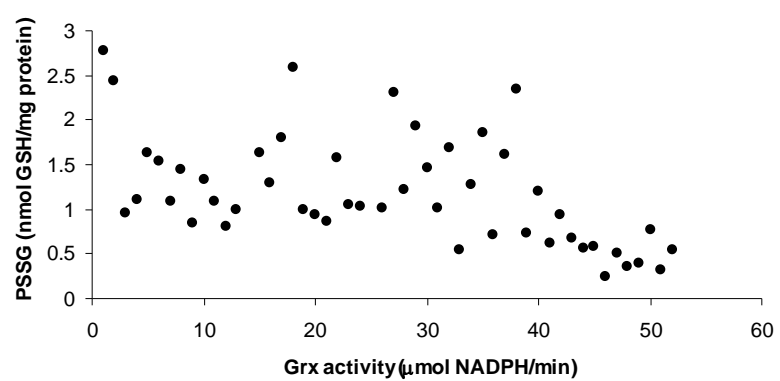

Figure 2: Correlations between Grx and PSSG. Negative correlations between PSSG and the Grx1 protein level (A) and total Grx activity (B) in induced sputum in the whole study group.

Correlations between the Grx1-PSSG axis in induced sputum and lung function When assessing the relations between the Grx1-PSSG axis and lung function parameters, we found PSSG levels positively correlated with FEV ${ }_{1}, F V C$, and $\mathrm{FEV}_{1} / \mathrm{FVC}$ in all subjects (Table 2). Grx1 protein levels on the other hand were negatively correlated with FVC and FEV1/FVC. No significant correlations were found for Grx activity. 
Correlations between the Grx1-PSSG axis in induced sputum and age and pack years smoked

We next assessed the possible relations between the Grx1-PSSG axis and age and pack years smoked. PSSG levels were negatively correlated with pack years smoked $(r=-0.344, p=0.018)$, as well as with age $(r=-0.570, p<0.001)$, whereas a positive correlation was observed between pack years smoked and Grx activity $(r=0.365, p=0.015)$, and Grx1 protein levels $(r=0.298, p=0.039)$. Lastly, Grx1 protein levels were also found to be positively correlated with age $(r=0.401$, $p=0.003$ ).

Sputum cell counts, inflammatory cytokines and their relation with the Grx1-PSSG axis

Minor significant differences were observed in cell profiles in induced sputum between groups, likely due to the large variability (Table 3). A positive correlation was however observed between sputum PSSG levels and the percentage of macrophages, epithelial and squamous cells in the whole study group. Moreover, the percentage of neutrophils and viable cells negatively correlated with PSSG in the whole study group. These correlations remained significant when considering stable patients alone (Table 4). Grx1 protein negatively correlated with squamous cells in the whole study group and in stable patients. On the other hand, Grx1 positively correlated with the percentage of viable cells in the whole study group. Grx activity was not found to correlate with sputum cells.

With respect to inflammatory mediators, only the reported molecules showed significant differences between groups (Table 3). IL8 was increased and IL12 decreased in stable patients compared to healthy smokers, although the difference in IL8 levels failed to reach statistical significance due to a large variability. In COPD patients with an acute disease exacerbation, increased levels of IL10, IL12 and IL1 $\beta$ were found compared to patients with stable disease. IL10 and IL12 levels were also increased in healthy smokers compared to non-smokers.

Grx1 protein levels were significantly and positively correlated with IL $1 \alpha(r=0.486$, $p=0.003)$, IL8 $(r=0.427, p=0.009)$, IL10 ( $r=0.349, p=0.043)$ and IL12 $(r=0.363$, $p=0.032$ ) in the whole study group. PSSG levels on the other hand negatively correlated with IL1 $\beta(r=-0.484, p=0.003)$ and IL8 $(r=-0.475, p=0.003)$.

The Grx1-PSSG axis in lung homogenates

Control subjects and COPD patients in which the Grx1-PSSG axis was assessed in lung tissue were well matched for age, gender and BMI. Patients had smoked more pack years compared to controls and exhibited poorer lung function (Table $5)$. 
Table 4: Correlations between the Grx-PSSG axis in induced sputum and sputum cell counts in COPD

\begin{tabular}{|c|c|c|c|c|}
\hline & & All subjects & Stable COPD & $\begin{array}{l}\text { COPD } \\
\text { Exacerbation }\end{array}$ \\
\hline \multirow[t]{8}{*}{$\overline{\overline{P S S G}}$} & \%macrophages & $0.535(<0.001)$ & $0.733(0.001)$ & n.s. \\
\hline & \%neutrophils & $-0.534(<0.001)$ & $-0.709(0.002)$ & n.s. \\
\hline & \%epithelial cells & $0.446(0.002)$ & $0.699(0.003)$ & n.s. \\
\hline & \%eosinophils & n.s. & n.s. & n.s. \\
\hline & \%lymphocytes & n.s. & n.s. & n.s. \\
\hline & \%squamous cells & $0.383(0.006)$ & n.s. & n.s. \\
\hline & \%viable cells & $-0.395(0.005)$ & n.s. & n.s. \\
\hline & total cells & $-0.643(<0.001)$ & $-0.652(0.006)$ & n.s. \\
\hline \multirow[t]{8}{*}{$\overline{\mathrm{Grx1}}$} & \%macrophages & n.s. & n.s. & n.s. \\
\hline & \%neutrophils & $0.286(0.052)$ & n.s. & n.s. \\
\hline & \%epithelial cells & n.s. & n.s. & n.s. \\
\hline & \%eosinophils & n.s. & n.s. & n.s. \\
\hline & \%lymphocytes & n.s. & n.s. & n.s. \\
\hline & \%squamous cells & $-0.400(0.004)$ & $-0.603(0.013)$ & n.s. \\
\hline & \%viable cells & $0.380(0.006)$ & n.s. & n.s. \\
\hline & total cells & $0.543(<0.001)$ & $0.570(0.021)$ & n.s. \\
\hline
\end{tabular}

In contrast to the sputum findings, pulmonary PSSG levels were significantly increased in COPD patients compared to controls (Fig. 3A). No significant difference was observed when assessing GOLD 2 and GOLD 4 patients separately. Grx activity on the other hand was decreased in COPD patients compared to controls, as well as in GOLD 4 patients compared to controls (Fig 3B). Accordingly, Grx1 protein levels were also decreased significantly in all patients compared to controls, as well as in GOLD 2 and GOLD 4 patients separately. Grx1 levels in GOLD 4 patients however, were significantly higher compared to Grx1 levels in GOLD 2 patients (Fig. 3C). 
Table 5: Subject demographics and lung function for lung tissue study

\begin{tabular}{|l|l||l|}
\hline & Controls & COPD patients \\
\hline Number of subjects & 8 & 20 \\
\hline \hline Age & $62.1 \pm 6.9$ & $61.0 \pm 10.5$ \\
\hline Sex, M/F & $5 / 3$ & $12 / 8$ \\
\hline Pack years & $16.9 \pm 17.0$ & $34.2 \pm 17.2^{*}$ \\
\hline \hline BMI $\left(\mathrm{kg} / \mathrm{m}^{2}\right)$ & $26.1 \pm 3.1$ & $25.5 \pm 4.7$ \\
\hline \hline FEV $\%$ predicted & $113.0 \pm 17.6$ & $45.3 \pm 24.1^{\star}$ \\
\hline FVC $\%$ predicted & $112.8 \pm 19.1$ & $83.5 \pm 15.8^{\star}$ \\
\hline \hline FEV $/$ FVC, \% predicted & $81.1 \pm 4.5$ & $41.9 \pm 18.3^{*}$ \\
\hline \hline GOLD II-IV & & $10 / 10$ \\
& & \\
\hline
\end{tabular}

*represents $p<0.05$ vs healthy controls

Table 6: Correlations between the Grx1-PSSG axis in lung homogenates and lung function and age in COPD from the whole group of subjects

$\begin{array}{llll}\text { All subjects } & \text { PSSG } & \text { Grx activity } & \text { Grx1 protein }\end{array}$

\begin{tabular}{llll}
\hline \hline FEV $_{1} \%$ predicted & n.s. & $0.438(0.02)$ & $0.388(0.041)$ \\
FVC\% predicted & n.s. & $0.430(0.022)$ & n.s. \\
FEV $_{1} /$ FVC $\%$ predicted & n.s. & $0.407(0.032)$ & $0.398(0.036)$ \\
Age & n.s. & n.s. & $-0.389(0.045)$
\end{tabular}

$r$ ( $p$-value)

n.s. non significant

Correlations between the Grx1-PSSG axis in lung homogenates and age and lung function

In contrast to the findings in sputum, no correlations of PSSG with lung function parameters or age were found. On the other hand, Grx activity was positively correlated with $\mathrm{FEV}_{1}, \mathrm{FVC}$ as well as $\mathrm{FEV}_{1} / \mathrm{FVC}$ in the whole subject group. Only the correlation with $\mathrm{FVC}$ remained significant when only considering the patients $(r=0.486, p=0.043)$. Grx1 protein levels were also positively correlated with $F E V_{1}$ and $F E V_{1} / F V C$ in the whole subject group, but not in the patients alone and negatively with age in the whole group (Table 6) and patients alone $(r=-0.476$, 
$p=0.039$ ). No correlations with pack years smoked were found, but Grx1 levels were found to be higher in ex smoking COPD patients compared to currently smoking patients $(0.81 \pm 0.48$ vs $0.35 \pm 0.21$ arbitrary units, respectively). Lastly, Grx1 protein levels positively correlated with total Grx activity in lung tissue in the whole study group $(r=0.421, p=0.026)$.

Figure 3

A

B
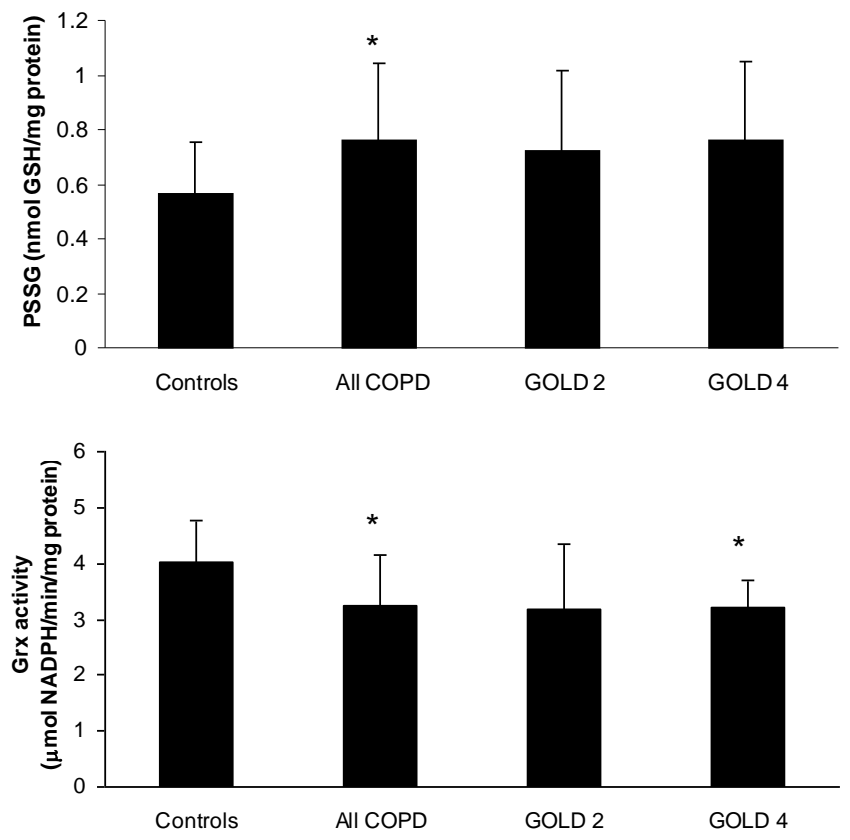

C

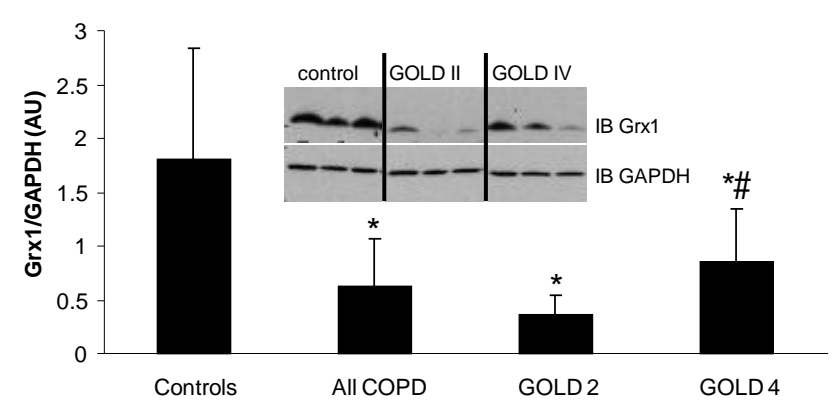

Figure 3: The Grx1-PSSG axis in lung tissue of control subjects and COPD patients. (A) Level of protein S-glutathionylation (PSSG) in lung tissue expressed as nmol GSH released per $\mathrm{mg}$ protein and represented as mean \pm SD. (B) Total Grx activity in lung tissue expresssed as mol NADPH per minute and per $\mathrm{mg}$ protein, represented as mean \pm SD. (C) Grx1 protein level in lung tissue assessed by Western blot. Data are expressed in arbitrary units (AU) where Grx1 levels were corrected for GAPDH and represented as mean \pm SD. The insert is a representative Western blot. * represents $p<0.05$ vs control and \# represents $p<0.05$ vs GOLD 2. 


\section{Discussion}

We here show decreased PSSG levels in conjunction with increased Grx1 protein and total Grx activity in induced sputum of COPD patients experiencing an acute exacerbation compared to stable patients. Despite the lack of differences in sputum between healthy smokers and stable patients, Grx1 protein levels and total Grx activity were decreased in lung tissue of patients compared to controls. Moreover, pulmonary PSSG levels were increased.

Data on Grx1 protein levels are fully in line with a previous publication on a smaller sample size [9]. This study also found increased Grx1 protein in sputum of patients with an exacerbation, albeit only compared to controls and not to stable disease. We extend these findings here by reporting increased total Grx activity and decreased protein glutathionylation. Also, in healthy smokers Grx1 levels were increased compared to non-smokers which was mirrored by increases in total Grx activity. Importantly, in line with the function of Grx1 PSSG levels negatively correlated with GRX1 protein levels and with total Grx activity. The observed extra band below the expected molecular weight of Grx1, in particular in exacerbation sputa is intriguing and could represent a degradation product. This hypothesis remains to be tested, but we previously demonstrated that caspase 3 and 8 are able to cleave human Grx1 to a product of about $8 \mathrm{kDa}$ in response to Fas ligand stimulation [14]. The fact that Grx1 levels positively correlated with the percentage of viable cells in the sputa fits the proposed non-classical export mechanism of the enzyme [9]. Grx1 levels were positively correlated with the pro-inflammatory cytokines IL1 $\beta$, IL8 and IL12, but also with the anti-inflammatory cytokine IL10. It should be further investigated if these inflammatory mediators or triggers of exacerbations modulate Grx1 expression or induce its export. This seems likely since it was shown that aspiration of LPS in mice enhanced Grx1 protein levels and Grx activity in BALF [15]. On the other hand, cigarette smoke might induce export of Grx1 since Grx1 and Grx activity positively correlated with pack years smoked and both were increased in healthy smokers. Cigarette smoke extract was found to decrease Grx1 expression in lung epithelial cells, but we did not investigate levels in culture medium [10]. Another question is from which cell types Grx1 originates. Macrophages and epithelial cells are the most likely candidates, although no significant correlations with these cell proportions in sputa were detected. A study that examined extracellular Grx1 found that it was mostly detected from non-adherent cells compared to adherent cells, making the macrophage a likely origin of sputum Grx1 [16].

In contrast to the sputum data, we observed decreased Grx1 protein levels and total Grx activity in lung homogenates of COPD patients compared to controls. These findings are in line with decreased Grx1 in lung tissue in COPD patients published previously [9]. No correlations with pack years smoked were observed, but Grx1 levels were found to be higher in COPD patients that were ex smokers 
compared to current smokers. This finding is confounded by the fact that most ex smokers were GOLD 4 patients. However, we did recently report that cigarette smoke extract reduces Grx1 mRNA and protein expression as well as total Grx activity in lung epithelial cells [10]. Importantly, we also demonstrated that Grx1 protected epithelial cells against cigarette smoke-induced cell death. It remains to be investigated whether decreased Grx1 levels in COPD patients are associated with increased death of resident cells.

When considering Grx as an antioxidant enzyme, the lower levels in patients with COPD fit with the general trend of decreased levels of this class of enzymes which include heme oxygenase $1, N A D(P) H$ quinine oxidoreductase 1 and glutamate-cysteine ligase modifier [17]. In lung tissue, Grx1 levels were also found to be negatively associated with age, which is in line with the oxidant theory of aging.

Pulmonary Grx1 levels and total Grx activity were positively correlated with the lung function parameters $\mathrm{FEV}_{1}, \mathrm{FVC}$ and their ratio. In contrast, sputum Grx activity was negatively correlated with $F V C$ and $F E V_{1} / F V C$. A better lung function seems thus associated with higher levels of Grx and activity in the lungs, but less in sputum.

PSSG is a reservoir of GSH, which can be liberated under conditions of oxidative stress by Grx to increase the antioxidant potential. Data obtained in sputum could be interpreted as such to attempt to scavenge the high levels of ROS during an exacerbation by increasing extracellular Grx. The fact that PSSG levels are attenuated in this condition strengthens this hypothesis. However, PSSG also protects protein thiols from further oxidations and decreased PSSG levels could thus negatively affect the proteins involved, leading to irreversible damage and accumulation or degradation [18-20]. PSSG levels in sputum were positively correlated with lung function, supporting this protective function. Interestingly, sputum PSSG levels were also negatively associated with age, which could be interpreted as diminished protection in ageing. Thirdly, the function of certain proteins, especially ones with conserved and functionally important cysteine residues, is modified by the binding of GSH. Examples include mediators of cell death and inflammation such as procaspase-3 [21], multiple members of the NF-KB pathway (reviewed in [22]), and matrix metalloproteases [23]. Inhibition has been shown for caspase 3, and NF-KB, whereas MMP9 was shown to be activated by this redox modification.

Positive correlations of sputum PSSG were found with macrophages, epithelial and squamous cells, indicating these cells as possible sources of extracellular GSH or PSSG. Epithelial cells are a known prominent source of extracellular GSH [24] and GSH regulation in macrophages has been shown to play a role in their functionality [25]. In contrast, the increased level of oxidative stress associated with neutrophils and dying cells [26-28] might underlie the negative association of PSSG with the percentage of these cells in sputum. Also, PSSG levels were negatively associated 
with the pro-inflammatory cytokines IL1 $\beta$ and IL8. The relation between the GrxPSSG axis and inflammation is apparent from the literature and is mostly centred on NF-KB. In general, S-glutathionylation of IKK $\beta$, p50 and p65 inhibits activation of $\mathrm{NF}-\mathrm{KB}$ dependent gene transcription, which is in accordance with the observed negative association between PSSG and inflammation in sputum. The positive correlation of Grx1 with inflammatory mediators in sputum is also in line with our previous publications that shows that LPS-induced NF-KB activation and cigarette smoke induced inflammation are repressed in mice lacking Grx1 [15, 29]. In contrast, a 3 day exposure to cigarette smoke was found to cause exaggerated NF-KB activation and inflammation in Grx1 k.o. mice compared to wild type controls. Smoke exposure in wild type mice decreased Grx1 and increased PSSG levels [30]. Our data in lung tissue with respect to the Grx-PSSG axis in lung tissue from COPD patients confirm the effects of acute smoke exposure in vitro and in mice. Unfortunately, it was not possible to perform an in depth analysis of in situ PSSG staining or inflammation.

In conclusion, this study highlights the importance of this new redox axis in COPD, both in stable condition and during acute exacerbations. Future research should examine in more detail the intricate relation with lung function and inflammation.

\section{Acknowledgements}

The authors would like to thank Claudia Geijselaers and Esther Theunisz for technical assistance.

\section{Funding sources}

This study was supported by NUTRIM, a VENI grant from NWO/ZonMW (016.086.090) awarded to NLR and IUAP (interuniversity attraction pole) P6/35 supported by the Belgian Federal Government.

\section{References}

[1] Pryor, W. A.; Prier, D. G.; Church, D. F. Electron-spin resonance study of mainstream and sidestream cigarette smoke: nature of the free radicals in gas-phase smoke and in cigarette tar. Environ Health Perspect 47:345-355; 1983.

[2] Cantin, A. M.; North, S. L.; Hubbard, R. C.; Crystal, R. G. Normal alveolar epithelial lining fluid contains high levels of glutathione. J Appl Physiol 63:152-157; 1987.

[3] Rahman, I. Regulation of glutathione in inflammation and chronic lung diseases. Mutat Res 579:58-80; 2005.

[4] Mieyal, J. J.; Gallogly, M. M.; Qanungo, S.; Sabens, E. A.; Shelton, M. D. Molecular mechanisms and clinical implications of reversible protein S-glutathionylation. Antioxid Redox Signal 10:1941-1988; 2008.

[5] Reynaert, N. L.; van der Vliet, A.; Guala, A. S.; McGovern, T.; Hristova, M.; Pantano, C.; Heintz, N. H.; Heim, J.; Ho, Y. S.; Matthews, D. E.; Wouters, E. F.; Janssen-Heininger, Y. M. Dynamic redox control of NF-kappaB through glutaredoxin-regulated S-glutathionylation of inhibitory kappaB kinase beta. Proc Natl Acad Sci U S A 103:13086-13091; 2006. 
[6] Klatt, P.; Molina, E. P.; Lamas, S. Nitric oxide inhibits c-Jun DNA binding by specifically targeted S-glutathionylation. J Biol Chem 274:15857-15864; 1999.

[7] Pineda-Molina, E.; Klatt, P.; Vazquez, J.; Marina, A.; Garcia de Lacoba, M.; Perez-Sala, D.; Lamas, S. Glutathionylation of the p50 subunit of NF-kappaB: a mechanism for redox-induced inhibition of DNA binding. Biochemistry 40:14134-14142; 2001.

[8] Cha, M. K.; Kim, I. H. Preferential overexpression of glutaredoxin3 in human colon and lung carcinoma. Cancer Epidemiol 33:281-287; 2009.

[9] Peltoniemi, M. J.; Rytila, P. H.; Harju, T. H.; Soini, Y. M.; Salmenkivi, K. M.; Ruddock, L. W.; Kinnula, V. L. Modulation of glutaredoxin in the lung and sputum of cigarette smokers and chronic obstructive pulmonary disease. Respir Res 7:133; 2006.

[10] Kuipers, I.; Guala, A. S.; Aesif, S. W.; Konings, G.; Bouwman, F. G.; Mariman, E. C.; Wouters, E. F.; Janssen-Heininger, Y. M.; Reynaert, N. L. Cigarette Smoke Targets Glutaredoxin 1, Increasing S-glutathionylation and Epithelial Cell Death. Am J Respir Cell Mol Biol 45:931-937; 2011.

[11] Fabbri, L.; Pauwels, R. A.; Hurd, S. S. Global Strategy for the Diagnosis, Management, and Prevention of Chronic Obstructive Pulmonary Disease: GOLD Executive Summary updated 2003. Copd 1:105-141; discussion 103-104; 2004.

[12] Gan, Z. R.; Wells, W. W. Purification and properties of thioltransferase. J Biol Chem 261:996$1001 ; 1986$.

[13] Rahman, I.; Kode, A.; Biswas, S. K. Assay for quantitative determination of glutathione and glutathione disulfide levels using enzymatic recycling method. Nat Protoc 1:3159-3165; 2006.

[14] Anathy, V.; Aesif, S. W.; Guala, A. S.; Havermans, M.; Reynaert, N. L.; Ho, Y. S.; Budd, R. C.; Janssen-Heininger, Y. M. Redox amplification of apoptosis by caspase-dependent cleavage of glutaredoxin 1 and S-glutathionylation of Fas. J Cell Biol 184:241-252; 2009.

[15] Aesif, S. W.; Anathy, V.; Guala, A. S.; Reiss, J. N.; Ho, Y. S.; Janssen-Heininger, Y. M. Ablation of glutaredoxin-1 attenuates lipopolysaccharide-induced lung inflammation and alveolar macrophage activation. Am J Respir Cell Mol Biol 44:491-499; 2011.

[16] Lundberg, M.; Fernandes, A. P.; Kumar, S.; Holmgren, A. Cellular and plasma levels of human glutaredoxin 1 and 2 detected by sensitive ELISA systems. Biochem Biophys Res Commun 319:801-809; 2004.

[17] Malhotra, D.; Thimmulappa, R.; Navas-Acien, A.; Sandford, A.; Elliott, M.; Singh, A.; Chen, L.; Zhuang, X.; Hogg, J.; Pare, P.; Tuder, R. M.; Biswal, S. Decline in NRF2-regulated antioxidants in chronic obstructive pulmonary disease lungs due to loss of its positive regulator, DJ-1. Am J Respir Crit Care Med 178:592-604; 2008.

[18] Reznick, A. Z.; Cross, C. E.; Hu, M. L.; Suzuki, Y. J.; Khwaja, S.; Safadi, A.; Motchnik, P. A.; Packer, L.; Halliwell, B. Modification of plasma proteins by cigarette smoke as measured by protein carbonyl formation. Biochem J 286 ( Pt 2):607-611; 1992.

[19] Panda, K.; Chattopadhyay, R.; Chattopadhyay, D.; Chatterjee, I. B. Cigarette smoke-induced protein oxidation and proteolysis is exclusively caused by its tar phase: prevention by vitamin C. Toxicol Lett 123:21-32; 2001.

[20] Dominy, J. E., Jr.; Hirschberger, L. L.; Coloso, R. M.; Stipanuk, M. H. Regulation of cysteine dioxygenase degradation is mediated by intracellular cysteine levels and the ubiquitin-26 $\mathrm{S}$ proteasome system in the living rat. Biochem J 394:267-273; 2006.

[21] Huang, Z.; Pinto, J. T.; Deng, H.; Richie, J. P., Jr. Inhibition of caspase-3 activity and activation by protein glutathionylation. Biochem Pharmacol 75:2234-2244; 2008.

[22] Janssen-Heininger, Y. M.; Poynter, M. E.; Aesif, S. W.; Pantano, C.; Ather, J. L.; Reynaert, N. L.; Ckless, K.; Anathy, V.; van der Velden, J.; Irvin, C. G.; van der Vliet, A. Nuclear factor kappaB, airway epithelium, and asthma: avenues for redox control. Proc Am Thorac Soc 6:249-255; 2009.

[23] Okamoto, T.; Akaike, T.; Sawa, T.; Miyamoto, Y.; van der Vliet, A.; Maeda, H. Activation of matrix metalloproteinases by peroxynitrite-induced protein S-glutathiolation via disulfide S-oxide formation. J Biol Chem 276:29596-29602; 2001.

[24] Krzywanski, D. M.; Dickinson, D. A.; Iles, K. E.; Wigley, A. F.; Franklin, C. C.; Liu, R. M.; Kavanagh, T. J.; Forman, H. J. Variable regulation of glutamate cysteine ligase subunit proteins affects glutathione biosynthesis in response to oxidative stress. Arch Biochem Biophys 423:116-125; 2004. 
[25] Vecchio, D.; Arezzini, B.; Pecorelli, A.; Valacchi, G.; Martorana, P. A.; Gardi, C. Reactivity of mouse alveolar macrophages to cigarette smoke is strain dependent. Am J Physiol Lung Cell Mol Physiol 298:L704-713; 2010.

[26] Ludwig, P. W.; Hoidal, J. R. Alterations in leukocyte oxidative metabolism in cigarette smokers. Am Rev Respir Dis 126:977-980; 1982.

[27] Schaberg, T.; Haller, H.; Rau, M.; Kaiser, D.; Fassbender, M.; Lode, H. Superoxide anion release induced by platelet-activating factor is increased in human alveolar macrophages from smokers. Eur Respir J 5:387-393; 1992.

[28] Richens, T. R.; Linderman, D. J.; Horstmann, S. A.; Lambert, C.; Xiao, Y. Q.; Keith, R. L.; Boe, D. M.; Morimoto, K.; Bowler, R. P.; Day, B. J.; Janssen, W. J.; Henson, P. M.; Vandivier, R. W. Cigarette smoke impairs clearance of apoptotic cells through oxidant-dependent activation of RhoA. Am J Respir Crit Care Med 179:1011-1021; 2009.

[29] Kuipers, I.; Bracke, K. R.; Brusselle, G. G.; Aesif, S. W.; Krijgsman, R.; Arts, I. C.; Wouters, E. F.; Reynaert, N. L. Altered cigarette smoke-induced lung inflammation due to ablation of grx1. PLoS One 7:e38984; 2012.

[30] Chung, S.; Sundar, I. K.; Yao, H.; Ho, Y. S.; Rahman, I. Glutaredoxin 1 regulates cigarette smoke-mediated lung inflammation through differential modulation of I\{kappa\}B kinases in mice: impact on histone acetylation. Am J Physiol Lung Cell Mol Physiol 299:L192-203. 


\title{
CHAPTER 7
}

\section{Decreased plasma protein S-glutathionylation in COPD; associations with glutaredoxin 1, glutathione-S- transferase and inflammation}

Ine Kuipers ${ }^{1}$, Nicole YP Souren ${ }^{2,3}$, Catherine Moermans ${ }^{4}$, Renaud Louis ${ }^{4}$, Mieke A Dentener ${ }^{1}$,Yvonne MW Janssen-Heininger ${ }^{5}$, Emiel FM Wouters ${ }^{1}$, Niki L Reynaert ${ }^{{ }^{*}}$

\begin{abstract}
Background: Glutathione directly scavenges free radicals and protects protein thiols from irreversible oxidation by binding them. This post translational modification, S-glutathionylation (PSSG) is induced by mild oxidative stress or promoted by glutathione S-transferase P1 (GSTP1) and can be reversed by glutaredoxins (Grx). Importantly, PSSG can also alter protein function and has been shown to inhibit inflammation through S-glutathionylation of NF-kB pathway members. In lung tissue of COPD patients Grx1 levels were shown to be decreased.
\end{abstract}

Methods: Since COPD can also manifest itself systemically through increased inflammatory mediator levels and oxidative stress, this study set out to investigate the levels PSSG, Grx1 and GSTP1 in plasma of 47 COPD patients versus 29 healthy controls and associations of these parameters with lung function and inflammation.

Results: PSSG was decreased in plasma of patients compared to controls and was positively correlated with lung function and negatively associated with the inflammatory markers CRP and IL-6. Also Grx1 protein levels in plasma and mRNA expression in blood were decreased in COPD, whereas GSTP1 protein levels and mRNA expression were unaltered. Total GST activity on the other hand was decreased in COPD patients compared to controls and was negatively associated with IL-6, and positively with lung function.

Conclusions: This is the first study to report an attenuation of PSSG, Grx1 levels and GST activity in COPD patients, without effects on GSTP1. In addition, significant correlations between the PSSG-Grx1-GSTP1-axis and lung function and systemic inflammation are demonstrated which indicate a role for PSSG and its mediators in the pathogenesis of COPD. 


\section{Background}

Chronic obstructive pulmonary disease (COPD) is a chronic inflammatory lung disease pathologically identified as a mixture of obstructive bronchiolitis and emphysema which is associated with airflow limitation that is progressive and not fully reversible [1]. The airflow limitation is linked to an abnormal inflammatory response of the lungs to noxious particles and gases [2], characterized by a marked increase in neutrophils and inflammatory mediators in bronchoalveolar lavage fluid (BALF) and sputum, which correlates with disease severity [3, 4]. A so called low-grade systemic inflammation is also present in a subset of patients, comparable with chronic inflammatory diseases of other organs $[5,6]$. Some of the systemic markers of inflammation, such as the acute phase protein C-reactive protein (CRP), are related to the systemic effects of COPD [7].

In addition, a myriad of studies has described oxidative stress in patients with COPD, locally in the lungs as well as in the systemic circulation [8]. Increased levels of both oxidants and oxidation products of proteins, lipids, DNA and sugars have been measured. Oxidative stress is generally correlated to inflammation, as inflammatory cells are the main source of oxidant production [9].

One of the most important antioxidant defences is the tripeptide glutathione. It is a redox buffer of the cells that is oxidized preferentially over macromolecules. Blood, as well as the lining fluid of the lungs contain high levels of glutathione to protect these compartments from irreversible oxidations and damage. The ratio between reduced (GSH) and oxidized (GSSG) glutathione is often reported a measure of oxidative stress. In COPD, there are disturbances in glutathione as well as in the enzyme systems involved in synthesis and reduction of glutathione (for review see [10]).

Oxidative stress can, in addition to direct oxidation of GSH to GSSG, induce the binding of glutathione to the sulfhydryl group of cysteine amino acids in proteins. This latter reaction is a posttranslational modification that is termed $\mathrm{S}$ glutathionylation. Glutathione binding to proteins has been proposed as a marker of oxidative stress and it has been shown to be increased in the blood of smokers [11]. On the other hand, protein S-glutathionylation (PSSG) is believed to protect proteins from further, irreversible oxidations. Targeted proteins can also be functionally influenced by the binding of GSH, such as for instance enzymes with catalytically important cysteines, cytoskeletal proteins and transcription factors, such as nuclear factor kappa B and AP-1 and upstream kinases. A strong link between protein S-glutathionylation and the response to inflammatory stimuli exists [12-14]. Importantly, S-glutathionylation is a reversible oxidation for which the removal of GSH is catalyzed by glutaredoxin (Grx) enzymes under physiological conditions [15], thereby liberating this reservoir of GSH. Grx1 expression in the lungs has been found to be predominantly localized in macrophages and bronchial epithelium. In patients with COPD, Grx1 was decreased and specifically the number of Grx1 positive macrophages was found to be positively correlated with 
lung function [16]. In line with these clinical findings, we have previously reported that cigarette smoke extract downregulated Grx1 levels, which was associated with increased protein S-glutathionylation in lung epithelial cells. In vivo on the other hand, we found smoke exposure to decrease protein S-glutathionylation, while also decreasing Grx1 levels and total Grx activity [17]. Importantly, primary epithelial cells from Grx1 knock out mice were more prone to smoke-induced cell death and displayed higher levels of protein S-glutathionylation compared to controls [18].

Although binding of GSH to proteins can be achieved non-enzymatically, there is some evidence that glutathione-S-transferase P1 (GSTP1) can catalyse this reaction $[19,20]$. GSTP1 is a member of the GST superfamily that catalyses the conjugation of GSH to various hydrophobic and electrophilic compounds to aid in detoxification. The $P$ isoform is expressed highly in lung tissue and was found to be increased in patients with mild COPD [21]. Functionally, in fibroblasts, deletion of GSTP1 has been shown to lead to apoptosis [22] while overexpression was protective against cigarette smoke extract induced cell death [23]. Polymorphisms in GSTP1 have been linked to COPD, and suggested to be due to a lack of sufficient detoxification of, and antioxidant protection against cigarette smoke and associated products. However, it is also plausible that GSTP1 can contribute to pathogenesis through its effects on S-glutathionylation, but also independent of its catalytic activities by interacting with proteins such as $\mathrm{c}$-jun- $\mathrm{N}$-terminal kinase (JNK) and tumor necrosis factor receptor-associated factor (TRAF) 2 [24-26]. However, no functional studies have been performed to date.

In this study we investigated whether protective plasma protein S-glutathionylation (PSSG) is decreased in patients with COPD and whether this is related to alterations in its regulatory enzymes glutaredoxin 1 and GSTP1. Also their relation to lung function was studied as well as correlations with markers of systemic inflammation given the intricate links of PSSG and the regulatory enzymes with inflammation.

\section{Methods}

\section{Study population plasma measurements}

For the present study, a subgroup from a larger cohort [27] was selected: 47 patients with clinically stable mild-moderate and severe COPD (Center of expertise for chronic organ failure (Ciro), Horn, the Netherlands) and 29 control subjects that are matched for age, gender and pack years smoked. Clinical history of COPD and the degree of disease severity were assessed according to the published Global Initiative for Chronic Obstructive disease (GOLD) guidelines. Research was carried out in accordance with the Declaration of Helsinki of the World Medical Association and the ethical review board of the University Hospital Maastricht approved the study, and all subjects gave their written informed consent. Patient information can be found in table 1 . 
Table 1. Characteristics of COPD patients and healthy controls

\begin{tabular}{|c|c|c|c|}
\hline Trait & Controls & COPD patients & $p$ \\
\hline $\mathrm{n}$ & 29 & 47 & \\
\hline Age (yrs) & $58.2 \pm 7.6$ & $59.8 \pm 7.8$ & 0.41 \\
\hline Male & $14(48.3 \%)$ & $24(51.1 \%)$ & 0.81 \\
\hline $\mathrm{BMI}\left(\mathrm{kg} / \mathrm{m}^{2}\right)$ & $27.3 \pm 3.0$ & $25.0 \pm 5.0$ & 0.02 \\
\hline Current smoker & $14(48 \%)$ & $19(40 \%)$ & 0.50 \\
\hline Smoking history, pack years-smoked & $34(26-38)$ & $40(27-45)$ & 0.21 \\
\hline $\mathrm{FEV}_{1}(\mathrm{~L})$ & $3.1 \pm 0.6$ & $1.2 \pm 0.6$ & $<0.001$ \\
\hline $\mathrm{FEV}_{1}(\%$ pred) & $107.3 \pm 13.1$ & $43.6 \pm 18.2$ & $<0.001$ \\
\hline $\mathrm{FVC}(\mathrm{L})$ & $3.9 \pm 0.9$ & $2.9 \pm 1.0$ & $<0.001$ \\
\hline FVC (\%pred) & $111.9 \pm 15.4$ & $84.7 \pm 21.0$ & $<0.001$ \\
\hline $\mathrm{FEV}_{1} / \mathrm{FVC}(\%)$ & $78.5 \pm 5.4$ & $43.4 \pm 12.1$ & $<0.001$ \\
\hline $\mathrm{CRP}(\mathrm{mg} / \mathrm{ml})$ & $1.6(0.2-3.9)$ & $4.7(1.8-11.1)$ & $<0.001$ \\
\hline IL-6 (pg/ml) & $0.6(0.4-1.0)$ & $2.3(1.2-4.0)$ & $<0.001$ \\
\hline
\end{tabular}

$\mathrm{BMI}=$ body mass index, $\mathrm{CRP}=\mathrm{C}$-reactive protein, FEV1 $=$ forced expiratory volume in the first second, FVC $=$ forced vital capacity, IL- $6=$ interleukin- 6 . Continuous data are expressed as mean \pm SD or median (inter quartile range). Categorical data are expressed as number of observations (\%). Controls versus COPD patients calculated using a t-test or a Wilcoxon rank-sum test for continuous data and a $\mathrm{X}^{2}$-test for categorical data.

\section{Clinical examination \& blood collection}

$\mathrm{FEV}_{1}$ and FVC were calculated from the flow-volume curve using standardized spirometry. $F E V_{1}$ was performed after inhalation of a $\beta_{2}$-agonist via a metered dose inhaler. BMI was calculated as body weight divided by squared height $\left(\mathrm{kg} / \mathrm{m}^{2}\right)$. Blood was collected in an evacuated tube containing EDTA (Sherwood Medical, St.Louis, Missouri, USA) and immediately placed on melting ice. After centrifugation twice at $800 \times \mathrm{gg}$ for $5-10 \mathrm{~min}$ at $4{ }^{\circ} \mathrm{C}$, plasma samples were subsequently stored at $-80^{\circ} \mathrm{C}$ until analysis.

\section{ELISAs}

GSTP1 (Argutus Medical. Dublin Ireland) and IL-6 (Sanquin, Amsterdam, the Netherlands) were assessed in plasma by commercially available ELISA kits according to the manufacturers' instructions and C-reactive protein by highsensitivity particle enhanced immunoassay (CRP, COBAS Mira Radiometer, Copenhagen). Grx1 levels in plasma were determined by ELISA using antibodies (Imco, Stockholm, Sweden) as previously published [28].

Quantitative determination of S-Glutathionylated proteins using 5,5'-dithio-bis(2nitrobenzoic acid) (dTNB) 
$200 \mu \mathrm{l}$ of plasma was acetone precipitated for 20 minutes at $-20^{\circ} \mathrm{C}$. Pellets were next resuspended and sonicated in $200 \mu \mathrm{l}$ of ice-cold extraction buffer containing $0.2 \%$ Triton-X 100 and $0.6 \%$ sulfosalicyclic acid in $0.1 \mathrm{M}$ potassium phosphate buffer with $5 \mathrm{mM}$ EDTA disodium salt (KPE), $\mathrm{pH}$ 7.5. After 2 freeze-thaw cycles, samples were centrifuged at $3000 \mathrm{xg}$ for $4 \mathrm{~min}$ at $4^{\circ} \mathrm{C}$. To remove glutathione (GSH) from proteins, the pellet was treated with $100 \mu \mathrm{l}$ of $1 \% \mathrm{NaBH}_{4}$ in water and neutralized with $40 \mu \mathrm{l}$ of $30 \%$ metaphosphoric acid. Samples were centrifuged at $1000 \mathrm{xg}$ for $15 \mathrm{~min}$ and the supernatant was used to determine the GSH content using the dTNB GSSG reductase recycling method [29]. $20 \mu \mathrm{l}$ of KPE, GSH standards and samples were pipetted into a 96-well microtiter plate and $120 \mu \mathrm{l}$ of freshly prepared, equal volumes of dTNB and GSSG reductase were added in the dark. After 30 seconds, $60 \mu \mathrm{l}$ of $\beta$-NADPH was added to start the conversion of dTNB to TNB and the absorbance at $412 \mathrm{~nm}$ was read every 30 seconds for 2 minutes. Calculations were performed using a concentration range of $\mathrm{GSH}$. $\mathrm{NaBH}_{4}$ was omitted for each sample, as a negative control and protein concentration was measured to express data as $\mathrm{nmol} \mathrm{GSH} / \mathrm{mg}$ protein.

\section{GST activity Assay}

$50 \mu$ plasma was added to the reaction mixture containing $0.1 \mathrm{M}$ phosphate buffer pH 6.5, CDNB $20 \mathrm{mM}, 20 \mathrm{mM}$ GSH. GST activities were assayed kinetically using 1 minute interval readings for 5 minutes at $340 \mathrm{~nm}$. Plasma GST activity was expressed as $\mathrm{nmol} \mathrm{GSH} / \mathrm{min} / \mathrm{mg}$ protein.

\section{Statistical analysis}

SPSS (version 19) was used for data analysis. For continuous data, group differences were analysed using Student's $t$-test or the Wilcoxon rank-sum test (when the distribution was skewed), while for categorical data a $X^{2}$-test was used. Correlations between variables were determined using spearman's rho. A $p$-value $<0.05$ was considered statistically significant.

\section{Study population for the micro-array}

Twenty COPD patients were recruited through the outpatient clinic and pulmonary rehabilitation center (CHU, Sart-Tilman, Liege). All COPD patients fulfilled the criteria proposed by the Global Initiative for Chronic Obstructive Lung Disease (GOLD): FEV1/FVC ratio less than 0.7 measured 20 minutes after the inhalation of $400 \mu \mathrm{g}$ of salbutamol. Healthy controls $(n=18)$ were recruited by advertisement among the hospital. Research was carried out in accordance with the Declaration of Helsinki of the World Medical Association. The protocol was approved by the local ethics committee and subjects gave written informed consent for participation.

\section{Micro-array}

All patients underwent blood collection and blood cells were kept in PAXgene blood RNA tube (PreAnalytix, Hombrechtikon, Switzerland) until RNA extraction. 
RNA was extracted using the RNeasy Mini Kit (Qiagen, Hilden, Germany) for the blood, the Paxgene Blood RNA Kit (PreAnalytix, Hombrechtikon, Switzerland) in accordance with the manufacturer's instructions. cDNA were synthesized using the High Capacity cDNA reverse transcription kit (Applied BioSystems, Foster city, $\mathrm{CA}$ ). The expression of 95 genes implicated in oxidative stress and inflammation were analysed with TaqMan® Gene Expression Assays (Applied Biosystems) and amplification was detected on Taqman 7900HT (Applied Biosystems). Data were then analysed using SDS v2.2 software. The Ct value of each gene was normalized to $18 \mathrm{~S}$ to obtain $\Delta \mathrm{Ct}$. Relative quantitation in gene expression were determined using the formula $2^{-\Delta \Delta C t}$, where $\Delta \Delta \mathrm{Ct}=$ median $\Delta \mathrm{Ct}$ of all COPD samples - median $\Delta \mathrm{Ct}$ of all healthy subjects. A difference in gene expression level between groups was considered significant when i) the comparison of the medians by the Mann-Whitney test gave a $p$ value $<0.05$ calculated according to the Benjamini and Hochberg Discovery Rate to reduce the chance of false positive, and ii) the fold change (median of all COPD/ median of all controls) expressed as median was $> \pm 1.5$ in the COPD group. In this manuscript only expression of Grx1 and GSTP1 is reported.

\section{Results}

The characteristics of the study population in which plasma was analysed are outlined in Table 1. Patients were current or former smokers with moderate-tosevere COPD. The control population which consisted of apparently healthy (ex)smoking volunteers was matched for age, gender, smoking status and pack years smoked. The BMI of healthy controls was slightly higher then that of COPD patients. $\mathrm{FEV}_{1}$ and $\mathrm{FVC}$ percent predicted, as well as their ratio were lower in the COPD patients compared to the controls $(p<0.001)$. Based on GOLD criteria, 4 patients were categorized as stage I, 13 patients as stage II, 16 patients as stage III and 14 patients as stage IV. Median levels of plasma CRP and IL-6 were found to be significantly higher in stable COPD patients than in healthy subjects, indicating the presence of systemic inflammation in this patient population.
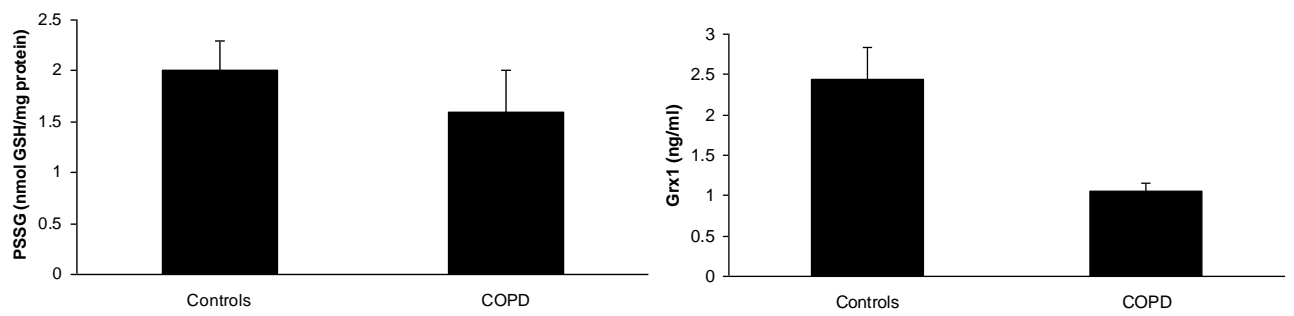

Figure 1: (Left) Plasma PSSG in healthy controls and patients with COPD. PSSG was determined biochemically, expressed in $\mathrm{nmol} \mathrm{GSH} / \mathrm{mg}$ protein and represented as mean $\pm \mathrm{SD}$. * represents $\mathrm{p}<0.05$ between controls and COPD patients.

Figure 2: (Right) Glutaredoxin 1 protein levels in plasma of healthy controls and COPD patients. Glutaredoxin levels were determined by ELISA, expressed in $\mathrm{ng} / \mathrm{ml}$ and represented as mean $\pm \mathrm{SD}$. * represents $p<0.05$ between controls and COPD patients. 
The PSSG level in plasma of COPD patients was decreased compared to that in healthy controls (Figure 1). Importantly, PSSG levels were not found to correlate with the number of pack years smoked or current smoking status (data not shown). In order to determine whether this decrease in PSSG could be attributed to alterations in the enzymatic regulators of PSSG, namely Grx and GSTP1, these were also assessed in plasma of patients and controls. Grx1 plasma levels in COPD patients were significantly lower than in healthy controls (Figure 2). GST activity was significantly decreased in COPD patients (Figure 3), while the GSTP1 levels in plasma determined by ELISA showed no difference between COPD patients and controls (Figure 4). Peripheral blood mononuclear cells (PBMCs) can be a source of Grx1 and it has been shown that transcriptional regulation of Grx1 within these cells can influence secreted levels. The gene expression data obtained from the second cohort indeed revealed a significantly reduced expression of Grx1 in whole blood of COPD patients compared to healthy controls (Figure $5 \mathrm{~A}$ ), confirming plasma protein data. Also in line with the plasma protein data from the first cohort, GSTP1 expression was not different between whole blood of COPD patients and controls (Figure 5B).

PSSG and Grx1 levels as well as overall GST activity were not only significantly lower in plasma of COPD patients, they were also found to be positively correlated with the lung function parameters $\mathrm{FEV}_{1} \%, \mathrm{FVC} \%$ and $\mathrm{FEV}_{1} / \mathrm{FVC}$ (Table 2), independent of BMI, gender, age and pack years-smoked. Grx1 expression in blood furthermore also positively correlated with all three lung function parameters (Table 5).

With respect to systemic inflammation, CRP and IL-6 were elevated in this patient population (Table 1) and importantly were both negatively correlated with PSSG levels and GST activity. These associations were independent of BMI, gender, age and pack years-smoked, but not independent of lung function. Grx1 on the other hand was positively correlated with IL-6 levels, but only in COPD patients (Table 3). Also, Grx1 expression in whole blood was found to be positively correlated with the total blood leukocyte count $(r: 0.560 ; p=0.03)$ and the neutrophil percentage ( $r: 0.540 ; p=0.04)$.

Table 2. Correlations between PSSG, Grx1, GST activity and GSTP1 and lung function

\begin{tabular}{|l|c|c||c||c||c|c|}
\cline { 2 - 7 } \multicolumn{1}{c|}{} & \multicolumn{2}{c||}{ FEV $_{1}(\%$ pred) } & \multicolumn{2}{c|}{ FVC $(\%$ pred $)$} & \multicolumn{2}{c|}{ FEV $_{1} /$ FVC } \\
\cline { 2 - 7 } & Whole group & COPD & Whole group & COPD & Whole group & COPD \\
\hline PSSG & $0.58(<0.01)$ & $0.46(<0.01)$ & $0.47(<0.01)$ & n.s. & $0.55(<0.01)$ & $0.34(<0.05)$ \\
\hline \hline Grx1 & $0.44(<0.01)$ & n.s. & $0.32(<0.01)$ & n.s. & $0.45(<0.01)$ & n.s. \\
\hline \hline GST activity & $0.32(<0.01)$ & n.s. & $0.24(0.05)$ & n.s. & $0.34(<0.01)$ & n.s. \\
\hline \hline GSTP1 & n.s. & n.s. & n.s. & n.s. & n.s. & n.s. \\
\hline
\end{tabular}

FEV1: forced expiratory volume in the first second, FVC: forced vital capacity, Data are expressed as Spearman's rank correlation coefficient ( $p$-value). 

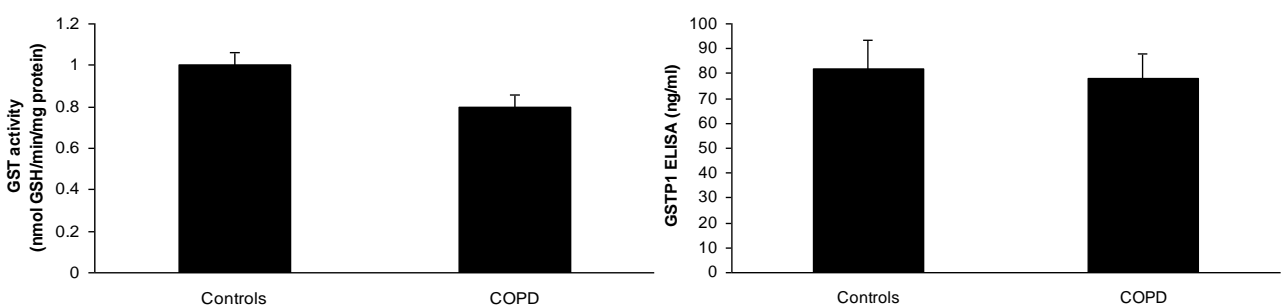

Figure 3: (Left) Plasma GST activity in healthy controls and patients with COPD. GST activity was determined using CDNB as substrate, expressed in $\mathrm{nmol} \mathrm{GSH} / \mathrm{min} / \mathrm{mg}$ protein and represented as mean \pm SD. * represents $p<0.05$ between controls and COPD patients.

Figure 4: (Right) Plasma GSTP1 levels in healthy controls and COPD patients. GSTP1 levels were determined by ELISA, expressed in $\mathrm{ng} / \mathrm{ml}$ and represented as mean \pm SD.
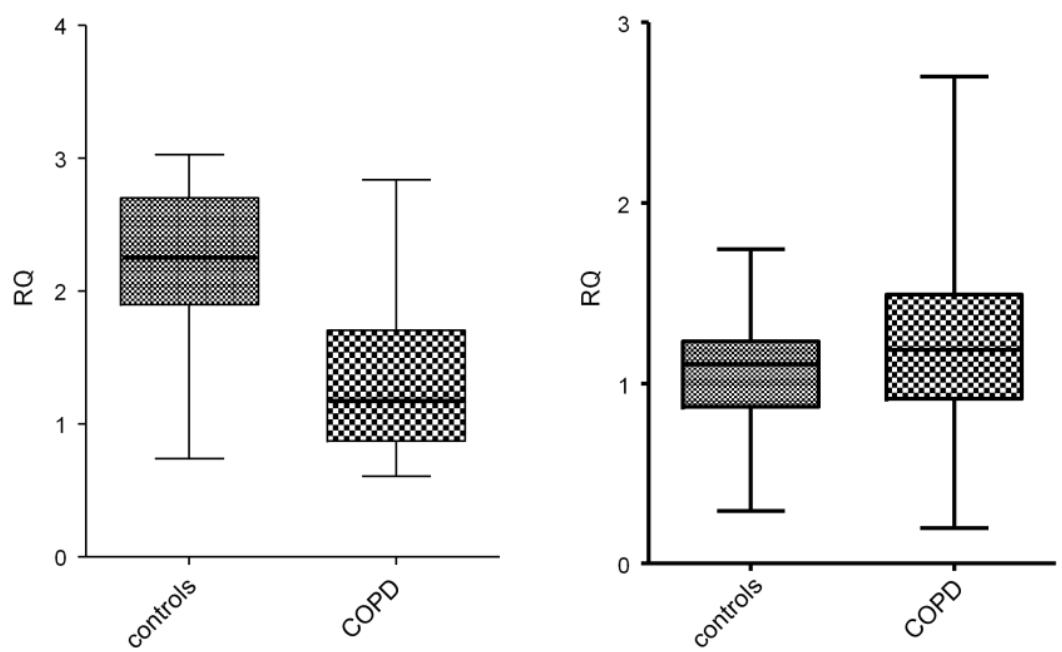

Figure 5: Glutaredoxin 1 and GSTP1 mRNA expression in whole blood of healthy controls and patients with COPD. Data are expressed as relative quantity (RQ) of Grx1 (A, Left) and GSTP1 (B, Right) mRNA. * represents $p<0.05$ between controls and COPD patients.

Table 3. Correlations between PSSG, Grx1, GST activity and GSTP1 and inflammatory markers

\begin{tabular}{|l||c||c||c||c|}
\cline { 2 - 5 } \multicolumn{1}{c|}{} & \multicolumn{2}{c||}{ CRP } & \multicolumn{2}{c|}{ IL-6 } \\
\cline { 2 - 5 } \multicolumn{1}{l||}{} & Whole group & COPD & Whole group & COPD \\
\hline PSSG & $-0.23(0.05)$ & n.s. & $-0.36(<0.01)$ & n.s. \\
\hline \hline Grx1 & n.s. & n.s. & n.s. & $0.32(<0.05)$ \\
\hline \hline GST activity & n.s. & n.s. & $-0.27(<0.05)$ & n.s. \\
\hline \hline GSTP1 & n.s. & n.s. & n.s. & n.s. \\
\hline
\end{tabular}

CRP = C-reactive protein, IL-6: interleukin-6. Data are expressed as Spearman's rank correlation coefficient ( $p$-value). 


\section{Discussion}

This study is the first to determine S-glutathionylation of proteins in plasma of healthy controls and COPD patients as well as to report on its association with GSTP1 and glutaredoxin 1, previously described as anti-oxidant enzymes responsible for pro- and deglutathionylation of proteins respectively under physiological conditions.

S-glutathionylation of proteins in blood of smokers has previously been described to be elevated compared to non smokers [11]. We are the first to report decreased S-glutathionylation of proteins in plasma of patients with COPD. In this study, we have not found an association of pack years or current smoking status with PSSG. The decrease in S-glutathionylation of plasma proteins in COPD patients compared to controls reported here might appear counterintuitive since PSSG is a marker of oxidative stress as it is induced by oxidants and it has been established that COPD patients indeed display systemic oxidative stress [8]. However, since protein S-glutathionylation can also be interpreted as a defence mechanism against further irreversible oxidations and the release of GSH from this protein pool a mechanism to increase the free GSH pool to counteract oxidants, the observed decreased level of glutathionylation of plasma proteins in COPD can be interpreted as a defective defence mechanism. Importantly, the plasma PSSG level was found to be positively correlated with multiple lung function parameters, which provides further support for its protective role.

Table 4. Characteristics of COPD patients and healthy controls used in microarray study

\begin{tabular}{|c|c|c|c|}
\hline Trait & Controls & COPD patients & $p$ \\
\hline$n$ & 18 & 20 & \\
\hline Age (yrs) & $58 \pm 7$ & $64 \pm 11$ & 0.054 \\
\hline Male & $10(55 \%)$ & $12(60 \%)$ & 0.78 \\
\hline $\mathrm{BMI}\left(\mathrm{kg} / \mathrm{m}^{2}\right)$ & $26 \pm 4$ & $25 \pm 5$ & 0.68 \\
\hline Current smoker & $2(11 \%)$ & $4(20 \%)$ & 0.45 \\
\hline Smoking history, pack years-smoked & $18(10-45)$ & $42(33-54)$ & 0.11 \\
\hline $\mathrm{FEV}_{1}(\mathrm{~L})$ & $3.10 \pm 0.86$ & $1.20 \pm 0.46$ & $<0.001$ \\
\hline $\mathrm{FEV}_{1}(\%$ pred) & $102 \pm 14$ & $43 \pm 12$ & $<0.001$ \\
\hline $\mathrm{FVC}(\mathrm{L})$ & $4.07 \pm 1.21$ & $2.64 \pm 1.12$ & $<0.001$ \\
\hline FVC (\%pred) & $111.9 \pm 15.4$ & $84.7 \pm 21.0$ & $<0.001$ \\
\hline $\mathrm{FEV}_{1} / \mathrm{FVC}(\%)$ & $109 \pm 15$ & $78 \pm 21$ & $<0.001$ \\
\hline
\end{tabular}

BMI : body mass index, FEV1: forced expiratory volume in the first second, FVC: forced vital capacity. Continuous data are expressed as mean \pm SD or median (inter quartile range). Categorical data are expressed as number of observations (\%). Controls versus COPD patients calculated using a t-test or a Wilcoxon rank-sum test for continuous data and a $\mathrm{X}^{2}$-test for categorical data. 
The plasma concentrations of two reported regulators of S-glutathionylation, glutaredoxins and glutathione S-transferases were also assessed to address whether the decreased S-glutathionylation of plasma proteins in COPD patients could be attributed to alterations in its enzymatic mediators. With this manuscript we show that plasma Grx1 protein levels are decreased in COPD patients compared to healthy controls, as are the Grx1 mRNA levels in blood. Previously it was reported that Grx1 levels were decreased in the lungs of COPD patients and especially, the number of Grx1 positive macrophages was found to be lower in patients and positively related to lung function [16]. Here we also observe a positive correlation of Grx1 in plasma with lung function parameters $\mathrm{FEV}_{1} \%, \mathrm{FVC} \%$ and $F E V_{1} / F V C$, indicating a protective function of this antioxidant enzyme not only in the lungs, but also in the circulation. We have published previously that cigarette smoke itself decreases Grx1 mRNA and protein expression in lung epithelial cells in vitro and have shown decreased levels of Grx1 in a mouse model of smoke exposure $[17,18]$. The decreased plasma levels of Grx1 and the lower level of Grx1 mRNA expression in blood of COPD patients are in line with these previously reported findings. However, no significant correlation between plasma Grx1 and pack years smoked was observed, and plasma Grx1 levels were not different between current and ex smokers.

Leucocytes are a likely source of plasma Grx1 as Grx1 mRNA expression in blood was positively associated with both total leukocyte counts and the percentage of neutrophils. Other cellular origins such as endothelial cells can however not be excluded. Regardless of the source, it remains a topic of further research how Grx1 would be secreted from these cells as Grx1 does not contain a secretory lead sequence. Altered levels of Grx1 in culture medium of PBMCs have previously been attributed to alterations in expression, similar to what we have shown here in vivo [28].

Table 5. Correlations of Grx1 mRNA expression in blood to lung function parameters.

\begin{tabular}{|c|c|c|c|c|c|c|}
\hline & \multicolumn{2}{|c|}{ FEV1 (\% pred) } & \multicolumn{2}{|l|}{ FVC (\%pred) } & \multicolumn{2}{|l|}{ FEV1/FVC } \\
\hline & Whole group & COPD & Whole group & |COPD & Whole group & |COPD \\
\hline $\begin{array}{l}\text { Grx1 } \\
\text { expression }\end{array}$ & $0.49(<0.01)$ & n.s. & $0.36(<0.05)$ & n.s. & $0.48(<0.01)$ & n.s. \\
\hline
\end{tabular}

Previous papers reporting on glutathione S-transferases in COPD mainly focused on genetic polymorphisms that occur in these enzymes, with an emphasis on the importance of GST enzymes in detoxifying metabolites and compounds to which the lungs are exposed. Since many polymorphisms of GST enzymes have been associated with COPD, it has been proposed that the lack of properly functioning GST enzymes might be the cause of insufficient detoxification and anti-oxidant levels against cigarette smoke in COPD. Recently however, the function of 
glutathione S-transferase $\mathrm{P} 1$ has been reported to also involve the proglutathionylation of proteins and binding properties [19, 20, 24]. Although GST activity was reported to be elevated in plasma of COPD patients compared to healthy controls [30] in a Chinese population, we here show a significant decrease in total GST activity in plasma of COPD patients (Figure 4). This decreased GST activity in COPD patients implies that the metabolism of smoke-related compounds such as acrolein and other aldehydes is attenuated. With respect to GSTP1 specifically, a previous study reported decreased plasma GSTP1 levels in COPD [31], whereas in this study, the protein level of GSTP1 in plasma was not found to be altered between controls and patients (Figure 5B). Given that the variability found in genetic studies could be attributed to different racial backgrounds, this might have to be taken into account for expression studies as well. Regardless, a protective role of GSTs is suggested by demonstrating for the first time that there is a positive association between GST activity and lung function parameters.

No significant correlations between plasma PSSG levels and Grx1, GSTP1 or GST activity were detected in this study. This suggests that plasma PSSG levels in COPD are decreased irrespective of the alterations in the investigated mediator enzymes. The de-glutathionylation enzyme Grx1 was found to be decreased, but we are unable to asses overall Grx activity towards S-glutathionylated proteins. Conventional Grx activity assays use hydroxyethyldisulfide or cysteine sulphate as substrates and are therefore not specific. Also for the forward reaction of $\mathrm{S}$ glutathionylation, it has to be taken into account that the GST activity performed here uses the general CDNB substrate. To fully exclude links between PSSG and Grx and GSTs, (de)glutathionylation specific assays should be developed in the future. Other possible mechanisms for decreased plasma PSSG levels include non-investigated redox enzymes such as thioredoxin or alternatively PSSG decreases could be a function of increased oxidative stress levels per se. These alternatives remain to be investigated.

Irrespective of the lack of an apparent interrelation between PSSG and Grx1, is the link between the PSSG/Grx1 axis and inflammation. Indeed, a negative correlation between the plasma PSSG level and CRP as well as IL6 was detected. These data are in line with the reported inhibitory effects of PSSG on inflammatory pathways as we and others have published previously. For instance, NF-kB, a major regulator of inflammation, as well as its upstream activators IKK alpha and beta can be inhibited by S-glutathionylation [14, 32], resulting in repressed inflammatory mediator production. In this study we show that plasma IL-6, a marker for systemic inflammation and transcriptionally regulated by NF- $\mathrm{kB}$, negatively correlated with plasma PSSG levels, providing supporting evidence for the in vitro established link between PSSG and NF- $\square$ B driven inflammation. Plasma IL-6 levels were also positively correlated with Grx1 levels, but only in COPD patients, whereas CRP levels did not correlate with Grx1. These data are difficult to interpret, especially since no significant correlation was observed between PSSG and Grx1. One complicating factor is that Grx1 levels have not only been shown to determine the 
extent of NF-KB activation and inflammatory mediator production through alterations in S-glutathionylation status of pathway proteins such as IKK $\beta$, but that inflammatory mediators such as LPS can also affect Grx1 expression [14, 33]. This latter study furthermore was not able to find substantial Grx1 expression in neutrophils recruited to the lungs, which is in contrast to the correlation of Grx1 with the blood neutrophil percentage. More mechanistic studies will be needed to further unravel the intricate relation between the Grx1/PSSG axis and inflammation, for which this manuscript provides further clinical evidence.

\section{Conclusions}

We here report the first measurement of PSSG in plasma of COPD patients and show a positive correlation with lung function, while being negatively correlated with systemic inflammatory markers CRP and IL-6. Decreased glutaredoxin 1 protein and mRNA levels and GST activity were observed in blood of COPD patients and controls as well, revealing interesting positive correlations between glutaredoxin 1 and GST activity and lung function. Taken together, this study provides clinical evidence for the importance of plasma PSSG levels and its mediators Grx1 and GST in lung function and inflammation of COPD patients. Further research will elucidate further the intricacies of the PSSG-Grx1-GSTP1 axis in COPD pathogenesis.

\section{Acknowledgements}

The authors gratefully acknowledge Dr GJ Wesseling, Dr DG Yanbaeva (Department of Respiratory Medicine, Maastricht University Medical Center, Maastricht), Dr H-J. Pennings, Dr MA Spruit, A van de Kruijs (Centre for Integrated Rehabilitation of Organ failure, Horn), and J Houben (Department of Health Risk Analysis and Toxicology, Maastricht University Medical Centre, Maastricht) for help with recruitment. We also thank A Derks (Centre for Integrated Rehabilitation of Organ failure, Horn) and N Drummen (Department of Respiratory Medicine, Maastricht University Medical Centre) for assistance with blood processing, CRP and IL-6 measurements and P Gopal (Department of Respiratory Medicine, Maastricht University Medical Centre) for logistical assistance and Donat Degroote (Probiox SA), Etienne Capieaux and Pierre Dorfman (Labolife SA) for providing the microarray.

\section{Author contributions}

Ine Kuipers and Catherine Moermans acquired and analysed data. Nicole YP Souren analysed data. Niki L Reynaert and Yvonne MW Janssen-Heininger conceived and designed the study. Ine Kuipers, Catherine Moermans, Nicole YP 
Souren, Renaud Louis, Mieke A Dentener, Yvonne MW Janssen-Heininger, Emiel FM Wouters and Niki L Reynaert interpreted data and drafted the manuscript.

\section{References}

1. Petsonk EL, Hnizdo E, Attfield M: Definition of COPD GOLD stage I. Thorax 2007, 62(12):1107-1108; author reply 1108-1109.

2. Rabe KF: Treating COPD--the TORCH trial, P values, and the Dodo. N Engl J Med 2007, 356(8):851-854.

3. Keatings VM, Collins PD, Scott DM, Barnes PJ: Differences in interleukin-8 and tumor necrosis factor-alpha in induced sputum from patients with chronic obstructive pulmonary disease or asthma. Am J Respir Crit Care Med 1996, 153(2):530-534.

4. Vernooy JH, Kucukaycan M, Jacobs JA, Chavannes NH, Buurman WA, Dentener MA, Wouters EF: Local and systemic inflammation in patients with chronic obstructive pulmonary disease: soluble tumor necrosis factor receptors are increased in sputum. Am J Respir Crit Care Med 2002, 166(9):1218-1224.

5. Wouters EF: Local and systemic inflammation in chronic obstructive pulmonary disease. Proc Am Thorac Soc 2005, 2(1):26-33.

6. Agusti AG, Noguera A, Sauleda J, Sala E, Pons J, Busquets X: Systemic effects of chronic obstructive pulmonary disease. Eur Respir J 2003, 21(2):347-360.

7. Broekhuizen R, Wouters EF, Creutzberg EC, Schols AM: Raised CRP levels mark metabolic and functional impairment in advanced COPD. Thorax 2006, 61(1):17-22.

8. MacNee W: Pulmonary and systemic oxidant/antioxidant imbalance in chronic obstructive pulmonary disease. Proc Am Thorac Soc 2005, 2(1):50-60.

9. Rahman I, Adcock IM: Oxidative stress and redox regulation of lung inflammation in COPD. Eur Respir J 2006, 28(1):219-242.

10. Rahman I, MacNee W: Lung glutathione and oxidative stress: implications in cigarette smoke-induced airway disease. Am J Physiol 1999, 277(6 Pt 1):L1067-1088.

11. Muscat JE, Kleinman W, Colosimo S, Muir A, Lazarus P, Park J, Richie JP, Jr.: Enhanced protein glutathiolation and oxidative stress in cigarette smokers. Free Radic Biol Med 2004, 36(4):464-470.

12. Pineda-Molina E, Klatt P, Vazquez J, Marina A, Garcia de Lacoba M, Perez-Sala D, Lamas S: Glutathionylation of the p50 subunit of NF-kappaB: a mechanism for redox-induced inhibition of DNA binding. Biochemistry 2001, 40(47):14134-14142.

13. Krysan K, Lou MF: Regulation of human thioltransferase (hTTase) gene by AP-1 transcription factor under oxidative stress. Invest Ophthalmol Vis Sci 2002, 43(6):18761883.

14. Reynaert NL, van der Vliet A, Guala AS, McGovern T, Hristova M, Pantano C, Heintz NH, Heim J, Ho YS, Matthews DE et al: Dynamic redox control of NF-kappaB through glutaredoxin-regulated S-glutathionylation of inhibitory kappaB kinase beta. Proc Natl Acad Sci U S A 2006, 103(35):13086-13091.

15. Mieyal JJ, Gallogly MM, Qanungo S, Sabens EA, Shelton MD: Molecular mechanisms and clinical implications of reversible protein S-glutathionylation. Antioxid Redox Signal 2008, 10(11):1941-1988.

16. Peltoniemi MJ, Rytila PH, Harju TH, Soini YM, Salmenkivi KM, Ruddock LW, Kinnula VL: Modulation of glutaredoxin in the lung and sputum of cigarette smokers and chronic obstructive pulmonary disease. Respir Res 2006, 7(1):133.

17. Kuipers I, Bracke KR, Brusselle GG, Wouters EF, Reynaert NL, Omdal R: Smoke decreases reversible oxidations s-glutathionylation and s-nitrosylation in mice. Free Radic Res 2012, 46(4):164-173.

18. Kuipers I, Guala AS, Aesif SW, Konings G, Bouwman FG, Mariman EC, Wouters EF, Janssen-Heininger YM, Reynaert NL: Cigarette Smoke Targets Glutaredoxin 1, Increasing 
S-glutathionylation and Epithelial Cell Death. Am J Respir Cell Mol Biol 2011, 45(5):931937.

19. Manevich $\mathrm{Y}$, Feinstein SI, Fisher AB: Activation of the antioxidant enzyme 1-CYS peroxiredoxin requires glutathionylation mediated by heterodimerization with pi GST. Proc Natl Acad Sci U S A 2004, 101(11):3780-3785.

20. Townsend DM, Manevich Y, He L, Hutchens S, Pazoles CJ, Tew KD: Novel role for glutathione S-transferase pi. Regulator of protein S-Glutathionylation following oxidative and nitrosative stress. J Biol Chem 2009, 284(1):436-445.

21. Harju T, Mazur W, Merikallio H, Soini $Y$, Kinnula VL: Glutathione-S-transferases in lung and sputum specimens, effects of smoking and COPD severity. Respir Res 2008, 9:80.

22. Ishii T, Fujishiro M, Masuda M, Nakajima J, Teramoto S, Ouchi Y, Matsuse T: Depletion of glutathione S-transferase P1 induces apoptosis in human lung fibroblasts. Exp Lung Res 2003, 29(7):523-536.

23. Ishii $T$, Matsuse $T$, Igarashi $H$, Masuda M, Teramoto $S$, Ouchi $Y$ : Tobacco smoke reduces viability in human lung fibroblasts: protective effect of glutathione S-transferase P1. Am J Physiol Lung Cell Mol Physiol 2001, 280(6):L1189-1195.

24. Townsend DM: S-glutathionylation: indicator of cell stress and regulator of the unfolded protein response. Mol Interv 2007, 7(6):313-324.

25. Adler V, Yin Z, Fuchs SY, Benezra M, Rosario L, Tew KD, Pincus MR, Sardana M, Henderson CJ, Wolf CR et al: Regulation of JNK signaling by GSTp. Embo J 1999, 18(5):1321-1334.

26. Gate L, Majumdar RS, Lunk A, Tew KD: Increased myeloproliferation in glutathione Stransferase pi-deficient mice is associated with a deregulation of JNK and Janus kinase/STAT pathways. J Biol Chem 2004, 279(10):8608-8616.

27. Yanbaeva DG, Wouters EF, Dentener MA, Spruit MA, Reynaert NL: Association of glutathione-S-transferase omega haplotypes with susceptibility to chronic obstructive pulmonary disease. Free Radic Res 2009, 43(8):738-743.

28. Lundberg M, Fernandes AP, Kumar S, Holmgren A: Cellular and plasma levels of human glutaredoxin 1 and 2 detected by sensitive ELISA systems. Biochem Biophys Res Commun 2004, 319(3):801-809.

29. Rahman I, Kode A, Biswas SK: Assay for quantitative determination of glutathione and glutathione disulfide levels using enzymatic recycling method. Nat Protoc 2006, 1(6):3159-3165.

30. Chan-Yeung M, Ho SP, Cheung AH, So LK, Wong PC, Chan KK, Chan JW, Ip MS, Mak JC: Polymorphisms of glutathione S-transferase genes and functional activity in smokers with or without COPD. Int J Tuberc Lung Dis 2007, 11(5):508-514.

31. Lakhdar R, Denden S, Mouhamed MH, Chalgoum A, Leban N, Knani J, Lefranc G, Miled A, Ben Chibani J, Khelil AH: Correlation of EPHX1, GSTP1, GSTM1, and GSTT1 genetic polymorphisms with antioxidative stress markers in chronic obstructive pulmonary disease. Exp Lung Res, 37(4):195-204.

32. Chung S, Sundar IK, Yao H, Ho YS, Rahman I: Glutaredoxin 1 regulates cigarette smokemediated lung inflammation through differential modulation of I\{kappa\}B kinases in mice: impact on histone acetylation. Am J Physiol Lung Cell Mol Physiol, 299(2):L192-203.

33. Aesif SW, Anathy V, Guala AS, Reiss JN, Ho YS, Janssen-Heininger YM: Ablation of glutaredoxin-1 attenuates lipopolysaccharide-induced lung inflammation and alveolar macrophage activation. Am J Respir Cell Mol Biol 2011, 44(4):491-499. 


\title{
CHAPTER 8
}

\section{Increased glutaredoxin1 and decreased protein S- glutathionylation in sputum of asthmatics}

Ine Kuipers ${ }^{1}$, Renaud Louis ${ }^{2}$, Maité Manise ${ }^{2}$, Mieke A Dentener ${ }^{1}$, Charles G Irvin ${ }^{3}$, Yvonne MW Janssen-Heininger $^{4}$, Christopher E Brightling ${ }^{5}$, Emiel FM Wouters ${ }^{1}$, Niki L Reynaert ${ }^{1^{*}}$

European Respiratory Journal 2013 Feb;41(2):469-72

\begin{abstract}
Many alterations in glutathione and associated enzymes have been demonstrated in asthma. Not investigated are the antioxidant enzyme glutaredoxin (Grx) and glutathione bound to proteins (PSSG). PSSG is a redox modification, named Sglutathionylation that affects protein function and is reversed by Grx.

In this study, we investigated Grx1 protein and PSSG levels in induced sputum of 9 healthy controls and 34 asthmatics.

Grx1 protein levels in sputum were significantly elevated in asthmatics compared to controls, whereas PSSG was significantly decreased in asthmatics. Grx1 protein levels were enhanced specifically in patients with eosinophilic and paucigranulocytic asthma. PSSG levels on the other hand were decreased in both eosinophilic and neutrophilic asthmatics compared to controls. PSSG levels positively correlated with the percentage of epithelial cells and lymphocytes and negatively correlated with Grx1 levels. With respect to lung function, $F E V_{1} \%$ predicted negatively correlated with sputum Grx1 levels and positively with PSSG. In a separate study, primary bronchial epithelial cells of asthmatics expressed more Grx1 mRNA compared to controls.

In this study we identify the Grx-PSSG axis as an important modulated redox pathway in asthmatics which has intricate connections to inflammation that remain to be further explored.
\end{abstract}




\section{Introduction}

Asthma is a chronic lung disease, hallmarked by airway inflammation and oxidative stress. Pulmonary oxidative stress in asthmatics is attributed to bulk oxidant production by infiltrated inflammatory cells, and to inhalation of environmental agents causing exacerbations [1]. To protect itself from damaging oxidants, lung tissue is equipped with a range of anti-oxidant enzymes and most importantly with high concentrations of glutathione [2]. The ratio of reduced glutathione (GSH) and its oxidized form GSSG provides information on the redox status of cells and tissues and is used to assess oxidative stress. Total GSH is increased and in some studies also increased amounts of GSSG have been found in BAL fluid and sputum of asthma patients [3], [4]. The anti-oxidant enzymes glutathione reductase, glutathione peroxidase, $\mathrm{Y}$-glutamyl-cysteinyl synthase, glutathione transferases and glutaredoxin, regulate the level and redox state of glutathione and some are found to be altered in asthma patients (reviewed in [5]). For instance, lungs of asthmatics have increased levels of extracellular glutathione peroxidase [6] and polymorphisms of glutathione-S-transferases are reported to be associated with asthma [7].

GSH with its redox cycle partners serves to maintain the reduced state of protein thiol groups. This can be achieved by direct scavenging of oxidants or by the covalent reversible binding of GSH to protein thiols. The latter occurs under physiological conditions, can be induced upon mild oxidative stress, and is known as S-glutathionylation or S-glutathiolation [8]. S-glutathionylation is believed to protect the targeted thiols from further irreversible oxidations. Additionally, Sglutathionylation can modulate protein function. For instance, Inhibitory kappa $B$ kinase $\beta$ (IKK $\beta$ ), the enzyme responsible for nuclear factor kappa $B$ kinase (NF-kB) activation under pro-inflammatory conditions, can be inhibited through $\mathrm{S}$ glutathionylation in lung epithelial cells [9]. DNA binding of NF-KB and activator protein (AP)-1 can also inhibited by S-glutathionylation of their respective p50 and C-jun subunits [10,11].

Under physiological conditions S-glutathionylation can be reduced by glutaredoxins (Grx), members of the thiol-disulfide oxidoreductase family that contain a thioredoxin fold [12]. It has been shown that glutaredoxins remove glutathione from thiol groups and can thereby restore function of proteins targeted by $\mathrm{S}$ glutathionylation [13]. Several mammalian Grxs have been identified. Grx1 localizes primarily to the cytosol and Grx2 is present in the mitochondria and nucleus. Grx1 can also reduce low molecular weight disulfides and proteins with functionally important disulfide bonds could thus also be affected by Grx1 alterations. 
In contrast to damaging oxidations and measurements of GSH per se, protein Sglutathionylation and Grx have rarely been studied in lung diseases, and never in conjunction. The number of Grx1 positive alveolar macrophages in chronic obstructive pulmonary disease (COPD) was found to negatively correlate with lung function and disease progression. Additionally, during COPD exacerbations levels of Grx1 in sputum were significantly higher [14]. Grx2 was not detectable in this study. In contrast, Grx1 expression was decreased in patients with sarcoidosis and allergic alveolitis, but not with interstitial pneumonia [15]. In mouse models, nitrogen dioxide inhalation, but not bleomycin instillation augmented Grx1 in lungs, while both causing increased protein S-glutathionylation [16]. In a murine model of allergic airways disease Grx1 was found to be significantly increased in the airways of mice following immunization and challenge with ovalbumin (OVA)[17].

Given the importance of oxidative stress in the pathogenesis of asthma and the critical role glutathione homeostasis plays herein, we conducted a study evaluating Grx1 levels and protein S-glutathionylation in induced sputum of patients with asthma. Furthermore, correlations between the Grx1-S-glutathionylation axis and inflammatory patterns as well as lung function were assessed.

\section{Methods}

\section{Study design and subject characteristics}

Patient demographic and functional characteristics as well as sputum eosinophil and neutrophil percentages are given in Table 1. We studied 34 asthmatics, recruited at the asthma clinic at CHU Liege Sart-Tilman [18]. Significant pulmonary co-morbidities had been excluded on the basis of high resolution chest computed tomography. Healthy subjects were recruited among hospital and laboratory staff members. They all had normal spirometry and PC20M $>16 \mathrm{mg} / \mathrm{ml}$. Both asthmatics and healthy subjects denied respiratory tract infections 4 weeks prior to sputum sampling.

\section{Sputum induction and processing}

After premedication with $400 \mu \mathrm{g}$ inhaled salbutamol, sputum was induced by inhalation of hypertonic saline ( $\mathrm{NaCl} 5 \%$ ) when $\mathrm{FEV} 1$ postsalbutamol was $\geq 65 \%$ predicted and isotonic saline ( $\mathrm{NaCl} 0.9 \%$ ) when $\mathrm{FEV} 1$ was $<65 \%$ predicted. Saline combined with salbutamol was delivered by an ultrasonic nebulizer (Ultra-Neb 2000; Devilbiss, Somerset, PA, USA) [19]. Each subject inhaled the aerosol for 3 consecutive periods of $5 \mathrm{~min}$ for a total time of $15 \mathrm{~min}$. For safety reasons, FEV1 was monitored every $5 \mathrm{~min}$, and the induction stopped when FEV1 fell by more than $20 \%$ from post-bronchodilation values.

Whole sputum was homogenized by adding three volumes of PBS, vortexed and centrifuged at $800 \mathrm{~g}$ for $10 \mathrm{~min}$ at $4^{\circ} \mathrm{C}$. Supernatant was separated from cell pellet, which was suspended in RPMI 1640 supplemented with $100 \mathrm{U}$ penicillin/ml, $100 \mu \mathrm{g}$ 
streptomycin $/ \mathrm{ml}$, and centrifuged at $400 \mathrm{~g}$ for $10 \mathrm{~min}$ at $4^{\circ} \mathrm{C}$. Squamous cells, total cell counts, and cell viability checked by trypan blue exclusion were performed with a manual hemocytometer. The differential cell count was performed on cytospins stained with Diff-Quick after counting 400 cells.

Table 1: Demographic and functional characteristics

\begin{tabular}{|c|c|c|c|c|c|}
\hline & $\begin{array}{l}\text { Healthy } \\
\text { controls }\end{array}$ & Asthmatics & eosinophilic & neutrophilic & paucigranulocytic \\
\hline Number of subjects & 9 & 34 & 15 & 8 & $\overline{c 10}$ \\
\hline Age & $47.0 \pm 8.1$ & $44.6 \pm 12.8$ & $44.5 \pm 3.7$ & $47.2 \pm 3.9$ & $41.9 \pm 4.0$ \\
\hline Sex, M/F & $6 / 3$ & $1818 / 16$ & $8 / 7$ & $4 / 4$ & $4 / 6$ \\
\hline $\begin{array}{l}\text { Smoking status } \\
\text { (never/ex or current) }\end{array}$ & $5 / 4$ & $17 / 17$ & $5 / 10$ & $7 / 1 \S$ & $5 / 5$ \\
\hline Pack years & $19.6 \pm 26.8$ & $21.4 \pm 17.7$ & $20.1 \pm 7.4$ & 60 & $13.9 \pm 4.9$ \\
\hline BMI $\left(\mathrm{kg} / \mathrm{m}^{2}\right)$ & $25.2 \pm 4.2$ & $25.7 \pm 4.6$ & $24.9 \pm 1.0$ & $24.7 \pm 1.7$ & $27.0 \pm 1.7$ \\
\hline FEV ${ }_{1} \%$ predicted & $108.6 \pm 16.9$ & $76.1 \pm 22.2^{*}$ & $70.9 \pm 7.1^{*}$ & $74.1 \pm 7.1^{*}$ & $85.1 \pm 4.5^{*}$ \\
\hline FVC\% predicted & $113.2 \pm 20.6$ & $86.5 \pm 22.7^{*}$ & $90.9 \pm 5.0^{*}$ & $73.8 \pm 13.3^{*}$ & $92.5 \pm 4.0^{*}$ \\
\hline $\mathrm{FEV}_{1} / \mathrm{FVC}$ & $82.0 \pm 8.9$ & $69.8 \pm 14.3^{*}$ & $65.0 \pm 4.1^{*}$ & $67.8 \pm 3.6^{*}$ & $76.8 \pm 3.8$ \\
\hline FeNO (ppb) & - & $17.9(3.7-235)$ & $43(10.6-235)$ & $22.2(5.4-66.3)$ & $11(3.7-80.9)^{8}$ \\
\hline Oral CS & - & - & 1 & 2 & 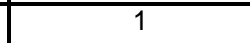 \\
\hline $\begin{array}{l}\text { Inhaled CS(eq } \\
\text { budesonide/day) }\end{array}$ & 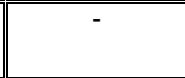 & 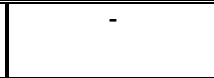 & $2000(0-6000)$ & $2000(0-3000)$ & $1600(0-4000)$ \\
\hline LABA & - & - & 11 & 7 & 8 \\
\hline LTRA & - & - & 7 & 4 & 5 \\
\hline Theophylline & - & - & 0 & 2 & 2 \\
\hline$\%$ sputum eosinophils & $0(0-3.2)$ & $0.9(0-72.2)^{\star}$ & $18.6(3.4-72.2)^{*}$ & $0(0-0.8)^{8}$ & $0.4(0-2.4)^{8}$ \\
\hline$\%$ sputum neutrophils & $16(0-62.8)$ & $48.3(4-100)^{*}$ & $44.2(4-65)$ & $94.8(75.7-100)^{1,8}$ & $46.7(17.6-69.6)^{\$}$ \\
\hline$\overline{\mathrm{ACQ}}$ & & $2.78 \pm 1.32$ & $2.7 \pm 0.4$ & $3.3 \pm 0.5$ & $2.3 \pm 0.3$ \\
\hline AQLQ & & $3.78 \pm 1.10$ & $3.9 \pm 0.3$ & $3.4 \pm 0.4$ & $4.1 \pm 0.4$ \\
\hline
\end{tabular}

${ }^{*}$ represents $p<0.05$ vs healthy control subjects, §represents $p<0.05$ vs eosinophilic asthma, \$represents $\mathrm{p}<0.05$ vs neutrophilic asthma

Data are expressed as mean and standard deviation, with the exception of FeNO, \%eosinophils and \%neutrophils which are expressed as median and range.

CS, corticosteroids; LABA, long acting beta 2 agonist; LTRA, leukotriene receptor antagonist 


\section{Western Blotting for Grx1}

Laemmli sample buffer containing DTT was added to $25 \mu \mathrm{l}$ of sputum and boiled for 10 minutes. Samples were loaded onto a 16,5\% polyacrylamide gel and transferred onto a PVDF membrane. The membrane was blocked for $1 \mathrm{~h}$ in $5 \%$ milk in Tris-buffered Saline (TBS) containing 0.05\% Tween 20 (TBST). After two washes in TBST, the membrane was incubated overnight at $4^{\circ} \mathrm{C}$ with primary antibody against Grx1 (Imco). After three washes, peroxidase-conjugated secondary antibody was incubated for $1 \mathrm{~h}$ and detected by chemiluminescence using the Pierce ECL Western Blotting Substrate (Thermo Scientific, Rockford, IL, USA). Films were quantified and data expressed as arbitrary units relative to diluted human Grx1 recombinant standard (Labfrontier) on each gel.

Quantitative determination of S-Glutathionylated proteins using 5,5'-dithio-bis(2nitrobenzoic acid) (dTNB)

$200 \mu \mathrm{l}$ of sputum was acetone precipitated for 20 minutes at $-20^{\circ} \mathrm{C}$ and spun for 5 minutes. Protein pellets were resuspended and sonicated in $200 \mu \mathrm{l}$ of ice-cold extraction buffer containing $0.2 \%$ Triton-X 100 and $0.6 \%$ sulfosalicyclic acid in 0.1 $M$ potassium phosphate buffer with $5 \mathrm{mM}$ EDTA disodium salt (KPE), pH 7.5. After 2 freeze-thaw cycles, samples were centrifuged at $3000 \mathrm{~g}$ for $4 \mathrm{~min}$ at $4^{\circ} \mathrm{C}$. To remove glutathione (GSH) from proteins, the pellet was treated with $100 \mu \mathrm{l}$ of $1 \%$ $\mathrm{NaBH}_{4}$ in water and neutralized with $40 \mu \mathrm{l}$ of $30 \%$ metaphosphoric acid. Samples were centrifuged at $1000 \mathrm{~g}$ for $15 \mathrm{~min}$ and the supernatant was used to determine the GSH content using the dTNB GSSG reductase recycling method [20]. $20 \mu \mathrm{l}$ of $\mathrm{KPE}, \mathrm{GSH}$ standards and samples were pipetted into a 96-well microtiter plate and freshly prepared, equal volumes of dTNB and GSSG reductase were added in the dark. After 30s, $\beta$-NADPH was added to start the conversion of dTNB to TNB and the absorbance at $412 \mathrm{~nm}$ was read every $30 \mathrm{~s}$ for 2 minutes. A standard curve was performed using a concentration range of $\mathrm{GSH}$. $\mathrm{NaBH}_{4}$ was omitted for each sample as a negative control. Values were corrected for protein content and data expressed as nmol GSH per milligram of protein.

Primary bronchial epithelial cell culture, RNA isolation and CDNA synthesis

Ciliated epithelial cells were isolated using cytology brushes during bronchoscopy in 3 healthy controls and 3 asthma patients (Table 3). Cells were shaken off from the brushes and first plated onto 1\% PureCol (Inamed Biomaterials, Nutacon, The Netherlands)-coated 12-well plates for the basal cells to expand in submerged culture using bronchial epithelial growth medium (Lonza Verviers, Belgium) supplemented with $0.3 \%$ Fungizone $\AA$ antimycotic (Gibco, Invitrogen, Pailey, UK) and $1 \%$ Antibiotic-Antimycotic (Gibco). Cells at passage 1 to 3 were seeded into $1 \%$ PureCol-coated $6 \mathrm{~cm}$ petri dishes for further expansion. When confluent, cells were lysed, scraped off, and RNA was extracted using RNeasy Mini Kit Plus with QIAshredder homogenisation and DNasel digestion (all from Qiagen, 
Crawley). RNA was quantified using NanoDrop spectrophotometer (Thermo

Scientific, Wilmington DE) and cDNA synthesized using the SuperScript VILO cDNA synthesis kit (Invitrogen).

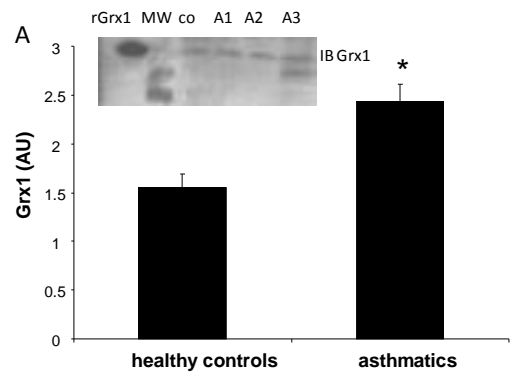

B

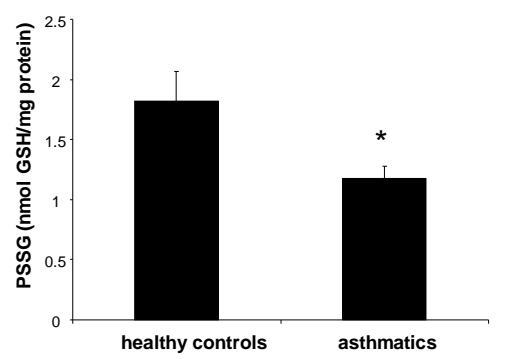

C

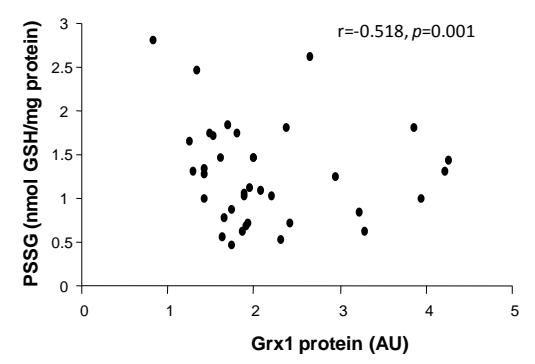

Figure 1

Figure 1: The Grx1-PSSG axis in induced sputum in asthma. (A) Grx1 protein levels in induced sputum of healthy controls and asthma patients, assessed by Western blot. Data are expressed in arbitrary units (AU) where Grx1 levels were corrected for a sample of recombinant human Grx1 on each gel and represented as mean $\pm S D$. * represents $p<0.05$. The insert is a representative Western blot loaded with recombinant human Grx1 sample in lane 1 ( $r$ rrx1), a molecular weight marker (MW), a healthy control sputum sample (co) and 3 asthma sputa (A1, A2, A3). (B) Level of protein S-glutathionylation (PSSG) in induced sputum of healthy controls and asthma patients. Data are expressed as nmol GSH that was released per $\mathrm{mg}$ protein and represented as mean $\pm S D$. * represents $p<0.05$. (C) Negative correlation between PSSG and Grx1 protein levels in induced sputum in the whole study group. 
QPCR analyses

QPCR was performed in duplicate using primers for Grx1

(FW: TCAGTCAATTGCCCATCAAA, Rev: AGATCACTGCATCCGCCTAT), Grx2 (FW: TTTACAAATGACTGGTGAAAGAAC, Rev: TGTCAGTTGCACCTCCAATAA) and GAPDH (FW: CGTCTTCACCATCAT, Rev: CGGCCATCACGCCACAGTTT) as a housekeeper. Relative quantity $(R Q)$ was calculated using the comparative CT method.

\section{Statistical analyses}

SPSS (version 15) was used for data analyses. Unless indicated otherwise, data are expressed as mean and standard deviation. Between-group comparisons were analyzed using the Kruskal-Wallis test, followed by Mann-Whitney $U$ test and correlations between variables were determined using Spearman's rho. Cell culture experiments were analysed by student's t-test. A $p$-value $<0.05$ was considered statistically significant.

\section{Results}

Biochemical assessment of the Grx1-PSSG axis in induced sputum samples of asthmatics

Healthy subjects and asthmatics were well matched for age, sex and smoking status (Table 1). Asthmatics exhibited poorer lung function compared to healthy controls as reflected by lower values of $F E V_{1}, F V C$ and a lower $F E V_{1} / F V C$ ratio. Raised sputum eosinophil and neutrophil counts were observed in asthmatics compared to healthy subjects.

The level of Grx1 protein detected in the sputum by Western blot was significantly increased in asthmatics compared to controls (Fig. 1A). Interestingly, an extra band was observed below that of Grx1 in $32 \%$ of patients which could indicate a degradation product (Fig. 1A, insert A3). Grx2 could not be detected in sputum supernatant. In line with Grx1's function of removing GSH from proteins, the level of protein S-glutathionylation (PSSG) was significantly decreased in sputum of asthmatics compared to controls (Fig. 1B). Importantly, in the whole study group a negative correlation was observed between Grx1 protein levels and PSSG in sputum samples (Fig. 1C).

The Grx1-PSSG axis in relation to asthma cellular phenotypes

Since an intricate relation between Grx/PSSG and inflammation has been observed in in vitro as well as mouse models of disease, we next asked whether these observed alterations in the Grx-PSSG axis were different between asthma cellular phenotypes. Therefore, asthmatics were categorized as eosinohilic, neutrophilic, paucigranulocytic or mixed based on published values for sputum eosinophil percentages [21] and the internal reference value of $76 \%$ for neutrophils from our clinic. Based on these criteria, 15 patients were labelled eosinophilic, 8 
neutrophilic and 10 paucigranulocytic. In this group of patients, none were of the mixed inflammatory subtype. Lung function did not differ significantly between the cellular phenotypes, nor did the asthma control or the quality of life score. The percentage eosinophils was greater in the eosophilic asthmatics compared to both neutrophilic and paucigranulocytic asthmatics as expected. Also, the percentage of sputum neutrophils was greater in neutrophilic asthmatics compared to eosinophilic and paucigranulocytic asthmatics (Table 1). Data in Figure 2A indicate that Grx1 protein levels were specifically enhanced in induced sputum of eosinophilic and paucigranulocytic asthmatics, but not in that of neutrophilic asthmatics. PSSG levels were found to be decreased only in eosinophilic and neutrophilic asthmatics compared to healthy controls, but not in sputum of paucigranulocytic asthma patients (Fig. 2B).

Figure 2

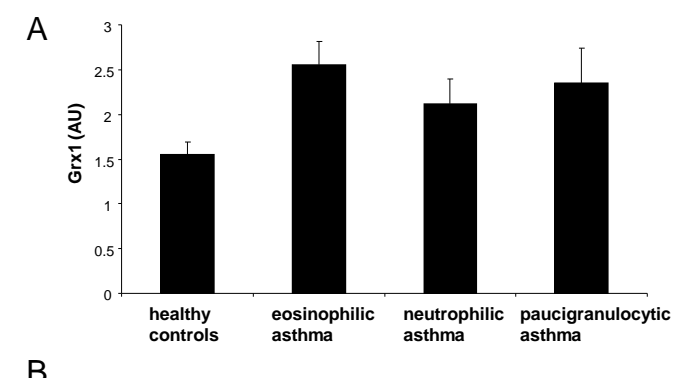

B

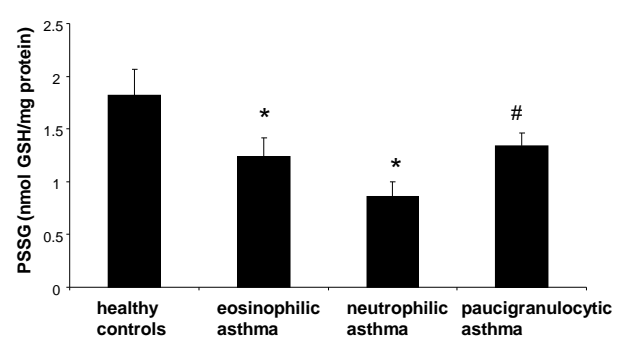

Figure 2: The Grx1-PSSG axis in relation to asthma cellular phenotypes. (A) Grx1 protein levels in induced sputum of healthy controls, eosinophilic, neutrophilic and paucigranulocytic asthma patients, assessed by Western blot. Data are expressed in arbitrary units (AU) where Grx1 levels were corrected for a sample of recombinant human Grx1 on each gel and represented as mean $\pm \mathrm{SD}$. * represents $\mathrm{p}<$ 0.05 compared to healthy controls. (B) Level of protein S-glutathionylation (PSSG) in induced sputum of healthy controls, eosinophilic, neutrophilic and paucigranulocytic asthma patients. Data are expressed as $\mathrm{nmol}$ GSH that was released per mg protein and represented as mean \pm SD. * represents $p<0.05$ compared to healthy controls and \# represents $p<0.05$ compared to neutrophilic asthma. 
Correlations between the Grx1-PSSG axis in induced sputum and lung function Importantly, $\mathrm{FEV}_{1} \%$ predicted negatively correlated with sputum Grx1 protein levels and positively with PSSG in the whole study group as shown in Figure 3. When restricting the analyses to all asthma patients, these correlations did not remain significant. However, Grx1 in eosinophilic asthmatics specifically still significantly negatively correlated with $\mathrm{FEV}_{1} \%$ predicted $(\mathrm{r}=-0.532 p=0.04)$ and PSSG positively correlated with $\mathrm{FEV}_{1} \%$ predicted in neutrophilic patients $(r=0.750, p=0.05)$.

Although the degree of asthma control assessed through the Juniper asthma control questionnaire (ACQ) was not significantly different between cellular phenotypes (Table 1), ACQ was found to be negatively associated with PSSG in neutrophilic asthmatics $(r=-0.750, p=0.05)$, indicating that as the disease is less well controlled in these patients, the protein GSH pool is depleted more.
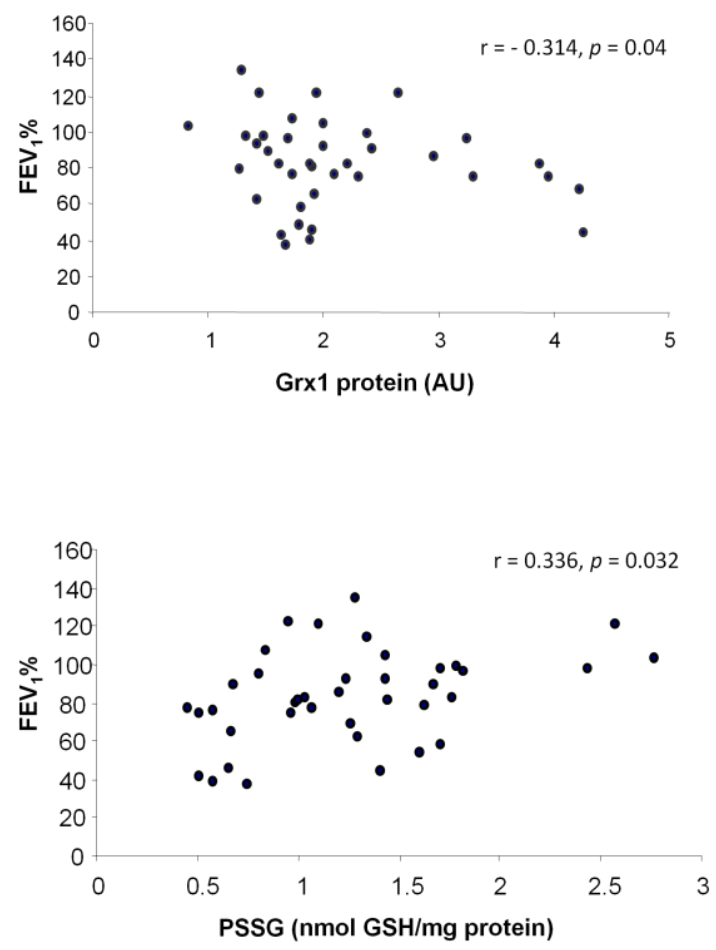

Figure 3: Correlations between lung function and the Grx1-PSSG axis. (A) A negative correlation was observed between $\mathrm{FEV}_{1} \%$ predicted and $\mathrm{Grx} 1$ protein levels in induced sputum in the whole study group. (B) A positive correlation was observed between $\mathrm{FEV}_{1} \%$ predicted and Grx1 protein levels in induced sputum in the whole study group. 
Correlations between the Grx1-PSSG axis in induced sputum and sputum cell counts in asthma

Since Grx1 and PSSG levels in induced sputum are different between cellular asthma phenotypes we assessed their associations with total and differential cell percentages in the induced sputum. Total cell numbers were found to be positively related to Grx1 levels, and negatively to PSSG levels (Table 2). Grx1 was found not to correlate with any specific cell type in the induced sputum. PSSG levels on the other hand were positively related to the percentage epithelial cells, squamous cells and lymphocytes and negatively with the percentage of viable cells in the entire study population as well as in the asthma patients alone.

Increased mRNA expression of Grx1 in primary bronchial epithelial cells of asthmatics

Grx1 sputum levels correlated with total sputum cell counts, but not with any specific cell type in the sputum. Since we previously observed markedly increased expression in airway epithelial cells in the mouse model of allergic airways disease, we investigated Grx mRNA expression in primary bronchial epithelial cells obtained from asthma patients and controls. The results shown in Fig. 4 demonstrate that indeed a higher level of Grx1 mRNA expression is present in epithelial cells isolated from asthma patients compared to cells isolated from healthy controls. Grx2 mRNA levels were not different, and importantly, as shown previously in various epithelial cells and mouse lung tissue, were lower then Grx1 mRNA levels.

Table 2: Correlations between the Grx1-PSSG axis in induced sputum and sputum cell counts in asthma

\begin{tabular}{llll} 
& & All subjects & All asthmatics \\
\hline PSSG & $\begin{array}{l}\text { Total cell number } \\
\text { \%eosinophils }\end{array}$ & $\begin{array}{l}-0.632(0.000) \\
\text { n.s. }\end{array}$ & $\begin{array}{l}-0.658(0.000) \\
\text { n.s. }\end{array}$ \\
& $\begin{array}{l}\text { \%epithelial cells } \\
\text { \%neutrophils }\end{array}$ & $0.601(0.000)$ & $0.502(0.003)$ \\
& n.s. & n.s. \\
& \%lymacrophages & n.s. & n.s. \\
& \%squamous cells & $0.355(0.025)$ & $0.399(0.024)$ \\
& \%viable cells & $-0.441(0.004)$ & $-0.479(0.006)$ \\
\hline \hline & Total cell number & $0.425(0.006)$ & n.s. \\
\hline
\end{tabular}




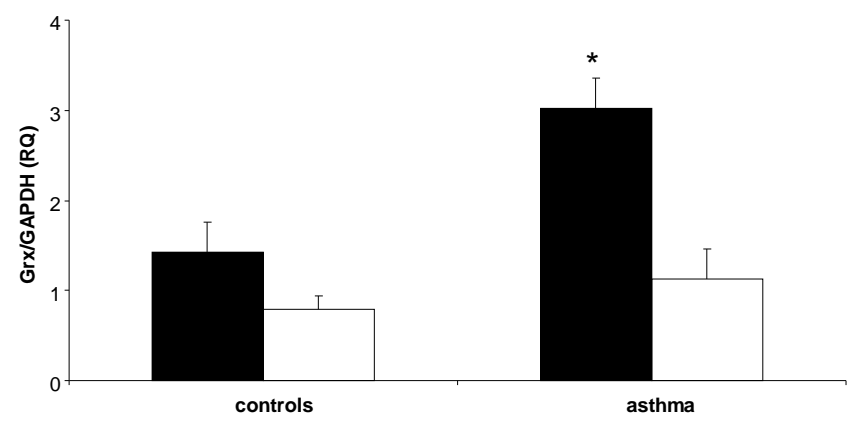

Figure 4

Figure 4: Grx1 expression is increased in primary epithelial cells of asthmatics. Grx1 (black bars) and Grx2 (white bars) mRNA expression corrected for GAPDH in primary bronchial epithelial cells of healthy controls and patients with asthma. Data are expressed as mean $R Q \pm S E M$ * represents $p<0.05$ compared to healthy controls.

\section{Discussion}

In this manuscript, we show an increase in Grx1 protein levels in induced sputum of asthmatics compared to healthy controls (Fig. 1A). These findings are in line with the increase in Grx1 in lung tissue in a murine model of allergic airways disease we have shown previously [17]. A statistical increase was found to occur in sputum of patients with eosinophilic and paucigranulocytic asthma (Fig 2A). The increase in Grx1 could be part of the protective response of the lungs to oxidative stress that is observed in asthmatics, since the function of Grx1 is to release GSH from proteins. Enhancing extracellular Grx1 levels could thus serve to increase free GSH in a direct manner as opposed to via transcriptional upregulation of $\square$ glutamylcysteinyl ligase. It has been demonstrated that in human lungs, Grx1 is predominantly present in macrophages and epithelial cells [15]. Grx1 levels in induced sputum did not correlate with the percentage of macrophages, nor importantly with the percentage of viable cells. These results are in line with the study first describing Grx1 in sputum of COPD patients since it demonstrated that its presence herein is not due to cell death, but likely involves an active secretion mechanism [14]. Bronchial epithelial cells are the most likely source since we observed a higher level of Grx1 mRNA expression in primary bronchial epithelial cells isolated from asthmatics compared to controls. In vitro studies have furthermore demonstrated the presence of Grx1 in culture supernatant which reflected expression profiles [22]. 
Table 3: Characteristics of subjects from which primary bronchial epithelial cells were isolated for mRNA analyses

\begin{tabular}{|lcc|}
\hline & Healthy controls & Asthmatics \\
\hline Number of subjects & 3 & 3 \\
Age & $36.0 \pm 6.1$ & $56.3 \pm 16.5$ \\
Sex, M/F & $1 / 2$ & $2 / 1$ \\
FEV ${ }_{1} \%$ predicted & $104.3 \pm 2.9$ & $74.3 \pm 32.3^{*}$ \\
FEV $1 /$ FVC & $86.2 \pm 32.8$ & $68.8 \pm 32.8$ \\
\hline
\end{tabular}

${ }^{*}$ represents $p<0.05$ vs healthy control subjects

Next to the increase in Grx1 protein levels in induced sputum of asthmatics, we also show in this study that the levels of protein S-glutathionylation in sputum significantly decreased in patients with asthma compared to healthy controls (Fig. 1B). When assessing PSSG in the different inflammatory cell phenotypes, PSSG was found to be decreased only in the two inflammatory phenotypes compared to healthy controls. The level in neutrophilic asthmatics was furthermore decreased compared to paucigranulocytic patients. Importantly, Grx1 protein and PSSG levels were found to be negatively correlated (Fig. 1C). Although Grx1 levels were not found to correlate with sputum cells, PSSG levels were negatively associated with the percentage of viable cells in the whole study group as well as in the asthma patients alone (Table 3). Despite the lower level of PSSG in the inflammatory phenotypes, no correlation with the percentage of either eosinophils or neutrophils was observed. This is in agreement with earlier observed lack of PSSG reactivity in neutrophils [23]. On the other hand, positive correlations of PSSG with lymphocytes, epithelial cells and squamous cells were found. This positive relation of sputum epithelial cells to PSSG contrasts the likelihood of epithelial cells as a prominent source of sputum Grx1, although epithelial cells in sputum could represent a different pool then cells isolated by brushing.

As described above, we hypothesize that GSH is removed from proteins to increase free GSH levels. The protein thiols could be returned to their reduced state, which is unlikely since the GSH/GSSG ratio is not increased in asthma [5]. On the other hand, S-glutathionylation of proteins is not only a sink for GSH it is also a reversible oxidation that protects proteins from further irreversible oxidation. A loss of this protective modification would thus leave proteins susceptible to damaging oxidations. Indeed, carbonylated albumin, as well as a1-antitrypsin have been detected in sputum of asthma patients [24]. Moreover, we recently reported that Grx1 itself is irreversibly oxidized and inhibited upon cigarette smoke extract exposure [25]. The observation of Grx1 of a lower then expected molecular weight in $32 \%$ of patients (Fig. 1A, insert) could be the result of such oxidative modification or possibly partial degradation. 
With respect to lung function, there was a significant negative correlation of Grx1 protein levels and a positive correlation of PSSG with $\mathrm{FEV}_{1} \%$ in the whole study group. These associations did not remain significant however when the analyses were restricted to the total group of asthma patients. FEV ${ }_{1}$ did remain significantly correlated with Grx1 in the eosinophilic phenotype and with PSSG in the neutrophilic phenotype (data not shown). A better lung function is thus associated with lower levels of Grx1 in induced sputum and a higher level of protein Sglutathionylation. A previous report in COPD showed that the number of Grx1 positive macrophages in lung tissue was positively correlated with $\mathrm{FEV}_{1} \%$ in the lungs of COPD patients, while there was no information on protein Sglutathionylation [14]. Here we lack information on the levels of S-glutathionylation in specific cell types. Moreover, it is difficult to extrapolate the current findings in sputum to what might be occurring to the Grx-PSSG axis in lung tissue. The increased expression of Grx1 in bronchial epithelial cells of asthmatics is in line with our previously reported findings in the OVA model in mice. In this model inflammatory cells were however, not investigated in detail as was protein Sglutathionylation [17]. Next to the positive correlation of PSSG with FEV ${ }_{1}$ in neutrophilic asthmatics and the relatively low level of sputum PSSG in this inflammatory phenotype compared to healthy controls and paucigranulocytic patients, PSSG in this phenotype also negatively correlated to the degree of disease control as assessed by the Juniper control questionnaire. So, there does appear to be a link between sputum PSSG and neutrophilic asthma that is associated with the degree of disease control. Together, these data show that GrxPSSG alterations either as a cause or a consequence of the disease are related to clinical manifestations.

When reviewing the list of proteins which functions have been demonstrated to be regulated by S-glutathionylation, a number of these are of significant relevance in asthma. For instance, the calcium pump sarco/endoplasmic reticulum $\mathrm{Ca}^{2+}$ ATPase (SERCA) has been shown to be activated by S-glutathionylation, increasing relaxation of smooth muscle [26]. Also with respect to muscle contractility, S-glutathionylation of the Ryanodine receptor calcium channel (RyR) was shown to be associated with impaired coupling [27]. Other potentially important effects include inhibition of caspase 3 [28], endothelial nitric oxide synthase (eNOS) [29] and phosphatase and tensin homologue (PTEN) [30], and inhibition of polymerization of G-actin [31]. With respect to inflammation, the transcription factors NF-KB [10], AP-1 [11] and signal transducer and activator of transcription factor (STAT)3 [32] have been shown to be negatively affected by Sglutathionylation. Moreover, we demonstrated that the extent to which NF-kB can be activated and pro-inflammatory mediators produced in lung epithelial cells is determined by Grx1 levels [9]. PSSG levels were found to be specifically lower in patients with either neutrophilic or eosinophilic asthma compared to healthy 
controls and to some extent paucigranulocytic asthmatics. Despite the significant correlation between sputum Grx1 and PSSG levels, these data with regard to inflammation indicate that PSSG as expected is influenced by Grx1 levels but likely also oxidative stress related to the inflammatory state of the lungs. Important to note is that anti-inflammatory therapy did not relate to PSSG or Grx1 levels.

In addition to studying alterations in mRNA and protein levels, classical posttranslational modifications and generic antioxidants, these data show that PSSG of targets relevant to asthma should be further investigated as they could play a key role in pathophysiology and possibly treatment since Grx-PSSG alterations as a cause or a consequence of the disease are related to clinical manifestations.

\section{Acknowledgments}

Funding sources: This study was supported by NUTRIM, a VENI grant from NWO/ZonMW (016.086.090) awarded to NLR and IUAP (interuniversity attraction pole) P6/35 supported by the Belgian Federal Government.

\section{References}

1. Bowler RP. Oxidative stress in the pathogenesis of asthma. Curr Allergy Asthma Rep 2004: 4(2): 116-122.

2. Cantin AM, North SL, Hubbard RC, Crystal RG. Normal alveolar epithelial lining fluid contains high levels of glutathione. J Appl Physiol 1987: 63(1): 152-157.

3. Kelly FJ, Mudway I, Blomberg A, Frew A, Sandstrom T. Altered lung antioxidant status in patients with mild asthma. Lancet 1999: 354(9177): 482-483.

4. Dauletbaev N, Rickmann J, Viel K, Buhl R, Wagner TO, Bargon J. Glutathione in induced sputum of healthy individuals and patients with asthma. Thorax 2001: 56(1): 13-18.

5. Reynaert NL. Glutathione biochemistry in asthma. Biochim Biophys Acta 2011: 1810(11): 1045-1051.

6. Comhair SA, Bhathena PR, Farver C, Thunnissen FB, Erzurum SC. Extracellular glutathione peroxidase induction in asthmatic lungs: evidence for redox regulation of expression in human airway epithelial cells. Faseb J 2001: 15(1): 70-78.

7. Malerba G, Pignatti PF. A review of asthma genetics: gene expression studies and recent candidates. J Appl Genet 2005: 46(1): 93-104.

8. Fernandes AP, Holmgren A. Glutaredoxins: glutathione-dependent redox enzymes with functions far beyond a simple thioredoxin backup system. Antioxid Redox Signal 2004: 6(1): 63-74.

9. Reynaert NL, van der Vliet A, Guala AS, McGovern T, Hristova M, Pantano C, Heintz NH, Heim J, Ho YS, Matthews DE, Wouters EF, Janssen-Heininger YM. Dynamic redox control of NFkappaB through glutaredoxin-regulated S-glutathionylation of inhibitory kappaB kinase beta. Proc Natl Acad Sci U S A 2006: 103(35): 13086-13091.

10. Pineda-Molina E, Klatt P, Vazquez J, Marina A, Garcia de Lacoba M, Perez-Sala D, Lamas S. Glutathionylation of the p50 subunit of NF-kappaB: a mechanism for redox-induced inhibition of DNA binding. Biochemistry 2001: 40(47): 14134-14142.

11. Klatt P, Molina EP, Lamas S. Nitric oxide inhibits c-Jun DNA binding by specifically targeted S-glutathionylation. J Biol Chem 1999: 274(22): 15857-15864. 
12. Mieyal JJ, Gallogly MM, Qanungo S, Sabens EA, Shelton MD. Molecular mechanisms and clinical implications of reversible protein S-glutathionylation. Antioxid Redox Signal 2008: 10(11): 19411988.

13. Yang Y, Jao S, Nanduri S, Starke DW, Mieyal JJ, Qin J. Reactivity of the human thioltransferase (glutaredoxin) C7S, C25S, C78S, C82S mutant and NMR solution structure of its glutathionyl mixed disulfide intermediate reflect catalytic specificity. Biochemistry 1998: 37(49): 1714517156.

14. Peltoniemi MJ, Rytila PH, Harju TH, Soini YM, Salmenkivi KM, Ruddock LW, Kinnula VL. Modulation of glutaredoxin in the lung and sputum of cigarette smokers and chronic obstructive pulmonary disease. Respir Res 2006: 7(1): 133.

15. Peltoniemi M, Kaarteenaho-Wiik R, Saily M, Sormunen R, Paakko P, Holmgren A, Soini Y, Kinnula VL. Expression of glutaredoxin is highly cell specific in human lung and is decreased by transforming growth factor-beta in vitro and in interstitial lung diseases in vivo. Hum Pathol 2004: 35(8): 1000-1007.

16. Aesif SW, Anathy V, Havermans M, Guala AS, Ckless K, Taatjes DJ, Janssen-Heininger YM. In situ analysis of protein S-glutathionylation in lung tissue using glutaredoxin-1-catalyzed cysteine derivatization. Am J Pathol 2009: 175(1): 36-45.

17. Reynaert NL, Wouters EF, Janssen-Heininger YM. Modulation of Glutaredoxin-1 Expression in a Mouse Model of Allergic Airway Disease. Am J Respir Cell Mol Biol 2007: 36(2): 147-151.

18. Lavorini F, Corrigan CJ, Barnes PJ, Dekhuijzen PR, Levy ML, Pedersen S, Roche N, Vincken W, Crompton GK. Retail sales of inhalation devices in European countries: So much for a global policy. Respir Med: 105(7): 1099-1103.

19. Delvaux M, Henket M, Lau L, Kange P, Bartsch P, Djukanovic R, Louis R. Nebulised salbutamol administered during sputum induction improves bronchoprotection in patients with asthma. Thorax 2004: 59(2): 111-115.

20. Rahman I, Kode A, Biswas SK. Assay for quantitative determination of glutathione and glutathione disulfide levels using enzymatic recycling method. Nat Protoc 2006: 1(6): 3159-3165.

21. Brightling CE. Clinical applications of induced sputum. Chest 2006: 129(5): 1344-1348.

22. Lundberg M, Fernandes AP, Kumar S, Holmgren A. Cellular and plasma levels of human glutaredoxin 1 and 2 detected by sensitive ELISA systems. Biochem Biophys Res Commun 2004: 319(3): 801-809.

23. Aesif SW, Anathy V, Guala AS, Reiss JN, Ho YS, Janssen-Heininger YM. Ablation of glutaredoxin-1 attenuates lipopolysaccharide-induced lung inflammation and alveolar macrophage activation. Am J Respir Cell Mol Biol 2011: 44(4): 491-499.

24. Nagai K, Betsuyaku T, Konno S, Ito Y, Nasuhara Y, Hizawa N, Kondo T, Nishimura M. Diversity of protein carbonylation in allergic airway inflammation. Free Radic Res 2008: 42(11-12): 921929.

25. Kuipers I, Guala AS, Aesif SW, Konings G, Bouwman FG, Mariman EC, Wouters EF, Janssen-Heininger YM, Reynaert NL. Cigarette Smoke Targets Glutaredoxin 1, Increasing Sglutathionylation and Epithelial Cell Death. Am J Respir Cell Mol Biol 2011: 45(5): 931-937.

26. Adachi T, Weisbrod RM, Pimentel DR, Ying J, Sharov VS, Schoneich C, Cohen RA. SGlutathiolation by peroxynitrite activates SERCA during arterial relaxation by nitric oxide. Nat Med 2004: 10(11): 1200-1207.

27. Dutka TL, Mollica JP, Posterino GS, Lamb GD. Modulation of contractile apparatus Ca2+ sensitivity and disruption of excitation-contraction coupling by $S$-nitrosoglutathione in rat muscle fibres. $J$ Physiol: 589(Pt 9): 2181-2196.

28. Klatt P, Pineda Molina E, Perez-Sala D, Lamas S. Novel application of S-nitrosoglutathioneSepharose to identify proteins that are potential targets for S-nitrosoglutathione-induced mixeddisulphide formation. Biochem J 2000: 349(Pt 2): 567-578.

29. Chen CA, Wang TY, Varadharaj S, Reyes LA, Hemann C, Talukder MA, Chen YR, Druhan $\mathrm{LJ}$, Zweier JL. S-glutathionylation uncouples eNOS and regulates its cellular and vascular function. Nature: 468(7327): 1115-1118. 
30. Yu CX, Li S, Whorton AR. Redox regulation of PTEN by S-nitrosothiols. Mol Pharmacol 2005: 68(3): 847-854.

31. Dalle-Donne I, Giustarini D, Rossi R, Colombo R, Milzani A. Reversible S-glutathionylation of Cys 374 regulates actin filament formation by inducing structural changes in the actin molecule. Free Radic Biol Med 2003: 34(1): 23-32.

32. Xie $\mathrm{Y}$, Kole S, Precht P, Pazin MJ, Bernier M. S-glutathionylation impairs signal transducer and activator of transcription 3 activation and signaling. Endocrinology 2009: 150(3): 1122-1131. 


\section{CHAPTER 9}

\section{Discussion}

\section{Grx1 regulation}

Altered expression of glutaredoxin 1 has been reported in several pulmonary diseases, like IPF, lung cancer and COPD [1-3]. How glutaredoxins are regulated at the transcriptional level however, has not been investigated in detail before. The only published data to date are that TGF $\beta$ decreased Grx1 expression, while IFNy and PMA augmented its levels $[4,5]$. Regulation by transcription factors remained unknown.

\section{Regulation of the Glrx1 gene by NF-KB}

We know from previoulsy conducted research in our laboratory that Grx1 levels have an impact on NF-kB activation by altering S-glutathionylation of IKK $\beta$ [6]. In chapter 2 of this thesis we expanded on this knowledge by showing that LPS affects S-glutathionylation of IKK . Specifically, protein S-glutathionylation of IKK $\beta$ was shown at protracted time points relative to $\mathrm{IKK} \beta$-mediated phosphorylation of IkBa when the NF-kB pathway was activated by exposure to LPS. Overexpression of Grx1 prevented IKK $\beta$ protein S-glutathionylation in response to LPS, resulting in prolonged degradation of $\mathrm{I} \mathrm{KBa}$, Rel $\mathrm{A}$ phosphorylation and nuclear translocation, and led to further increased expression of NF-KB proinflammatory cytokines. Secondly, it was investigated whether NF-kB also influenced Grx1 expression. Indeed, activation of the NF-KB pathway by LPS as well as by genetic manipulation induced the expression of glutaredoxin 1 in lung epithelial cells and lung macrophages. ChIP assays revealed that, upon LPS exposure, Rel A binds to the Glrx1 promoter. Therefore, it can be speculated that the activation of the Glrx1 gene by NFKB signaling can be seen as a feedforward mechanism to prolong NF$\mathrm{KB}$ activation by deglutathionylation of IKK $\beta$. Figure 1 schematically represents how protein S-glutathionylation of $\mathrm{IKK} \beta$ is suggested to be responsible for the glutaredoxin 1 regulated redox modulation of NFKB activation. Other members of the NF-KB family that were previously described to be functionally altered by Sglutathionylation, including p50 and p65, were not investigated in this study and need attention in future research.

NF-KB in addition to inflammation also regulates cell growth and wound healing. In our experiments, CA-IKK $\beta$ overexpression caused increased wound closure in lung 
epithelial cells in vitro. When Grx1 expression was decreased using siRNA in the context of CA-IKK $\beta$ overexpression, the increased wound closure was found to be inhibited, suggesting a role for Grx1 regulation by NF-KB in the mediation of either cell proliferation or migration. These results correspond with earlier data reporting an inverse correlation of Grx1 and Grx2 with proliferation and differentiation in patients with non-small cell lung cancer [1].

\section{Effects of cigarette smoke on Grx1}

The focus of our laboratory is on research into COPD. Since Grx1 has been reported to be decreased in macrophages and epithelial cells of COPD patients [2], we set out to investigate whether this could be due to cigarette smoke exposure. Both in vitro and in vivo, we have detected a decrease in Grx1 expression at the mRNA and protein level in lung cells after exposure to cigarette smoke. In a human lung epithelial cell line as well as primary mouse epithelial cells of the trachea, diminished Grx1 mRNA expression in cigarette smoke extract exposed cells compared to controls was detectable after a minimum of 24 hours. This protracted time of measurable differences to controls implies that Grx1 expression is not directly impacted by cigarette smoke extract, but is more likely regulated through an indirect signaling pathway. The in vitro data can also be viewed in a different manner in that over time Grx1 expression is upregulated in control conditions, but not so when treated with cigarette smoke extract. The upregulation in control conditions might be attributed to NFKB activation due to proliferation that still occurs in cells at subconfluency. This hypothesis fits with the data presented in chapter 2. The lack of upregulation of Grx1 expression over time in the CSE exposed cells, giving it the appearance to be downregulated compared to controls at each timepoint, could then be attributed to a decrease in proliferation. To test this hypothesis it would be necessary to investigate whether cells proliferate less upon cigarette smoke extract exposure, compared to controls and therefore express less Grx1, or whether overexpression of Grx1 could restore normal proliferation or even provide a growth benefit as could be speculated based on the relation of Grx1 expression to lung cancer [1]. We showed here that Grx1 at least provided protection against cigarette smoke -induced cell death at higher concentrations of CSE.

In accordance to our findings in vitro, lungs of mice exposed to cigarette smoke for four weeks expressed less Grx1 compared to their air exposed controls. A further reduction at 6 months of exposure was found (data are not shown in this thesis). Also, in lung tissue and plasma of patients with COPD compared to controls a decreased level of Grx1 protein was found. We did not examine where the differential regulation of Grx1 was occurring in response to cigarette smoke in mouse lung tissue or in patients with COPD. Grx1 is predominantly found in lung epithelial cells and macrophages [5], and it can therefore be speculated that altered expression in these cell types upon cigarette smoke exposure is 
responsible for the decreased levels of Grx1 found in lungs of mice and humans. The decreased level in plasma could be attributed to a decreased expression of Grx1 mRNA in white blood cells as shown in chapter 7, although the lungs, endothelial cells or other organs cannot be excluded.

We furthermore have shown that acrolein in cigarette smoke extract also directly affects Grx1 and its activity by binding to Grx1 itself, implying that cigarette smoke can affect Grx1 expression as well as modify Grx1 protein post-translationally. No effects of cigarette smoke Grx2 mRNA were observed, in vitro, in the mouse model, as well as in the patient samples, which is in line with previous studies in which only levels of Grx1 were affected by the stimuli used [4]. Grx2 at the protein level could not always be assessed due to the lack of a good commercially available antibody. It is however also possible that the activity of Grx2 is altered by smoke exposure, as this isoform is activated when the active site is opened upon monomerization, which can be accomplished by oxidation [7]. The activity assay used in this thesis furthermore does not distinguish between the different isoforms of glutaredoxin. Together this could explain why the strong effects observed on Grx1 expression and on recombinant Grx1 activity after cigarette smoke exposure do not always translate into equally strong effects on total cellular Grx activity.

\section{Regulation of Grx1 by other pathways}

Besides NF-KB binding sites discussed in this thesis, putative activator protein-1 (AP-1) sites and estrogen receptor binding elements (ERE) were previously reported in the mammalian Glrx1 gene [8,9] and imply regulation of Grx1 by multiple pathways. Nuclear factor (erythroid-derived 2)-like 2 (Nrf2) induces expression of many antioxidant enzymes, like glutathione S-transferase, heme oxygenase-1, glutamate-cysteine ligase and NADPH quinone oxidoreductase 1, by binding to antioxidant response elements (ARE) in the upstream promoter region of their encoding genes [10]. Nrf2 overexpression provides a protective role in cigarette smoke induced emphysema in mice [11]. Furthermore, patients with advanced COPD have lower levels of Nrf2 [12, 13]. In this thesis we reported that Grx1 is decreased in patients with COPD, which positively correlates with lung function, and has a protective role in cigarette smoke induced cell death in vitro, trends that are similar to that of Nrf2. Upon closer examination of the promoter of the Glrx1 gene, we identified putative ARE sites and therefore started investigating whether Grx1 is indeed an Nrf2 dependent gene. This research is currently ongoing and provides an interesting and promising follow up for this particular chapter of the thesis. 


\section{Extracellular Grx1}

Grx1 is also present in induced sputum of healthy controls and levels were unaffected in stable COPD, in contrast to an observed decrease in lung tissue. In induced sputum of patients with acute disease exacerbations however, the Grx1 level was increased compared to patients with stable disease (chapter 6). This increase in Grx1 in sputum of patients with acute exacerbations is in line with earlier reported data [2]. The difference from the lung tissue data could be due to the difference in reaction of newly recruited inflammatory cells versus more chronically exposed epithelial cells or resident macrophages whose regulatory pathways already have been affected by oxidative stress.

Our laboratory previously has shown that Grx1 was significantly increased in the airways of mice following immunization and challenge with the antigen ovalbumin (OVA) as a model of allergic airways disease [4]. In accordance with these data we show in chapter 8 of this thesis an increase in Grx1 protein levels in induced sputum of asthmatics compared to healthy controls.

The increase in Grx1 in both stable asthma and COPD patients experiencing a disease exacerbation could be part of the protective response of the lungs to oxidative stress, since the function of Grx1 is to release GSH from proteins. Enhancing extracellular Grx1 levels could thus serve to increase free GSH in a direct manner as opposed to via transcriptional upregulation of $\square$-glutamylcysteinyl ligase. Since we have shown in chapter 3 that Grx1 can be irreversibly oxidized and inhibited upon cigarette smoke extract exposure, we might speculate that Grx1 is less activate, either through oxidative modifications or possible partial degradation. Strengthening these speculations are the observations of a lower than expected molecular weight of Grx1 in the sputum of some of the refractory asthma patients and COPD patients experiencing an exacerbation (chapters 6 and 8). COPD and asthma are both chronic lung diseases with increased oxidative stress.

It is still unknown from which cell types sputum Grx1 originates. It has been demonstrated that in human lungs, Grx 1 is predominantly present in macrophages and epithelial cells [5], although no significant correlations with these cell proportions in sputa of COPD patients were detected in chapter 6 or in patients with asthma in chapter 8. A study that examined extracellular Grx found that only Grx1 could be detected in plasma and conditioned cell culture media, and not Grx2. Extracellular Grx1 was furthermore mostly detected from non-adherent cells compared to adherent cells, making the macrophage the most likely origin of sputum Grx1 in COPD exacerbations [14]. In patients with asthma on the other hand, we found that Grx1 sputum levels correlated with total cell counts, but not with any specific cell type in the sputum. On the other hand, Grx1 protein levels were enhanced in induced sputum of eosinophilic and paucigranulocytic asthmatics, but not in that of neutrophilic patients. These data are in line with the findings of an absence of enhanced Grx1 levels in stable COPD. In addition, 
primary epithelial cells isolated from asthma patients displayed a higher level of Grx1 mRNA expression compared to cells isolated from healthy controls.

Sequence analysis of Grx1 did not identify classical secretory signal sequences [15].The fact that we and others have reported that Grx1 levels were positively correlated with the percentage of viable cells in the sputa proposes a non-classical export of the enzyme from cells [2], for which the mechanism remains to be established.

\section{Grx activity}

Grx1 expression data did not always match up with Grx activity measurements in our studies. Arguments can be made that this lack in correlation can be due to the fact that the activity assay performed for Grx activity is not specific for Grx1 alone, but is general for all glutaredoxins present in the sample. Changes in Grx2 activity, which could be provoked by oxidative modification, can mask altered Grx1 activity and vice versa. Also, the Grx activity assay uses a commercially available, chemically stable mixed disulfide L-cysteine-S-sulfate as a substrate, rather than an S-glutathionylated protein. Taken together, the Grx activity assay used is not specific for Grx1 nor is it specific for deglutathionylation. In order to obtain more specific Grx1 activity profiles, radiolabeled glutathionylated substrates could be used or purification of Grx1 prior to analyses can be performed. Summary of Grx activity measured in this thesis can be found in Table 1 .

\section{Understanding changes in protein S-glutathionylation}

Mild oxidative stress can, in addition to direct oxidation of GSH to GSSG, induce the binding of glutathione to the sulfhydryl group of cysteine amino acids in proteins. As such, GSH binding to proteins has been proposed as a marker of oxidative stress and its measurement is more accurate then measuring the rapidly changing GSH/GSSG ratio. It should also be noted that PSSG contains an important pool of GSH that can be specifically liberated by glutaredoxins, but that it is typically overlooked in classical measurements of GSH/GSSG.

Previously PSSG has been shown to be increased in the blood of smokers [16] and in this thesis we have expanded this knowledge by investigating PSSG levels in lung epithelial cells, mice exposed to cigarette smoke and lung tissue and plasma of COPD patients.

Decreased PSSG levels, as observed in lungs of mice exposed to cigarette smoke for four weeks, in plasma of patients with stable COPD and sputum of stable asthma and exacerbating COPD patients, can be interpreted as the liberation of this reserve in GSH after the depletion of the pool of free GSH due to severe oxidative stress, especially in the extracellular milieu. On the other hand, because protein S-glutathionylation is believed to protect proteins from further irreversible oxidations, decreased PSSG might make proteins more prone for overoxidation. 
Increased PSSG, as reported in cells exposed to CSE acutely and lungs of COPD patients could thus be interpreted as a response to protect proteins under conditions of mild oxidation stress, especially in tissue.

This increased PSSG level in lung epithelial cells exposed in vitro to cigarette smoke extract and lung tissue of COPD patients was in accordance with a lower level of Grx1 expression (chapter 3 and 6). Also in sputum of asthmatics and COPD patients, as well as plasma of COPD patients PSSG levels negatively correlated with Grx1. PSSG levels were however not inversely correlated with Grx1 expression in mice exposed to cigarette smoke; lowered Grx1 levels, as well as lower overall PSSG level in lung tissue was found here (chapter 4). One could speculate whether the concentrations and frequency of cigarette smoke exposure to mice is too high and over-oxidation or irreversible oxidation occurs, without the possibility of the lungs to restore their anti-oxidant capacity. It is furthermore difficult to compare smoking in humans with forced cigarette smoke inhalation in mice; exact recapitulation of damage accumulated over years of exposure to cigarette smoke in humans is not possible in laboratory rodents. Another explanation for the decreased PSSG is that upon broncho alveolar lavage the inflammatory cells in the lungs are flushed away, leaving only the epithelial cells to contribute in the overall measured PSSG. This theory is further strengthened by increased levels of PSSG in the BAL fluid of mice exposed to cigarette smoke compared to mice exposed to air (chapter 4). Inflammatory cells in the BAL fluid may not yet have adapted to the chronic exposure of high concentrations of cigarette smoke, given their short lives and rapid turnover as well as their acute recruitment to the site of inflammation. Lasit, not only glutaredoxins, but multiple other factors determine the balance between reduced cysteines (PSSH), PSSG and overoxidation of proteins. Although protein S-glutathionylation can be achieved non-enzymatically upon the presence of mild oxidative stress, there is some evidence that glutathione-S-transferase $\mathrm{P} 1$ can catalyse this reaction $[17,18]$ and therefore counteract the actions of Grx1. In chapter 7, GSTP1 protein levels and mRNA expression were found to be unaltered in plasma of COPD patients. Total GST activity on the other hand was decreased in COPD patients compared to controls and was negatively associated with IL-6 and positively correlated to lung function.

Lastly, targeted proteins can be functionally influenced by the binding of $\mathrm{GSH}$, such as enzymes with catalytically important cysteines, including proteins that are of importance in lung physiology. With respect to inflammation, the transcription factors NF- $\square$ B [19], AP-1 [20] and STAT3 [21] have been shown to be negatively affected by S-glutathionylation. Second, the calcium ATPase pump SERCA has been shown to be activated by S-glutathionylation of cysteine 674 , leading to increased relaxation of smooth muscle [22]. Also with respect to muscle contractility, S-glutathionylation of the Ryanodine receptor calcium channel (RyR) was shown to be associated with impaired coulping [23]. Other effects include 
inhibition of caspase 3 [24], eNOS [25] and PTEN [26], and inhibition of polymerization of G-actin [27].

\section{Role of Grx1-PSSG in inflammation}

Given the intricate relation that was already shown between inflammation and the Grx1-PSSG axis, and the additional data we presented in the second chapter of this thesis, as well as in patients with COPD and asthma, we used a mouse model in which Glrx1 is ablated to investigate whether down regulation of Grx1 had a role in cigarette smoke-induced pulmonary inflammation. Although there was no difference in total cell counts between control and Glrx1 KO mice, the pattern of inflammation was altered in the absence of Grx1. Accumulation of macrophages, but lower levels of neutrophils and dendritic cells in the BAL fluid were reported, together with decreased levels of cytokines and chemokines. Our laboratory previously described the necessity of Grx1 in macrophage maturation in mice upon LPS exposure [28]. Although macrophage numbers were increased in response to smoke in Glrx1 KO mice, it is likely that these macrophages are less mature then in the wild type mice. In support of this hypothesis, Glrx1 KO macrophages did not induce KC production in response to CSE, but further increased PSSG levels. The level of maturity might also be the cause of enhanced macrophage accumulation in the BAL fluid. Investigating the impact of Glrx1 ablation on NF-KB activity in mice exposed to cigarette smoke was not possible because no nuclear NF-KB localization could be detected after the time lapse between the last cigarette smoke exposure and harvesting the mice. However, the cytokines altered by ablation of Glrx1 were all NF-KB dependent, implying that the NF-KB pathway was negatively regulated by the increased S-glutathionylation that resulted from Glrx1 ablation as our laboratory has shown previously [6, 28].

\section{Summary and future perspectives}

Given our currently level of understanding, direct investigations into the relevance of Grx1 alterations in COPD, especially given its role in cigarette smoke induced inflammation in mice and cell death in vitro, as demonstrated in this thesis, a 6 month exposure model in Glrx1 KO mice should be performed. This is a true mouse model of emphysema and would help to determine the potential role of Grx1 in disease pathogenesis. Furthermore, the use of the Glrx1 KO mice and transgenic mice over-expressing Grx1 specifically within the parenchyma of the lung, would provide an invaluable resource for elucidating the role of Grx1 in disease as well as protein targets of smoke induced S-glutathionylation.

Data published thus far have demonstrated roles for the AP-1 transcription factor and NF-kappa B transcription factor family in the regulation of Grx1 expression. Given the inflammatory nature of this proposed regulation, the question as to whether or not transcription of a redox response enzyme, i.e. Grx1, is regulated in 
a redox response dependent manner, remains unanswered. Further investigation into this potential redox inducible regulation would lend credence to the feedforward, anti-oxidant function of the Grx1/protein S-glutathionylation axis laid out thus far in this thesis.

In order to gain more insight into the influence on the activity of Grx1, a more specific activity assay would have to be created. Highly specific antibodies for Sglutathionylated proteins would be helpful in determining targets that are affected by changes in Grx1 expression or in the presence of oxidative stress.

In general, unravelling the impact of differences in the Grx1/protein Sglutathionylation axis on protein function and cell homeostasis would make a stronger case for its pharmaceutical targeting in order to inhibit further oxidative damage.

Taken together this thesis has attempted to answer the vigorously debated question as to whether or not Grx1 and PSSG are overall protective in regard to the pathophysiology of COPD. A definitive answer to this question, despite the data presented in this thesis, remains elusive. We have shown that Grx1 protects against CSE induced cell death, can mediate NF-KB regulated and smoke-induced inflammation and is positively correlated with lung function (chapter 6). Curiously however, given the role of Grx1 in reversing the S-glutathionylation of proteins, Grx1 expression inversely correlated with PSSG formation, which also positively correlated with lung function. This seeming paradox actually highlights several yet incompletely and unexplored facets of Grx1 and PSSG biology, namely the genetic regulation of Grx1 expression, and the mechanisms through which Grx1 targets and interacts with the proteins it ultimately deglutathionylates. As we have put forth previously in this thesis, protein S-glutathionylation, much like O-phosphorylation, has been reported to inhibit as well as enhance protein function depending on the target protein. To that same end, it has become abundantly clear in the decades following the discovery of protein kinases, that their activities are intimately dependent on the innumerable intermediary molecules (i.e. small G-proteins, linker proteins, phospholipids, etc.) that direct these enzymes to their intended substrates. We would speculate that ultimately the answer to the question of the role of Grx1 inthe pathogenesis COPD may lie in understanding what intermediary molecules regulate the spatial and temporal targeting of Grx1 to the reversal of any one particular S-glutathionylated protein.

Our data in this thesis have convincingly established the correlation between the Grx1-PSSG axis and epithelial cell death, inflammation and lung function, all of which have been implicated in the pathogenesis of COPD. Defining the ultimate role of Grx1 in protein S-glutathionylation in the pathogenesis of COPD will require further understanding of the genetic as well as posttranslational regulation and targeting of Grx1. However, we do not think it is premature to consider therapeutic intervention of the Grx1-PSSG axis in the potential treatment of COPD. 
Table 1: Summary of data on Grx1/PSSG axis in studies performed in this thesis. All data compared to respective controls.

CSE In vitro epithelial cells

4wks CS in mice lung tissue

4wks CS in mice BAL cells

COPD lung tissue

COPD sputum stable

COPD sputum

exacerbation

COPD plasma

Asthma sputum
PSSG Grx1 expression

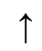

$\downarrow$

$\uparrow$
$\uparrow$
$=$

$=$

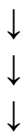

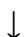

$=$

$=$

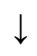

$=$

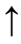

$=$

\section{References}

1. Fernandes, A.P., et al., Expression profiles of thioredoxin family proteins in human lung cancer tissue: correlation with proliferation and differentiation. Histopathology, 2009. 55(3): $p$. 313-20.

2. Peltoniemi, M.J., et al., Modulation of glutaredoxin in the lung and sputum of cigarette smokers and chronic obstructive pulmonary disease. Respir Res, 2006. 7(1): p. 133.

3. Fernandes, A.P. and A. Holmgren, Glutaredoxins: glutathione-dependent redox enzymes with functions far beyond a simple thioredoxin backup system. Antioxid Redox Signal, 2004. 6(1): p. 63-74.

4. Reynaert, N.L., E.F. Wouters, and Y.M. Janssen-Heininger, Modulation of Glutaredoxin-1 Expression in a Mouse Model of Allergic Airway Disease. Am J Respir Cell Mol Biol, 2006.

5. Peltoniemi, M., et al., Expression of glutaredoxin is highly cell specific in human lung and is decreased by transforming growth factor-beta in vitro and in interstitial lung diseases in vivo. Hum Pathol, 2004. 35(8): p. 1000-7.

6. Reynaert, N.L., et al., Dynamic redox control of NF-kappaB through glutaredoxin-regulated Sglutathionylation of inhibitory kappaB kinase beta. Proc Natl Acad Sci U S A, 2006. 103(35): p. 13086-91.

7. Lillig, C.H., et al., Characterization of human glutaredoxin 2 as iron-sulfur protein: a possible role as redox sensor. Proc Natl Acad Sci U S A, 2005. 102(23): p. 8168-73.

8. Park, J.B. and M. Levine, The human glutaredoxin gene: determination of its organization, transcription start point, and promoter analysis. Gene, 1997. 197(1-2): p. 189-93.

9. Kenchappa, R.S., et al., Thioltransferase (glutaredoxin) mediates recovery of motor neurons from excitotoxic mitochondrial injury. J Neurosci, 2002. 22(19): p. 8402-10.

10. Nguyen, T., P. Nioi, and C.B. Pickett, The Nrf2-antioxidant response element signaling pathway and its activation by oxidative stress. J Biol Chem, 2009. 284(20): p. 13291-5.

11. Ishii, Y., et al., Transcription factor Nrf2 plays a pivotal role in protection against elastaseinduced pulmonary inflammation and emphysema. J Immunol, 2005. 175(10): p. 6968-75. 
12. Malhotra, D., et al., Decline in NRF2-regulated antioxidants in chronic obstructive pulmonary disease lungs due to loss of its positive regulator, DJ-1. Am J Respir Crit Care Med, 2008. 178(6): p. 592-604.

13. lizuka, T., et al., Nrf2-deficient mice are highly susceptible to cigarette smoke-induced emphysema. Genes Cells, 2005. 10(12): p. 1113-25.

14. Lundberg, M., et al., Cellular and plasma levels of human glutaredoxin 1 and 2 detected by sensitive ELISA systems. Biochem Biophys Res Commun, 2004. 319(3): p. 801-9.

15. Padilla, C.A., et al., Purification from placenta, amino acid sequence, structure comparisons and cDNA cloning of human glutaredoxin. Eur J Biochem, 1995. 227(1-2): p. 27-34.

16. Muscat, J.E., et al., Enhanced protein glutathiolation and oxidative stress in cigarette smokers. Free Radic Biol Med, 2004. 36(4): p. 464-70.

17. Manevich, Y., S.I. Feinstein, and A.B. Fisher, Activation of the antioxidant enzyme 1-CYS peroxiredoxin requires glutathionylation mediated by heterodimerization with pi GST. Proc Natl Acad Sci U S A, 2004. 101(11): p. 3780-5.

18. Townsend, D.M., et al., Novel role for glutathione S-transferase pi. Regulator of protein SGlutathionylation following oxidative and nitrosative stress. J Biol Chem, 2009. 284(1): p. 43645.

19. Pineda-Molina, E., et al., Glutathionylation of the p50 subunit of NF-kappaB: a mechanism for redox-induced inhibition of DNA binding. Biochemistry, 2001. 40(47): p. 14134-42.

20. Klatt, P., E.P. Molina, and S. Lamas, Nitric oxide inhibits c-Jun DNA binding by specifically targeted S-glutathionylation. J Biol Chem, 1999. 274(22): p. 15857-64.

21. Xie, Y., et al., S-glutathionylation impairs signal transducer and activator of transcription 3 activation and signaling. Endocrinology, 2009. 150(3): p. 1122-31.

22. Adachi, T., et al., S-Glutathiolation by peroxynitrite activates SERCA during arterial relaxation by nitric oxide. Nat Med, 2004. 10(11): p. 1200-7.

23. Dutka, T.L., et al., Modulation of contractile apparatus Ca2+ sensitivity and disruption of excitation-contraction coupling by S-nitrosoglutathione in rat muscle fibres. J Physiol. 589(Pt 9): p. 2181-96.

24. Klatt, P., et al., Novel application of S-nitrosoglutathione-Sepharose to identify proteins that are potential targets for S-nitrosoglutathione-induced mixed-disulphide formation. Biochem J, 2000. 349(Pt 2): p. 567-78.

25. Chen, C.A., et al., S-glutathionylation uncouples eNOS and regulates its cellular and vascular function. Nature. 468(7327): p. 1115-8.

26. Yu, C.X., S. Li, and A.R. Whorton, Redox regulation of PTEN by S-nitrosothiols. Mol Pharmacol, 2005. 68(3): p. 847-54.

27. Dalle-Donne, I., et al., Reversible S-glutathionylation of Cys 374 regulates actin filament formation by inducing structural changes in the actin molecule. Free Radic Biol Med, 2003. 34(1): p. 23-32.

28. Aesif, S.W., et al., Ablation of glutaredoxin-1 attenuates lipopolysaccharide-induced lung inflammation and alveolar macrophage activation. Am J Respir Cell Mol Biol. (In press). 


\section{Samenvatting}

De binding van glutathion aan cysteines in eiwitten wordt ook eiwit Sglutathionylatie genoemd en is omkeerbaar met behulp van antioxidant enzymen glutaredoxines. Eiwit S-glutathionylatie wordt gevormd wanneer er een lichte vorm van oxidatieve stress gedetecteerd wordt in de cel en doet dienst als bescherming tegen verdere, onomkeerbare oxidatieve stress schade. Vermits het roken van sigaretten een zware oxidatieve stress veroorzaakt in de longen en dit tot onomkeerbare schade en aandoeningen zoals COPD (chronisch longlijden) kan leiden, hebben we in dit proefschrift uitgezocht wat voor impact roken en COPD hebben op eiwit S-glutathionylatie en glutaredoxines. Hierdoor kan men beter begrijpen wat de oorzaak van onomkeerbare schade is en uiteindelijk proberen deze schade te verhinderen. De veranderingen in eiwit S-glutathionylatie en glutaredoxines na rookblootstellingen werden onderzocht in vitro, met behulp van cellijnen en rookextracten, alsook cellen geïsoleerd uit longen van aan rook blootgestelde muizen. In vivo werden de longen en broncho-alveolaire vloeistof van muizen blootgesteld aan rook onderzocht evenals sputum, plasma en longweefsel samples van patienten met COPD en astma. De resultaten waren niet altijd extrapoleerbaar van celkweek schaaltje naar organisme en ook niet van muis naar mens. We zijn er niet in geslaagd om een definitief antwoord te geven op de vraag of glutaredoxines en eiwit S-glutathionylatie een beschermende rol hebben voor de pathofysiologie van COPD. We kunnen echter wel concluderen op basis van data voorgelegd in dit proefschrift, dat glutaredoxine 1 een beschermende werking heeft tegen sigarettenrook extract geïnduceerde celdood en het ook de regulatie van $\mathrm{NF}-\mathrm{kB}$ en rook-geinduceerde inflammatie kan mediëren en tenslotte ook positief correleerd met longfunctie. Hoewel de volledige rol van glutaredoxine 1 en eiwit S-glutathionylatie in the pathogenese van COPD nog niet is beschreven en verder onderzoek nodig is, zijn wij er toch van overtuigd dat therapeutische interventie van de glutaredoxine 1 - eiwit S-glutathionylatie as een positieve weerslag kan hebben voor COPD patiënten. 


\section{List of publications}

Kuipers I, Bracke KR, Brusselle GG, Aesif SW, Krijgsman R, Arts IC, Wouters EF, Reynaert NL. Altered cigarette smoke-induced lung inflammation due to ablation of grx1. PLoS One (Epub June 2012)

Kuipers I, Louis R, Manise M, Dentener M, Wouters EFM, Reynaert NL. Increased glutaredoxin 1 and decreased protein S-glutathionylation in sputum of refractory asthmatics. Eur Respir J. 2013 Feb;41(2):469-72

Kuipers I, Bracke KR, Brusselle G, Wouters EFM and Reynaert NL. Smoke decreases reversible oxidations S-glutathionylation and S-Nitrosylation in mice. Free Radic Res. 2012 Feb;46(2):164-73

Aesif SW and Kuipers I, Anathy V, Guala AS, Janssen-Heiniger YMW. Activation of the glutaredoxin-1 gene by nuclear factor kappa $B$ enhances signaling. Free Radical Biology and Medicine, 2011 Sep 15;51(6):1249-57

Kuipers I, Guala AS, Aesif SW, Wouters EFM, Janssen-Heininger YMW, Reynaert NL. Cigarette smoke targets Grx1, causing increases in S-glutathionylation and epithelial cell death. American Journal of Respiratory Cell \& Molecular Biology. 2011 Nov;45(5):931-7

Aesif SW, Anathy V, Kuipers I, Reiss JN, Ho YS, Janssen-Heininger YMW. Ablation of Glutaredoxin-1 Attenuates Lipopolysaccharide-Induced Lung Inflammation and Alveolar Macrophage Activation. American Journal of Respiratory Cell \& Molecular Biology 2011 Apr;44(4):491-9

Caers J, Hose D, Kuipers I, Bos TJ, Van Valckenborgh E, Menu E, De Bruyne E, Goldschmidt H, Van Camp B, Klein B, Vanderkerken K. Thymosin beta4 has tumor suppressive effects and its decreased expression results in poor prognosis and decreased survival in multiple myeloma. Haematologica. 2010 Jan;95(1):163-7 


\section{Curriculum vitae}

Ine Kuipers was born on April 23, 1985 in Hasselt, Belgium. In 2003 she started her bachelors degree at the University of Hasselt for the study of biomedical sciences. In 2006, she finished her Masters in Biomedical Sciences at the Free University of Brussels with great distinction. Shortly after, she started working for the department of Respiratory Medicine at Maastricht University Medical Centre as a PhD student. For her work on the project 'The glutaredoxin 1/ protein Sglutathionylation axis in inflammatory lung disease', she worked for two years at the department of Pathology at the University of Vermont, USA. She currently lives with her family in Washington, DC. 


\section{Dankwoord / Acknowledgements}

Ik wil deze thesis graag afsluiten met woorden van dank aan iedereen die mij heeft geholpen en bijgestaan in de voorbije leerrijke jaren van mijn doctoraat.

Eerst en vooral wil ik mijn promoter, Professor Wouters, bedanken om mij de mogelijkheid te geven om te promoveren en mij te ondersteunen in mijn onderzoek. $U$ zorgde ervoor dat ik de rode draad niet kwijt raakte en aan de basis van vele hoofdstukken in dit proefschrift liggen uw samenwerkingen met universiteiten in België en de VS. Dank u wel om in mij te geloven, het was een waar genoegen om $u$ als promoter te mogen hebben.

Niki, ik weet zelfs niet goed waar ik moet beginnen met jou te bedanken! Jij was er van de start, mijn eerste sollicitatie gesprek, mijn eerste experiment in het lab, mijn eerste voet op Amerikaanse grond... Dank je wel om mijn mentor te zijn en me te begeleiden in de dagelijkse ups and downs die nu eenmaal bij onderzoek komen kijken. Ik kon en kan altijd bij jou terecht, ook al was het vaak per mail of (slechte skype verbinding) telefoon. Je leerde me hoe ik het best experimenten kon opzetten en stuurde me in de juiste richting tijdens het schrijven van mijn manuscripten, maar gaf me toch de vrijheid om mijn eigen weg te zoeken. Ook een woordje van dank aan je hele familie, om mij te helpen settelen in Burlington en voor de vele gezellige etentjes. Ik hoop dat we contact blijven houden en je weet de weg nu naar mijn nieuwe thuis, daar zijn jullie altijd welkom.

Yvonne, dank je wel dat ik in je lab in UVM mocht werken en voor de hulp bij het publiceren van manuscripten.

Ik wil ook graag de leden van mijn leescommissie, Prof. dr. B. Kramer, Prof. dr. E.J.M. Speel, Prof. dr. A. Bast, Prof. dr. A. van Oosterhout en Dr. Roel Schins, bedanken voor het beoordelen van mijn proefschrift.

Ik wil graag mijn collegas op de twee continenten bedanken voor hun hulp in het lab en hun vriendschap. Het was altijd een leuke sfeer in het pulmo lab, labuitjes en uitjes in het nachtleven droegen daar zeker toe bij. Bedankt Marco, Frank, Koen, Nicky, Bram, Valery, Alex, Anon, Astrid, Pascal, Ramon, Harry, Irene, Poornima, Mieke, Juanita en iedereen in het pulmo lab voor de leuke tijd en de vele vlaai! Claudia, Nadja en Renske, dank je wel voor de hulp bij experimenten en de vriendelijke babbels en mails. Bettine en Céline, ik heb altijd genoten van onze etentjes en onze AIO tijd samen. Evike, you are simply the best $\odot$, bedankt voor de plezante uitstapjes naar het sportpaleis, de goed gevulde glazen lekkers in Bilzen en om mij in je appartement te laten wonen. Voor jou staan hier de aardappelkes en Belgische kost altijd klaar, stap in je auto (hoge drempels best 
vermijden (:) en kom maar af! Gonda, jouw vriendschap ging verder dan koffies op 4, samen koken na het werk en juichen van geluk in de doka als we bandjes zagen... het bracht ons ondermeer tot in Italië, Malta, New York City, Grand Canyon en de Bahamas! Buiten een heel gamma aan foto's van indrukwekkende bomen (:) en gekke bekken, heb ik aan jou heel veel mooie herinneringen en avonturen te danken. A big thanks to my colleagues Jane, Jess, Elianne, Sidra, Jimmy, Jos, Juliana, Vikas, Amy and Karrie in Vermont as well. You all made my home sickness a lot more bareble. I am also thankful for the happy hour crew : Juliana, Karina, Ed, Reid and Jen: cheers! Sherrill, Jedd, Max, Tim, Stacie and Joyce, being lab neighbours was a lot of fun! And Sherrill never forget our song: you are awesome $:$.

Ook een dikke merci voor mijn paranimf An. Op jou kon en kan ik altijd rekenen: voor een goeie babbel om mijn hart te luchten, om al onze (AIO) zorgen eraf te shaken op de Brugstraat, voor de vele skype en MSN gesprekken (met en zonder weeën (:) en je kwam me zelfs al tot twee maal toe in de VS bezoeken. Bedankt voor alle leuke momenten en voor onze vriendschap, het betekent enorm veel voor mij.

Dank je wel Natalie en Evie om jullie vakantie met mij in de VS te komen spenderen en mij mee te nemen op onvergetelijke roadtrips! Ik hoop van harte dat we blijven contact houden, jullie zijn geweldig toffe madammen.

Mama, papa en Goele, dank je wel voor jullie steun doorheen mijn studietijd. Door jullie vele skype gesprekken lijkt België nooit zo heel ver weg.

And last but certainly not least, I would like to thank Scott for being my best friend and loving husband. I love that we not only share our love for each other and our family, but also a love for science and research. Thank you for all your support, believing in my abilities as a researcher and mother and challenging me to get more first author papers than you $(;)$ I am looking forward to the rest of our lives together, discussing new experiments at our kitchen table while watching Lynden grow up. Thanks for making me happy.

\section{Tne}


